\title{
Mapping and characterization of LCA networks
}

Bjørn, Anders; Owsianiak, Mikolaj; Laurent, Alexis; Molin, Christine; Westh, Torbjørn Bochsen; Hauschild, Michael Zwicky

Published in:

Book of abstracts - SETAC 18th LCA Case Study Symposium and 4th NorLCA Symposium

Publication date:

2012

Document Version

Publisher's PDF, also known as Version of record

Link back to DTU Orbit

Citation (APA):

Bjørn, A., Owsianiak, M., Laurent, A., Molin, C., Westh, T. B., \& Hauschild, M. Z. (2012). Mapping and characterization of LCA networks. In Book of abstracts - SETAC 18th LCA Case Study Symposium and 4th NorLCA Symposium: Sustainability Assessment in the 21st century - Tools, Trends and Applications (pp. 157157)

\section{General rights}

Copyright and moral rights for the publications made accessible in the public portal are retained by the authors and/or other copyright owners and it is a condition of accessing publications that users recognise and abide by the legal requirements associated with these rights.

- Users may download and print one copy of any publication from the public portal for the purpose of private study or research.

- You may not further distribute the material or use it for any profit-making activity or commercial gain

- You may freely distribute the URL identifying the publication in the public portal 


\section{SETAC $18^{\text {th }}$ LCA \\ Case Study Symposium}

$4^{\text {th }}$ NorLCA Symposium

Sustainability Assessment in the $21^{\text {st }}$ century

Tools, Trends \& Applications

1. Programme overview..................................2

2. Information for presenters...........................3

3. Programme schedule...................................4

4. Symposium abstracts...................................20 


\section{Programme Overview}

\begin{tabular}{|c|c|c|c|c|c|c|c|c|c|c|}
\hline & & \multicolumn{2}{|c|}{ Vandrehallen } & Congress room & Room 101 & Room 102 & Room 104 & Room 105 & Room 206 & Room 215 \\
\hline \multirow{10}{*}{ 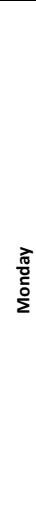 } & \begin{tabular}{|l|}
$7: 30-8: 30$ \\
$8: 30-12: 00$ \\
\end{tabular} & \multirow{9}{*}{ 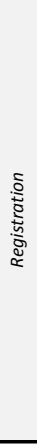 } & \multirow{9}{*}{$\begin{array}{l}\text { Life Cycle } \\
\text { Market Place }\end{array}$} & & \multirow{2}{*}{$\begin{array}{l}\text { Workshop } 1 \\
\text { LCSA }\end{array}$} & \multirow[b]{2}{*}{$\begin{array}{l}\text { Course } 1 \\
\text { USEtox } \\
\end{array}$} & & & \multirow[b]{2}{*}{$\begin{array}{c}\text { Course } 2 \\
\text { LCA and waste }\end{array}$} & \multirow[b]{2}{*}{$\begin{array}{c}\text { Course } 3 \\
\text { EcoSpold } 2\end{array}$} \\
\hline & 9:00 - 12:00 & & & & & & & & & \\
\hline & $12: 00-13: 00$ & & & & & & Installat & f posters & & \\
\hline & 13:00 - 14:00 & & & Opening & & & \multirow{6}{*}{\multicolumn{2}{|c|}{$\begin{array}{l}\text { Display/Installation of posters } \\
(13: 00-18: 30)\end{array}$}} & & \\
\hline & $14: 00-15: 20$ & & & $\begin{array}{l}\text { RS-01 Carbon } \\
\text { footprinting }\end{array}$ & RS-02 Social LCA & $\begin{array}{l}\text { RS-03 LCA of energy } \\
\text { systems }\end{array}$ & & & & \\
\hline & $15: 20-15: 50$ & & & Break & Break & Break & & & & \\
\hline & 15:50 - 17:10 & & & $\begin{array}{l}\text { RS-01 Carbon } \\
\text { footprinting }\end{array}$ & RS-02 Social LCA & \begin{tabular}{|c|}
$\begin{array}{c}\text { RS- } 03 \text { LCA of energy } \\
\text { systems }\end{array}$ \\
\end{tabular} & & & & \\
\hline & $17: 10-18: 30$ & & & \multirow[t]{2}{*}{$\begin{array}{l}\text { Workshop } 2 \text { Social } \\
\text { LCA }\end{array}$} & \multirow[t]{2}{*}{ Ecodesign Session } & \begin{tabular}{|c|} 
Installation of posters \\
$(17: 40-18: 30)$
\end{tabular} & & & & \\
\hline & 18:30 - 19:00 & & & & & & & & & \\
\hline & 19:00 - 21:30 & & & & & \multicolumn{3}{|c|}{ Poster session (Dine \& Discuss) } & & \\
\hline \multirow{11}{*}{ 荵 } & $8.30-9: 00$ & \multirow{10}{*}{ 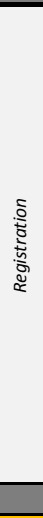 } & \multirow{10}{*}{$\begin{array}{c}\text { Life Cycle } \\
\text { Market Place }\end{array}$} & & \multirow{2}{*}{$\begin{array}{l}\text { SS-01 Teaching } \\
\text { sustainability }\end{array}$} & & \multirow{4}{*}{\multicolumn{2}{|c|}{$\begin{array}{l}\text { Dismounting of posters (posters } \\
\text { from room } 102 \text { will be transferred } \\
\text { here by the organizers on Monday) }\end{array}$}} & & \\
\hline & 9:00 - 10:00 & & & $\begin{array}{l}\text { RS-04 Non-carbon } \\
\text { footprints }\end{array}$ & & RS-05 LCM & & & & \\
\hline & 10:00 - 10:40 & & & Break & Break & Break & & & & \\
\hline & 10:40 - 12:00 & & & $\begin{array}{l}\text { RS-04 Non-carbon } \\
\text { footprints }\end{array}$ & $\begin{array}{l}\text { SS-01 Teaching } \\
\text { sustainability }\end{array}$ & $\begin{array}{l}\text { RS-06 LCA in infrastr. } \\
\text { \& build. \& waste }\end{array}$ & & & & \\
\hline & 12:00 - 13:00 & & & \multicolumn{7}{|c|}{ Lunch break } \\
\hline & $13: 00-14: 40$ & & & $\begin{array}{l}\text { RS-07 Tools \& new } \\
\text { approaches }\end{array}$ & $\begin{array}{l}\text { RS-08 LCA of } \\
\text { nanotech. }\end{array}$ & $\begin{array}{l}\text { RS-06 LCA in infrastr. } \\
\text { \& build. \& waste }\end{array}$ & & & & \\
\hline & $14: 40$ - 15:40 & & & Break & Break & Break & & & & \\
\hline & |15:40 - 17:00 & & & $\begin{array}{c}\text { RS-07 Tools \& new } \\
\text { approaches }\end{array}$ & $\begin{array}{l}\text { RS-09 LCA of } \\
\text { biotech. }\end{array}$ & $\begin{array}{l}\text { RS-06 LCA in infrastr. } \\
\text { \& build. \& waste }\end{array}$ & & & & \\
\hline & \multirow{2}{*}{\multicolumn{8}{|c|}{\begin{tabular}{|l|}
$17: 00-18: 00$ \\
$18: 00-19: 00$ \\
\end{tabular}}} & & \\
\hline & & & & & & & & & & \\
\hline & 19:00 & \multirow{6}{*}{\multicolumn{2}{|c|}{ 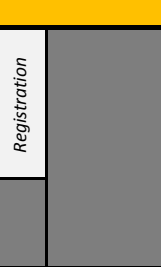 }} & & & pposium Dinner in Christ & tiania (see map) & & & \\
\hline \multirow{5}{*}{ 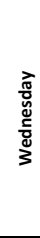 } & \multicolumn{8}{|c|}{ 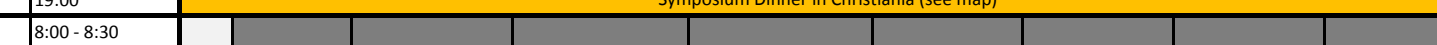 } & & \\
\hline & 9:00 - 10:20 & & & RS-09 LCA of & RS-10 LCSA & SS-02 LCA networks & & & & \\
\hline & 10:20 - 10:50 & & & Break & Break & Break & & & & \\
\hline & $10: 50$ - 12:10 & & & $\begin{array}{l}\text { RS-09 LCA of } \\
\text { biotech. }\end{array}$ & RS-10 LCSA & $\begin{array}{l}\text { RS-11 LCA of } \\
\text { transport. }\end{array}$ & & & & \\
\hline & $12: 20-13: 00$ & & & Closure & & & & & & \\
\hline
\end{tabular}




\section{Information for Presenters}

Arrive at least 15 minutes prior to the beginning of your session and bring your presentation on a USB stick to upload on the computer. Please take this opportunity to introduce yourself to the chairperson.

\section{Regular Sessions}

You are given a total of $20 \mathrm{~min}$ for presentation in regular sessions, including 5 min discussion with the audience (Questions and Answers).

\section{Special Session SS-01}

You are given a total of $15 \mathrm{~min}$ for presentation in SS-01, including 5 min discussion with the audience (Questions and Answers). A time slot at the end of the session will support general discussions on the topic with the audience (moderated by the chairpersons).

\section{Special Session SS-02}

You are given a total of 10 min for presentation in SS-02. No "Questions and Answers" will be allocated to individual presentations. Instead, a time slot at the end of the session will support general discussions on the topic with the audience (moderated by the chairpersons).

\section{Poster Session (Dine \& Discuss)}

The poster session will take place Monday 26th from 13:00 until 21:30. Posters should be mounted between 12:00 and 13:00. Poster boards with abstract numbers will be found in room 104 and 105 including the adjacent corridor. From 13:00 the poster session will be open, however poster presenters arriving after 13:00 will still have the possibility to mount their poster until 18:30. Presenters are not expected to be by their poster between 13:00 to 18:30.

At 18:30 posters in the corridor adjacent to room 104 and 105 will be moved to room 102 by the organizers. The Dine \& Discuss event will take place from 19:00 to 21:30 in room 102, 104 and 105. The event is designed to put the posters in highlight and to facilitate discussion between the presenters and the audience. Food and beverages will be provided throughout the Dine \& Discuss event. During the Dine \& Discuss event poster presenters are expected to be by their posters.

Each poster theme cluster will be sign posted. Pins or stickers will be handed out to presenters to mount their poster(s). Presenters are advised to provide an envelope where people can leave their business cards to obtain a digital copy of the poster and/or more information. 


\section{Monday, Session Schedules}

\section{Workshops}

\begin{tabular}{|l|l|}
\hline \multicolumn{2}{|l|}{ Monday, 26 November } \\
\hline Workshops & Room 101 \\
\hline 08:30 - 12:00 & $\begin{array}{l}\text { Life Cycle Sustainability Assessment - research needs? } \\
\text { A Jørgensen, Technical University of Denmark, A Zamagni, ENEA, Italy }\end{array}$ \\
\hline 17:15 - 19:00 & $\begin{array}{l}\text { Assessing social impacts in the product life cycle } \\
\text { A Wangel, KP Bozhilova-Kisheva, Technical University of Denmark }\end{array}$ \\
\hline
\end{tabular}

\section{Short Courses}

\begin{tabular}{|l|l|l|}
\hline \multicolumn{2}{|l|}{ Monday, 26 November } \\
\hline Short Courses \\
\hline 09:00 - 12:00 & $\begin{array}{l}\text { Modelling human and ecosystem impacts for life-cycle assessment: The USEtox model } \\
\text { RK Rosenbaum, Technical University of Denmark }\end{array}$ & Room 102 \\
\hline 09:00 - 12:00 & $\begin{array}{l}\text { LCA modelling of solid waste management systems } \\
\text { A Damgaard, Technical University of Denmark }\end{array}$ & Room 206 \\
\hline 09:00 - 12:00 & $\begin{array}{l}\text { EcoSpold 2 data format and creating datasets in the free ecoeditor tool } \\
\text { B Weidema, ecoinvent centre, Switzerland }\end{array}$ & Room 215 \\
\hline
\end{tabular}

\section{Interactive Events}

\begin{tabular}{|c|c|c|}
\hline Monday, $26 \mathrm{~N}$ & ovember & \\
\hline Interacti & e Events & \\
\hline $14: 00-19: 00$ & $\begin{array}{l}\text { Life Cycle Market Place } \\
\text { C Molin, Technical University of Denmark }\end{array}$ & Vandrehallen \\
\hline $17: 15-19: 00$ & $\begin{array}{l}\text { Ecodesign Session } \\
\text { N Bey, Technical University of Denmark }\end{array}$ & Room 101 \\
\hline
\end{tabular}

\section{Opening Session and Invited Speaker}

\begin{tabular}{|l|l|l|}
\hline 13:00 - 14:00 & Monday, 26 November & Congress Room \\
\hline Opening & Session and Invited speaker & \\
\hline $13: 00$ & $\begin{array}{l}\text { Welcome address } \\
\text { MZ Hauschild, Technical University of Denmark, AA Jensen, NIPSECT }\end{array}$ \\
\hline $13: 10$ & $\begin{array}{l}\text { Environmental footprint - the environmental footprint guidelines based on the life cycle approach- status on } \\
\text { the development of the harmonized European methodology for the calculation of products and companies } \\
\text { environmental footprint } \\
\text { M Galatola, European Commission, Brussels }\end{array}$ \\
\hline
\end{tabular}




\section{Monday, Oral Presentations, RS-01}

\begin{tabular}{|l|l|l|}
\hline 14:00 - 17:10 & Monday, 26 November & Congress Room \\
\hline RS-01: Carbon footprinting \\
\hline Chairpersons: C Bauer, S Ahonen \\
\hline $14: 00$ & $\begin{array}{l}\text { Modelling of electricity in life cycle inventory and carbon footprint schemes - compari- } \\
\text { sons and recommended approach. Schmidt, JH }\end{array}$ & MORS01-01 \\
\hline $14: 20$ & $\begin{array}{l}\text { Application of voluntarily purchased electricity products in carbon footprints (CFP). } \\
\text { Raadal, HL }\end{array}$ & MORS01-02 \\
\hline $14: 40$ & $\begin{array}{l}\text { Agrifood products: A comparison of existing carbon footprint systems in the world. Le } \\
\text { Pochat, S }\end{array}$ & MORS01-03 \\
\hline $15: 00$ & Case study: Environmental Assessment of pâté products. Teixeira, RFM & MORS01-04 \\
\hline $15: 20$ & Coffee break and Life Cycle Market Place visit & \\
\hline $15: 50$ & $\begin{array}{l}\text { Carbon foot-print analysis and life cycle assessment of mayonnaise production. A } \\
\text { comparison of their results and messages. Hetherington, AC }\end{array}$ & MORS01-05 \\
\hline $16: 10$ & Challenges in the use of carbon footprint for the wine sector. Vázquez-Rowe, I & MORS01-06 \\
\hline $16: 30$ & Carbon footprint of seaweed as a biofuel. Fry, JM & MORS01-07 \\
\hline $16: 50$ & $\begin{array}{l}\text { Carbon footprint of private consumption in metropolitan area, cities, semi-urban and } \\
\text { rural municipalities in Finland. Rantsi, JP }\end{array}$ & MORS01-08 \\
\hline
\end{tabular}

\section{Monday, Oral Presentations, RS-02}

\begin{tabular}{|l|l|l|}
\hline 14:00 - 17:10 & Monday, 26 November & Room 101 \\
\hline RS-02: Social Iife Cycle assessment & \multicolumn{2}{|l|}{} \\
\hline Chairpersons: C Macombe, A Jørgensen & MORS02-01 \\
\hline $14: 00$ & Aggregation in social LCA case studies. Ciroth, $A$ & MORS02-02 \\
\hline $14: 20$ & $\begin{array}{l}\text { Inclusion of occupational safety in life cycle assessment - experiences from industrial } \\
\text { practitioner. Huuskonen, AJA }\end{array}$ & MORS02-03 \\
\hline $14: 40$ & $\begin{array}{l}\text { Streamlining the social hotspots database system for the assessment of 100 product } \\
\text { categories. Aulisio, } D\end{array}$ & MORS02-04 \\
\hline $15: 00$ & Identifying social impacts in use phase scenarios: The school lunch. Wangel, $A$ & \\
\hline $15: 20$ & Coffee break and Life Cycle Market Place visit & MORS02-05 \\
\hline $15: 50$ & $\begin{array}{l}\text { Social dimension of a multi-scale life cycle assessment: The urban heat island mitiga- } \\
\text { tion in New York City. Susca, } T\end{array}$ & \\
\hline $16: 10$ & $\begin{array}{l}\text { Social impacts across the life cycle of mobile phones and improvement implications. } \\
\text { Hutchins, MJ }\end{array}$ & MORS02-06 \\
\hline $16: 30$ & $\begin{array}{l}\text { Genesis, realisation and follow up of the S-LCA of milk production in Canada: Les- } \\
\text { sons learned and challenges. Revéret, JP }\end{array}$ & MORS02-07 \\
\hline $16: 50$ & Social life cycle assessment of assembled systems with ceramic facing. Cuerda, I & MORS02-08 \\
\hline
\end{tabular}




\section{Monday, Oral Presentations, RS-03}

\begin{tabular}{|c|c|c|}
\hline $14: 00-17: 10$ & Monday, 26 November & Room 102 \\
\hline \multicolumn{3}{|c|}{ RS-03: LCA of energy systems } \\
\hline \multicolumn{3}{|c|}{ Chairpersons: C Herrmann, A Schmidt } \\
\hline 14:00 & $\begin{array}{l}\text { Mitigation of carbon dioxide }\left(\mathrm{CO}_{2}\right) \text { emissions in the future Swiss power sector: } \\
\text { Which options are most sustainable? Volkart, } K A\end{array}$ & MORS03-01 \\
\hline $14: 20$ & $\begin{array}{l}\text { Impact of geographical scope and method choice when modelling Chinese electricity } \\
\text { for carbon footprint-assessment (and LCl modelling). Løkke, S }\end{array}$ & MORS03-02 \\
\hline $14: 40$ & Life cycle assessment of regional energy supply scenarios. Rixrath, $D$ & MORS03-03 \\
\hline 15:00 & $\begin{array}{l}\text { Jam today versus jam tomorrow: The role of life cycle thinking in strategizing for a low } \\
\text { carbon energy mix in the immediate and long term. Kelly, } A\end{array}$ & MORS03-04 \\
\hline 15:20 & Coffee break and Life Cycle Market Place visit & \\
\hline $15: 50$ & $\begin{array}{l}\text { Regional carbon footprints of housing and relevance of user-inventions for heat } \\
\text { pumps. Mattinen, MK }\end{array}$ & MORS03-05 \\
\hline $16: 10$ & $\begin{array}{l}\text { Life-cycle assessment as a guided-research tool to reduce the environmental impact } \\
\text { of polymer solar cells. Espinosa, } N\end{array}$ & MORS03-06 \\
\hline $16: 30$ & $\begin{array}{l}\text { USEtox and ERA comparison for TCM (CCS Technology Centre Mongstad, Norway). } \\
\text { Askham, C }\end{array}$ & MORS03-07 \\
\hline 16:50 & Life cycle assessment of amine based post combustion carbon capture. Mertens, $J$ & MORS03-08 \\
\hline
\end{tabular}




\title{
Monday, Poster Overview, Dine \& Discuss session
}

\author{
Monday, Posters, RS-01
}

\begin{tabular}{|c|c|}
\hline 19:00 - 21:30 $\quad$ Monday, 26 November & Poster Area \\
\hline \multicolumn{2}{|l|}{ RS-01: Carbon footprinting } \\
\hline LCA and carbon footprint of innovative plastic masterbatches. The Granic ${ }^{\circledR}$ case. Benveniste, $G$ & MPRS01-01 \\
\hline $\begin{array}{l}\text { Assessing greenhouse gases emissions of sewage sludge and disposal routes - from theory to prac- } \\
\text { tice through the use of a carbon footprint tool named GESTABoues. Pradel, } M\end{array}$ & MPRS01-02 \\
\hline Evaluating improvements in farming practices with carbon footprint and energy index. Finér, A-HJ & MPRS01-03 \\
\hline Evaluation of the carbon footprint of a holiday farm: What functional unit to use? Cerutti, $A K$ & MPRS01-04 \\
\hline Carbon footprints of printing: When it is taken as a service. Chen, $S$ & MPRS01-05 \\
\hline $\begin{array}{l}\text { Carbon footprint of cyclamen production system. Main drawbacks in the application of PAS } 2050.1 . \\
\text { Anton, } A\end{array}$ & MPRS01-06 \\
\hline Remarks on consideration of life cycle assessment of jute fiber. Wong, $D$ & MPRS01-07 \\
\hline Carbon footprint of the Catalan fruit sector (focused on apple and peach). Gasol, $M$ & MPRS01-08 \\
\hline $\begin{array}{l}\text { Greenhouse gas emissions of conventional and organic beef and pork production in Lower Austria. } \\
\text { Kral, I }\end{array}$ & MPRS01-09 \\
\hline $\begin{array}{l}\text { Sustainable needs for controlling the greenhouse gas emissions as a result of the containerboard } \\
\text { production, based on the results of the LCA application. Case study: Smurfit Kappa Mexico. Carpio, } \\
\text { JC }\end{array}$ & MPRS01-10 \\
\hline Approaches to allocation of responsibility in GHG emissions. A new proposal. Berzosa, $A$ & MPRS01-11 \\
\hline
\end{tabular}

\section{Monday, Posters, RS-02}

\begin{tabular}{|c|c|}
\hline 19:00 - 21:30 Monday, 26 November & Poster Area \\
\hline \multicolumn{2}{|l|}{ RS-02: Social life cycle assessment } \\
\hline $\begin{array}{l}\text { SIS - Social Interaction Scheme Social LCA development of local communities, people and commer- } \\
\text { cial business. Junker, } K\end{array}$ & MPRS02-01 \\
\hline Integration of social aspects in product design. Franze, $\mathrm{J}$ & MPRS02-02 \\
\hline $\begin{array}{l}\text { Social assessment of sustainable recycling strategies in developing countries with focus on the infor- } \\
\text { mal sector. Case studies from Peru. Aparcana, SR }\end{array}$ & MPRS02-03 \\
\hline A tomato case study using subcategory assessment method for social life cycle assessment. Petti, $L$ & MPRS02-04 \\
\hline $\begin{array}{l}\text { Metrics for sustainable production in process industry - background, theory and development work for } \\
\text { social indicators. Husgafvel, RK }\end{array}$ & MPRS02-05 \\
\hline $\begin{array}{l}\text { Sustainability assessment of complex systems: A methodological contribution based on a case study } \\
\text { on informal collection and Re-Use of bulky waste. Obersteiner, } G\end{array}$ & MPRS02-06 \\
\hline
\end{tabular}




\section{Monday, Posters, RS-03}

\begin{tabular}{|c|c|c|}
\hline 19:00 - 21:30 & Monday, 26 November & Poster Area \\
\hline \multicolumn{3}{|c|}{ RS-03: LCA of energy systems } \\
\hline \multicolumn{2}{|c|}{$\begin{array}{l}\text { Life cycle assessment and geographical dependence study of the environmental impact of a } 222 \mathrm{kWp} \\
\text { gridconnected CdTe photovoltaic system. Serrano, SL }\end{array}$} & MPRS03-01 \\
\hline \multicolumn{2}{|c|}{ Comparative life cycle assessment of three battery types. Koroneos, $J$} & MPRS03-02 \\
\hline \multicolumn{2}{|c|}{$\begin{array}{l}\text { Towards sustainability in new energy technologies: Challenges and method of environmental impacts } \\
\text { and costs assessments through CEA's batteries assessment case studies. Naveaux, E }\end{array}$} & MPRS03-03 \\
\hline
\end{tabular}

\section{Monday, Posters, RS-04}

\begin{tabular}{|c|c|c|}
\hline 19:00 - 21:30 & Monday, 26 November & Poster Area \\
\hline \multicolumn{3}{|c|}{ RS-04: Non-carbon footprints } \\
\hline \multicolumn{2}{|c|}{$\begin{array}{l}\text { Water footprint accounting to support raw material selection: The case study of a paper company. } \\
\text { Niero, } M\end{array}$} & MPRS04-01 \\
\hline \multicolumn{2}{|c|}{ Calculating pesticide emissions for chemical footprinting of kiwifruit. Dijkman, TJ } & MPRS04-02 \\
\hline \multicolumn{2}{|c|}{$\begin{array}{l}\text { Assessing environmental sustainability in architecture through embodied energy ande ecological } \\
\text { footprint analysis. Cerutti, AK }\end{array}$} & MPRS04-03 \\
\hline \multicolumn{2}{|c|}{$\begin{array}{l}\text { A comparison between environmental indicators. Qualitative analysis and educational aspects in a } \\
\text { perspective of environmental sustainability. Cerutti, } A K\end{array}$} & MPRS04-04 \\
\hline \multicolumn{2}{|c|}{$\begin{array}{l}\text { Nitrogen footprint vs. LCIA methods - analysis of environmental impact assessment methods from a } \\
\text { nitrogen perspective and comparison with the emerging nitrogen footprint concept. Skenhall, SA }\end{array}$} & MPRS04-05 \\
\hline
\end{tabular}

\section{Monday, Posters, RS-05}

\begin{tabular}{|l|l|l}
\hline 19:00 - 21:30 & Monday, 26 November & Poster Area
\end{tabular}

\section{RS-05: Life cycle management and stakeholder involvment}

Active co-operation on comparable carbon footprinting in Finnish food sector. Pulkkinen, IM

Bridging the gap between the sustainability pillars. Ekvall, $T$ 


\section{Monday, Posters, RS-06}

\begin{tabular}{|c|c|}
\hline Monday, 26 November & Poster Area \\
\hline \multicolumn{2}{|l|}{ RS-06: LCA in infrastructure, building and waste management sectors } \\
\hline A new modeling framework for environmental assessment of waste and energy systems. Clavreul, $J$ & MPRS06-01 \\
\hline $\begin{array}{l}\text { Modified and mechanized car dismantling for improved profitability, recycling rate and environmental } \\
\text { performance of end-of-life vehicle management. Rydberg, } T\end{array}$ & MPRS06-02 \\
\hline $\begin{array}{l}\text { Sludge as a multifunctional resource - system expansion to include recycling of phosphorous from } \\
\text { Danish wastewater treatment plants. Pizzol, } M\end{array}$ & MPRS06-03 \\
\hline $\begin{array}{l}\text { Life cycle assessment of clinker manufactured in Mexico with two types of fuel: Coke or coke and } \\
\text { refuse derived fuel. Güereca, } L P\end{array}$ & MPRS06-04 \\
\hline Assessing environmental impacts of a multifunctional biogas production system. Manninen, $K R$ & MPRS06-05 \\
\hline $\begin{array}{l}\text { Comparative life cycle assessment of treatment and disposal of sewage sludge: An Italian case } \\
\text { study. Barberio, } G\end{array}$ & MPRS06-06 \\
\hline Challenges in applying LCA in landscaping. Silvenius, FMW & MPRS06-07 \\
\hline $\begin{array}{l}\text { LCA of construction and demolition waste management strategies: Case study of Rio de Janeiro, } \\
\text { Brazil. Nunes, RA }\end{array}$ & MPRS06-08 \\
\hline $\begin{array}{l}\text { Evaluation of long-term cost-effectiveness of the smart recycling for sustainable development. Fujii, } \\
M\end{array}$ & MPRS06-09 \\
\hline $\begin{array}{l}\text { Challenges in performing an LCA of an emerging technology: Active windows with micro mirror ar- } \\
\text { rays. Neumann, } U\end{array}$ & MPRS06-10 \\
\hline $\begin{array}{l}\text { A case-study comparison of life cycle inventory methodologies commonly applied to LCA studies } \\
\text { in the built environment, including the qualification and quantification of the associated uncertainty. } \\
\text { Wolff, } D K\end{array}$ & MPRS06-11 \\
\hline Luxembourg's waste management footprint. Igos, $E$ & MPRS06-12 \\
\hline $\begin{array}{l}\text { Understanding the potential environmental advantages and disadvantages of building reuse and } \\
\text { retrofit. Humbert, } S\end{array}$ & MPRS06-13 \\
\hline
\end{tabular}

\section{Monday, Posters, RS-07}

19:00 - 21:30 Monday, 26 November

Poster Area

\section{RS-07: Tools and new approaches for sustainability assessment}

\begin{tabular}{|l|l|}
\hline Application of LCA to urban metabolism as method for gauging urban sustainability. Goldstein, BP & MPRS07-01 \\
\hline Modelling choices: How the database choice affects the LCA results. Bonou, A & MPRS07-02 \\
\hline Life cycle assessment of building concepts and designs during the planning phase. Rixrath, D & MPRS07-03 \\
\hline Modelling economic and environmental impacts of the Finnish mining sector. Tuusjärvi, M & MPRS07-04 \\
\hline $\begin{array}{l}\text { Life cycle impacts assessment as a support for risks management: The case of chemotherapy drug } \\
\text { waste in a Brazilian hospital. De Souza, RG }\end{array}$ & MPRS07-05 \\
\hline
\end{tabular}




\section{Monday, Posters, RS-08}

\begin{tabular}{|l|l|l} 
19:00 - 21:30 & Monday, 26 November & Poster Area
\end{tabular}

\section{RS-08: Sustainability of nanotechnologies and nanomaterials}

New coating technologies - what does 'more sustainable' mean? Peñaloza, DF

MPRS08-01

Characterization of aggregation and dissolution rate constants of metal oxide nanoparticles in fresh- $\quad$ MPRS08-02

water. Salieri, $B$

Life cycle assessment of novel catalytic technology for water purification based on nanocatalysts.

Yaseneva, $P$

MPRS08-03

\section{Monday, Posters, RS-09}

\begin{tabular}{|c|c|}
\hline Monday, 26 November & Poster Area \\
\hline \multicolumn{2}{|l|}{ RS-09: Sustainability of bio-based products and biotechnologies } \\
\hline $\begin{array}{l}\text { Environmental sustainability assessment of bio-based products: A case study of a disposable diaper. } \\
\text { Mirabella, } N\end{array}$ & MPRS09-01 \\
\hline Life cycle impact assessment of a selection of green solvents. Khoo, $\mathrm{HH}$ & MPRS09-02 \\
\hline $\begin{array}{l}\text { Comparison of environmental performance of tractor and animal traction using a hybrid-LCA. Cerutti, } \\
A K\end{array}$ & MPRS09-03 \\
\hline $\begin{array}{l}\text { The importance of land use in a comparative life cycle assessment of a timber construction and a solid } \\
\text { structure in residential buildings. Sala, } S\end{array}$ & MPRS09-04 \\
\hline $\begin{array}{l}\text { A sustainability assessment of the implementation of anaerobic digestion as a biomass valorization } \\
\text { strategy. De Meester, } S\end{array}$ & MPRS09-05 \\
\hline $\begin{array}{l}\text { Competition for wood: Sustainability assessment of the different uses of wood in south-east Germany. } \\
\text { Lubenau, C }\end{array}$ & MPRS09-06 \\
\hline $\begin{array}{l}\text { Life cycle assessment of starch products - methodology and data availability as a challenge. Boonen, } \\
K B\end{array}$ & MPRS09-07 \\
\hline $\begin{array}{l}\text { Preliminary life cycle assessment of energy and carbon results of high ligno-cellulosic biomass pyroly- } \\
\text { sis coupled with anaerobic digestion. Salieri, B }\end{array}$ & MPRS09-08 \\
\hline $\begin{array}{l}\text { Crotonic acid production by thermal degradation of transgenic biomass and recycled bio-plastic - a } \\
\text { sustainability assessment. Nawaz, MM }\end{array}$ & MPRS09-09 \\
\hline $\begin{array}{l}\text { Life cycle assessment of biobased composite materials from flax fibers and linseed oil polymer. Deng, } \\
Y\end{array}$ & MPRS09-10 \\
\hline Petroleum-based and bio-based products in comparison. Rigamonti, $L$ & MPRS09-11 \\
\hline Ecological and economical assessment of wood biomass production in Japan. Makoto, MO & MPRS09-12 \\
\hline $\begin{array}{l}\text { Updating South African biofuel LCA studies with new inventory data relating to synthetic liquid fuels. } \\
\text { Aboyade, } A\end{array}$ & MPRS09-13 \\
\hline $\begin{array}{l}\text { The effects of sensitivity analysis in determining the optimal environmental pathway of energy crop } \\
\text { production in Ireland. Murphy, F }\end{array}$ & MPRS09-14 \\
\hline Production of wood-based ethylene in Sweden - what are potential environmental hot spots. Liptow, C & MPRS09-15 \\
\hline Environmental impact assessment of microalgae cultivation in Finnish conditions. Manninen, $K R$ & MPRS09-16 \\
\hline
\end{tabular}




\section{Monday, Posters, RS-10}

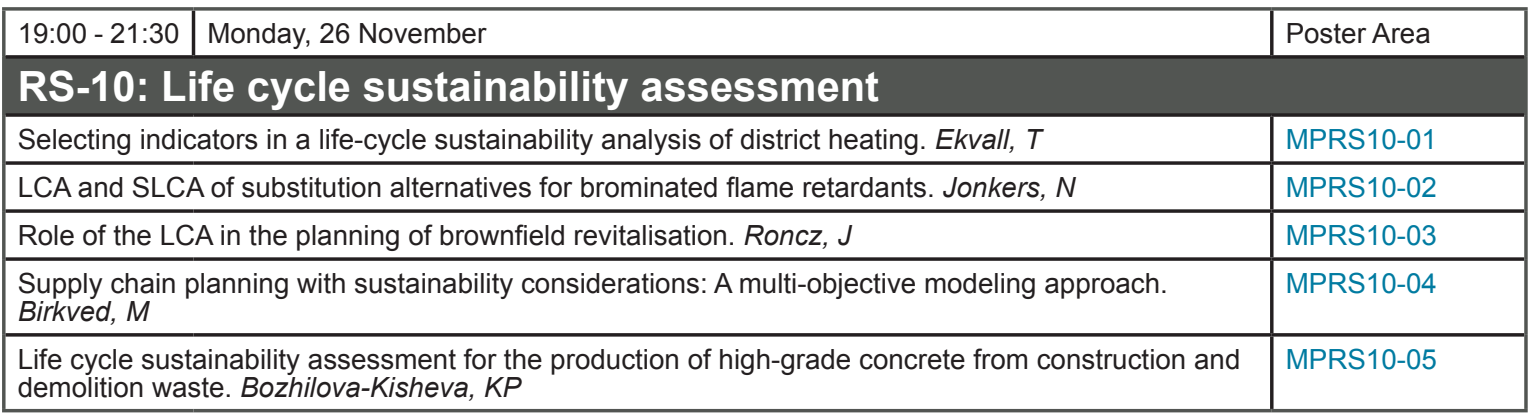

\section{Monday, Posters, RS-11}

\begin{tabular}{|c|c|}
\hline Monday, 26 November & Poster Area \\
\hline \multicolumn{2}{|l|}{ RS-11: LCA of transportation and communication } \\
\hline LCA comparison of two systems for bread packaging and distribution. Judl, $J$ & MPRS11-01 \\
\hline Life cycle assessment of the innovative electric vehicle concept MUTE. Reuter, $B$ & MPRS11-02 \\
\hline Ecodesign of operating energy rack for full electric vehicle. Sanfelix, JS & MPRS11-03 \\
\hline Challenges in assessing environmental impacts of smartphones. Judl, $J$ & MPRS11-04 \\
\hline $\begin{array}{l}\text { Challenges in environmental assessment of new media solutions - case studies of Alma Media news- } \\
\text { papers. Arushanyan, } Y\end{array}$ & MPRS11-05 \\
\hline Carbon and ecological footprints of a magazine: Print vs. tablet editions. Achachlouei, $M$ & MPRS11-06 \\
\hline
\end{tabular}

\section{Monday, Posters, RS-12}

\begin{tabular}{|c|c|c|}
\hline 19:00 - 21:30 & Monday, 26 November & Poster Area \\
\hline \multicolumn{3}{|c|}{ RS-12: LCA of food products } \\
\hline \multicolumn{2}{|c|}{ Sustainability assessment of diets-environmental and health aspects. Karlsson, EM } & MPRS12-01 \\
\hline \multicolumn{2}{|c|}{$\begin{array}{l}\text { Life cycle analysis of pesticide affects: Case of tomato production in greenhouses in Antalya. Yelboga, } \\
\text { MNM }\end{array}$} & MPRS12-02 \\
\hline \multicolumn{2}{|c|}{ Comprehensive life cycle assessment for cheese and whey products in U.S. Thoma, G } & MPRS12-03 \\
\hline \multicolumn{2}{|c|}{ The LCA of extraction processes in the food industry. Vermersch, $E$} & MPRS12-04 \\
\hline
\end{tabular}




\section{Monday, Posters, RS-13}

\begin{tabular}{|c|c|c|}
\hline 19:00 - 21:30 & Monday, 26 November & Poster Area \\
\hline \multicolumn{3}{|c|}{ RS-13: Sustainability of materials and manufacturing technologies } \\
\hline \multicolumn{2}{|c|}{ Life cycle inventory of some selected industrial minerals: A study from the IMA-Europe. Shtiza, $A$} & MPRS13-01 \\
\hline \multicolumn{2}{|c|}{$\begin{array}{l}\text { Life cycle inventory of quicklime and hydrated lime: A study from the European Lime Association } \\
\text { (EuLA). Shtiza, } A\end{array}$} & MPRS13-02 \\
\hline \multicolumn{2}{|c|}{$\begin{array}{l}\text { Comparative LCA of production of different carbons for their use as anode in Li-polymer battery. } \\
\text { Belboom, SM }\end{array}$} & MPRS13-03 \\
\hline \multicolumn{2}{|c|}{$\begin{array}{l}\text { Parameterisation of the dyeing process for the environmental optimisation of the textile production } \\
\text { chain. Faist Emmenegger, MC }\end{array}$} & MPRS13-04 \\
\hline \multicolumn{2}{|c|}{ Life cycle assessment of colloidal silica production. Collotta, $M C$} & MPRS13-05 \\
\hline \multicolumn{2}{|c|}{$\begin{array}{l}\text { An assessment of the availability and quality of } \mathrm{LCI} \text { data on packaging materials to support The } \\
\text { Sustainability Consortium's SMRS program. Humbert, } S\end{array}$} & MPRS13-06 \\
\hline
\end{tabular}

\section{Monday, Posters, RS-14}

19:00 - 21:30 Monday, 26 November

Poster Area

\section{RS-14: Guidelines and standardization in LCA}

Harmonizing LCA methodology for the European construction sector. Lasvaux, $S$

MPRS14-01

Applicability, contribution and limitation of new international standards for IT services environmental footprint characterization: Feedbacks and key learnings on the LCA of a cloud computing service. Orgelet, $J$

Who takes the blame? - PEF vs. EPD burden distribution in a case study of a tire - turf - fuel material utilization sequence. Hallberg, $E$

A new industry standard for sustainability classification of offshore suppliers. Pettersen, JB

\section{Monday, Posters, SS-01}

\begin{tabular}{|c|c|c|}
\hline 19:00 - 21:30 & Monday, 26 November & Poster Area \\
\hline \multicolumn{3}{|c|}{$\begin{array}{l}\text { SS-01: Teaching sustainability: Paving the way to a common understanding } \\
\text { and meaningful actions }\end{array}$} \\
\hline \multicolumn{2}{|c|}{$\begin{array}{l}\text { Teaching management of sustainable development in an integrated lecture at the university level. } \\
\text { Scheumann, } R\end{array}$} & MPSS01-01 \\
\hline \multicolumn{2}{|c|}{ Sustainability in energy engineering curriculum. Mälkki, H } & MPSS01-02 \\
\hline \multicolumn{2}{|c|}{$\begin{array}{l}\text { Integrating sustainability and LCA in a course on LCA and energy systems - concept and experiences. } \\
\text { Piringer, G }\end{array}$} & MPSS01-03 \\
\hline \multicolumn{2}{|c|}{ Sustainability seminars to promote life cycle thinking among value chain partners. Alles, $C M$} & MPSS01-04 \\
\hline \multicolumn{2}{|c|}{ Die Lernfabrik - teaching sustainability in production engineering. Herrmann, $C$} & MPSS01-05 \\
\hline
\end{tabular}




\section{Monday, Posters, SS-02}

19:00 - 21:30 Monday, 26 November

Poster Area

SS-02: LCA networks: What exists and how do they work?

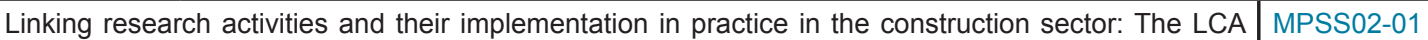
Construction 2012 experience. Lasvaux, S

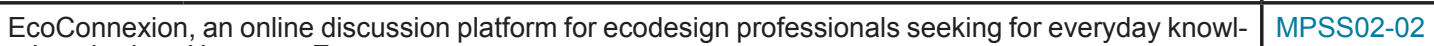
edge sharing. Naveaux, $E$ 


\section{Tuesday, Session Schedules}

\section{Tuesday, Interactive Events}

Tuesday, 27 November

Interactive Events

09:00 - 18:00

Life Cycle Market Place

C Molin, Technical University of Denmark

Vandrehallen

\section{Tuesday, Oral Presentations, SS-01}

\begin{tabular}{|c|c|c|}
\hline 08:30 - 12:00 & Tuesday, 27 November & Room 101 \\
\hline \multicolumn{3}{|c|}{$\begin{array}{l}\text { SS-01: Teaching sustainability: Paving the way to a common } \\
\text { understanding and meaningful actions }\end{array}$} \\
\hline \multicolumn{3}{|c|}{ Chairpersons: RK Rosenbaum, SI Olsen } \\
\hline 08:30 & A strategy for teaching sustainability assessment. Olsen, SI & TOSS01-01 \\
\hline 08:45 & $\begin{array}{l}\text { Science Master's Program (SMP) in sustainability: Fueling innovation through gradu- } \\
\text { ate education. Krogmann, } U\end{array}$ & TOSS01-02 \\
\hline 09:00 & Teaching LCA at an advanced level - accomplishments and challenges. Løkke, S & TOSS01-03 \\
\hline 09:15 & Learning by doing - bringing real-life case studies into the classroom. Hauschild, MZ & TOSS01-04 \\
\hline 09:30 & $\begin{array}{l}\text { Teaching life cycle management with an integrated approach of business game and } \\
\text { lecture. Egede, } P\end{array}$ & TOSS01-05 \\
\hline 09:45 & $\begin{array}{l}\text { Role-plays for teaching sustainability - paths towards ethical, critical, systemic and } \\
\text { transdisciplinary thinking. Gasso-Tortajada, } V\end{array}$ & TOSS01-06 \\
\hline 10:00 & Coffee break and Life Cycle Market Place visit & \\
\hline 10:40 & $\begin{array}{l}\text { How to integrate LCA in industry to promote its usefulness and avoid greenwashing. } \\
\text { Humbert, } S\end{array}$ & TOSS01-07 \\
\hline $10: 55$ & $\begin{array}{l}\text { The International Life Cycle Academy: A quality network for teaching in quantitative } \\
\text { sustainability assessment - the why and the how. Weidema, } B\end{array}$ & TOSS01-08 \\
\hline 11:10 & $\begin{array}{l}\text { Teaching environmental assessment methods to agronomists: Didactical problems } \\
\text { and opportunities for their curriculum. Cerutti, AK }\end{array}$ & TOSS01-09 \\
\hline $11: 25$ & ry discussion moderated by the chairs & \\
\hline
\end{tabular}




\section{Tuesday, Oral Presentations, RS-04}

\begin{tabular}{|c|c|c|}
\hline 09:00 - 12:00 & Tuesday, 27 November & Congress Room \\
\hline \multicolumn{3}{|c|}{ RS-04: Non-carbon footprints } \\
\hline \multicolumn{3}{|c|}{ Chairpersons: T Rydberg, M Birkved } \\
\hline 09:00 & $\begin{array}{l}\text { Water assessment of a hand dishwashing product using an LCA approach: Opportu- } \\
\text { nities and limitations. Van Hoof, } G\end{array}$ & TORS04-01 \\
\hline 09:20 & Integrating water footprinting into eco-design: Case study of a chair. Carteron, $E$ & TORS04-02 \\
\hline 09:40 & Estimation of the carbon and water footprint of beverages. Amienyo, $D$ & TORS04-03 \\
\hline 10:00 & Coffee break and Life Cycle Market Place visit & \\
\hline 10:40 & $\begin{array}{l}\text { Sustainability assessment of water supply in Copenhagen - what is the impact of fresh- } \\
\text { water withdrawal? Godskesen, } B G\end{array}$ & TORS04-04 \\
\hline 11:00 & Assessing chemical footprint of Europe. Sala, $S$ & TORS04-05 \\
\hline $11: 20$ & $\begin{array}{l}\text { Exploring the feasibility of chemical footprint assessment - the case of eco-toxicologi- } \\
\text { cal impacts on freshwater from pesticide use in Denmark. Bjørn, } A\end{array}$ & TORS04-06 \\
\hline 11:40 & $\begin{array}{l}\text { PlasticsEurope Eco-profiles: How to measure the sustainability of an industry? Mer- } \\
\text { siowsky, I }\end{array}$ & TORS04-07 \\
\hline
\end{tabular}

\section{Tuesday, Oral Presentations, RS-05}

\begin{tabular}{|l|l|l|}
\hline 09:00-10:00 & Tuesday, 27 November & Room 102 \\
\hline RS-05: Life cycle management and stakeholder involvement \\
\hline Chairpersons: \\
\hline 09:00 Rebitzer, N Unger \\
\hline 09:20 & $\begin{array}{l}\text { Metso LCA pilot project: Studying the feasibility of LCA framework from industrial } \\
\text { point of view. Huuskonen, AJA }\end{array}$ & TORS05-01 \\
\hline 09:40 & $\begin{array}{l}\text { Application of eco-design including life cycle assessment for improving product envi- } \\
\text { ronmental performance at Hultafors Group. Zackrisson, MO }\end{array}$ & TORS05-02 \\
\hline & $\begin{array}{l}\text { Clarifying the role of life cycle assessment in technical research and development } \\
\text { projects: Recommendations for project planning. Sandin, } G\end{array}$ & TORS05-03 \\
\hline
\end{tabular}

\section{Tuesday, Oral Presentations, RS-06}

\begin{tabular}{|c|c|c|}
\hline $10: 40-12: 00$ & Tuesday, 27 November & Room 102 \\
\hline \multicolumn{3}{|c|}{ RS-06: LCA in infrastructure, building and waste management sectors } \\
\hline \multicolumn{3}{|c|}{ Chairpersons: HF Larsen, A Damgaard, P Fantke } \\
\hline 10:40 & $\begin{array}{l}\text { LCA applied to solid waste management systems: A comprehensive review. Bakas, } \\
\text { IG }\end{array}$ & TORS06-01 \\
\hline 11:00 & $\begin{array}{l}\text { Environmental benefits from end of life treatment of composite materials - model and } \\
\text { results. Schmidt, } A\end{array}$ & TORS06-02 \\
\hline $11: 20$ & $\begin{array}{l}\text { Sensitivity and uncertainty analysis to support raw materials selection for tissue pa- } \\
\text { per: A case study of different rolls from virgin and recycled materials. Niero, } M\end{array}$ & TORS06-03 \\
\hline $11: 40$ & $\begin{array}{l}\text { The misuse of LCA-based methods to claim environmental sustainability of remedia- } \\
\text { tion technologies. Owsianiak, } M\end{array}$ & TORS06-04 \\
\hline $12: 00$ & Lunch break & \\
\hline
\end{tabular}




\section{Tuesday, Oral Presentations, RS-06}

\begin{tabular}{l|l|l|}
$\begin{array}{l}\text { Continued } \\
\text { 13:00 }\end{array}$ & Towards a modular LCA approach in urban wastewater. Morera, SM & TORS06-05 \\
\hline $13: 20$ & LCA of advanced treatment for pharmaceuticals removal from wastewater. lgos, $E$ & TORS06-06 \\
\hline $13: 40$ & $\begin{array}{l}\text { Comparative life cycle assessment of gaseous biofuels production from waste-based } \\
\text { industrial effluents. Masilela, } P\end{array}$ & TORS06-07 \\
\hline $14: 00$ & $\begin{array}{l}\text { Use of hydrated lime to improve environmental footprint of hot mix asphalt and road } \\
\text { durability. Schlegel, TS }\end{array}$ & TORS06-08 \\
\hline $14: 20$ & $\begin{array}{l}\text { The research and application of life cycle assessment in Chinese materials industry } \\
\text { Gong, } X Z\end{array}$ & TORS06-09 \\
\hline $14: 40$ & Coffee break and Life Cycle Market Place visit & \\
\hline $15: 40$ & Urban water cycle eco-efficiency assessment using LCA and LCC. Marín, D & TORS06-10 \\
\hline $16: 00$ & $\begin{array}{l}\text { Use of natural resources in the building sector: Sustainability of natural plaster materi- } \\
\text { als. Dotelli, G. }\end{array}$ & TORS06-11 \\
\hline $16: 20$ & $\begin{array}{l}\text { Environmental assessment of building in existing structures - a bottom-up approach. } \\
\text { Dettmer, } T\end{array}$ & TORS06-12 \\
\hline $16: 40$ & $\begin{array}{l}\text { Comparative life cycle assessment (LCA) of a green roof system with VYDRO® sub- } \\
\text { strate versus two conventional green roof systems using the CEN/TC 350 framework } \\
\text { Peeters, } K\end{array}$ & TORS06-13 \\
\hline
\end{tabular}

\section{Tuesday, Oral Presentations, RS-07}

\begin{tabular}{|c|c|c|}
\hline $13: 00-17: 00$ & Tuesday, 27 November & Congress Room \\
\hline \multicolumn{3}{|c|}{ RS-07: Tools and new approaches for sustainability assessment } \\
\hline \multicolumn{3}{|c|}{ Chairpersons: JC Holst, AA Jensen } \\
\hline 13:00 & User experiences of a streamlined sustainability assessment tool. Horn, $S$ & TORS07-01 \\
\hline 13:20 & $\begin{array}{l}\text { Developing and testing a model which is based on Nordic consensus on evaluating } \\
\text { bridge sustainability. Høibye, } L \text {. }\end{array}$ & TORS07-02 \\
\hline 13:40 & $\begin{array}{l}\text { Beyond eco-efficiency: Measuring environmental sustainability by extending LCA with } \\
\text { Network Analysis. Pizzol, M }\end{array}$ & TORS07-03 \\
\hline 14:00 & $\begin{array}{l}\text { Assessing the environmental and economic impacts of industrial sectors: A process- } \\
\text { based approach. Amienyo, } D\end{array}$ & TORS07-04 \\
\hline $14: 20$ & $\begin{array}{l}\text { Hybrid LCA towards sustainable management of metals: Quality- and dilution losses in } \\
\text { recycling. Nakamura, S }\end{array}$ & TORS07-05 \\
\hline $14: 40$ & Coffee break and Life Cycle Market Place visit & \\
\hline 15:40 & $\begin{array}{l}\text { Sustainability assessment and methodology for optimizing the recycling of flat panel } \\
\text { displays. Ljungkvist, } H V K\end{array}$ & TORS07-06 \\
\hline 16:00 & $\begin{array}{l}\text { Electricity producing technologies and electricity markets in ecoinvent version 3. Trey- } \\
\text { er, } K\end{array}$ & TORS07-07 \\
\hline $16: 20$ & $\begin{array}{l}\text { If you cannot measure it, you cannot manage it. Assessing environmental sustainabil- } \\
\text { ity at higher education institutions. Faghihimani, } M\end{array}$ & TORS07-08 \\
\hline $16: 40$ & $\begin{array}{l}\text { Comparing process LCA and IO-LCA: Electricity generation in a solar thermal power } \\
\text { plant in Spain. De la Rúa, C }\end{array}$ & TORS07-09 \\
\hline
\end{tabular}




\section{Tuesday, Oral Presentations, RS-08}

\begin{tabular}{|c|c|c|}
\hline $13: 00-14: 40$ & Tuesday, 27 November & Room 101 \\
\hline \multicolumn{3}{|c|}{ RS-08: Sustainability of nanotechnologies and nanomaterials } \\
\hline \multicolumn{3}{|c|}{ Chairpersons: P Masoni, SI Olsen } \\
\hline 13:00 & LCA applied to nanotechnologies: A critical review. Laurent, $A$ & TORS08-01 \\
\hline 13:20 & $\begin{array}{l}\text { Addressing challenges faced in the LCA of nanomaterials: Metal organic frameworks } \\
\text { and beyond. Griffiths, } O\end{array}$ & TORS08-02 \\
\hline 13:40 & LCA of metal nanomaterial production. Miseljic, $M$ & TORS08-03 \\
\hline 14:00 & $\begin{array}{l}\text { A framework for establishing sound inventory data of the production of engineered } \\
\text { nanomaterials and of the releases of nano objects along the complete life cycle. His- } \\
\text { chier, } R\end{array}$ & TORS08-04 \\
\hline 14:20 & LCA of nano-enabled products: Filling data gaps. Janer, $G$ & TORS08-05 \\
\hline
\end{tabular}

\section{Tuesday, Oral Presentations, RS-09}

\begin{tabular}{|l|l|l|}
\hline 15:40 - 17:00 & Tuesday, 27 November & Room 101 \\
\hline RS-09: Sustainability of bio-based products and biotechnologies \\
\hline \multicolumn{2}{|l|}{ Chairpersons: $G$ Van Hoof, MZ Hauschild, J Seppälä } \\
\hline 15:40 & $\begin{array}{l}\text { Challenges in developing a sustainability assessment framework for a new bio based } \\
\text { packaging material - experiences and findings from the Flexpakrenew project. Pih- } \\
\text { kola, HK }\end{array}$ & TORS09-01 \\
\hline 16:00 & $\begin{array}{l}\text { Using life cycle assessment to document sustainability benefits of enzymes applied in } \\
\text { the leather industry. Kløverpris, JH }\end{array}$ & TORS09-02 \\
\hline $16: 20$ & $\begin{array}{l}\text { Life cycle assessment study of a biopolymer based weed control system. Boonen, } \\
\text { K }\end{array}$ & TORS09-03 \\
\hline 16:40 & $\begin{array}{l}\text { Attributional and consequential life cycle assessment of bioethanol-based PVC. } \\
\text { Alvarenga, RAF }\end{array}$ & TORS09-04 \\
\hline
\end{tabular}




\section{Wednesday, Session Schedules}

\section{Wednesday, Oral Presentations, RS-09}

\begin{tabular}{|c|c|c|}
\hline 09:00 - 12:10 & Wednesday, 28 November & Congress Room \\
\hline \multicolumn{3}{|c|}{ RS-09: Sustainability of bio-based products and biotechnologies } \\
\hline \multicolumn{3}{|c|}{ Chairpersons: G Van Hoof, J Seppälä } \\
\hline 09:00 & Lifecycle assessment of BioMTBE- a 2nd generation biofuel. Mehta, $R$ & WORS09-01 \\
\hline 09:20 & $\begin{array}{l}\text { What is the best use of sugar crops? Environmental assessment of two potential ap- } \\
\text { plications: Biofuels vs. bioproducts. Belboom, SM }\end{array}$ & WORS09-02 \\
\hline 09:40 & $\begin{array}{l}\text { Comparative life cycle assessment of Danone Activia cups made from polystyrene } \\
\text { and polylactid. Deibl, C }\end{array}$ & WORS09-03 \\
\hline 10:00 & $\begin{array}{l}\text { Natural fibre reinforced plastics and solid wood - a comparison of terrace floorings } \\
\text { using LCA. Schmid, } M\end{array}$ & WORS09-04 \\
\hline 10:20 & Coffee break & \\
\hline $10: 50$ & $\begin{array}{l}\text { Assessing sustainability of a low-input single-farm vegetable box-scheme using } \\
\text { emergy and LCA methodology. Markussen, } M V\end{array}$ & WORS09-05 \\
\hline 11:10 & $\begin{array}{l}\text { Economical-ecological optimization asing life cycle assessment and material flow } \\
\text { cost accounting for a wood based product - an empirical study. Rieckhof, } R\end{array}$ & WORS09-06 \\
\hline $11: 30$ & $\begin{array}{l}\text { Environmental sustainability assessment of short forestry-wood chain for alpine wood } \\
\text { furniture. Mirabella, } N\end{array}$ & WORS09-07 \\
\hline $11: 50$ & $\begin{array}{l}\text { Consistent inclusion of deforestation in life cycle assessment of food products. Hum- } \\
\text { bert, } S\end{array}$ & WORS09-08 \\
\hline
\end{tabular}

\section{Wednesday, Oral Presentations, RS-10}

\begin{tabular}{|c|c|c|}
\hline $09: 00-12: 10$ & Wednesday, 28 November & Room 101 \\
\hline \multicolumn{3}{|c|}{ RS-10: Life cycle sustainability assessment } \\
\hline \multicolumn{3}{|c|}{ Chairpersons: A Zamagni, W Klöppfer } \\
\hline 09:00 & Sustainability in international standardization. Christiansen, $K$ & WORS10-01 \\
\hline 09:20 & $\begin{array}{l}\text { Holistic sustainability evaluation methods including the social dimension for industry } \\
\text { and agriculture. Saling, } P R\end{array}$ & WORS10-02 \\
\hline 09:40 & $\begin{array}{l}\text { 'Visual footprint' a new assessment tool to measure corporate sustainability leader- } \\
\text { ship integrating LCA \& SLCA aspects - a Sri Lankan case study. Fernando, C }\end{array}$ & WORS10-03 \\
\hline 10:00 & $\begin{array}{l}\text { Investigation of the prospective use of the Eco-Care-Matrix - an empirical study. } \\
\text { Skelton, } K\end{array}$ & WORS10-04 \\
\hline 10:20 & Reporting from the workshop on Life cycle sustainability assessment, Jørgensen, A & \\
\hline $10: 35$ & Coffee break & \\
\hline $10: 50$ & $\begin{array}{l}\text { Safeguarding the needs of future generations in life cycle sustainability assessment. } \\
\text { Mattila, TJ }\end{array}$ & WORS10-05 \\
\hline $11: 10$ & $\begin{array}{l}\text { Social and economic impacts in environmental indicators - electronic industry product } \\
\text { case study. Valerio, } P R\end{array}$ & WORS10-06 \\
\hline $11: 30$ & $\begin{array}{l}\text { A multi-criteria comparison of solar photovoltaic systems using thin-film or crystalline } \\
\text { silicon panels in a UK context. Howard, } R\end{array}$ & WORS10-07 \\
\hline 11:50 & $\begin{array}{l}\text { Use of LCA, LCC and SLCA-approach for sustainability assessment of water treat- } \\
\text { ment technologies - a case study. Lehmann, } A\end{array}$ & WORS10-08 \\
\hline
\end{tabular}




\section{Wednesday, Oral Presentations, SS-02}

\begin{tabular}{|c|c|c|}
\hline 08:30 - 10:20 & Wednesday, 28 November & Room 102 \\
\hline \multicolumn{3}{|c|}{ SS-02: LCA networks: What exists and how do they work? } \\
\hline \multicolumn{3}{|c|}{ Chairpersons: P Masoni, S Valdivia } \\
\hline 08:30 & Mapping and characterization of LCA networks. Bjørn, $A$ & WOSS02-01 \\
\hline 08:40 & $\begin{array}{l}\text { The ILCD Data Network: a distributed IT infrastructure for sharing and searching } \\
\text { quality-assured LCA data. Recchioni, RM }\end{array}$ & WOSS02-02 \\
\hline 08:50 & $\begin{array}{l}\text { Network among production engineering researchers - CIRP LCE (Life cycle engineer- } \\
\text { ing scientific community). Alting, } L\end{array}$ & WOSS02-03 \\
\hline 09:00 & $\begin{array}{l}\text { Life cycle assessment in Mexico: Overview and development of the Mexican LCA } \\
\text { network. Güereca, } L P\end{array}$ & WOSS02-04 \\
\hline 09:10 & From data formats to business opportunities. Rex, $E$ & WOSS02-05 \\
\hline 09:20 & $\begin{array}{l}\text { Mainstreaming life cycle approaches in Northern France through the collaborative } \\
\text { platform [avniR]. Adibi, } N\end{array}$ & WOSS02-06 \\
\hline 09:30 & CASE-LCA network - Experiences from the beginning. Tóth, KS & WOSS02-07 \\
\hline 09:40 & LCADB.sudoe: Life cycle inventories database of the southwest of Europe. Gasol, M & WOSS02-08 \\
\hline 09:50 & $\begin{array}{l}\text { Regional and country based LCA networks: Multi-stakeholder and multi-region col- } \\
\text { laboration for consistent LCA data and related databases. Sonnemann, G }\end{array}$ & WOSS02-09 \\
\hline $10: 00$ & Summary discussion moderated by the chairs & \\
\hline
\end{tabular}

\section{Wednesday, Oral Presentations, RS-11}

\begin{tabular}{|l|l|l|}
\hline 09:00 - 12:10 & Wednesday, 28 November & Room 102 \\
\hline RS-11: LCA of transportation and communication & \multicolumn{2}{|l|}{} \\
\hline Chairpersons: $N$ Bey, $W$ Dewulf \\
\hline $10: 50$ & $\begin{array}{l}\text { Comparative LCA of an electric light weight and conventional vehicle in urban driving. } \\
\text { Dura, } H E\end{array}$ & WORS11-01 \\
\hline $11: 10$ & Meta-analysis of lithium-ion traction battery LCAs. Simon, $B$ & WORS11-02 \\
\hline $11: 30$ & $\begin{array}{l}\text { The environmental impact of fluid milk delivery systems for the in-home consumption } \\
\text { in the U.S. - LCA study. Thoma, } G\end{array}$ & WORS11-03 \\
\hline $11: 50$ & $\begin{array}{l}\text { High speed rail in Norway: Method, results and reception in use of LCA for policy. } \\
\text { Pettersen, JB }\end{array}$ & WORS11-04 \\
\hline
\end{tabular}


Programme

Symposium Abstracts 


\title{
RS-01: Carbon footprinting
}

\section{MORS01-01}

\author{
Modelling of electricity in life cycle inventory and carbon footprint schemes - comparisons and \\ recommended approach
}

IH Schmidt

Aalborg University, AALBORG, Denmark

The modelling of electricity in life cycle inventory (LCI) can be done in different ways which may lead to significantly different results of life cycle based studies. Different carbon footprint schemes and practises within life cycle assessment operate with different modelling assumptions; examples are; attributional modelling in LCI, consequential modelling in LCI (short term and long term), the ILCD Handbook, the GHG-protocol, and PAS2050. The differences have given rise to debates during the last decades. Significant issues in the debate are related to the geographical delimitation of markets, spatial delimitation of the mix (historical, current, future, short-term and long-term), average electricity mix versus marginal electricity mix where constrained suppliers are excluded, and the modelling of co-products, especially when electricity is co-produced with heat.

The current presentation compares the modelling assumptions and results for GHG-emissions of electricity generation in Denmark for the following footprint schemes and modelling practises: attributional modelling, different consequential scenarios, the ILCD Handbook, the GHG-protocol, and PAS2050. The attributional and consequential modelling assumptions include the inventories available in ecoinvent v3.

Further, each of the significant issues in the debate is discussed, and a default approach is recommended for each issue. Based on this, an operational approach for identifying consistent national and regional electricity inventories for all countries and regions in the world is proposed. The proposed approach involves easy accessible data from the International Energy Agency, outlook data on electricity generation as well as fuel specific emission factors and LCI data. Further, the proposed inventory enables for calculating life cycle emissions for electricity using different consequential and attributional scenarios.

The present differences in the modelling of electricity are a source of inconsistency among footprint and LCA studies as well as a source of misleading footprint and LCA results. Hence, there is a strong need for knowing the implied assumptions behind the modelling practises and for working towards a more uniformed way of model electricity. The current presentation seeks to facilitate this by comparing different footprint schemes, addressing the significant issues and by proposing a flexible and operational approach for modelling electricity.

\section{MORS01-02}

\section{Application of voluntarily purchased electricity products in carbon footprints (CFP)}

$\underline{\text { HL Raadal }}$

\section{Ostfold Research, KRÅKERØY, Norway}

Guarantees of Origin (GOs) and Renewable Energy Certificates (RECs) represent voluntary electricity products which give consumers the possibility of demanding a specific electricity generation technology. The systems related to such voluntarily purchased electricity products open up the possibility of changing the electricity market's relationship with customers, moving from "fixed"average grid mixes (based on the geographical location of companies and electricity production facilities) to specific electricity mixes based on customers demand and choices. Thus, the system makes it possible to treat purchased electricity like the purchase of other products chosen by a company by letting the customers demand renewable electricity. However, there is a need for reaching an internationally common understanding regarding the principle of whether such products should be allowed, or not, in CFPs and LCAs. Different principles of calculating the relevant electricity mixes may cause large variations in the results. As electricity consumption represents an input to almost all CFPs/ LCAs, most of them will, to a greater or lesser degree, be affected by how this question is handled.

A GO/REC represents both a tracking instrument for proving the origin of electricity and a contractual obligation between suppliers and customers. This should make the products applicable for representing a specific electricity mix in accordance with the attributional LCA approach. The acceptance of GOs in LCAs 
means, however, that one has to accept the electricity product being divided into two separate products: (1) the environmental attributes related to the generation of the electricity, and (2) the physical electricity being delivered, whereas the environmental attributes relate to the LCA.

The presentation will show the statistics and growth in the sale of GOs/RECs in Europe and US, respectively. Examples of how CFP will be affected whether or not these products are taken into consideration will be presented, as well as proposals for major criteria for applying GOs/RECs in Carbon footprint calculations.

\title{
MORS01-03
}

\section{Agrifood products : A comparison of existing carbon footprint systems in the world}

\author{
$\underline{\text { S Le Pochat, E Laurent, R Bellino }}$
}

EVEA, NANTES, France

In 2011, EVEA and Savin Martinet Associés carried out a study on behalf of the French Agriculture Ministry (MAAPRAT 2012). The aim of this study was first to compare the different product carbon footprint (PCF) systems of agrifood products around the world, and second to give a risk analysis of competing distortion from a world trade point of view.

38 PCF systems were checked off. These systems are disseminated worldwide: Europe, North America, Asia, and Oceania. Distinctions were made firstly by system category (PCF, labels, or tools), and secondly by origin (public or private, retailer).

From these 38 systems, 14 of them providing existing PCF of agrifood products on the market were deeply analysed, 10 of which in Europe and 2 in Asia.

Furthermore, a comparison of PCF of several products was carried out. Around 300 PCF of products were reported from the 14 analysed systems and some detailed comparisons were made for 9 specific products (milk, wine, ham, bread, rice, olive oil, yogurt, potatoes, and French beans) both within a same system (intracomparison) and between different systems (inter-comparison).

Each time, interpretation has been conducted from these comparisons confronting on one hand the PCF figures and on the other hand available information related to these PCF (calculation rules, allocation, etc). For each product and each PCF system, this analysis led to identify the main influencing parameters (packaging, organic production or not, origin, varieties, recipe, etc.) and their respective level of influence on the PCF result.

Moreover, a juridical analysis was carried out in order to confront the PCF systems to the regulation rules of the 4 main following international organizations: WTO, OECD, European Union, and FAO. Indeed, regarding the specific French context about environmental labelling, the issue was: can a mandatory environmental labelling system for consumer products be authorized on the French market by international organizations?

Regarding the risk of a competing distortion that would be a case of no-compliance with the rules of the world trade, the main conclusions from this juridical focus are that such systems cannot be imposed as mandatory by a country except if they fully respect three conditions : transparency about the elaboration process of the standard, no-discrimination about the origin, and of the means regarding the claimed objectives

Conclusion

The study leads to the following conclusions:

- The different PCF systems present a great diversity regarding their respective features and in particular regarding the applied methodologies

- There is a huge variability of the PCF of products, and some methodological divergences have been demonstrated. Furthermore, very little information is usually available and most of the systems are absolutely not transparent and thus are not compliant with the only internationally recognized standard (ISO 14020). All these items lead to the conclusion that for a same product different PCF calculated within different systems are objectively not comparable. This can be very problematical for customers when different systems co-exist in the same market (eg. in France).

- For now none of the existing labelling systems could be considered as compliant with the rules of the world trade for a state to make it compulsory. 


\section{MORS01-04}

\section{Case study: Environmental assessment of pâté products}

\section{RFM Teixeira, A Himeno, L Gustavus}

\section{Bluehorse Associates, NEUILLY-SUR-SEINE, France}

Product environmental footprint, and particularly product carbon footprint $(\mathrm{PCF})$, is now driving sustainable business strategy. PCF is particularly important for food and agriculture companies, since food products have high impacts throughout their lifecycle, and particularly during the agricultural stage.

French company Hénaff (http://www.henaff.com/) based in the Bretagne region took a first step three years ago to assess the impacts of its activity by calculating the overall organization greenhouse gas (GHG) emissions ("Bilan Carbone"in France). The main conclusion was that around 90\% of the company's impact was due to sourcing materials such as food ingredients. In 2011, Hénaff partnered with Bluehorse Associates, a sustainability metrics company based in Paris, and the École Centrale Paris, to conduct its first PCF study and inquire further into the life cycle impacts of its activity. The study targeted nine different pork patés, produced with pork from different meat production systems (conventional, organic and other quality certifications), and the life cycle considered is shown in Figure 1 . The PCF study also included a detailed analysis of product nutrition. We used software application Carbonostics (http://www.carbonostics.com/), a smart lifecycle management tool designed to pinpoint the hotspots of any food product or menu along three key criteria: cost + carbon + nutrition.

Results show that the GHG emissions of Hénaff patés range from 200-330 g CO2e per 100g of product. This number is significantly lower than available international benchmarks. This is related to the fact that studies available for pork production in Bretagne (Basset-Mens and van der Werf, 2005) reveal lower emissions than pork produced elsewhere. The whole life cycle of pork production was, confirming the Bilan Carbone report, the main hotspot in the carbon footprint, accounting for more than $80 \%$ of the total GHG emissions. Energy spent for processing and packaging, the only life cycle step that Hénaff controls directly, accounts for less than $10 \%$ of the impact.

We also found that organic products have higher GHG emissions, which is an indirect consequence of the lower productivity of swine feed ingredients. Conventional pork paté has the lower emissions.

On the other hand, nutritional indicators are better for organic and certified pork patés and worse for conventional patés. So, if the reference flow is unit of nutritional indicator (e.g. calories, protein, etc.) instead of mass of product, results can be inverted. This fact highlights the difficulty of choosing a functional unit for studies on food products. The function of a food product is to provide quality nutrition, but since there are many different indicators life cycle assessment practitioners normally use simple comparisons between amounts. This may lead to biased results.

Pork meat was particularly challenging as a case study also because the choice of allocation method for pork parts has a dramatic effect on results. Patés use parts such as pork neck and fat, which share the majority of the pork production impacts. We used economic and mass allocation, and results changed significantly (more than 10\%). Some international standards recommend economic allocation (e.g. PAS2050 in the UK), while others recommend mass allocation (e.g. BPX 30323, GHG Protocol). This discrepancy is a strong limitation to interstudy comparability. 


\title{
MORS01-05
}

\section{Carbon foot-print analysis and life cycle assessment of mayonnaise production. A comparison of their results and messages}

\author{
$\underline{\text { AC Hetherington }}^{1}, \mathrm{MC} \mathrm{McManus}^{1}, \mathrm{DA} \mathrm{Gray}^{2}$ \\ ${ }^{1}$ University of Bath, BATH, United Kingdom \\ ${ }^{2}$ University of Nottingham, Division of Food Sciences, NOTTINGHAM, United Kingdom
}

A comparison of Carbon Foot-print analysis (CFA) and Life Cycle Assessment (LCA) results was performed for the mayonnaise production system. The purpose of the analysis was to ascertain both the carbon footprint and wider environmental burdens thereby identifying whether the methodologies provide a consistent message concerning hotspots within the system and determine to what extent a full LCA would provide enhanced understanding.

Mayonnaise is an oil in water emulsion containing approximately 70 - 80\% fat (Depree and Savage (2001)) .The type of oil used varies according to brand, with Kraft using predominantly soybean oil (www.kraftrecipes. com) and Hellmann's using rapeseed oil (www.hellmanns.co.uk). This paper reports on the cradle to gate CFA and LCA performed using a rapeseed oil based mayonnaise as the end product, with the functional unit of '1 tonne of rapeseed oil mayonnaise produced in UK, packaged in $600 \mathrm{~g}$ jars, palletised and ready for distribution'.

Analysis was performed in accordance with PAS2050:2011 and ISO 14040:2006 using SimaPro 7.3.2 with Life cycle impact assessment (LCIA) performed using IPCC (2007) and ReCiPe (2008) at both mid and endpoint levels.

The carbon footprint of 1 tonne of packaged \& palletised Mayonnaise was found to be 1.95 tonne $\mathrm{CO}_{2} \mathrm{e}$, with rapeseed oil providing the largest contribution, with $53.89 \%$ of the footprint. The next largest contributors were packaging glass and power consumption, with $21.43 \%$ and $13.31 \%$ of the footprint respectively.

LCIA using $\mathrm{ReCiPe}(2008)$ revealed that at the endpoint level, the largest contributors to single score were again rapeseed oil, glass and power although the most significant impact category for each of these was fossil depletion, rather than climate change, which ranked second. Similarly, climate change is not the most significant impact category when reviewing the normalised midpoint data, with the toxicity and eutrophication categories having far greater impacts. Midpoint analysis does however confirm rapeseed oil as the largest relative contributor.

The analysis performed shows that climate change is not indicated as the most significant environmental burden at either the mid or endpoint stage when the full spectrum of environmental impacts are analysed within an LCA. However whether analysed using CFA or LCA, the contribution from rapeseed oil is highlighted as the most significant within the process. Thus, information from either study would result in impact reduction efforts being targeted consistently.

\section{References}

Depreee, J.A and Savage, G.P. 2001. Physical and flavour stability of mayonnaise. Trends in Food Science \& Technology, Vol. 12, Issues 5-6, 2001, Pages 157-163

http://www.kraftrecipes.com/Products/ProductInfoDisplay.aspx?SiteId=1\&Product=2100064014, accessed $09 / 07 / 2012$

http://www.hellmanns.co.uk/products/mayonnaise.html, accessed 09/07/2012

ISO 14040:2006. Environmental management - Life cycle assessment - Principles and Framework

PAS 2050:2011, Specification for the assessment of the life cycle3 greenhouse gas emissions of goods and services, $\mathrm{BSi}$, 


\title{
MORS01-06
}

\section{Challenges in the use of carbon footprint for the wine sector}

\author{
I Vázquez-Rowe, B Rugani, E Benetto
}

CRP henri Tudor, ESCH-SUR-ALZETTE, Luxembourg

The appropriateness of using Carbon Footprint (CF) as a mechanism for communicating life cycle environmental results has prompted many firms in the wine industry to move towards eco-labelling and more sustainable production practices. However, several issues can be identified that still determine high variability in the interpretation and effectiveness of CF results and their dissemination, such as data sources and methodological assumptions, the study of organic vs. conventional farming systems and the perceived quality of the wine, the role of wine life-cycle phases, typology and market, the combination of Life Cycle Assessment (LCA) with other methods and CF calculators, the $\mathrm{CF}$ responsibility and its reporting track and guidelines.

The assimilation of $\mathrm{CF}$ for reporting in the wine sector was based on the reproduction of environmental dissemination patterns previously developed in other food and beverage sectors, but current available literature fails to provide a solid basis for the selection of this indicator for wine, as well as the advantages and limitations of using this indicator. For instance, a recent study published by Vázquez-Rowe et al. (2012) showed that important interannual variations can be found within the same appellation regarding GHG emissions, as well as strong differences when comparing available wine CF publications, highlighting the uncertainties that can be encountered in this type of studies.

Consequently, the main aim of this study is to calculate the CF of a total of 9 different wine appellations in three European countries (Italy, Luxembourg and Spain), taking into consideration the same methodological assumptions (FU, allocation, assessment methods) to determine the main causes for differing CF values between appellations, as well as the consequences that these discrepancies may originate in terms of $\mathrm{CF}$ reporting and eco-labelling.

Results show a wide range of differing values depending on the appellation and on the wine type. The mains reasons associated with these variations are linked to the different levels of input optimization in the production process, the aging time of the wine, the fertilisation and plant protection requirements of the viticulture stage or the availability and quality of data.

$\mathrm{CF}$ values prove to be difficult to standardize in a specific protocol to communicate $\mathrm{GHG}$ emission results in the wine sector, due to the variable potential markets of the different wine products and due to the potential discrepancies that may exist between the environmental and wine quality standards for a specific wine product. Nevertheless, the appropriateness of CF dissemination on a stakeholder level to report the environmental profile of wine is enriched by the popularity of the methodology and the strong relationship existing between energy inputs and other environmental impacts.

References

Vázquez-Rowe et al. 2012. Environmental analysis of Ribeiro wine from a timeline perspective: Harvest year matters when reporting environmental impacts. J Environ Manage 98, 73-83.

\section{MORS01-07}

\section{Carbon footprint of seaweed as a biofuel}

JM Fry, S Aumonier, J Joyce

ERM, OXFORD, United Kingdom

The Crown Estate manages large proportions of the UK foreshore and seabed. Part of its role is to issue leases for commercial aquaculture cultivation operations, mainly salmon and shellfish production. Apart from a food source, The Crown Estate sees further commercial potential in using the marine waters around Scotland for cultivating marine biomass, particularly seaweed, for energy purposes. As part of knowledge gathering, a study was conducted to provide a better understanding of the potential carbon footprint of large-scale seaweed cultivation in Scotland and the use of this seaweed as a feedstock for the production of: biomethane via anaerobic digestion; and bioethanol via fermentation.

The study considered the 'cradle-to-grave' impacts of biofuels, from seaweed seedling production, through to cultivation, harvesting, processing, distribution and sale, and use. To calculate the carbon footprint, the methods 
and data treatment as set out in Annex V of the EU Renewable Energy Directive (2009/28/EC) and the BSI Publicly Available Specification (PAS) 2050 (PAS 2050:2011) were used.

The results suggest that efforts to reduce the impacts of climate change from biofuel production from seaweed should focus on increasing the seaweed yield per quantity of net and on optimising the fuel conversion process. This should focus on optimising the use of co-products and, for the fermentation process, the use of enzymes as well.

\title{
MORS01-08
}

\section{Carbon footprint of private consumption in metropolitan area, cities, semi-urban and rural municipalities in Finland}

\author{
JP Rantsi, AE Nissinen
}

Finnish Environment Institute, SYKE, HELSINKI, Finland

City planning can greatly affect the carbon footprint of private consumption. It has been well recognized that by planning the greenhouse gas emissions from housing and personal traffic can be decreased, but evidently the urban structure affects also the shopping behavior and use of services. Recently it has been claimed, by using studies on consumer expenditure, that people on average tend to consume more and have larger greenhouse gas emissions from consumption in cities than in rural areas. However, when designing new urban form, the crucial question is: would the same people and households consume more and have higher emissions in cities than in rural areas? We aim to get more insight to this question by looking the consumption statistics and subsequent greenhouse gas emissions in more detail, by looking at households that belong in the same consumption expenditure category in each type of area. In the consumption expenditure survey, municipalities in Finland have been divided into four groups: Helsinki metropolitan area, cities, semi-urban and rural municipalities. Households in each municipality are divided into ten different groups (deciles) according to the money expenditure on consumption, the expenditure ranges of the groups being determined by the national average data. In the survey residents record how much money they use for the various products and services. The last survey was done 2006, and size of the sample was 4007 households and 9858 residents. The greenhouse gas emissions and carbon footprint of consumption is determined by KUHILAS model, which is so called hybridLCA model. Process-LCA approach is used for e.g. household energy use, and environmentally extended input-output-analysis of Finnish economy, i.e. ENVIMAT-model, is used for the various product and service groups. As a result, the differences between the households that belong to the same consumption expenditure in different areas are not similar as for the average consumers in different areas, and reveal interesting features. The impact of the dominant type of urban form in municipalities is evidently quite different for households that have different incomes and different possibilities to consume money. Furthermore, although the analysis reveals interesting features of the existing situation, it also implicates that the method were municipalities are divided into these four classes at the scale metropol-rural produce relevant knowledge for modeling the carbon footprint of consumption only if the new urban form supports similar consumption as the existing ones. However, availability of products and services and possibilities for e.g. local energy production are rapidly changing in both cities and rural areas, and design of urban form is one important agent in this progress.

\section{MPRS01-01}

LCA and carbon footprint of innovative plastic masterbatches. The Granic ${ }^{\circledR}$ case

G Benveniste $^{1}$, M Anglada $^{1}$, L Ferrer $^{2}$, V Oliva $^{2}$

${ }^{1}$ Cyclus Vitae Solutions S.L., BARCELONA, Spain

${ }^{2}$ Gestora Catalana de Residuos, BARCELONA, Spain

This case study introduces the Life Cycle Assessment (LCA) analysis, performed by Cyclus Vitae Solutions S.L, of the plastic products Granic ${ }^{\circledR}$ (plastic masterbatches with mineral content) produced at their plant in Barcelona (Spain). The aim of the LCA analysis is to determine and compare the environmental performance of these pellets in comparison to traditional and equivalent $100 \%$ polymer pellets. The following groups of products have been assessed: Granic ${ }^{\circledR}$ 422, Granic ${ }^{\circledR}$ 321, Granic ${ }^{\circledR} 1042$, Granic ${ }^{\circledR}$ 2042, Granic ${ }^{\circledR} 1051$ and Granic ${ }^{\circledR} 535$. This study analyzes the life cycle of these 6 products from raw materials (virgin plastic and minerals) up to the 
moment the product is sold from cradle to factory gate). Granic pellets are mineral based plastic masterbatches, combined with recycled or virgin polymers reducing the use of petrochemical derivates. Granic ${ }^{\circledR}$ masterbatches contain Calcium Carbonate and Talc that partly enable the substitution of petrochemical polymers in the total composition. The environmental impact categories assessed are:- AP: Acidification Potential - GWP: Global Warming Potential - EP: Eutrophication Potential- ADP-element: Abiotic Depletion PotentialThis study also includes a comparative analysis between the contributions to the Carbon Footprint for the pellet obtained from polymer materials and from the 6 different typologies of Granic ${ }^{\circledR}$ pellets. In order to carry out this comparison, data from the association Plastics Europe available at the PE INTERNATIONAL database in

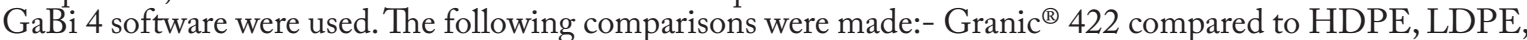
LLDPE- Granic ${ }^{\circledR} 321$ compared to HDPE, LDPE, LLDPE and recycled PE (HD, LD and LLD)- Granic ${ }^{\circledR}$ 1042 compared to virgin PP-Granic ${ }^{\circledR} 2042$ compared to virgin PS- Granic ${ }^{\circledR} 1051$ compared to virgin PPGranic $^{\circledR} 535$ compared to virgin HDPE, LDPE, LLDPEAs a general rule, for all the 6 typologies of Granic ${ }^{\circledR}$ pellet under assessment, the raw materials production stage contributes the most to all of the impact categories. This is mainly due to the fact that most of the Granic ${ }^{\circledR}$ composition is made from plastic virgin materials, whose production implies a considerable amount of resources and energy consumption. This claim is supported by the fact that for those Granic ${ }^{\circledR}$ formulation containing recycled plastic, the values for the environmental impacts categories decrease. In addition, it should be highlighted that Granic ${ }^{\circledR}$ pellets, due to their mineral content, have a significant lower carbon footprint (up to 5 times lower) compared to their equivalent plastic pellets containing polymer exclusively. For the other impact categories (acidification potential, eutrofication potential or abiotic depletion potential), it can be highlighted that the Granic $^{\circledR}$ masterbatches compared to their equivalent polymers have a lower environmental impact, due to the introduction of the mineral content in their composition.Furthermore, it is important to note that the thermal conductivity of Granic ${ }^{\circledR}$ masterbatches improves the energy efficiency of the injection process. For this reason, future studies will focus on the analysis of the environmental performance of final products containing Granic ${ }^{\circledR}$ for different applications, with the aim of assessing the environmental benefits of the use of this product in replacement of traditional $100 \%$ polymer formulations.

\title{
MPRS01-02
}

\section{Assessing greenhouse gases emissions of sewage sludge and disposal routes - from theory to practice through the use of a carbon footprint tool named GESTABoues}

\author{
M Pradel, AL Reverdy
}

\section{Irstea, MONTOLDRE, France}

Sewage sludge production in France increases continuously reaching almost 20\% (946 700 tons of dry matters in 2003 to 1118795 tons of dry matters in 2007) during the last decade. In 2007, 70\% of the produced sewage sludge was spread (directly or after composting). The remaining $30 \%$ was incinerated (with or without household wastes) or landfilled. Nowadays, sludge reduction is a major concern. This activity has to become more sustainable and stakeholders have to be careful to the environmental impacts of sludge treatment and disposal routes. To help stakeholders to better understand the carbon footprint of sludge treatment and disposal options, we developed a tool called GESTABoues.

This paper aims to present the method used to quantify material and energy flows as well as GHG emissions all along the sludge treatment and disposal processes implemented in this tool and to highlight the use of this tool through a case study.

The carbon footprint method we developed is adapted to sludge treatment and disposal processes and based on the French 'Bilan Carbone ${ }^{\oplus}$ method (ADEME 2009). GHG emissions generated by our system are quantified for $\mathrm{x}$ tons of sludge produced by a wastewater treatment plant (WWTP) of $\mathrm{x}$ per-captia-equivalents (PCE) during one year.

For each process involved in the sludge treatment and disposal routes system, three GHG are recorded (carbon dioxide, methane and nitrous oxide) and three types of emissions are considered (direct, indirect and avoided emissions). Biogenic carbon was not taken into account but its sequestration was for two types of disposal routes (land spreading and landfilling). Direct emissions are generated by each process. Indirect emissions are due to energy and chemical consumptions (combustible or electricity) to operate each process. Transports emissions (for consumables, sludges and ashes) and civil engineering emissions were taken into account. Avoided emissions are generated when products are not used and replaced by recyclable products (heat, electricity, fertilizer..).

GHG data were collected through a literature review for each type of emissions and each process of sludge treatment and disposal routes. All collected data were implemented in GESTABoues, developed with VBA 
Excel. This tool can be used in a four step procedure: wastewater treatment plant creation, implementation of sewage sludge treatment and disposal processes used for each WWTP, possibility of system comparison and GHG and mass and energy balance results export on Microsoft Word.

As a conclusion, this paper will highlight the methodological problem underlying to the assessment of sludge treatment and disposal routes as well as the possible use of such decision tool for stakeholders to identify which processes have the worst environmental impact all along the treatment and disposal chain, which emission is overwhelming and to help them selected the most interesting system from an environmental point of view through a case study.

\title{
MPRS01-03
}

\section{Evaluating improvements in farming practices with carbon footprint and energy index}

\author{
A-HJ Finér, TM Hirvi, J Laurinen, PT Lähdetie
}

\section{Raisio Group, RAISIO, Finland}

Finnish food chain effect on climate change is estimated to be $14 \%$ of total climate change effect of Finnish consumption.

Most of the food chain emissions are originated from agriculture. These emissions represents $69 \%$ of the total climate change impacts from the food chain. Based on this estimation there is a need to actively follow greenhouse gas emissions from agriculture and identify ways and means to reduce these emissions.

A method for determining the energy efficiency and environmental impact of a production of cultivation plants and for increasing positive environmental impact has been developed for Raisio Group's contractual farmers. Environmental impact and energy efficiency are characterized from contractual farmers agricultural inputoutput data. Production parameters for cultivation are selected and cultivation procedures are performed by farmers, and further, the performed procedures are documented to give required information for environmental impact assessment and energy efficiency calculation.

Farm specific input-output data is collected after a produced crop yield is harvested. A representative sample of the crop yield is delivered to laboratory analysis with the required information. The grain sample is analysed and energy content of the yield is measured. Energy index and carbon footprint of the crop yield are calculated using the representative sample information. The system boundary used for energy index and carbon footprint calculation is cradle-to-farm gate. Energy index represents a ratio of energy content of the crop yield per hectare and energy used in cultivation practices per hectare. Functional unit for carbon footprint is a grain tonne.

Agricultural input-output information has been collected from contractual farmers during harvesting seasons 2008 to 2011. The input-output database includes 2000 to 2500 grain variety specific datasets from every season. Energy index together with $\mathrm{CO} 2$ emissions of contractual farmers farming practices are estimated since 2008. Other greenhouse gas emissions are taken into account and a carbon footprint of contractual farmers' grain yield is calculated since 2009.

Development of the carbon footprint and the energy index trends are followed and the most significant factors for development are identified. Information is used for instructional purposes and also for grain product carbon footprint calculation. The method is also used to benchmark different cultivation practices and estimate new innovations' potential to reduce energy use and greenhouse gas emissions in agriculture. 


\section{MPRS01-04}

\section{Evaluation of the carbon footprint of a holiday farm: What functional unit to use?}

$\underline{\text { AK Cerutti }}^{1}$, E Cavaglià $^{1}, \mathrm{~S}$ Bruun $^{2}, \mathrm{GL}$ Beccaro $^{1}, \mathrm{D}_{\mathrm{D}}$ Donno $^{1}, \mathrm{G}$ Bounous $^{1}$

${ }^{1}$ University of Turin, GRUGLIASCO, Italy

${ }^{2}$ University of Copenhagen, COPENHAGEN, Denmark

Farm-based tourism has a long tradition in Central Europe. In recent years, there has been a significant growth in the supply of farm-based tourism in Italy. Using farms to host tourists has become more widely seen as an effective means of addressing the socio-economic problems of rural areas in general and the agricultural sector in particular. As farm tourism could support local economies and contribute to the preservation of landscapes and cultural heritage in the countryside, farm-based tourism is considered one of the most environmentally sustainable activities among touristic options. Nevertheless, environmental sustainability of holiday farms has still to be assessed. No applications of an environmental assessment method (EAM) to touristic farms can be found in the literature. This study therefore aims at modelling the environmental impacts of a farm holiday as a case study for discussing guidelines in the application of environmental certifications for this commercial activity.

The analysis has been conducted in the holyday farm "Tetto Garrone", located in Roata Rossi (Cuneo, Northern Italy). The farm covers 15 hectares of orchards (hazelnut, chestnut and walnut) managed according to the organic production protocol. The hosting system is structured as a Bed \& Breakfast: it includes a communal breakfast room and eight guest rooms which resulting from the barn conversion. The kitchen and the laundry are managed by the farm owner. Furthermore, on the roof there are photovoltaic panels which supply the whole system with electricity.

As in most holiday farms, in Tetto Garrone both the productive and the hosting sections are fully active. Therefore both sub-systems produce their specific goods or services: orchards produce nuts, accordingly the most common functional units (FU) in fruit production systems are tons of product or hectares of plantations, but the hosting structure produces a touristic service which may be accounted as number of guests multiplied by nights in one year. Furthermore, the two sub-systems are connected because, even if nut production is mostly sold outside the farm, a significant amount of fruit is consumed by guests.

In order to give a precise evaluation of the farm, the performance of four FU have been tested. We considered two simple FU of (I) 1 ton of nuts and (II) 1 guest*night; and two combined FU: (III) $1 €$ earned by the owner, this unit considers both hostelling and production, in particular, in 2011, for each euro earned, about $0,36 €$ are allocated to the touristic activity and $0,64 €$ are allocated to nut production; (III) the sum of X tons of nuts and $Y$ guest*nights of the farm, where $\mathrm{X}$ is the amount of nuts produced at the farm and $\mathrm{Y}$ is the number of guest*nights produced at the farm. This last unit would be preferred in comparative assessments, because it is possible to produce this in alternative ways in the other scenarios. Results of the fourth FU correspond to the impacts of the whole farm, but this unit allows comparison with other alternative ways of producing the same service. Results from each of the four units are compared, assessing the strengths and weaknesses of each method.

A full Life Cycle Assessment has been performed, in accordance with the guidelines and requirements of the ISO 14040, but just the characterization results in Global Warming Potential have been considered, in order to assess the Carbon Footprint of the system. 


\section{MPRS01-05}

\section{Carbon footprints of printing: When it is taken as a service}

$\underline{\mathrm{S} C h e n}{ }^{1}, \mathrm{Y}-\mathrm{P} \mathrm{Li}{ }^{1}, \mathrm{~L} \mathrm{Cao}{ }^{2}, \mathrm{~W}-\mathrm{C} \mathrm{Yue}{ }^{2}, \mathrm{Y}-\mathrm{X} \mathrm{Chen}^{3}$

${ }^{1}$ Beijing University of Technology, BEIJING, China

${ }^{2}$ Environmental Authentication Center of Ministry of Environmental Protection, BEIJING, China

${ }^{3}$ Chinese Printing Association, BEIJING, China

In concern about Global Warming, standard methodologies are required in order to quantitative evaluate GHG emissions and their reduction. Life cycle assessment is the extensively leading tool to calculate carbon footprints of products and processes. Within in the printing industry LCA was commonly performed to compare environmental impacts of various printing products. Consequentially according to the results of most of case studies, pulp and paper production were clearly an important contributors to the life cycle impacts of printing, not printing process itself.

In this study, we took printing as a service for printing products according to the current status printing industry in China, a carbon footprints calculates model of printing was built based on LCA and PAS2050. The printing process was divided into three unit processes: pro-printing, in-printing and after-printing. Differently with a product LCA assessment, only one functional unit being chosen, one printing plate was chosen as functional unit at pro-printing process, meanwhile one printed sheet was chosen functional unit at in-printing and afterprinting. Then database related to printing could be built according to the functional unit in various printing factories. It is convenient for data collecting and comparing the carbon footprints of printing processes. And when carbon footprints of a printing product are concerned, it is easy to plus the carbon footprints from the printing process to the product. In the model, data quality and results uncertainty were discussed. Two cases of printing were studies using the model.

Acknowledgement: This study is funded by the support programme of National $12^{\text {th }}$ five- year science and technology (NO. 2011BAC04B003)

\section{MPRS01-06}

\section{Carbon footprint of cyclamen production system. Main drawbacks in the application of PAS 2050.1}

$\underline{\text { A Anton }}^{1}, \mathrm{M}_{\text {Torrellas }}{ }^{1}, \mathrm{~A}$ Petit $^{2}, \mathrm{C} \mathrm{Martínez-Gassol}^{2}$

${ }^{1}$ IRTA, CABRILS (BARCELONA), Spain

${ }^{2}$ Inedit Innovació, S.L., CABRILS (BARCELONA), Spain

Carbon footprint calculations are increasingly applied to agricultural products. The specific characteristics of the agricultural sector make difficult the application of standerised rules.

A PAS 2050.1 specific requirements for horticulture was launched in March 2012, with the aim of providing supplementary requirements used in conjunction with PAS2050 (Specification for the assessment of the lifecycle greenhouse gas emissions from goods and services). Several horticultural trials, involving producers, consultancies, and research institutes have conducted to test the standards. Here, we present the case study for the calculation of the carbon footprint of cyclamen (Cyclamen persicum) production, a flower crop grown in a commercial greenhouse by the producer Cultius Itxart in Vilassar de Mar (Catalonia, Spain) in accordance with the PAS 2050.1 standard.

As specific objectives, the following points were analysed:

To calculate carbon footprint applying the specification for flower and horticulture production sector.

To determine whether the specification is a valuable addition to the existing PAS 2050.

To identify key stages/inputs/processess to include in order to establish the scope/system boundaries.

To help to define what primary data the producer needs to compile the carbon footprint of an ornamental crop.

To identify secondary data sources

After a detailed description of the inventory, we present results for the analysisi of $\mathrm{CO}_{2}$ eq $\mathrm{GHG}$ emissions. 
However, our main interest was to point out main problems found in the analyses and the assumptions taken to calculate the carbon footprint of the cyclamen production in order to improve further revisions of the standard. The main drawbacks were divided according to the following groups: functional unit, substrate, energy consumption, water consumption, fertilizers, pesticides, plant pots and trays, transport, waste management, nursery, fertilizer emissions and land use change.

The main drawbacks found were: the lack of approppiate secondary data, general consensus on the emission calculations model and the use of global data instead of local data.

\section{MPRS01-07}

\section{Remarks on consideration of life cycle assessment of jute fiber}

D Wong ${ }^{1}, \mathrm{YM} \mathrm{Sun}^{2}$

${ }^{1}$ SGS Hong Kong Ltd., HONG KONG., China

${ }^{2}$ SGS-CSTC Standards Technical Services Co., Ltd., SHANGHAI, China

The textile industry plays the important role in the global economy. Not only the consumers are looking for 'greener' products, but also the leading brands and retailers are looking for 'eco-fiber' alternatives in the supply chain in order to move forward to the sustainable production expected by the markets and the governments worldwide. The demands for "eco-fiber"are increasing nowadays.

Jute fiber is one of the many alternatives in the market, it is considered to be a potential "green"option for creating "greener" products. It demonstrates well applicable physical characteristics and offers a wide range of applications requiring durability and washability, such as sackcloth, gloves, carpets, coverings and so on. Some studies show that the land requirement for cultivating and producing the same amount of dried jute fiber comparing with other common fibers, such as wool, cotton, hemp, etc, is generally lower. In the cultivation of jute plant, the $\mathrm{CO} 2$ assimilation rate during the plant growth is higher than that of trees which is served as an important feature to support carbon sink and bringing potential positive impact to global warming. Comparing with synthetic fiber, jute also has distinct advantage especially in the amount of (fossil) energy required, which is significantly less than those synthetic ones.

The attempt to understand the current agricultural practices of jute fiber production and to identify environmental hotspots for improvements based on life cycle assessment urges the need of an aligned approach to this practice. This paper briefly describes some technical considerations when the life cycle assessment study is deduced for jute fiber. It focuses on analyzing the life cycle of jute fiber production and discusses some remarks when considering the boundary and characterizing the impacts in the hope of reaching a consistent approach for general application.

\section{MPRS01-08}

\section{Carbon footprint of the Catalan fruit sector (focused on apple and peach)}

I Vinyes, P Muñoz, M Gasol, J Rieradevall

\section{Universitat Autònoma de Barcelona (UAB), CERDANYOLA DEL VALLÈS, Spain}

In recent years, the food industry is taking actions to adapt to new habits and consumer preferences, resulting from the social and demographic changes that our society experiences. This industry is also becoming aware of the environmental implications that involves the production and consumption of their products, and is committed to open new horizons towards sustainable production to use production methods that are more efficient. Because the food industries develop a proper environmental management is essential to know the main environmental indicators of their products and production processes (emissions, energy, efficiency and water consumption, waste generation, etc.).

The carbon footprint (CFP) is an indicator of environmental sustainability which measures the total emissions of carbon dioxide (CO2-eq) generated during the Lifecycle of a product or service. The Lifecycle of a food product includes the stages of production of raw materials and transportation, production process, packaging and safe packaging manufacturing and auxiliary elements, distribution, consumption and management waste and by-products. CFP provides additional information on product features that allows some companies to set 
targets to improve its production process and its environmental performance can also be an improvement in its image in the international market.

The present paper aims to calculate the CFP of two relevant products of the fruit sector in Catalonia (region of northern Spain): apple and peach. To calculate CFP of the Catalan fruit sector, it will apply the methodology described in Standard PAS 2050, together with the methodology of Life Cycle Analysis (LCA), also the IPCC guidelines and other environmental tools. PAS 2050 Standard is based on existing methods for evaluating the life cycle established through BS EN ISO 14040 and BS EN ISO 14044 which specifies the general requirements for the assessment of life emissions of greenhouse gases (GHG) cycle of goods and services. This methodology is recent and general; this means that sometimes not at all suited to specific scenarios such as food products, which can mean that the results are highly variable. Recently a review of PAS 2050 has been published (PAS 2050-1:2012) which includes more specific requirements for calculating the carbon footprint in horticulture.

The expected results of this paper are to obtain useful environmental information and to detect critic points of fruit production process, which serve to the Catalan fruit sector and others as a tool for decision making and also to provide added value to the fruit sector, to make it more competitive, especially in the topic of exports. The results obtained will be adapted to the PAS 2050-1 because the companies involved in the fruit sector who wish may certify the carbon footprint of their products.

\section{MPRS01-09}

\section{Greenhouse gas emissions of conventional and organic beef and pork production in Lower Austria}

\section{$\underline{\text { I Kral }}$}

University of Natural Resources and Life Sciences, Vienna, VIENNA, Austria

Agriculture generates a large share of greenhouse gas (GHG) emissions worldwide. Mitigation measures in this sector can therefore contribute substantially to climate protection. The main objective of this study was to quantify GHG emissions of beef and pork production in Lower Austria. A second objective was to compare organic and conventional beef and pork production methods in terms of GHG emissions, and a third objective was to identify GHG emission hotspots for these production systems.

The study includes the entire meat production system following a life-cycle approach. The functional unit is one kilogram of beef or pork as delivered to a large commercial kitchen. The GHG emission model follows IPCC guidelines. Data are from Austrian farming statistics, Austrian farm management surveys, expert interviews and questionnaires, supplemented by data from literature and from a commercial database.

Results show that agricultural processes are responsible for $99 \%$ of the total beef GWP of $15.2 \mathrm{~kg} \mathrm{CO}_{2}$-eq (conventional) and $12.7 \mathrm{~kg} \mathrm{CO}$-eq (organic). The most important contributions to conventional and organic beef GWP are from enteric fermentation with $43 \%$ and $45 \%$, respectively, of the total GWP. Fodder production - including GHG emissions from land use change - accounts for $27 \%$ of the organic total and for $39 \%$ of the conventional total. For pork, the total GWP is estimated at $5.04 \mathrm{~kg} \mathrm{CO}$-eq for conventional production and at $3.57 \mathrm{~kg} \mathrm{CO}$-eq for organic production. Again, $98 \%$ of the total GWP stems from agriculture. Fodder production is the main contributor, with $52 \%$ and $78 \%$ of the total GWP for organic and conventional production, respectively. The second largest contributor in the agricultural sector is manure management with $15 \%$ of the total conventional GWP, and $39 \%$ of the total organic GWP.

Not surprisingly, the production of beef in Austria generates significantly higher GHG emissions than the production of an equivalent mass of pork, due to the negligible emissions of enteric fermentation in pigs. Organic production of both beef and pork has a markedly lower impact on climate change than production of conventional meat. Since downstream steps have little impact on total GHG emissions, it appears advisable to focus climate protection measures on the agricultural sector. 


\title{
MPRS01-10
}

\section{Sustainable needs for controlling the greenhouse gas emissions as a result of the containerboard production, based on the results of the LCA application. Case study: Smurfit Kappa Mexico}

\author{
LC Carpio $^{1}$, LP Güereca $^{2}$
}

\author{
${ }^{1}$ Smurfit Carton y Papel de Mexico S.A. de C.V., MEXICO, Mexico \\ ${ }^{2}$ Instituto de Ingeniería de la UNAM, MEXICO, Mexico
}

Considering the relevance that the greenhouse effect has taken in the environmental protection agendas in most of the countries, the study of the impact that every product generates is important. It has to be also considered that the packaging products also imply emissions of greenhouse gases. Mexico's "National Chamber of Pulp and Paper Industries"revealed that in 2011, from the production of 6,894 kTonnes of paper and board, the $57 \%$ of the total amount was for packaging purposes. The Chamber also revealed that in 2010 the national and imported secondary fiber utilization had the higher index in the history of the country with an 86.9.

This research aims to present a case study of Smurfit Kappa Mexico, one of the main containerboard producers leading the Latin-American packaging market with best environmental practices. Smurfit Kappa operations are defined in 20 different locations in Mexico, which include 5 paper machines, more than 3,500 employees and a national fibers collection system.

The Life Cycle Assessment (LCA) is used for this study with the objective of making a comparison between the use of virgin and the use of recycled fibers in the production of containerboard, as a complete industrial process with its implications. The inventories were constructed with the information provided by Smurfit Kappa Mexico and other official and non-official entities that who helped to complete the inventories with 2010 available data that corresponds to this industrial process.

During the results interpretation, from a direct projection of 100 years of the Greenhouse Effect impact, it is noticed that the production of containerboard with virgin fibers has a negative contribution of 30\% over the production using recycled fibers. The situation of the higher contribution of the production with virgin fibers, can be explained with the additional processes implied in the generation of the pulp which requires a bigger amount of resources as water and energy.

Because of the importance that has acquire in the present day the production of containerboard with recycled fibers in Mexico, it was decided to continue with a more sensitive interpretation of the results from the LCA application of this specific scenario. The results show that the production of the containerboard itself contributes with an $80 \%$ of the total in the Greenhouse Effect emissions, and a $14 \%$ is attributed to the transportation required for the fibers collection.

The complexity of the national collection system is originated from all the locations where the fibers have to be collected. The area and the density of population represent difficulties for the collection in some locations as the Metropolitan Area of Mexico City. In addition, the highways infrastructure in Mexico with a combination of the use of a considerably amount of high emissions trucks implies that the $\mathrm{CO}_{2}$ emissions will be higher if the innovation in logistics and different concepts are not applied for this activity.

Generally, different environmental impacts are identified in the containerboard production. For most of them there are policies and procedures. Most of the difficulties that are generated in the production of containerboard with recycled fibers, could be decreased mostly with the solution of different social situations, such as, the industrial and domestic separation of the containerboard from other wastes, which also help decreasing the emissions from the production process. 


\section{MPRS01-11}

\section{Approaches to allocation of responsibility in GHG emissions. A new proposal}

A Berzosa $^{1}$, JM Barandica ${ }^{1}$, G Fernández-Sánchez ${ }^{2}$

${ }^{1}$ Universidad Complutense de Madrid, MADRID, Spain

${ }^{2}$ Universidad Europea de Madrid, MADRID, Spain

In recent years several methodologies have been developed for the quantification of GreenHouse Gases (GHG). However, it is equally or more important to determine who is responsible for these emissions. The most widely used approach is the assignment to the producer, based on the Kyoto Protocol, although there are also proposals for their allocation to consumer (ecological footprint perspective) or a hybrid approach, called shared responsibility. In this paper it is analyzed the existing proposals and standards regarding the allocation of responsibilities of GHG emissions, focusing on its main advantages and problems. It is also proposed a new model of shared responsibility based on Best Available Technologies (BATs) that overcomes some of the existing conflicts. This new approach allocates the responsibility between the producers and the final consumer based on the capacity of each agent to save emissions. A simple case study is showed in order to exemplify the proposal. This model meets the characteristics demanded by the standards and publications for assignment of responsibilities. It constitutes a fair way to assign responsibilities pushing all the actors in the product chain (including also the consumer) to be less pollutant. 
Abstracts 


\title{
RS-02: Social life cycle assessment
}

\section{MORS02-01}

\author{
Aggregation in social LCA case studies
}

A Ciroth

GreenDeltaTC, BERLIN, Germany

As any other life cycle assessment approach, Social Life Cycle Assessment (S-LCA) requires aggregation of information over the analysed life cycle, be it inventory information or indicators that are obtained for single elements in the life cycle (i.e., for single processes for example).

Due to the nature of information in S-LCA (partly qualitative, potentially biased, ..) this aggregation is challenging, and it is more challenging than in other life cycle approaches.

The presentation will provide an overview of requirements and issues of aggregation in S-LCA; it will present and discuss solutions applied in S-LCA case studies available today, from the author and others, and, finally, provide recommendations for a sound aggregation of information in S-LCA case studies.

The presentation will use an existing real Social LCA case study on nanotextiles for demonstrating the line of argumentation.

\section{MORS02-02}

\section{Inclusion of occupational safety in life cycle assessment - experiences from industrial practitioner}

\author{
$\underline{\text { AJA Huuskonen }}^{1}$, A Korvenoja $^{2}$
}

${ }^{1}$ Metso Corporation, HELSINKI, Finland

${ }^{2}$ Metso Pulp, Paper and Power, TAMPERE, Finland

Metso has been studying the environmental impacts of a waste gasification plant through a life cycle assessment started in 2011. The study was set to cover numerous different LCA applications ranging from product development to the development of communications material. As a further aspect of the study, it was decided to study the feasibility of including occupational safety aspects in life cycle assessment. The study of occupational safety was carried out by quantifying the amounts of occupational accidents over the entire life cycle of the product. The significance of occupational accidents was assessed by calculating their impacts on human health using DALYs as metrics. The human health impacts resulting from occupational accidents were then compared with those resulting from the release of emissions to air, water and soil in order to determine their relevance considering the big picture. This also provided information about possible trade-offs between environmental impacts and occupational accidents. The outcomes of this study indicate that there is a potential for trade-offs between environmental impacts and occupational safety. The study also highlights the findings of earlier studies: the occupational accidents are not the main source of impacts on human health. Still, there is a need to evaluate the impacts of any decisions made based on LCA studies in order to determine their impacts on occupational safety. There are however some severe drawbacks when it comes to including occupational safety in LCA. They are mainly related to uncertainties, but also to unavoidable value choices and some methodological issues. Due to these limitations, quantitative LCA might not be the best tool for studying occupational safety from life cycle perspective. It is nonetheless a necessary intermediate step when developing better solutions to address the problem. 


\title{
MORS02-03
}

\author{
Streamlining the Social Hotspots Database system for the assessment of 100 product categories \\ D Aulisio, C Benoît Norris, GA Norris
}

New Earth, YORK BEACH, ME, United States of America

Data collection, or the inventory step, is often the most labor-intensive undertaking of any Life Cycle Assessment (LCA) study. Collecting site-specific information on a company-by-company, or unit process, basis would be ideal, but with the complexity of supply chains for most of today's globalized products, this bottom-up approach is impractical. As a precursor to a full Social LCA study, Social Hotspots should be identified first in order to refine the analyst's data collection efforts. Hotspots are production activities in the life cycle (i.e., unit processes), associated with a country-specific sector (CSS), that provide a higher opportunity to address issues of concern (e.g., human and worker rights, community well-being, etc.), as well as highlight potential risks of violations, damage to reputation, or issues that need to be considered when doing business in a specific sector and country [1].

The Social Hotspots Database (SHDB, www.socialhotspot.org) developed by New Earth provides generic (i.e., top-down) country and sector-level statistics relative to social issues in product life cycles. Social Theme Tables, such as Child Labor, Occupational Hazards, Human Health, etc. are populated with relevant quantitative indicators and qualitative information, which are then characterized for their level of risk (e.g., low, medium, high, very high) within a CSS. The SHDB system also comprises a Worker Hours Model, built from global economic input-output data derived from the Global Trade Analysis Project's database. Both the ranking of worker hour intensity and the risk levels across multiple Social Themes for the CSS within a product category supply chain are used to calculate Social Hotspots Indexes using an additive weighting method. The CSS with the highest Indexes are highlighted as Social Hotspots within the supply chain of the product in question.

The SHDB was used effectively for seven detailed pilot studies [2] and the system was then streamlined for approximately 100 different consumer products. Results of the streamlined product category assessments will be applied in The Sustainability Consortium's Sustainability Measurement and Reporting System. For the platform presentation, a comprehensive representation of the streamlined SHDB methodology will be illustrated with an example of a single product category. An overview and summary of the entire set of results will also be presented. The limits of the approach and some future research avenues for improving the robustness of this type of analysis will be outlined. Most importantly, as we shed light on these social impacts of production using the SHDB and Social LCA, it is still imperative to find and propose workable solutions that will improve the social conditions in those areas where workers, their families and communities, and society at large are most vulnerable.

[1] UNEP/SETAC, Benoît, C., Mazijn B. (eds) (2009): Guidelines for Social Life Cycle Assessment of Products, United Nations Environment Programme.

[2] Benoît Norris, Catherine, Deana Aulisio, Gregory A. Norris. (forthcoming). Working with the Social Hotspots Database - Methodology and Findings from 7 Social Scoping Assessments. 19th CIRP International Conference on Life Cycle Engineering, Berkeley.

\section{MORS02-04}

\section{Identifying social impacts in use phase scenarios: The school lunch}

\section{A Wangel}

Technical University of Denmark, KGS. LYNGBY, Denmark

Only a few cases of Social Life Cycle Assessment (SLCA) addressing the use phase exist. One problem seems to be that SLCA inherits from LCA a strict focus on technical utility and the requirement of functional equivalence when comparing products. In the UNEP-SETAC Guidelines for SLCA 2009, only limited attention is paid to the social and symbolic functions for the consumer of a particular product. As such, SLCA does not respond to e.g. the users' needs satisfaction, the value of the product for the user or society or the changes in the users' behaviour as a result of using the product. The paper will explore three different scenarios of delivering the functional unit of a varied and nutritious meal on a daily basis provided for school children at a certain age:

(a) the meal is prepared at home by the parents as part of the household consumption and activities; 
(b) the meal is prepared in a central, industrial kitchen and delivered by a catering service company;

(c) the meal is prepared by the schoolchildren themselves as part of the teaching activities,

to discuss which are the relevant social impacts for each scenario of delivering that 'technical' utility, and how can indicators be defined to adequately reflect these impacts. This may include social indicators on personal identity and freedom, social coherence, health education etc. Also, the integration of environmental and social impact assessment will be discussed.

The scenarios further involve the challenge to current SLCA studies that they refer not only to a range of stakeholder groups, but to an institutional context of stakeholder relations. The paper will discuss options for a participatory process of identifying impact categories and defining indicators, and discuss possible implications for the assessment of product-service systems.

\section{MORS02-05}

\section{Social dimension of a multi-scale life cycle assessment: the urban heat island mitigation in New York City}

\section{T Susca}

\section{ENEA, BOLOGNA, Italy}

In the next years the number of cities plagued by the urban heat island (UHI) will likely grow because of the increase in urban population. This will cause the increase in heat-related mortality especially among old people and people with social or physical vulnerability and the exacerbation of cardiovascular and respiratory diseases. Previous studies show that the raise in urban albedo - for instance obtained through the conversion of dark roofs into high-albedo ones - can contribute to mitigate the UHI. Recent studies have evaluated, through the use of the Life Cycle Assessment (LCA) methodology, the environmental burdens of white roofs considering the contribution of the surface albedo on radiative forcings. However, no LCA studies have been found in published literature in which the interaction between surface albedo and urban climate has been evaluated.

The main aims of this study are:

- to evaluate the effect deriving by the urban-wide increase in rooftops' albedo on urban climate and then on human health;

- to broaden the application of LCA methodology to the urban environment and to increase its spatial resolution through the use of a hybrid analysis and a multi-scale approach.

The case study of the urban-wide conversion of black roofs into white ones has been hypothesized in New York City. The case study of New York City has been chosen because it is the most populous metropolitan area in the U.S. and the mitigation of its UHI can contribute to the well-being of many people.

In the common practice the city-wide substitution of black roofs with white ones would be downscaled to a functional unit - for instance one square meter of roof - by omitting the effect on climate and then on human health. In this study the effect of the decrease in summer temperature and the consequent social impacts (i.e., the impact on human health) have been evaluated. The impact on human heath has been evaluated in the timehorizon of 100 years and has been referred to the use-phase of the roof instead of to its supply chain.

The research has been developed as follows:

- the UHI in the city has been detected through the use of climatological data;

- the decrease in summer temperature due to the city-wide increase in rooftop albedo has been assessed through the use of an existing climatological model;

- epidemiological data have been used for assessing the decrease in mortality for natural causes during summer due to the UHI mitigation;

- through the use of statistical data, the avoided deaths, due to the UHI mitigation, have been converted in disability adjusted life years and downscaled to one square meter of roof;

- a LCA study about one square meter of white roof has been conducted and the incidence of avoided impact on human health has been calculated.

In the life cycle inventory of the white roof all the elementary flows of a common roof representative of most roofs in New York City have been considered. Just the energy use has been omitted since it varies from one building to another. Thus any generalization about it would be incorrect because it would assume that it is 
uniform and this rarely happens.

By the analyses it results that the raise in the city-wide rooftop albedo significantly decreases the impact on human-health impact category revealing the importance of the use of an LCA multi-scale approach especially when the urban environment is involved.

\title{
MORS02-06
}

\section{Social impacts across the life cycle of mobile phones and improvement implications}

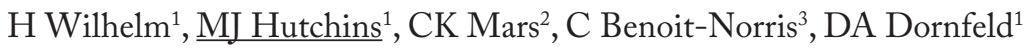

${ }^{1}$ University of California, Berkeley, BERKELEY, United States of America

${ }^{2}$ Arizona State University, TEMPE, United States of America

${ }^{3} \mathrm{New}$ Earth, YORK BEACH, United States of America

With the rising importance of sustainability, academia and industry have a shared interest in further developing life cycle sustainability assessment (LCSA) methodologies which consider the impacts from all three pillars of sustainability - society, environment, and economics. There are substantial challenges to identifying the social impacts associated with industrial activities and consumer products in order to complete such an assessment. Furthermore, social, environmental, and economic impacts are often linked and mechanisms for exploring those linkages are lacking. The electronics industry has been a leader in understanding how to incorporate a triple bottom line approach into their operations due to early recognition of the global reach of its supply chain and the breath of potential environmental and social impacts throughout the life cycle of an electronic product. While there is an understanding of the social impacts associated with some products (e.g., notebook computers), and some life cycle phases (e.g., chemical exposure during manufacturing), there is only a nascent understanding of the social impacts of the life cycles of electronics products.

The research presented here seeks to expand the understanding of social impacts of the electronics sector by examining the life cycle of mobile phones and considering the environmental and economic ramifications of addressing the identified social impacts. The objectives are three-fold: to identify i) the social impacts across the life cycle of mobile phones, ii) opportunities to improve those impacts and iii) potential environmental and economic impacts of implementing those improvement opportunities. Through this case study on mobile phones, a framework for considering different improvement opportunities that can affect social impacts is presented. A second framework for considering the potential environmental and economic impacts of implementing the improvement opportunities is also presented. This work highlights that i) there are both the positive and negative social impacts of electronic products, ii) many improvements to social impacts have an economic and environmental benefit, and iii) trade-offs are sometimes necessary when addressing sustainability holistically.

\section{MORS02-07}

\section{Genesis, realisation and follow up of the S-LCA of milk production in Canada: Lessons learned and challenges}

\author{
IP Revéret $^{1}, \mathrm{~J}$ Parent ${ }^{1}, \mathrm{JM}$ Couture ${ }^{2}$
}

${ }^{1}$ International Chair on Life Cycle, Polytechnique/ESG UQAM, MONTREAL, Canada

${ }^{2}$ Groupe AGECO, QUEBEC, Canada

Over the years, the agricultural sector and the livestock and dairy sectors in particular have been increasingly criticised for their environmental impacts, especially in regards to greenhouse gases emissions. At the same time, there has been a growing awareness that farm activities equally induce significant social and economic impacts over a wide range of stakeholders.

In order to face the new challenges arising from this context and to clarify the path towards sustainable milk production in Canada, the Dairy Farmers of Canada (DFC) commissioned the realisation of the Social and Environmental Life Cycle Assessment (SELCA) of Canadian Milk. Launched in 2010, this project ended in September 2012. This project was conducted as part of the Dairy Research Cluster. 
The study was conducted by three partners -two consulting firms (Groupe AGECO and Quantis) and a research centre (CIRAIG) based at the Montreal Polytechnic, in collaboration with a team at University of Quebec in Montreal- and aimed at providing a comprehensive assessment of the Canadian milk production sector in respect to sustainability. The main deliverables include an environmental profile of the average kilogram of milk produced in Canada, as well as an evaluation of the socioeconomic performance of the Canadian dairy sector.

In this presentation we shall first address the results and the methodological as well as conceptual advances in the social component of the LCA. We shall also share the numerous occasions when we were faced with the limits of some poorly-debated issues in the SLCA literature and in the "guidelines"(UNEP/SETAC 2009) such as the need of symmetry for the social and environmental systems' boundaries and the relevance of reporting social performance over the functional unit.

We shall also look at this project in its institutional context and explore its genesis from the initial discussions with the client. Upstream of the project we shall explore how it was developed in a multidimensional context in which increasing recognition of the role of Corporate Social Responsibility (CSR) in agriculture and the adoption of enabling agricultural financing programs facilitated its conception. We propose to read this increasing interest in LCA (both social and environmental) by considering the practical role of LCA researchers and practitioners in Quebec and Canada to stimulate the adoption of enabling policies and programs. This analysis will be grounded on the approach in terms of epistemic community (Haas 1992, Smouts 2001) applied to the LCA community.

Downstream of the project, we shall consider some issues linked to the different types of use that are considered by the client and how the project team can contribute to this post study series of activities. In particular we shall explore how the different organisational levels mobilised by the project -the DFC, the provincial organisations and the individual farms- did not necessarily have the same understanding of the issues at stake and therefore of the priorities of action.

Haas, P. (1992) Introduction: epistemic communities and international policy coordination, International Organization 46:1, 1-35

Smouts, M.C. (2001) Forêts tropicales, Jungles internationales: Les revers d'une écopolitique mondiale. Presses de Sciences Po. Paris

UNEP/SETAC (2009). Guidelines for Social Life Cycle Assessment of Products. United Nations Environment Programme. Paris.

\section{MORS02-08}

\section{Social life cycle assessment of assembled systems with ceramic facing}

\section{Cuerda, FJ Neila}

Technical University of Madrid, MADRID, Spain

Finding ways to evaluate the sustainable behaviour of the Construction sector has become a priority in scientific and political level. Construction sector is not only responsible of environmental impacts and high consumption of energy but also for 20 million workers in the European Union. Life Cycle Thinking has been recognize as a valuable approach to guide the evaluation of sustainability in products and this has lead to the adoption of the Environmental Life Cycle Assessment methodology as the baseline for the drafting of the documents dealing with the assessment of social aspects.

On the scientific level the assessment of social aspects has been addressed in the past years in several works. The main goals of those works were to find the protection areas or topics that had to be analyzed and to find the right indicators to measure them. There are not many cases regarding the construction sector and their products.

On the standardisation level the Working group 5 "Social performance assessment of building" of the CEN 350 "Sustainability of construction works"technical committee is carrying out the works in Europe for the assessment of the social performance. Nowadays there are two normative references: EN 15643-3 Sustainability of construction works "' Assessment of buildings "' Part 3: Framework for the assessment of social performance, and prEN 16309 Sustainability of construction works - Assessment of social performance of buildings Methodology. In both cases there are generic documents, it is acknowledge by the editors themselves that they will change substantially in their next versions.

The objective of the work is to evaluate the social impact of different solutions to assembled systems with a ceramic facing. The expected impact of the project, promoted by the ceramic tile sector, is to help architects to 
select the better ceramic tile for their building. This goal will be achieved by giving them information about the performance of the different solutions in order to give them the chance to choose between them. In the project there will be taken into account not only social performance but also technical, environmental and economic performance.

A methodology, based on the UNEP-SETAC Guidelines for Social Life Cycle Assessment of Products and the Methodological Sheets of Sub-Categories of Impact for a Social LCA, has been developed inside the project to evaluate the social performance of the different assembled systems. The methodology takes into account all the phases of the life cycle of the assembled system and evaluates the impact into the diverse stakeholders involved in the different phases. There are results of the social assessment for two façades, two vertical partitions and two horizontal partitions.

The work was made without the participation of the ceramic tile companies. The main learning extracted from the work is that the results can be useful to individuate hotspots of the impacts in each stakeholder and to help to focus the following research on them. There has been individuated the need to get into touch with the different stakeholders to be able to define the indicators to measure what they think it is important and to have accurate data. The indicators used are still too general and there is also an important lack of data about impact on society due to the construction sector.

\title{
MPRS02-01
}

\section{SIS - Social Interaction Scheme Social LCA development of local communities, people and commercial businesses}

\author{
K Junker, P Eriksen
}

\section{Moth \& Partners International A/S, SLAGELSE, Denmark}

Introduction

SIS is a global "ready-to-use"conceptual LCA management tool increasing values of projects in local communities (Social and Commercial).

SIS utilizes existing systems in a new holistic way to develop local communities and eases the transition between politics and people.

SIS strengthens local businesses, personal identities, social network, environment, skills raising and innovation.

SIS works in the gap between stakeholders, where it breaks up, and re-thinks existing patterns to drive positive behavior changes to people.

Where to use SIS

SIS can be used in Building projects, Social related projects, Developing countries and Disaster areas

SIS achieves

Using the SIS scheme creates local involvement, local employment, increased skills, social responsibility, sustainable leadership, local involvement, networking, improved life quality, sustainable projects and targeted micro environments.

Research and further studies

The concept is developed from Moth \& Partners extensive knowledge as building sector consultants in cooperation with universities working with social topics, private enterprises and governmental bodies.

Further studies will include concept development, transition between governmental bodies and communities as well as behaviour changes for communities and people living in them.

www.sis-scheme.co.uk 


\section{MPRS02-02}

\section{Integration of social aspects in product design}

J Franze, A Ciroth

\section{GreenDeltaTC, BERLIN, Germany}

The conduction of Life Cycle Analyses is in general very resource intensive what deters many companies from conducting such studies, but particularly for companies as product designers and producers it would very important to analyse product performance in a life cycle perspective to avoid negative impacts on society. The high intensity of labour is especially an issue in the product design phase where a large part of future impacts are determined, though, defining the characteristics of products and thus indirectly also large parts of their life cycle. For the environmental dimension there are already methods which meet these special requirements. However, there are no corresponding tools for the social dimension.

First of all, the presentation will dwell on special requirements for "socio-design"methods. Then a sociodesign approach, based on the SLCA methodology, will be introduced. The concept provides that in a first step social acceptable purchase opportunities for used materials are checked: 1 . Is the material produced in a social acceptable way? 2. Is there enough social acceptable material available in the market with regard to the planned production volume? In a second step, materials that are not available in a social acceptable version or not in sufficient quantity are whenever possible replaced through others. Specific purchase decisions, e.g. which material from which supplier, are taken in the buying department and do not concern the design process.

\section{MPRS02-03}

\section{Social assessment of sustainable recycling strategies in developing countries with focus on the informal sector. Case studies from Peru}

\section{$\underline{\text { SR Aparcana }}$}

Institute of Waste Management, University of Natural Resources and Life Sciences, VIENNA, Austria

The goal of this work is the social assessment of sustainable waste management strategies using the case of Peru as an example. The main aspect is the formalisation of the informal sector involved in different stages of a waste management system. This sector is defined as the individuals or groups that carry out various activities within the waste management system. The informal sector focuses mainly on recycling and therefore contributes significantly to the recycling rates and to the waste management of many cities in developing and emerging countries. For example, in Lima and Callao (Peru), about $19.7 \%$ of the municipal waste is recycled by the informal sector and only about $0.3 \%$ is recycled by the formal sector.

Common social problems of this sector are the inappropriate working conditions that endanger health and safety. Frequently children, pregnant women, the elderly and other people who have no opportunity to work in the formal sector work in the informal sector. With the implementation of formalisation strategies the reduction or elimination of these problems are expected. However these positive social impacts are mainly assumed and have not be precisely measured and evaluated. The strategies for the informal recyclers' integration into the formal recycling system are expected to be socially sustainable and to improve of their social conditions; nevertheless these social effects cannot be verified.

In order to assess the formalisation strategies in relation to their contribution to the social sustainability an approach oriented towards the Social Life Cycle Assessment Methodology was developed. sLCA is under development and is originally applied for products and their production chains. Its procedures and methods of characterisation are not available or standardised yet. For the developed approach to assess the social impacts of formalisation strategies, only the impacts in relation to the formalised recyclers are considered.

Based on a literature review three social impact categories were identified to determine the social impacts on recyclers: human rights, working conditions and society. These were subdivided into 10 social impact subcategories, e.g. Child labour, working hours, social acceptance, etc. Regarding the indicators to express the data of each subcategory 27 semi quantitative indicators were developed. Examples of the indicators are: the non-existence of working children (child labour), average wage is equal to or higher than the average wage in this sector, absence of unjustified wage reductions, full access to health care programs, etc. Regarding the proposed characterisation approach a scoring system based on the compliance and no compliance of social criteria for each impact subcategory was developed. The final aggregation is done by adding up the scores and 
calculating their average by each subcategory.

In a recent field investigation a data collection of three Peruvian communities was done; two based on cooperation with association of recyclers and the other one with a municipal waste management system with recyclers as formal municipal workers. The information was collected through interviews with the local stakeholders linked to the waste management systems. The aim was the assessment of this data using the proposed methodology and the previously defined indicators. Currently the obtained data is being analysed and the results will be reported in the next phase of this work.

\title{
MPRS02-04
}

\section{A tomato case study using subcategory assessment method for social life cycle assessment}

\author{
PK Sanchez Ramirez ${ }^{1}$, CM Lie Ugaya ${ }^{2}, \mathrm{RV}$ Vicoli $^{1}, \mathrm{~S}$ Vaira $^{3}, \underline{L}_{\text {Petti }}{ }^{1}$
}

${ }^{1} \mathrm{G}$. d'Annunzio University, PESCARA, Italy

${ }^{2}$ Federal Technological University of Parana, CURITIBA, Brazil

${ }^{3}$ Ortogranda, PIEMONTE, Italy

Social issues are becoming among the most relevant factors for competitiveness and profitability of enterprises. To address systematically the responses from companies to social issues the methodologySocial Life Cycle Assessment (S-LCA) is becoming more and more widespread. S-LCA is a new technique which assesses potential positive and negative social impacts of all life-cycle stages, from cradle to grave, of products and services. S-LCA is still considered new in the scientific community. Although, S-LCA presents a well-defined structure, based on ISO 14040, and guidelines, from UNEP and SETAC (2009), there is a need for case studies to help its improvement. S-LCA follows four phases, similarly to an (environmental) LCA: goal and scope definition, inventory analysis, impact assessment and interpretation; nevertheless it requires adaptations. This paper focuses on the impact assessment phase, which goes from raw data to impacts. Over the years, some limited methods for stakeholder categories related to subcategories have been presented in the literature. Ramirez et al. (2012) developed SAM (Subcategory Assessment Method, which enables analysing the organization behaviour in four levels (A, B, C and D) for each subcategory. Fulfilling Level B means that the organization fulfils a basic requirement defined for each subcategory, based on International Agreements. Level A means that the organization shows a proactive behaviour than established in the basic requirement. Levels C and D do not meet the basic requirement and are differentiated by generic data, which provides background information concerning the possibility environment to have a positive outlook to social issues. SAM was applied to the "cuore di bue"tomato from Ortogranda, which proved the feasibility of collecting data and evaluating the product with SAM. The method could also be implemented for the entire product life cycle, notwithstanding, it should be clear that S-LCA is as time and work demanding as (environmental) LCA, because the information changes from company to company, sector to sector and region to region.

\section{MPRS02-05}

\section{Metrics for sustainable production in process industry - background, theory and development work for social indicators}

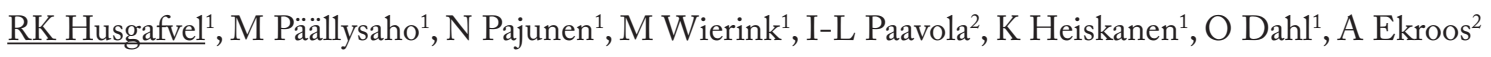

${ }^{1}$ Aalto University, ESPOO, Finland

\section{${ }^{2}$ University of Helsinki, HELSINKI, Finland}

Sustainable development as the leading global development paradigm and sustainability as a cornerstone of modern industrial development have guided this development work for social metrics for process industry. It is recognised that informed decision-making and strategic management require continuous feed of comprehensive information concerning the sustainability performance of industrial production covering all elements of sustainability: economic, social and environmental. This study addressed the development of social metrics for process industry and for metal production at the plant level in particular. The developed social indicators are one part of the overall sustainability index which aims at presenting a balanced and holistic view of plant level sustainability performance encompassing information on all the different dimensions. In general, 
the current indicators of industrial sustainability mainly satisfy the needs of corporate level management and capital investors. Therefore, plant level indicators are critically needed to support and fill in potential gaps in corporate level assessments and management with special emphasis on local and plant level activities, conditions and sustainable development trends. Additionally, the purpose for the development of social indicators was to bring the concept of the sustainability and associated performance to the operational plant level. Consequently, the social part of the overall index provides information on both in-plant sustainability performance and on the direct and in-direct impacts of plant operations on the surrounding society including various stakeholders, interest groups and citizens.

\section{MPRS02-06}

Sustainability assessment of complex systems: a methodological contribution based on a case study on informal collection and re-use of bulky waste

$\underline{\text { G Obersteiner }^{1}}$, J Den Boer ${ }^{2}$, R Linzner ${ }^{1}$

${ }^{1}$ Institute of Waste Management, VIENNA, Austria

${ }^{2}$ Wameco, WROCLAW, Poland

Informal waste collection - picking up recyclable materials from the waste stream in order to make a living by processing or reselling secondary raw materials or goods - is well known from developing countries. So called scavengers or waste pickers collect waste (mostly recyclables, like metals, plastics, glass) from landfills or directly from households or streets. Yet, also waste electrical and electronic equipment (WEEE) is collected and dismantled by actors in the informal sector to separate valuable metals. Existence of a similar situation also in Central Europe has more or less been neglected to date. If something is not used or does not work anymore it ends up as waste. In our modern consumer society people rarely think of these items as being valuable. But for informal collectors this waste - actually re-usable items - has a great value.

The European informal collectors are collecting commodities in one of the economic well-developed EU member states, bring it to their home countries (in most of the cases they come from CEE countries) and sell it at flea markets. In contrast to the situation in developing countries mainly bulky waste, metal, WEEE and textiles are collected. On the other hand the formal system of modern waste management depends on revenues from recyclable fractions for the funding of their necessary infrastructures. Therefore the activities from those waste pickers are disliked as illegal.

The project TransWaste (www.transwaste.eu), a project within the CENTRAL EUROPE programme cofinanced by the ERDF, provides the opportunity to investigate the potential impacts of this informal activities but also tries to look at possible formalized scenarios. Within the project the environmental, social and economic effects were investigated. The presentation will focus on the social effects and will present the methodological challenges of this study. Two main approaches have been chosen to assess a) the current situation of informal activities, concerning the collection, transport and trade of used items and b) alternative formalisation scenarios, which are solution to improve the current situation.

To assess the informal current situation a selection of social criteria from literature (Spillemaeckers et al. 2004, Benoît and Mazijn 2009 and Jørgensen, 2010) was made by checking existing criteria against different properties like relevance for the specific situation, distinctive power of criteria, site specification.

For the assessment of the formalised scenarios stakeholders were identified and for each of the stakeholders relevant social aspects and subsequent indicators were provided after a long intensive discussion process within the project team. For all of the indicators scores from -2 (change for the worse) to +2 (change for the good compared to the current situation) could be given. 
Abstracts 


\title{
RS-03: LCA of energy systems
}

\section{MORS03-01}

\author{
Mitigation of carbon dioxide $\left(\mathrm{CO}_{2}\right)$ emissions in the future Swiss power sector: Which options are most \\ sustainable?
}

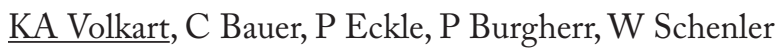

Paul Scherrer Institut, VILLIGEN PSI, Switzerland

Switzerland has issued a law on carbon dioxide $\left(\mathrm{CO}_{2}\right)$ emissions by the end of 2011. The goal is a reduction of domestic $\mathrm{CO}_{2}$ emissions from energetic use by $20 \%$ until 2020 compared to the 1990 level. Today, the Swiss power sector is almost " $\mathrm{CO}_{2}$-free" with electricity production from hydropower (56.5\%) and nuclear power (38.1\%). Given the 2011 decision of the Swiss Federal Council on the nuclear-phase out until 2034, electricity production from natural gas-fired power plants and therefore a substantial increase of domestic $\mathrm{CO}_{2}$ emissions have become very likely. To fulfil the objectives of the $\mathrm{CO}_{2}$ law, domestic $\mathrm{CO}_{2}$ reduction options have to be defined, analysed and compared in order to identify advantages and disadvantages of specific options and find the most sustainable solution(s).

The goal of this case study is the evaluation of power generation technologies that are able to mitigate $\mathrm{CO}_{2}$ emissions in the future Swiss power sector with respect to a business-as-usual scenario, in which the growing electricity demand is predominantly supplied by natural gas-fired power plants. The comparative sustainability assessment is performed using Multi Criteria Decision Analysis (MCDA) methodology considering specific stakeholder preference profiles.

The power generation options to be considered for $\mathrm{CO}_{2}$ mitigation are identified by comparing their life-cycle $\mathrm{CO}$ emissions with those of the prospective natural gas-fired power plants. The criteria and indicators for the MCDA are determined and grouped into the categories environment, economy, society and security of supply and additional subcategories in a hierarchical structure. The indicators are quantified using Life Cycle Impact Assessment (LCIA), risk assessment, cost estimations and expert judgement. In the next step, stakeholders can weight the criteria according to their preferences. Based on the weighted sum approach, the indicators are aggregated resulting in single performance indices which can be used for an overall ranking of the options. The MCDA is carried out using a customized web-based tool (http://www.mightymcda.net/) recently developed by the Laboratory for Energy Systems Analysis (LEA) at PSI that allows for transparent and user-friendly stakeholder interaction.

The MCDA of the $\mathrm{CO}_{2}$ mitigation options in the future Swiss power sector gives a transparent illustration of the strengths and weaknesses of the alternatives together with a ranking depending on subjective weighting profiles. Objective and subjective assessments of options are thus separated and combined in a transparent way. Depending on the preferences of the stakeholders, i.e. on their indicator weighting profile, the comparative evaluation of the $\mathrm{CO}_{2}$ reduction options can lead to very different results. MCDA can facilitate decisionmaking by making complex problems manageable. Additionally, the MCDA can help on understanding tradeoffs and barriers in effective $\mathrm{CO}_{2}$ reduction strategies besides purely economic or technological issues.

This assessment is carried out as part of the research project CARMA, a joint research activity involving various partners from the ETH domain and private institutions, aiming at the exploration of the potential and feasibility of Carbon dioxide Capture and Storage (CCS) systems deployment in Switzerland within the framework of future energy scenarios (http://www.carma.ethz.ch/). 


\title{
MORS03-02
}

\section{Impact of geographical scope and method choice when modelling Chinese electricity for carbon footprint-assessment (and LCI modelling)}

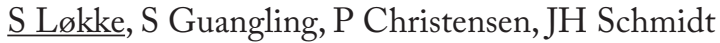

Aalborg Univerisy, AALBORG, Denmark

The methods for assessing the impacts of electricity in the life cycle of a product have been, and remain to be, a highly debated question (see e.g. Earles and Halog 2011, Frischknecht and Stucki 2010, Finnveden et al. 2009, and Schmidt et al. 2011). This paper investigates different approaches to this assessment. Focus is on the importance of geographical scope in the consequential modelling of electricity supply, based on the method developed by Schmidt et al. (2011). This method is a systematic approach to the description of country specific electricity for LCA, and the approach has been used by the same authors for calculating a number of country specific inventories, including an inventory for China (Merciai et al. 2011). However, China covers a large geographical area with a supply grid, that arguable is equal to or less integrated than compared to the European grid. Therefore, we suggest an approach to achieve a geographical subdivision of the Chinese electricity grid, corresponding to the seven interprovincial regional power grids, namely the northeast, the north, the central, the northwest, the south China power grid, and the Xinjiang and Tibet power grids. The approach combines information from the Chinese five-year plans on planned capacity changes in both production and distribution grid, with regional planning, and knowledge on resource availability. The analysis combines this information to achieve a systematic approach for the determination of region specific electricity supply in China. The paper discusses the differences between the results achieved by using the long term consequential inventory modelling suggested by Merciai et al. (2011), the PAS 2050 attributional approach based on average supply (BSi 2011), and the regionalised consequential modelling developed here. Furthermore, it is discussion how to handle the planned, increased integration of the separate Chinese grids.

BSi 2011, PAS 2050:2001 Specification for the assessment of the life cycle greenhouse gas emissions of goods and services, British Standards Institution, London.

Earles, J.M. \& Halog, A. 2011, 'Consequential life cycle assessment: A review', International Journal of Life Cycle Assessment, vol. 16, no. 5, pp. 445-453.

Finnveden, G., Hauschild, M.Z., Ekvall, T., Guinée, J., Heijungs, R., Hellweg, S., Koehler, A., Pennington, D. \& Suh, S. 2009, 'Recent developments in Life Cycle Assessment', Journal of environmental management, vol. 91, no. 1, pp.1-21.

Frischknecht, R. \& Stucki, M. 2010, 'Scope-dependent modelling of electricity supply in life cycle assessments', International Journal of Life Cycle Assessment, vol. 15, no. 8, pp. 806-816.

Merciai, S., Schmidt, J.H. \& Dalgaard, R. 2011, Inventory of country specific electricity in LCA - China. Inventory report v2, 2.0 LCA Consultant, Aalborg.

Schmidt, J.H., Merciai, S., Thrane, M. \& Dalgaard, R. 2011, Inventory of country specific electricity in LCA Consequential and attributional scenarios. Methodology report v2, 2.0 LCA Consultant, Aalborg.

\section{MORS03-03}

\section{Life cycle assessment of regional energy supply scenarios}

$\underline{\text { D Rixrath }}^{1}$, G Piringer ${ }^{2}$, A Ragossnig ${ }^{1}$

${ }^{1}$ University of Applied Science FHS Burgenland GmbH, PINKAFELD, Austria

${ }^{2}$ University of Natural Resources and Life Science BOKU Wien, WIEN, Austria

The Austrian province of Burgenland has significant renewable energy resources, in particular wind and solar energy. To assess the environmental and economic sustainability of an increased development of renewables, the provincial technology agency asked the authors to study the potential environmental and economic impacts of such a development, with 2020 as the reference year.

Three scenarios - each with a different degree of development of renewables - were developed and their impacts compared. The first scenario is the least favourable with regard to the extent of energy provision by renewables, as it "freezes"the renewable energy supply of Burgenland in 2020 at current levels. The second scenario assumes 
a somewhat increased use of renewables in 2020, based on an extrapolation of renewables development in recent years. The third scenario assumes the most intense development of renewables. The demand in 2020 for heat and electricity is assumed to be met entirely by renewables from the province. Fifteen per cent of the demand for transportation-related energy are also met by renewables. The remaining transportation energy needs are assumed to be covered by imports of fossil fuels, but these are compensated by renewable electricity exports on an annual energy-equivalence basis. The environmental analysis of the three scenarios considered the various energy supply chains involved in each scenario. It used an Austrian life-cycle assessment software and database (GEMIS Ósterreich). The impact assessment was limited to five energy-related categories - the global warming potential (GWP, 100-year basis), the tropospheric ozone formation potential (POFP), and dust, $\mathrm{SO}_{2}$, and $\mathrm{CO}$ emissions into the air. The economic analysis estimated the direct net costs of the various energy supply chains in each scenario, both in terms of payments made within the province and payments leaving the province.

The results of the environmental analysis indicate that an intensive development of renewables has the potential to reduce the total GWP by $52 \%$, and the total POFP by $41 \%$, (scenario three relative to scenario one). Higher levels of biomass combustion are responsible for only $2 \%$ reductions of total dust emissions and even an increase of total $\mathrm{CO}$ emissions by $3 \%$. In all three scenarios, the combustion of fossil transportation fuels causes more than half of the total GWP and POFP. The economic analysis shows that the intensified development of renewables increases income from energy-related payments in the province to a significant extent. Relative to the first scenario, energy payments leaving the province decrease by $11 \%-88 \%$ in the third scenario, while energy payments within the province increase between $480 \%$ and $550 \%$. The range of these numbers is due to varying literature assumptions on future costs for energy technologies and energy carriers. Overall, the study demonstrates that the province's energy demand could conceivably be met entirely by renewables on an annual net basis, and that this would result in significant environmental and economic benefits for the region. The environmental and economic sustainability of the province's energy system would increase considerably.

\title{
MORS03-04
}

Jam today verses jam tomorrow: The role of life cycle thinking in strategizing for a low carbon energy mix in the immediate and long term

\author{
A Kelly, C McManus
}

University of Bath, BATH, United Kingdom

In 2008, the UK Government enforced the target to reduce the net UK carbon account for the year 2050 to at least $80 \%$ less than the 1990 baseline. In order to meet this ambitious target it is widely thought that the UK energy future should be 'electrified' as a suite of low carbon generation technologies provide ever increasing proportions of electricity supply. Scenario studies have been carried out to aid the process of deciding what that suite of technologies might consist of, however, these studies have typically only considered basic on site emissions. The UK Transition Pathways research consortium has generated a set of three low carbon scenarios, together with the corresponding technology mixes at intervals up until 2050. Uniquely, however, the consortium has completed carbon focused life cycle assessments, inclusive of upstream emissions. The life cycle approach is slowly being realized as essential to estimating 'real' carbon intensity and, hence, examining the relative roles that different technologies can (or can't) play in pursuit of a low carbon UK. Furthermore, the need to draw comparisons with an evolving grid in order to assess the contribution that any individual technology could make is becoming clear. The work presented utilizes work completed by the Transition Pathways Consortium and aims to inform its next stage.

Life cycle case studies were completed on two technology examples that could make significant contributions to low carbon power supply in the UK. That of industrial CHP and tidal power: the former case study being on an existing CHP plant and the latter being the Severn barrage scheme as it was proposed until 2010. Both the Severn barrage and widespread CHP are solutions based on proven technology but both have a long and disappointingly sluggish history in the UK. In terms of the potential contribution to the UK's energy future, however, they represent two polarized approaches. CHP implementation, particularly on industrial sites, has a short lead time (relative to other low carbon options) and can provide carbon reductions compared to the current supply, helping slow climate change today. However, it is feared that primary fuelled CHP could become an anachronism in the 'all electric' future in comparison to an increasingly decarbonised National grid. In contrast, installation of the Severn barrage would take at least 8 years plus the time required to re-review the proposal before construction can even begin. However, if/when the barrage is commissioned it would generate predictable, renewable energy for a design life of 120 years, probably longer, stretching far beyond 
2050. Furthermore, the case study revealed that the largest contribution to overall impact would be from the National grid itself, which would meet electricity demand outside of generating hours, so the carbon intensity of power from the barrage would only improve the longer it operates and the lower the carbon intensity of the National grid becomes.

The work presented demonstrates the importance of life cycle thinking in the development of a low impact energy strategy. It showcases the importance of the relationship between focused studies on individual technologies and over arching studies of the full grid mix. It also opens the discussion on the temporal aspects of LCA application for energy planning and the potential implications of a formal approach to evaluating environmental gains in the immediate versus the long term.

\section{MORS03-05}

\section{Regional carbon footprints of housing and relevance of user-inventions for heat pumps}

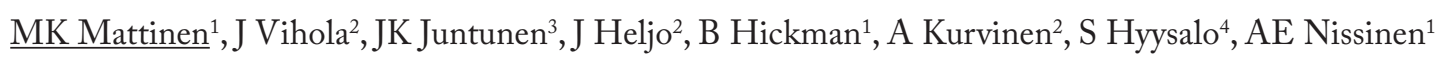

${ }^{1}$ Finnish Environment Institute, HELSINKI, Finland

${ }^{2}$ Tampere University of Technology, TAMPERE, Finland

${ }^{3}$ Aalto University School of Economics, HELSINKI, Finland

${ }^{4}$ Aalto University School of Arts and Design, HELSINKI, Finland

Housing and different buildings cause roughly one third of direct greenhouse gas emissions in Finland. The so called 20-20-20 targets set by the European Union encourage seeking efficient paths towards improved energy efficiency and thus reduced greenhouse gas emissions in all sectors. Residential building stock simulations on a national level are a common practice in order to evaluate energy efficiency and greenhouse gas reduction potentials. However, there is increased demand for modeling energy performance of housing on sub-national and regional levels due to municipalities and cities setting their own emissions and carbon footprint targets. Furthermore, it is important to identify the most cost-efficient ways to decrease emissions at each region. In addition, user-inventions can be important to increase the energy-efficiency of homes.

In Finland, the urban structure monitoring system (YKR) offers unique data to analyze in detail the built environment in both national and different sub-national, and regional scales. The system includes geographical data about buildings and their characteristics, such as location, volume, occupancy, used heating fuel, and year of construction.

The energy consumption from residential buildings is modeled with the aid of the physically based bottom-up EKOREM model that makes use of the National Building Code of Finland. The main modeling parameters are thermal transmittances of structural elements, cooling and heating degree days, fuel mix used for heating, number of dwellers and volume and area of the stock.

We analyze and estimate greenhouse gas emission reduction potential in residential houses in different regional and local scales. In this study, user-induced inventions related to different types of air heat pumps are modeled and their potential impact on the carbon footprints of the housing sector in a couple of different regions in Finland is analyzed. The life cycle impacts of innovative air heat pumps, as well as the upstream emissions of energy production are accounted and compared to conventional systems. The importance of LCA approach for the estimates of greenhouse gas emissions (GHGE) is analyzed and discussed. The data are collected mainly from user run internet forums and interviews.

As a result we are able to compare the potential decrease in GHGE due to different types of installations of heat pumps and inventions on these devices. Moreover, we are able to link the GHGE with a geographical location and thus spatially analyze the impacts of these inventions. The knowledge gained from these kinds of regional analyses will be useful for planning different kinds of energy interventions, as the properties of the buildings, population, infrastructure and the potential for different renewable energy sources can be accounted for. 


\section{MORS03-06}

\section{Life-cycle assessment as a guided-research tool to reduce the environmental impact of polymer solar cells}

$\underline{N_{\text {Espinosa }}}{ }^{1}, \mathrm{R}_{\text {García-Valverde }}{ }^{1}, \mathrm{~L}_{\text {Serrano }}{ }^{1}, \mathrm{~A} \mathrm{Urbina}^{1}, \mathrm{FC} \mathrm{Krebs}^{2}$

${ }^{1}$ Universidad Politécnica de Cartagena, CARTAGENA, Spain

${ }^{2}$ Danmarks Tekniske Universitet, ROSKILDE, Denmark

When applied to energy systems, Life-Cycle Assessment studies are carried out for the determination of energy payback times and carbon footprints. These studies constitute therefore a powerful tool to potentially prevent the impacts that a new technology can cause in the environment.

Photovoltaic technologies offer one of the lower carbon footprints. Traditional solar cells based on inorganic semiconductors have efficiencies of up to $15-20 \%$, but at a fairly high price. Alternatively, it is possible to think in terms of completely new types of solar cells, which fundamentally break with the manufacturing costs; organic photovoltaics is one of these emerging technologies.

Organic Photovoltaics (OPV) are now produced by roll-to roll methodologies, which greatly enhance the throughput, and they offer apart of the possibility of being produced cheaply, the advantage of being flexible, low weighted and designed as a semi-transparent technology absorbing selected bands of Sun light or working under artificial light.

Even for the current state of the technology, still characterized by relatively low module efficiencies (2-5\%)and limited lifetimes (Krebs et al.2009), previous life-cycle assessment studies carried out for this type of OPV cells have shown very promising energy payback times below 2 years (Anctil et al., 2012; Roes et al.2009). Roll to roll techniques for producing OPV devices lead to very low values for the embodied energy in their manufacturing: right now on the order of only $150-400 \mathrm{MJ} / \mathrm{m}^{2}$ (Espinosa et al.2011). Preliminary calculations (Espinosa et al.2012) in this regard have proved these figures could be even on the order of 100 days with the replacement of some problematic materials, as the case of Indium the main constituent of the widespread transparent electrode Indium Tin Oxide (ITO), or with thinner outlines and lower thermal budgets.

Polymer solar modules are made of up to $80 \%$ PET, representing therefore a large amount of the total embedded energy in the modules. Because of the immaturity of the technology, no recycling methods have been proposed for organic PV yet; the end-of-life phase of the modules has not been considered. Recycling OPV scrap and re-introducing the waste as raw material in the manufacture, cannot only be a cost-cutting measure but it can make more sustainable the technology: a real cradle-to-cradle.

The purpose of this work is to reduce the environmental impact of polymer solar cells prepared by $\mathrm{R} 2 \mathrm{R}$ techniques under ambient conditions, by using LCA as a multidisciplinary tool. With the feedback provided by LCA analyses, a large variety of processes to manufacture OPV modules, including the improvements mentioned above, have been tested at Energy Conversion DTU. The key environmental impacts of preliminary options for recycling OPV modules, made of a range of plastic materials, will be presented highlighting the importance the substrate and encapsulation components choice on the overall environmental profile.

\section{References}

Anctil, A., et al (2012). Progress in Photovoltaics: Res. and Appl.in press

Espinosa, N., García-Valverde, R., Urbina, A., Krebs, F.C. (2011).Solar Ener. Mat. and Solar Cells, 95(5),1293.

Espinosa, N., Hösel, M., Angmo, D., \& Krebs, F. C. (2012).Energy Environ. Sci., 5(1),5117-5132.

Krebs, F. C., et al (2009). Journal of Materials Chemistry,19(30),5442-5451.

Roes, A.L., Alsema, E.A., Blok, K., \& Patel, M.K. (2009). Prog. in Photovoltaics:Res. and App,17(6), 372-393. 


\title{
MORS03-07
}

\section{USEtox and ERA comparison for TCM (CCS Technology Centre Mongstad, Norway)}

\author{
C Askham, A Brekke
}

\section{Ostfold Research AS, KRAAKEROEY, FREDRIKSTAD, Norway}

LCA studies of carbon capture and storage (CCS) suggest that the technology yields improvement in global warming potential, but results for other environmental impact categories are less favourable. Toxicity impacts have not been fully addressed in many LCAs for CCS. Toxicity issues have often been addressed by authorities by using Environmental Risk Assessment (ERA). ERA has been performed for CCS at the Technology Centre Mongstad (TCM) site. The ERA considers potential future emission levels compared to threshold limits for potential exposure to toxic substances for the local population. ERA is fit for purpose in assessment of local environmental risk, but broader consideration of the overall environmental impact across the life cycle of a CCS facility requires LCA. The threshold limit approach is appropriate for ERA, but this ignores the life cycle impacts of products and resources (such as solvents and their production) required for CCS. ERA is concerned with exposure below a given threshold in a given location, but not minimisation of impacts as a whole. In theory this can lead to sub-optimisation of product value chains, as potential emissions from only one specific site are considered at a time. There is no link to the function, or functions, that the production site is contributing to fulfilling. LCA can aid decision-makers to minimise the environmental impacts associated with fulfilling a function for the whole life-cycle of a product, or service. This study examines the similarities and differences between the LCA and ERA approaches for carbon capture (using amine scrubbing to capture the carbon dioxide from gas power station flue gas) for toxic impacts (ecosystems and human health). The model for ERA used for decision-making for government authorities about permits to operate is compared with USEtox and the LCA approach. Potential local adaptations of USEtox fate models are explored for this specific case. Both methodological and data input aspects are considered. Data gaps identified in previous work are addressed and the applicability of the results to appropriate levels of decision-making are discussed. This study has been carried out as part of a long term research project (EDecIDe) funded by the Norwegian Research Council concerning public acceptance of CCS.

\section{MORS03-08}

Life cycle assessment of amine based post combustion carbon capture

JMertens $^{1}$, R Frischknecht ${ }^{2}$, H Huynh Thi Ngoc ${ }^{1}$

${ }^{1}$ LABORELEC/GDF SUEZ, LINKEBEEK, Belgium

${ }^{2}$ ESU services Ltd., USTER, Switzerland

The study describes the Life Cycle Assessment (LCA) of mono-ethanol-amine (MEA) based post combustion carbon capture for a coal fired power plant. Amine based carbon capture faces two challenges: (i) optimising the energy penalty associated to the capture process and (ii) minimising the organic and inorganic emissions. The study implements the current knowledge of the energy requirements and emissions based on research in-situ pilot installations, using a unique modelling layout, incorporating feedback loops.

The electricity and steam consumption during the capture process produces extra $\mathrm{CO}_{2}$ which needs to be captured requiring again electricity that again produces $\mathrm{CO}_{2}$ etc.. This peculiar feature has been implemented by the development of a model consisting of the incorporation of site internal feedback loops for both the electricity as well as the steam consumption. The mathematical incorporation of these feedback loops allows calculating the effect of varying:

(i) energy requirements of the post-combustion carbon capture process and

(ii) associated emissions on both the environmental impact and the energy penalty of the electricity production process.

Carbon Capture can reduce the Global Warming Potential (GWP) of one kWh of electricity by more than $70 \%$ but increases the environmental impact of all other impact categories (eg. acidification, fossil fuel use, eutrophication, toxicity, ...). This increase is to a large extent due to upstream processes (ie. fuel supply chain) which become dominant in many impact categories when implementing CCS: eg. $52 \%$ of the GWP and up to $67 \%$ of the acidification potential are due to the fuel supply chain. The overall environmental impact of the CCS process depends therefore on the weight given to the GWP reduction. An energy penalty between 6 and 
$8.5 \%$-points is calculated according to the data source used for energy consumption. Scenario analyses on both the energy penalty as well as the emissions are also presented.

This model forms the basis of future research and can be updated as soon as new information becomes available from EU pilot/demo plants. The unique layout of the model allows a rapid integration of these data and its consequent use to calculate the effect on environmental impacts but also on power plant's efficiency. It is important for GDF SUEZ to have a good insight in the environmental advantage and burdens of the carbon capture process since currently LCA analyses are becoming one of the decision criteria taken into account by utility companies when developing new projects.

\title{
MPRS03-01
}

Life cycle assessment and geographical dependence study of the environmental impact of a $222 \mathrm{kWp}$ gridconnected CdTe photovoltaic system

\author{
$\underline{\text { L Serrano }}^{1}$, AG Ossers $^{1}, \mathrm{~N}$ Espinosa ${ }^{1}$, VR García-Valverde $^{2}$, A Urbina $^{1}$ \\ ${ }^{1}$ University of Cartagena, CARTAGENA, Spain \\ ${ }^{2}$ SOLTEC, MURCIA, Spain
}

We have applied Life-Cycle Assessment (LCA) methodology to analyze the environmental impact of a sustainable energy technology such as Cadmium Telluride thin film photovoltaic technology. In particular, a $222 \mathrm{kWp}$ grid-connected system has been built and monitorized on a parking roof in Murcia, Spain; the system has been delivering reliable data of the solar electricity production for more than two years.

A detailed LCA data of the system, including the construction phase and maintenance has been performed, which together with the real electricity production data collected, allowed us to estimate the energy payback time (EPBT) of the system, which is 2.06 years. Since this installation is $7^{\circ} \mathrm{E}$ and has not the optimum inclination because of the architectural requirements of the parking roof, a second case, in which the same size installation is ground-mounted, and where modules are tilted at the optimal inclination, has been considered in order to study the trade-off of the integration when compared with a system which can be designed without any constraint. In this latest case, an EPBT of 1.42 years was obtained.

The LCA protocol has been implemented using SimaPro software which delivered a full set of environmental impact parameters following the Eco-indicator methodology, which was applied to both cases. It was found that Fossil Fuels Depletion, Climate Change, Carcinogens and Respiratory Inorganic Pollution had the greatest impacts. Despite the fact that the parking case has a 5\% higher environmental impact compared to the groundmounted installation, the former presents the great advantage of double land use and providing a shading service on the cars. Also the addition of the LCA of the parking without photovoltaic system plus the LCA of the ground mounted system delivers a larger combined impact which confirms the advantage of the integration.

Additionally, a geographical dependence study has been performed. The environmental impact of the system is affected by the location of manufacturing (through the embedded energy calculation) and the location of installation (through the electricity output during its lifetime). A set of geographical alternatives shows how the final environmental impact can be tuned depending on the choice of both locations. Transport has a minor impact, while the energy mix of both locations has the major impact. The temporal evolution of these impacts taking into account a large scale deployment of photovoltaic systems has also been assessed. 


\section{MPRS03-02}

\section{Comparative life cycle assessment of three battery types}

J Koroneos $^{1}$, G Xydis ${ }^{2}$, E Nanaki ${ }^{3}$, D Rovas ${ }^{1}$

${ }^{1}$ LHTEE Aristotle University of Thessaloniki, THESSALONIKI, Greece

${ }^{2}$ Risø DTU National Laboratory for Sustainable Energy, ROSKILDE, Denmark

${ }^{3}$ University of Western Macedonia, KOZANI, Greece

Batteries are the most important energy storage utility which is used in a wide range of products and applications by a large number of consumers. The global market of batteries has had an annual increase by almost $9 \%$ since 1989. In the European Union alone, every year approximately 800.000 tones of automotive batteries, 190.000 tones of industrial batteries and 160.000 tones of portable batteries are marketed. Taking into consideration the development and insertion of new electronic devices, the increase of the car fleet, and the rapid introduction of electric/hybrid vehicles in transportation, it is clear that there will be an increasing tense in battery market.

The batteries have negligible environmental impacts during their use and storage life cycle stages, but at the production and end use life cycle stages there is a great number of environmental impacts which are related to the type and the amount of their construction materials (hazardous and toxic) and the energy use.

The objective of this study is a comparative analysis of the environmental performance of three battery types for automotive use. The Lead Acid ( $\mathrm{PbA}$ ), the Nickel - Cadmium (NiCa), and the Nickel -MetalHybride (NiMH) battery types, are investigated using the Life Cycle Assessment methodology. The stages taken into consideration are the production stage and the end use (recycling) stage. The functional unit is taken to be the 1.0 Wh of energy output. The results of the analysis indicate that the PbA batteries have the best environmental performance as compared to the other two. Thus, without taking in consideration their giver economic feasibility, the $\mathrm{PbA}$ batteries should be used as the dominant battery type for use in transportation sector for the next years.

\section{MPRS03-03}

Towards sustainability in new energy technologies: challenges and method of environmental impacts and costs assessments through CEA's batteries assessment case studies

\section{E Naveaux, A Brunot}

\section{Alternative Energies and Atomic Energy Commission (CEA), France, GRENOBLE CEDEX 9, France}

To respond to the international challenge of growing energy demand while reducing greenhouse gas emissions, CEA has brought all its new energy technology (NET) initiatives together within the Laboratory for Innovation in New Energy Technologies and Nanomaterials (LITEN). LITEN is developing innovative solutions and prototypes at laboratory and pilot scales before potential transfer to partners for the industrialization and commercialization part. L2ED (laboratory of Design, Assessment \& field Demonstration of Energy processes) is in charge of measuring the sustainability of LITEN's technologies and facilitating the identification of new sources of innovations. This team uses Life Cycle Assessment and simplified environmental analysis methods. Regarding costs issues, we implement the Activity Based Costing method.

In order to assess and to cover completely related technological research topics, the practice of these acknowledged methods is adjusted. Environmental impacts and costs assessments specific practice comes from the diversity, the maturity and the dynamic of LITEN's knowledge developments.

The diversity of LITEN's knowledge developments consists in the multiplicity of technical options existing at the beginning of a study to define the detailed conception of a product. LITEN has an integrated approach; it develops innovative solutions from nanomaterials like active materials or additives to final products like battery cells or pack. In order to cover all those possibilities and to reduce the time required to assess all technical options, L2ED is building topic related booklets of environmental and costs assessments evaluations.

Knowledge maturity on LITEN's technology is determining available modeling data corresponding to the studied system during the life cycle inventory phase. New energy technologies need for instance very technical chemicals that might not be modeled in databases. L2ED has to model them itself even though LITEN might not have satisfactory information. Knowledge maturity varies with studied systems and has an impact on the time taken to inventory and model data. 
The dynamic of LITEN's knowledge developments is gathering knowledge diversity and maturity evolutions through time. Elements of the system directly linked to its basic function are developed first, contrary to elements that contribute to secondary and support functions. The later research works on the use or recycling phases also make sense since these phases happen later in the product's life cycle. Developments dynamic of LITEN's research vary from a level of product definition to another and from a step of its life cycle to another.

To sum up, diversity, maturity and dynamic of LITEN's knowledge developments cause some challenges in investigating environmental and cost issues. Defining systems boundaries, conducting inventories and modeling systems are more demanding than in other studies for a commercial product. However, studying a non-existing product facilitates the integration of recommendations on future new designs.

By assessing at least one object of every topic of research and enhancing data reliability with the progress of technical developments, L2ED is able to reduce the time required to complete future studies while building topic related booklets of evaluations. This environmental impacts and costs assessments practice will be illustrated through the work conducted on LITEN's batteries. 
Abstracts 


\section{RS-04: Non-carbon footprints}

\section{TORS04-01}

Water assessment of a hand dishwashing product using an LCA approach: Opportunities and limitations

$\underline{\text { G Van Hoof }^{1}}$, A Kounina ${ }^{2}$, B Buyle ${ }^{1}$, S Humbert $^{2}$

${ }^{1}$ Procter \& Gamble, STROMBEEK-BEVER, Belgium

${ }^{2}$ Quantis, LAUSANNE, France

Only since a few years, LCA studies are including metrics to evaluate products from a water use impact perspective. Few methods are ready to use, some are under development. However, the applicability of the existing methods has been primarily demonstrated on agricultural materials or products. For example, water irrigation requirements in food production can be water intensive. In view of an increasing interest on water impact from different products, we ran a study on the water impact a hand dishwashing product. A number of water assessment methods were applied with the purpose of identifying both product improvement opportunities as well as understanding the state of the art both from a database and a method perspective.

The study focused on environmental issues related to water use, looking in depth at inventory methods, midpoint and endpoint methods (14 in total) and covered the entire life cycle of the product. The use of a single product with the same global supply chain, sourced from one location was evaluated in two countries with a different water scarcity conditions.

The study suggests that the consumer use stage is the most important one (99\% using the Ridoutt and Pfister method), driven by both direct water use (dishwashing process) as well as indirect water use (electricity to heat the water). Therefore, the largest improvement opportunity is to build consumer awareness on habits and practices in water scarce regions. The study also showed a very different profile if spatially explicit methods are applied on one product used with the same use conditions.

From a methodological approach, a lot more work is necessary to develop good inventory databases (in terms of flows covered and accurate data), which is key for all methods. This will be necessary for the application of water assessment methods in a business context. A number of the applied methods are not regionalized, which was demonstrated to be a critical aspect in comparing the overall water profile of the product. Finally, improvements to some methods are suggested.

\section{TORS04-02}

\section{Integrating water footprinting into eco-design: Case study of a chair}

$\underline{\text { E Carteron }}^{1}$, S Zinck ${ }^{1}$, L Lessard ${ }^{2}$, S Vionnet ${ }^{2}$, S Humbert $^{2}$

${ }^{1}$ Steelcase, SCHILTIGHEIM, France

${ }^{2}$ Quantis, LAUSANNE, Switzerland

Evaluating the environmental impacts related to water is an increasingly important topic for governments or companies to be integrated within their strategy and to mitigate their impacts. It is therefore increasingly important to account for water in addition to other traditional life cycle assessment impact categories in ecodesign processes. However, current inventory databases provide limited data on water and do not address the recently developed methods concerning water impacts. In consequence, Quantis and a consortium of companies, including Steelcase, created the Quantis Water Database: an exhaustive water life cycle database based on the existing Ecoinvent database.

In order to evaluate the interest of water footprint assessment on a non-agro based product and to integrate water impacts into an eco-design process, a case study has been undertaken on a chair (EASTSIDE) by Steelcase with the support of Quantis.

The study takes into account a comprehensive water inventory, including balanced input and output flows, the standard life cycle impact assessment indicators and some recent methods as Pfister et al. (impacts from water consumption), Maendly \& Humbert (impacts from turbined water) and Verones et al. (impacts from thermal 
pollution) to complete the water footprint indicators.

The study has been carried out on the complete life cycle of the chair and the processes inventories have been regionalized through the modification of electrical grid mix among others.

This study aims at evaluating the water footprint of a reference chair and, in a second step, at identifying the best eco-design options in a list of conceivable eco design solutions.

The assessment of the reference scenario provides an overview of the water footprint of the chair and hot spots. For all indicators studied, the material stage is the main contributor, but the external and internal production phases are also important contributors in terms of ecosystem quality and water withdrawal.

The assessment of the different eco-design options allowed the identification of two best scenarios, which combine different options: the first is a chair with similar comfort but with a small water footprint benefit compared to the reference chair and the second is a chair with a lower level of comfort but with a greater water footprint benefit compared to the reference chair. For the first case, the eco-design choices indicate a water footprint benefit until around $40 \%$ for the water stress assessment.

This study confirms eco-design priorities which were previously identified by Steelcase: efforts must be undertaken on the choice of materials and external production. However, obtaining a significant water footprint benefit is relatively complex due to design and marketing constraints. These constraints are important because it is difficult to modify the product while maintaining the concept, which is at the heart of the eco-design concept.

This study highlighted some limitations. Due to a lack of primary data or to the quality of the dataset, small differences in terms of results are not important enough to make a decision due to high uncertainty. In consequence, high quality data are the key to a successful eco-design process. Moreover, in order to obtain a complete view of environmental impacts in an eco-design process, it is important to complement the water footprint by a comprehensive multi-indicator LCA and also takes into account, for instance, the climate change.

\section{TORS04-03}

\section{Estimation of the carbon and water footprint of beverages}

HK Jeswani, D Amienyo, A Azapagic

The University of Manchester, MANCHESTER, United Kingdom

Alongside climate change mitigation, water conservation is a key environmental challenge for the beverage industry due to its agricultural supply chain. In an attempt to contribute to a better understanding of the climate change and water use impact of the beverage industry, this paper presents the carbon and water footprint of three beverage supply chains - a carbonated soft drink produced in the UK, beer produced in Switzerland and wine produced in South Australia for the UK retail market.

The carbon footprints have been estimated in accordance with the ISO 14044 life cycle assessment methodology and the stress-weighted water footprints are calculated for each beverage type by taking into account the water stress of the watersheds where the supply chain is located. The major factors contributing to the carbon and water footprints of each beverage type are also identified. The findings of the study suggest that the carbon footprints range from 0.56 to $1.67 \mathrm{~kg} \mathrm{CO}$ eq. $/ 1$ of beverage. Compared to the carbon footprint, the water footprint varies hugely between the types of beverages, ranging from 1.8 to 2461 eq./1 of beverage. For carbon footprint, the packaging is the main 'hotspot' for carbonated soft drink and beer, whereas for wine, raw materials and transport are also the main contributors. On the other hand, the agricultural production of key ingredients i.e. grapes, barley, sugar, is responsible for most of the water footprint impacts for wine, beer and carbonated soft drinks. The analysis also highlights that the mitigation strategies for water footprint should focus on agricultural aspects of supply chain, while for carbon footprint, the main focus should be on the production of drinks and packaging materials. 


\section{TORS04-04}

\section{Sustainability assessment of water supply in Copenhagen - what is the impact of freshwater withdrawal?}

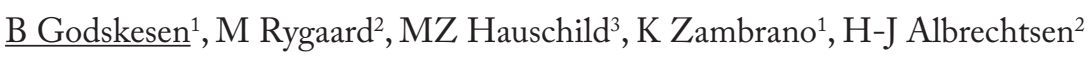

${ }^{1}$ Copenhagen Energy, COPENHAGEN, Denmark

${ }^{2}$ Technical University of Denmark, Dep. of Environmental Engineering, COPENHAGEN, Denmark

${ }^{3}$ Technical Universit of Denmark, Dep. of Management Engineering, COPENHAGEN, Denmark

Freshwater withdrawal impact and life-cycle assessment were implemented to compare 4 cases for water supply in Copenhagen, a part of Denmark with high population density and relatively low available water resources due to political prioritization of protection of freshwater environments. The study included the urban water cycle from water intake and treatment over distribution and effects of water hardness to wastewater transport and treatment. The freshwater withdrawal impact (FWI) was based on an existing method for water use impact assessment which was applied and further developed for local water catchments. The assessment was based on data from the national implementation of the EU Water Framework Directive and FWI was included as a separate impact category in the standard Life-cycle assessment (LCA).

The base case (A0) of the study was the current practice of groundwater abstraction from well fields situated near Copenhagen. The 4 cases studied were A1: Rain- \& stormwater harvesting from several blocks in the city; A2: Today's groundwater abstraction (A0) with compensating actions applied in the affected freshwater environments to ensure sufficient water flow in water courses; A3: Establishing well fields for groundwater abstraction further away from the city; and A4: Seawater desalination.

The standard LCA showed that the Rain- \& stormwater harvesting case (A1) had the lowest overall environmental impact $\left(82.5 \mu \mathrm{PET} / \mathrm{m}^{3}\right)$ followed by the cases relying on groundwater abstraction $(\mathrm{A} 0, \mathrm{~A} 2$ and A3) (123.5-137.8 $\left.\mu \mathrm{PET} / \mathrm{m}^{3}\right)$, and that A4 (desalination) had a relatively small but still important increase in environmental impact $\left(196.8 \mu \mathrm{PET} / \mathrm{m}^{3}\right)$. Rain- \& stormwater harvesting and desalination had a markedly lower environmental impact in the use stage compared to the base case, due to the reduced water hardness leading to e.g. a decrease in electricity consumption in households. For a relevant comparison, it is therefore essential to include the effects of water hardness when the environmental impacts of water system of different hardness are compared. Considering the FWI assessment the cases Rain- \& stormwater (A1) and Desalination (A4) had lower impact $\left(<0.01 \mathrm{mPET} / \mathrm{m}^{3}\right)$ than the cases based on groundwater resources $(11.3-14.9 \mathrm{mPET} /$ $\mathrm{m}^{3}$ ). This study emphasizes the necessity of respecting the relevant geographical scale when considering groundwater reserves, i.e. focus the assessment on the local water catchments affected by the water withdrawal, rather than on the regional watersheds. Our work shows that methods previously used on a regional level can also be applied to local water catchments and integrated into the standard LCA as a local impact category and even when choosing the lowest weighting according to the distance-to-political-target method of FWI, this is still the most important impact category for the production of drinking water. When standard LCA is extended to include impacts of freshwater withdrawal rain- \& stormwater and seawater were the resources with least environmental impact in the considered region.

\section{TORS04-05}

\section{Assessing chemical footprint of Europe}

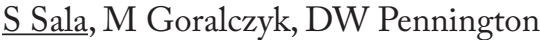

Joint Research Centre- European Commission, ISPRA, Italy

In the last few years, environmental footprint concept has obtained an increasing interest by both the scientific and political communities. Nowadays, EC-JRC is developing a life-cycle based methodology for assessing EF (EC-JRC and DG ENV, 2012) based on ILCD recommendation (EC-JRC, 2011).

Amongst the other footprints, the chemical footprint evaluation aims at assessing at which extent actual emission of chemicals harm the ecosystems above their capability to recover (the so-called carrying capacity of the system).

In a recent (2009) paper in Nature, Rokstrom et al highlighted that for some environmental problem thresholds for a safe space for humanity were already set and evaluation of the relative performance of human activities against this threshold is possible. For chemical pollution, the thresholds setting is uppermost relevant even if 
very critical to be defined. Actually, the potential harm caused by a particular amount of a chemical released to the environment depends on a number of interrelated factors, including the properties of the chemical and the medium to which they are released. Due to the complexity of this interaction, especially for ecosystem, a specific multidisciplinary effort has to be made to perform this assessment.

At national and international level some attempts have been made and projects are ongoing to define this chemical footprint, but usually the methodological approach comes from different disciplines and lack of a real integrated and multidisciplinary assessment. To support the sustainability assessment of chemicals, a framework for the chemical footprint assessment has been recently developed by JRC, starting from a conceptual model definition.

Adopting a Life-cycle based approach, the steps of the calculation are as follows: (i) the masses of chemicals released during each phase of product life cycle, from raw material extraction to end of life are taken into account in the Life Cycle Inventory; (ii) using Multimedia fate models in order to calculate fate factors in different compartments ; (iii) through the Life Cycle Impact Assessment phase, fate factors for each chemical are multiplied by a characterisation factors derived from the chosen impact assessment model. The chemical footprint may be calculated using a life cycle based methodology in either a production or consumption based perspective.

An example of the calculation of the chemical footprint at EU level is presented and discussed, following a hybrid approach, in which production based data form European emissions are combined with consumption base data on import and export.

This will support also the calculation of normalisation factors at European level, for toxicity related impact categories. At the present level of methodological development of LCA-based approaches, a link between the magnitude of the impacts and the planetary boundaries is missing. The link could be defined trough effect thresholds: policy- based thresholds (e.g. "distance to target" in LCIA methods) and science-based thresholds.

The evaluation of the chemical footprint and the presented case study aim at enhancing the discussion on the role of LCA for bringing together approaches and results from various disciplines (from ecotoxicology to ecology, from ecological/human risk assessment) supporting the future development of policy both for environmental protection and green economy.

\section{TORS04-06}

\section{Exploring the feasibility of chemical footprint assessment - the case of eco-toxicological impacts on freshwater from pesticide use in Denmark}

\section{A Bjørn, M Birkved, MZ Hauschild}

Technical University of Denmark, KGS. LYNGBY, Denmark

Expressing environmental impacts as footprints has advantages over many traditional LCA impact indicators because the results are highly communicable to the general public and because it allows for indirectly addressing ecological boundaries. An ecological boundary should in this context be understood as the maximum level of impact (be that in the form of resource consumptions or emissions of pollutants) allowed in order not to transgress the carrying capacity of a given ecosystem. The challenge of addressing boundaries has recently been revitalized as a consequence of the planetary boundary concept. A planetary boundary for chemical pollution has been proposed, but no clear definitions are available.

This study explores the feasibility of developing and applying an ecological indicator for chemical footprint. Following the logic of the ecological footprint concept, a chemical footprint can be conceptually understood either as the physical area needed to absorb a given chemical emission to the environment or as the physical area needed to make up for the loss of biocapacity resulting from the chemical emission. The study will explore the most appropriate way of dealing with this ambiguity.

The case of eco-toxicological impacts on freshwater (excluding groundwater) from pesticide use in Denmark has been chosen, because high quality disaggregated data on the application of active ingredients (AI) for more than a decade are available. The use of pesticides is expected to be the dominating contributor to the total ecotoxicological impacts in Danish freshwater bodies. This gives an opportunity to validate the results.

The methodological stages in quantifying the chemical footprint in the case study is composed of i) Data gathering and calculation of quantities of AI in pesticides applied to different types of crops ii) Life Cycle Inventory modeling of the amount of active ingredients emitted to surface water and air after field application using PestLCI 2.0, iii) Life Cycle Impact Assessment modeling of fate, exposure and effect of emitted active 
ingredients using USEtox, and iv) Conversion of the USEtox ecosystem damage indicator (PAF $\mathrm{m}^{3}$ day) into a meaningful chemical footprint indicator.

The results of the case study will be presented and interpreted with emphasis on the feasibility of expressing eco-toxicological impacts on freshwater as a footprint. Issues such as the physical interpretation of the indicator, the existence of ecological thresholds and application in a decision making context will be addressed.

\section{TORS04-07}

PlasticsEurope Eco-profiles: How to measure the sustainability of an industry?

$\underline{\text { I Mersiowsky }^{1}, \text { G Castelan }}{ }^{2}$

${ }^{1}$ DEKRA Consulting GmbH, STUTTGART, Germany

${ }^{2}$ PlasticsEurope aisbl, BRUSSELS, Belgium

The PlasticsEurope sectoral methodology for Life Cycle Inventory is developing into an emerging harmonised standard for the global plastics industry. First and foremost among on-going projects are a general update of relevant precursors and polymers until 2013, and pilot testing the European Environmental Footprint methodology. Furthermore, lessons learnt from recent projects include performance improvements due to technological progress, but also pitfalls where inconsistent modelling practices (e.g. cracker) had to be overcome. The presentation concludes with an outlook as to how recent developments, such as water footprint, are integrated into the methodology, and what the future of industrial LCA and sustainability footprinting may look like.

\section{MPRS04-01}

\section{Water footprint accounting to support raw material selection: The case study of a paper company}

\section{A Manzardo, M Niero, S Toniolo, A Scipioni}

University of Padova, PADOVA, Italy

Water use and consumption has become a main issue debated at international level. Many companies are facing relevant risks such as water resource availability, accessibility and image among stakeholders that affect their market and competitiveness. To support companies in the management of such risks at product level, the concept of Water Footprint emerged. In this paper the water footprint accounting of a tissue paper produced in Italy is performed using the method developed by Hoekstra (Hoekstra et al., 2011) adopting a life cycle perspective. The objective of the study were to support the company in the chemical pulp selection, the main raw material used to produce the tissue paper, through the use of water footprint accounting indicator. A cradle to gate approach is used, from raw material selection to tissue paper production in Italy. Data refer to 2011 and are obtained from different sources: on site data and literature data. Considering the characteristic of the tissue paper, the study took in consideration the main chemical pulp suppliers of the company, their location (Brazil, Chile, USA), the specific meteorological condition of the harvesting and production sites, the supplier operation and the different typologies of tree used. The results of the study shows how the final product water footprint accounting, that ranges from $1.008 \mathrm{~m} /$ ton 3 to $5.090 \mathrm{tm} 3 /$ ton, is highly influenced by the choice of the chemical pulp (from $96 \%$ to $99 \%$ of the overall water footprint accounting) and that the main contribution is from green water footprint. Suppliers from Brazil harvesting pine trees, because of the low level of evapotranspiration and forest management practices, resulted to be the ones with lowest green water footprint and therefore the preferable for raw material selection in the specific case study. The results helped the company to integrate environmental issues within supply chain management, supporting strategies to reduce final product water footprint. 


\title{
MPRS04-02
}

\section{Calculating pesticide emissions for chemical footprinting of kiwifruit}

\author{
TJ Dijkman ${ }^{1}, \mathrm{~K}_{\text {Müller}}^{2}, \mathrm{M}$ Birkved $^{1}$
}

${ }^{1}$ Technical University of Denmark, KGS. LYNGBY, Denmark

${ }^{2}$ New Zealand Institute for Plant \& Food Research, HAMILTON, New Zealand

Carbon and water footprints for kiwifruit production in New Zealand have recently been published. Aiming to obtain a more comprehensive overview on the sustainability of kiwifruit production, a pesticide footprint is currently under development. Contributing to the development of the pesticide footprint, pesticide emissions from kiwifruit orchards have been modeled using PestLCI 2.0 and Ecoinvent, and subsequently characterized using USEtox in order to calculate their potential human toxicity and freshwater ecotoxicity impacts. The research presented here focused on the spatial variations of emissions and impacts.

PestLCI 2.0 is a Life Cycle Inventory model to estimate pesticide emissions from the technosphere, which was defined as the orchard, to air, surface water and groundwater. In the Ecoinvent approach, it is assumed that all pesticide applied is emitted to the agricultural soil.

The Bay of Plenty (BOP) district is the heart of New Zealand's kiwifruit production. Within the BOP, four climatic regions and four dominant soil types were identified. Combining climate and soil data yielded nine realistic PestLCI scenarios under which kiwifruits are produced. Using these nine scenarios, emissions were calculated for the ten compounds used in kiwifruit production according to the growers'spray logs.

Emissions and impacts calculated with the Ecoinvent approach did not show any spatial variation due to the modeling approach. In contrast, the emissions calculated with PestLCI 2.0 showed limited spatial dependence, but the variations were usually no more than an order of magnitude. Emissions to air were virtually spatially independent because wind drift emissions, the main source of emissions to air, are climate-independent in the PestLCI 2.0 modeling approach. For surface water emissions, dependence was dominated by soil type. For groundwater emissions, the largest variations were attributed to climatic circumstances. The applied characterization factors were not location-dependent. Therefore the same variations observed in the emissions were also found for the potential human toxicity impacts.

\section{MPRS04-03}

Assessing environmental sustainability in architecture through embodied energy and ecological footprint analysis

\author{
$\underline{\mathrm{AK} \mathrm{Cerutti}}{ }^{1}, \mathrm{~A} \mathrm{Zanzo}^{2}, \mathrm{~S} \mathrm{Contu}^{3}$ \\ ${ }^{1}$ University of Turin, GRUGLIASCO, Italy \\ ${ }^{2}$ Technical University, II Faculty of Architecture, TORINO, Italy \\ ${ }^{3}$ Interdisciplinary Research Institute of Sustainability, TORINO, Italy
}

Several product categories have tried to reinvent themselves molding by the concept of environmental sustainability. Recently the disciplines of Architecture and Building construction were influenced by such ideas and they both have welcomed the environmental sustainability. Nevertheless, it is helpful to proceed with caution in every phase of changing, to prevent that the situation becomes more problematic than the real problem. This is the reason why a lot of environmental sustainability indicators, able to monitor and to show the way to follow to go toward the process, were defined. In the framework of environmental sustainability assessment, Embodied Energy (EE) and Ecological Footprint (EF) have recently applied in Architecture. In this work we tried to explain the potential and the limit of their working method. The main objects are: a) to compare two different typologies of buildings to understand which are the differences in results; b) to show the advantages and disadvantages of using the two indicators, considering the best way to perform the assessment.

Two study cases are analyzed in this work: the first approaches the ecological evaluation, using the EE and the EF, on two different buildings: a) a single family residential welling, built with concrete and bricks, b) a single family residential welling, built with laminar wood system (X-lam). The analysis has tried to pick the difference of environmental impact of the construction out, estimating the consumption of energy and raw materials using in the production of every single piece of the welling shown. The result of EE shows a better 
energetic performance in the wood house with 3326 GJ versus 5801 GJ used by concrete house. Regarding the EF, concrete house consumes 89,9 gha versus 146,8 gha used by a wood house. In this case we have opposite results. Indeed, in order to calculate the EF, we have to consider the impact of all the organic material used. The biggest impact is the one of glue laminated timber buildings, which is much bigger than concrete or brick buildings. The reason is because non-renewable construction materials must be evaluated just for their 'energy land' impact, not for the 'forest'.

In the second study case we analyzed the use of X-lam in construction using both indicators. In this case we evaluated the ecological impact of every phase of the construction process. The result of this suggestion was compared with the results of our first study case in order to evaluate the accuracy of the simplifications used at the building scale. From this investigation we see that the EE of one single X-lam panel rises by 25,9\%, otherwise the EF grows up to $15.9 \%$ compared with the one calculated at building scale. Through the direct investigation of these indicators several remarks may be highlighted. First the value of these results together with other architectural indicators, picking the ability of building reading out. Although scenarios are based on experimental data and not on-site surveys, it is possible to assess environmental performance of the considered construction method and to simulate scenarios with the changing of the way to build our houses and cities. Our results confirm that environmental assessment methods are becoming a fundamental tools in the hand of the planner.

\section{MPRS04-04}

\section{A comparison between environmental indicators. Qualitative analysis and educational aspects in a perspective of environmental sustainability}

$\underline{\text { AK Cerutti }}{ }^{1}$, A Marchioni $^{1}$, S Contu $^{2}$

${ }^{1}$ University of Turin, GRUGLIASCO, Italy

${ }^{2}$ Interdisciplinary Research Institute of Sustainability, TORINO, Italy

The current situation of exploitation of resources exceeds the regenerative capacity of nature, putting us in a state of 'overshoot'.

The socio-economic metabolism express complex relations between human activities and natural systems: to represent this relationship, and how much nature we are 'consuming', we use the environmental accounting.

Life cycle thinking is becoming a keystone of environmental studies, nevertheless LCA results may be difficult to be understood by non-experts. LCA analyzes the overall impact and takes into consideration a lot of data, that could be simplified through the use of environmental indicators which measure environmental performance of products and processes. In this work we used:

the material flow analysis (MFA), which measures the physical exchanges (in tons) between anthroposphere and environment, activated during the process;

the ecological footprint (EF), which calculates the area of land and water ecosystems required to produce, in a sustainable manner, and to absorb all the resources, always in a sustainable manner, all the emissions generated by a system;

the water footprint (WF), which measures the total volume of used and polluted water useful to produce goods and services;

the carbon footprint $(\mathrm{CF})$, which measures the total amount of greenhouse gas emissions caused directly and indirectly by anthropogenic activity or accumulated during the life of a product;

the eMergy, which expresses all the amount of energy (with only one value, called eMergy value) used, directly or indirectly, to produce a good or a service.

We considered two case studies: in the first we tested with environmental indicators the production of meat for food; it was possible to clarify which aspects of the supply chain could be quantified with the various indicators and how. It became evident, although no quantitative analyzes, environmental impact generated by the production of meat. We tried to imagine alternative scenarios by considering alternative supply chains to evaluate if the results could vary positively with better values of indicators (obtaining, for example, lower values of $\mathrm{EF})$.

In the second case, we developed a pattern of educational program (focused on the production of military aircraft) to highlight - through the use of the tools described above - as issues like the aircraft production are 
only apparently unrelated to environmental issues. Thanks to the arguments of LCA we were able to estimate the extent of environmental impact on the production of a fighter jet, highlighting how any type of product is related with the environment in at least one phase of its lifecycle, impacting on the nature in a more or less consistent way.

Finally, we identified some aspects of nature that the use of indicators neglects or underestimates: the loss of biodiversity, the greenhouse gas effect, the change of use of land. This analysis allowed us to highlight that only a truly interdisciplinary approach can provide insights on these issues: indicators individually can only highlight some aspects of environmental problems, while a multiplicity of perspectives can address them more adequately, taking into account their complexity.

Finals results are that it is possible to build training projects, designed to show the complexity of reasoning on sustainability, which would allow users of such training to enhance their look into the complex issues related to socio-economic systems.

\title{
MPRS04-05
}

\section{Nitrogen footprint vs. LCIA methods - analysis of environmental impact assessment methods from a nitrogen perspective and comparison with the emerging nitrogen footprint concept}

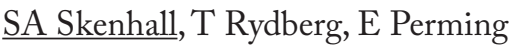

\author{
IVL Swedish Environmental Research Institute, STOCKHOLM, Sweden
}

Nitrogen is part of several reactive substances that have environmental effects when emitted to water and air, such as eutrophication, acidification and photochemical ozone creation. These effects have not received much attention in the recent environmental debate; instead the focus has been on carbon. However, due to the diversity of nitrogen substances created in society, the range of environmental impacts they cause, and the severity of these impacts, nitrogen is once again starting to rise as an important topic in the scientific discourse.

Nitrogen footprint is a newly introduced concept among the environmental footprints. It strives to account for the total nitrogen released during the life cycle of a product or similar. In life cycle impact assessment (LCIA) methods, nitrogen substances are assessed among other substances in several impact categories. The Nitrogen footprint method and the LCIA methods from CML 2001 for Global warming, Eutrophication, Acidification, Photochemical ozone formation and Stratospheric ozone depletion, were analyzed in a case study of Swedish tomatoes grown in greenhouses. The methods were compared and evaluated with regard to how nitrogen species are assessed in the impact categories.

The Nitrogen footprint method does so far not distinguish between different nitrogen species or their potential environmental severity, but recalculates into elemental nitrogen. Therefore the environmental impacts can currently not be identified with this method. The LCIA methods analyzed are more comprehensive as they recognize the environmental impacts induced by different nitrogen species by identifying scientifically derived factors, thereby giving a more comprehensive description of the spectra of impacts. However, it became evident during the study that the LCIA method Stratospheric ozone depletion, does not recognize nitrous oxide (N2O) as an ozone-depleting substance. It was also identified that the assumptions regarding synergies and influences from non-nitrogen substances, and their concentration, to derive the factors in the category Photochemical ozone creation, are coarse and would need refinement to sufficiently describe the potential impact from nitrogen substances.

The Nitrogen footprint concept applied in a broader perspective could be used as a tool to communicate and raise awareness in society of the importance of nitrogen. If the footprint method included environmental impacts from nitrogen emissions, it could be a complement to LCA studies. Conclusively, the Nitrogen footprint could be valuable in bringing the nitrogen perspective back into the environment and climate debates, as well as be used for improving the nitrogen assessment in LCIA methods. 


\section{RS-05: Life cycle management and stakeholder involvement}

\section{TORS05-01}

\section{Metso LCA pilot project: Studying the feasibility of LCA framework from industrial point of view}

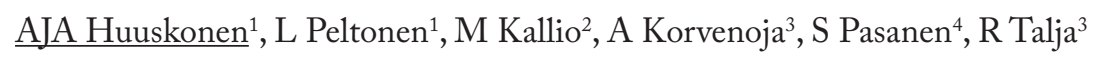

${ }^{1}$ Metso Corporation, HELSINKI, Finland

${ }^{2}$ Metso Mining and Construction, TAMPERE, Finland

${ }^{3}$ Metso Pulp, Paper and Power, TAMPERE, Finland

${ }^{4}$ Metso Automation, TAMPERE, Finland

Metso started a life cycle assessment (LCA) pilot project in 2010 in order to study the feasibility of LCA and to determine the best possible ways of incorporating life cycle thinking (LCT) into Metso's operating structure. Before this, LCA had been identified as a key competence area for Metso. Four different products were chosen for the pilot project, all of which came from different business areas. The studied products included a biomass power plant, mobile stone crusher, parts of a paper making line and an automation system for the condition management of wind power plants. The range of products covered machines weighting hundreds of tons and small automation devices consisting of components weighting some micrograms. During the course of the project numerous difficulties were identified that make it difficult to use LCA in companies such as Metso. These difficulties covered issues related to all aspects of the LCA framework. On the other hand, the studies provided Metso also with a lot of valuable information and proved to be a very valuable learning process. Metso has since continued working with LCA and LCT, and strives to deepen the understanding in the field. The lessons learned during the pilot project have eased our way in later studies and LCT approaches. They can also be helpful for other companies that are taking the first steps in the world of LCA or striving to apply life cycle thinking for a diverse variety of products and services.

\section{TORS05-02}

Application of eco-design including life cycle assessment for improving product environmental performance at Hultafors Group

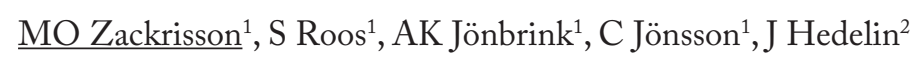

${ }^{1}$ Swerea IVF, STOCKHOLM, Sweden

${ }^{2}$ Hultafors Group, HULTAFORS, Sweden

Hultafors Group strives to develop and produce products that fulfill the sustainability requirements to contribute to a better society long-term. As a first step in this direction Swerea IVF has previously conducted sustainability training of Hultafors staff. This paper will describe the organizations further development involving application of eco-design including life cycle assessment for improving the environmental performance of ladders, tools and workwear manufactured and sold by the Hultafors Group. The methodology applied consist of three phases: 1) the LCA including scoping, data collection, impact assessment and interpretation; 2) idea generation workshops engaging cross functional teams of Hultafors staff; and 3) the implementation of ideas and knowledge in product development procedures and projects.Seven different products, textile products and tools, were assessed by LCA with the aim of giving a general picture of the environmental impact of Hultafors' products. The following products were studied: one cotton T-shirt, a pair of cotton trousers, a pair of nylon trousers, a winter jacket, a hammer, a measuring tape and a ladder. By choosing these products, material impacts, process impacts and other life cycle phase impacts for most of Hultafors Group's product portfolio were covered. In the environmental assessment the common impact categories (climate impact, acidification, ozone depletion, eutrophication and photochemical smog) were used; in addition for some production phases, use of certain risk chemicals, energy consumption and water use were considered.For all textile products, the fabric production (from cradle to gate) contributes to the largest portion of the environmental impact. For 
all tools and ladders, different use scenarios were used and gave very different environmental impacts along the life cycle, thus different design recommendations.A large number of product improvement ideas were created at two idea generation workshops with Hultafors staff. The workshops took off from the results of the LCAs with the aim to find ideas to minimise product environmental impact. The workshops, which were led by eco-design experts from Swerea IVF, involved around 30 Hultafors key staff from product development, management, purchasing and marketing and thus also served to discuss and spread the knowledge gained about their products' environmental performance including materials and processes used. The ideas generated are used as inspiration when deciding on new products and market opportunities.For product design, ecodesign guidelines based on the LCA results have been compiled and implemented in the ordinary product development documents and processes. The guidelines consist of the general lessons learned from the LCAs and recommendations for product development as well as company specific data about relevant materials and processes. The improvement ideas, the eco-design guidelines and all the knowledge gained in organisation have greatly improved the confidence and the ability of the Hultafors Group to make an important contribution towards sustainable development.

\section{TORS05-03}

\section{Clarifying the role of life cycle assessment in technical research and development projects: Recommendations for project planning}

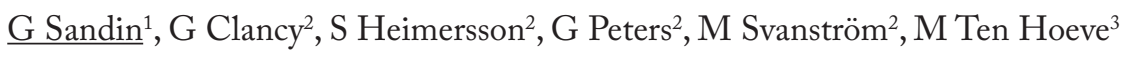

${ }^{1}$ SP Technical Research Institute of Sweden, BORÅS, Sweden

${ }^{2}$ Chalmers University of Technology, GOTHENBURG, Sweden

${ }^{3}$ University of Copenhagen, COPENHAGEN, Denmark

In technical Research and Development $(\mathrm{R} \& \mathrm{D})$ projects, such as those funded within the European $7^{\text {th }}$ Framework Programme, there is often a requirement to conduct an environmental Life Cycle Assessment (LCA) of the technology under development. No requirements or recommendations are provided on the role of LCA within different types of projects; hence the role of LCA tends to be unclear and arbitrary, and LCA work may not be adequately designed for the needs of the project.

There is much literature on LCA and its use in R\&D, often on case studies, on development of assessment methods or on possibilities and limitations of LCA in the R\&D context. There is also more general research on environmental consideration in $\mathrm{R} \& \mathrm{D}$, often with a focus on intra-organisational projects. However, there is a need to explore the role of LCA in inter-organisational technical R\&D projects, in order to improve project planning and enable projects to make use of the full potential of LCA.

In this study, we draw on experiences from LCA work in such projects in order to identify project characteristics which are decisive for what the role of the LCA can be. Four specific projects are used to illustrate how these characteristics have practical consequences for project planning, before or early in the project. The purpose is to help project planners and LCA practitioners to characterise their project and, consequently, plan the project in a more deliberate way for efficient use of LCA.

The following key project characteristics were identified:

Potential influence on environmental performance: whether the technology under development is a major or minor contributor to the environmental impact of a product's life cycle.

Flexibility of development process: to what extent the direction of the project is fixed, which may set limits to the opportunities the LCA has for influencing the project.

LCA dependency on project progress: if key variables in the LCA depend on decisions taken or results obtained within the project.

Appropriate audience of LCA results: stakeholders within or external to the project that the LCA should be directed towards.

Potential influence on environmental performance, flexibility of development process and LCA dependency on project progress, are crucial for whether there is a need for an early screening LCA of the proposed development routes. For example, this could depend on whether life cycle impacts mainly depend on the production processes or the functional properties of the technology under development. Furthermore, flexibility of development process, LCA dependency on project progress and appropriate audience of the LCA results are central for 
scheduling the time plan for project deliverables and for deciding how and to whom the LCA results are to be communicated. Also, all four characteristics influence to what degree the LCA should be integrated with other parts of the project: whether LCA is to influence technology development, or whether it is sufficient with a stand-alone LCA that is delivered at the end of the project.

The LCA practitioner and any project partner with pre-knowledge of the technology's environmental impact should be engaged in evaluating the above listed key characteristics. In this way, the role of LCA can be clarified, positively contributing to a more efficient use of LCA in the project. This can also help in creating realistic expectations and, thereby, limit disappointment and stress within the project.

\section{MPRS05-01}

\section{Active co-operation on comparable carbon footprinting in Finnish food sector}

\section{$\underline{\text { IM Pulkkinen }}$}

\section{MTT Agrifood Research Finland, HELSINKI, Finland}

Life cycle thinking is spreading among companies around the world. Growing efforts to mitigate climate change and development of life cycle assessment methodologies have pushed and enabled also food sector to act. Due to the growing interest in the food sector in Finland, in 2009 and 2010 two large projects were initiated in Finland: one on carbon footprint methdology and the other on communication of product carbon footprints.

In the beginning of Foodprint Tools - project, two large food companies and one large retailer (all jointly with their own suppliers) took part through their own R\&D projects. In the public project national product carbon footprint methodology guidelines were developed. The guidelines are based on the existing more generic international standards and guidelines, as well as, on 10-years experiences and best existing practises of LCA methodologies on food. The guidelines are more practical than other standards for food sector, offering clear rules to assessment makers in decision making situations they face when conducting LCA and aiming towards more comparable carbon footprinting.

To create a commonly accepted guidelines, which would harmonise carbon footprinting in Finland, large number of stakeholders were involved in the work. Representatives from food, beverages, retail, packaging, fertilizer and feed industries were invited, as well as government administration, trade and food associations, consumer and environmental NGOs, research organisations, LCA consultancy etc. To enable participation of these different actors there were several workshops and comment rounds among the stakeholders, and hearings of several national and international LCA experts.

Product carbon footprinting has been discussed in Finland also from consumer point of view as several food companies have started communicating their products' carbon footprints. In the first Climate Communication -project 2009-2011 six active companies together with other three stakeholders started the discussions on national approach to product carbon footprint communication. In 2011 eleven companies and four different stakeholders initiated the second Climate Communication -project. In both projects different background surveys and studies have been made to inform the industry on current international and national developments.

In addition to active steering group discussions in all projects, larger and smaller workshops for the food chain players and their stakeholders have been organised nearly twice a year. In the workshops different kind of product carbon footprint information types has been evaluated, problems in conducting product carbon footprint studies and the new methodology guideline drafts have been discussed. Additionally, companies have shared their own experiences among the others.

More knowledge on LCA is still needed in the sector and among its stakeholders, and active companies need to be engouraged to be more open of their activities. It has been acknowledged that when LCA is used for communication to third parties, it is critical to bring together different industries in the process in order to develope harmonised and somewhat fair methodology. For instance, common allocation rules are needed to attain these goals. The hopes are high that in future the active co-operation in the industry will lead to more reliable and harmonised product carbon footprint studies and which would be communicated to consumers in understandable and meaningful way. 


\section{MPRS05-02}

\section{Bridging the gap between the sustainability pillars}

$\mathrm{T} \mathrm{Ekvall}^{1}, \mathrm{~L}$ Åkesson ${ }^{2}$, O Eriksson ${ }^{3}$, G Finnveden ${ }^{4}$, M Ljunggren Söderman $^{1}$, P Söderholm ${ }^{5}, J_{-O}$ Sundqvist ${ }^{1}$, C Von Borgstede ${ }^{6}$

${ }^{1}$ IVL Swedish Environmental Research Institute, GÖTEBORG, Sweden

${ }^{2}$ Lund University, LUND, Sweden

${ }^{3}$ University of Gävle, GÄVLE, Sweden

${ }^{4}$ Royal Institute of Technology, STOCKHOLM, Sweden

${ }^{5}$ Luleå University of Technology, LULEÅ, Sweden

${ }^{6}$ University of Gothenburg, GOTHENBURG, Sweden

A thorough assessment of the sustainability performance of a product, a system, or a decision requires expertise on environmental, economic, and social aspects. In an assessment that involves researchers from different disciplines, communication is challenging because of different background knowledge, terminology, research traditions, etc.

In the research program Towards Sustainable Waste Management, a new approach to interdisciplinary interaction was tested. The program included a group of researchers on life cycle assessment (LCA) and systems analysis of waste management. To this group, specialists in national economy, environmental psychology, and ethnology were linked in various projects. In each specific research project at least $20 \%$ of the budget was allocated to a waste LCA expert, who, through participating actively in the project, would be an interpreter, a two-way bridge between the disciplines. The first purpose of this LCA expert was to interpret the sustainability questions and to help make the research relevant for the overall purpose of the research program. The second purpose was to interpret the results of the specialists' research and to help making the results useful for the overall program.

Our experience demonstrates that this set-up forces the specialists and their interpreters/bridges to face the challenge of understanding each other. Establishing such an interdisciplinary interaction requires that the researchers share a mutual interest in trying to reach understanding. However, despite this interest and despite the significant resources made available for the participation, our collaboration was restricted by the fact that it can be difficult for the specialists to find suitable tasks in their projects for the LCA expert. The chance of the interaction being successful increases if the background knowledge of the researchers in the project overlaps, if they have similar research cultures, if they share a common interest in the research questions, and/or if the disciplinary scientists are accustomed to interdisciplinary collaboration. 


\section{RS-06: LCA in infrastructure, building and waste management sectors}

\section{TORS06-01}

\section{LCA applied to solid waste management systems: A comprehensive review}

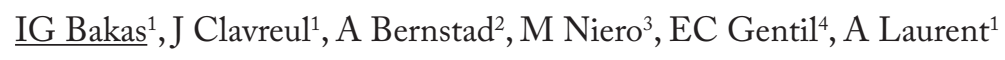

${ }^{1}$ Technical University of Denmark, KGS. LYNGBY, Denmark

${ }^{2}$ Department of Chemical Engineering, Lund University, LUND, Sweden

${ }^{3}$ Department of Chemical Engineering, University of Padua, PADUA, Italy

${ }^{4}$ Copenhagen Resource Institute, COPENHAGEN, Denmark

Life Cycle Assessment (LCA) applied to solid waste management systems can support decision-making with respect to sustainability by comparing and evaluating the environmental performances of different technologies or waste treatment options. However, the credibility of LCA results can only be guaranteed as long as the standardized methodology is properly applied. We therefore conducted a comprehensive literature review on LCA case studies published since the mid-90s in the field of solid waste management to examine the methodological approaches used and to identify potential misapplications in the LCA practice. In order to select relevant case studies, a number of criteria were established, including the necessity for studies to have been through a peer-review process and to include more than one impact category, e.g. ruling out sole global warming assessments. About 200 scientific articles and publicly available reports were thus identified and reviewed in depth. Analyses of several aspects within the standardized phases in the conduct of an LCA, i.e. goal definition, scope definition, inventory analysis, impact assessment and interpretation, were performed. The results of the review show that the amount of case studies has overall increased until 2010. The studies are largely concentrated within Europe and to a lesser extent in some countries and regions of Asia. Most cases investigate municipal solid waste within a current waste management system or through the comparison of traditional treatment options, although emerging technologies are also assessed or compared with conventional alternatives. The application of the LCA methodology typically comes with some flaws, which are primarily observed in scientific articles. The absence of explicitly defined goals put in perspective with their context, the unclear and sometimes unjustified definition of system boundaries and the confusion in the handling of multifunctional processes are among the gaps and inconsistencies that can frequently be observed. We provide recommendations to LCA researchers and practitioners in order to overcome these limitations and homogenize the LCA applications on solid waste management.

\section{TORS06-02}

Environmental benefits from end of life treatment of composite materials - model and results

\section{$\underline{\text { A Schmidt }}$}

FORCE Technology, LYNGBY, Denmark

Composites are increasingly used in a broad range of applications. Windmill blades constitute a large and very visible part of the consumption, but the use in automotive applications (boats, trains, cars, planes) and in products like waste containers, bus shelters and building components is also significant. Composite materials will in general consist of a mixture of a polymer matrix material and a glass or carbon fiber component as the main raw materials, but also mineral fillers are used in many products.

Handling of composite products in the most sustainable way at their end of life (EOL) is an increasing challenge for producers, product owners and legislators. The amount of end-of-life and production waste generated by the glass thermoset composite market is expected by the recycling industry to be more than 300.000 tons in 2015, but especially the dramatically increasing demand for renewable energy may result in much larger waste amounts arising in a not-so-distant future. Today, the dominant disposal route is landfilling (allegedly accounting for about 98\%), but alternative treatment routes for composite waste are being investigated with respect to both technological possibilities and environmental potential. The results of these efforts should 
of course be made available to all types of decision-makers as soon as possible, simply because the present treatment of EOL composite waste can be regarded as a waste of valuable resources.

FORCE Technology has developed a dedicated model for calculation of the environmental impacts and benefits from five different types of EOL treatment, i.e. landfill, incineration with energy recovery, co-incineration in a cement kiln, recycling of ground composites, and pyrolysis. Using system expansion and a consequential LCA approach, the model quantifies in its simple version the consequences of using different EOL treatment routes with respect to energy consumption/savings and contribution to climate change, but it can also calculate a much broader range of environmental impacts, if so desired.

The model can easily be adapted to specific products and EOL technologies, giving a very precise overview of the environmental benefits that can be realized by choosing other treatment routes than disposal at a controlled landfill. Examples of the results of EOL treatment of two different, generic composite materials (UP-resin with glass fiber and mineral filler and PUR with carbon fiber reinforcement) is presented in the paper. The preliminary results indicate that from a theoretical point of view pyrolysis is the preferred EOL treatment for both types of composite, but with large variation in the benefits that can be achieved per ton of composite material. The full benefits of pyrolysis can, however, only be achieved if and when the recovered fibers are used to substitute virgin fiber material in new applications. The practical obstacles in creating a market for recycled glass fiber should therefore not be neglected when future scenarios for EOL treatment of composites are investigated. Co-incineration in a cement kiln also shows significant benefits in the examined impact categories. The cement industry can probably handle large future supplies of composite waste, but presence of heavy metals and halogens can limit the possibilities in practice. The paper will present some of the most imminent problems faced by the actors in the composite sector.

\title{
TORS06-03
}

\section{Sensitivity and uncertainty analysis to support raw materials selection for tissue paper: A case study of} different rolls from virgin and recycled materials

\author{
$\underline{\text { M Niero }}^{1}$, A Manzardo $^{2}$, A Scapinello $^{2}$, A Scipioni $^{2}$ \\ ${ }^{1}$ CESQA, University of Padova, PADOVA, Italy \\ ${ }^{2}$ University of Padova, PADOVA, Italy
}

The influence of assumptions on the final results is very important when a company aims to compare the environmental performances of its products through Life Cycle Assessment. The ISO 14040-44 standards provide some techniques for enhance confidence in the results of an LCA study, such as sensitivity and uncertainty analysis. These techniques are not always taken into account within the interpretation phase, but if the goal of the LCA is to make an environmental claim regarding the superiority of one product versus another product with the same function, they should not be neglected, even if the products are manufactured by the same company.

One of the most active industrial sectors towards the minimization of its impacts on the environment is the paper tissue industry. There is indeed an open issue, whether the use of recovered fibers to manufacture new tissue paper products is actually better for the environment than using new fibers. This paper contributes to this debate, considering the case study of an Italian company which conducted a comparative LCA between three different rolls, made using different raw materials: virgin pulp, waste paper and paper obtained from the recycling of beverage cartons. The objective of the paper is to test the reliability of the comparative LCA results by the means of sensitivity and uncertainty analysis.

The LCA methodology as defined by ISO 14040 standards was used. According to the Product Footprint Category Rules (PFCR) for Intermediate Paper Products under development, the functional unit is $1 \mathrm{~kg}$ of tissue paper. A cradle to gate perspective was adopted, including all the processes from raw and auxiliary materials extraction, manufacturing, packaging of the final product, and waste management and transports. The cut-off approach was taken into account with regard to the recycling of paper. ReCiPe method was used to perform impact assessment at midpoint level, considering the following impact categories: climate change, particulate matter formation, agricultural land occupation, fossil depletion, photochemical oxidant formation, terrestrial acidification, freshwater eutrophication. Data for the LCI step were mainly primary data from one specific plant which manufactures all the three types of tissue rolls, considering 2010 as reference year.

The results of impact assessment show that rolls made by virgin pulp have the greatest environmental impacts for all the impact categories considered, except for the climate change for which virgin fiber rolls and waste paper rolls have the same impact. The less impacting products are rolls made by the paper from beverage 
carton recycling. The main impacting life cycle stage is paper manufacturing, which in the case of virgin pulp includes the chemical pulp production. The sensitivity analysis was performed changing the impact assessment methodology (Impact 2002+). The uncertainty analysis was performed using a mixed approach, based on the Pedigree Matrix and the Monte Carlo algorithm, comparing two products at a time. The results of both sensitivity and uncertainty analysis confirmed the LCA results, enhancing the confidence in the conclusions of the comparative LCA. Further work needs to be carried out in continuation of this study in order to improve data collection and test how the optimization of the production process can influence the environmental performances of the tissue paper products under study.

\title{
TORS06-04
}

\section{The misuse of LCA-based methods to claim environmental sustainability of remediation technologies}

\author{
G Lemming, M Owsianiak
}

\section{Technical University of Denmark, KGS. LYNGBY, Denmark}

Integrating sustainability into remediation projects is attracting more and more attention from remediation practitioners. Frameworks for sustainable remediation emerge which are accompanied by the development of integrated assessment tools. Here, we critically evaluate published LCA case studies on remediation technologies for contaminated sites and provide recommendations for better and consistent use of life-cycle based methods in the future.

Results of our review of all 28 LCA case studies published in the period from 1999 to 2012 show that most studies cover technologies that are well established and have already found field-scale applications. Emerging technologies such as chemical reduction by source zone mixing with zerovalent nanoscale iron and electrokinetic-enhanced bioremediation have not been assessed. The studies focus on recognized contaminants, such as metals, hydrocarbons or chloroethenes. No studies deal with emerging threats such as pharmaceuticals or nanomaterials. The lag between the occurrence of pollutants in the environment and their occurrence in case studies indicates that achieving sustainability goals for remediation of emerging contaminants and technologies can be limited. Even if inventories are made for the relevant remediation processes, characterization factors for some pollutants may not be available.

The assessment of primary impacts, i.e. local toxic impacts associated with the contamination of the site is also problematic because it requires the use of site-specific fate and exposure models. Primary impacts were only evaluated in fourteen studies and this trend is decreasing. This is a drawback as primary impacts can contribute substantially to human health impact categories and their inclusion in the assessment can change the comparative ranking among remediation alternatives.

While the above-mentioned critical points can be solved in the future as science progresses and more effort is put into assessments, a lot can be done already now by applying simple rules which relate to the generic LCA methodology. Many of the case studies employed simplified life-cycle based assessment methods to compare remediation alternatives without specifying system boundaries or even without clearly defining a functional unit. Such assessments may bias the comparison of remediation alternatives or result in burden-shifting due to the exclusion of potentially relevant impact categories and incomplete characterization of emissions. Often the technology is claimed "green"or "sustainable"based on minor differences in the results without considering the associated uncertainties. Simple, universal rules about conducting LCAs and interpreting results should minimize the number of potentially misused assessments.

On the other hand, there is an increasing trend in number of case studies which integrate (full) LCA with other assessment tools, such as environmental risk assessment or multicriteria decision analysis. There is also an agreement between studies that bioremediation-based methods have advantages compared to alternative methods for cleaning-up contaminated sites. Such integrated studies and meta-analyses provide valuable information for remediation practitioners and hopefully direct towards more energy efficient and less polluting remediation technologies. Given methodological inconsistencies and knowledge gaps when conducting LCAs however, more research is needed to claim their environmental sustainability. 


\title{
TORS06-05
}

\section{Towards a modular LCA approach in urban wastewater}

$\underline{\text { SM Morera }}^{1}$, LLC Corominas $^{2}$, JC Comas $^{1}$, M Rigola $^{1}$

${ }^{1}$ University of Girona, GIRONA, Spain

${ }^{2}$ Catalan Institute for Water Research, GIRONA, Spain

A common practice in life cycle assessment (LCA) studies applied to wastewater treatment processes is to consider the system as a whole and not taking into account the different unit processes of the system. Therefore, there is little information about unit processes for wastewater treatments in the databases (e.g. in Ecoinvent). Moreover, there is not much information about different wastewater treatment technologies involved in the urban water cycle. These two aspects are limiting the proper use of LCA in practice within the water treatment field because as a final user can only select in the databases within a limited range of full treatment technologies or classes of Wastewater treatment plants (as stated in databases).

These different classes of wastewater treatment covers different plant sizes based on equivalent person, but without specifying wastewater treatments. In these processes the unique information about wastewater treatments is that there are a mechanical, biologic, and chemical treatment for water and a digestion for the sludge. Something similar happens with data about plant construction, there is information about the construction for different sizes but without specifications for any unit processes. Another limitation is the information about technology, this information is from Switzerland for year 2000, and now probably there are changes in technology.

To overcome this limitation, a new approach in LCA studies in the urban wastewater is proposed. The so called "modular LCA"aims at developing a tool which will allow perform LCA studies in any wastewater collection and treatment system, considering the plant size but also the real layout with the different unit operation and relationships among them. This tool will cover all the stages of the life cycle of a wastewater treatment plant from construction to dismantling. In order to be able to build this tool, three representative sizes will be considered of the system under study, e.g. large, medium and small wastewater treatment plants, and a detailed inventory analysis for the main technologies used in each unit operation will be carried out.

When applying this new approach, an adequate combination of the different unit operations (previously studied and included in the database) together with an interpolation of the impact factors based on the size and technology will allow a confident representation of the system configuration under study. Finally, the application of LCA for each of these unit processes will allow obtaining a complete and better LCA study. An example of the first studies conducted will be shown at the conference where we will see a comparison between the construction of a real plant from Catalonia and a plant from the databases provided in SimaPro and a first interpolation for a unit processes.

\section{TORS06-06}

\section{LCA of advanced treatment for pharmaceuticals removal from wastewater}

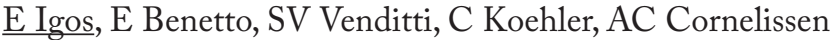

Public Research Centre Henri Tudor, ESCH-SUR-ALZETTE, Luxembourg

Pharmaceuticals, excreted by the human body after ingestion, are released into the sewer system. These compounds, inefficiently removed by conventional Waste Water Treatment Plants (WWTPs), cause detrimental effects on the ecosystems. This is why the partners of the European Interreg IVB project PILLS have developed pilot plants coupling biological and advanced treatment at hospitals (point sources). Three advanced technologies were separately investigated: ozonation (O3), activated carbon (AC) adsorption and ultra violet (UV) radiation. The aim of this study is to estimate which one is the most sustainable in terms of environmental impacts, evaluated through the Life Cycle Assessment (LCA) methodology.

The potential environmental impacts of the three scenarios are assessed for the treatment of $1 \mathrm{~m}^{3}$ of wastewater. The net impact is calculated from the impacts generated by the treatment (consumption of electricity and chemicals) and the impacts avoided with respect to the direct release to the environment (removal of selected pollutants: 10 pharmaceuticals, nitrogen, phosphorous and 22 heavy metals).

The required data for the inventory can be very different from a partner to another (variation until 3 orders of 
magnitude), due to the different quality of water or infrastructures. In that case, the minimum and maximum values were kept for the scenarios. Values of pollutants removal were similar among the plants.

Concerning the impact assessment, two methods have been used to develop characterisation factors for pharmaceuticals: EDIP and USEtox. For the first one, the toxicity assessment is based on the PNEC value (Predicted No Effect Concentration) adjusted with an assessment factor depending on the derived endpoint. USEtox method is based on the EC50 value (concentration affecting 50\% of the population tested) with the use of extrapolation factors if needed. Since this method only evaluates human- and eco-toxicity, it has been coupled with the state-of-the-art method ReCiPe. The impact categories are normalised and the results expressed in person equivalent.

The results show a negative net impact for all the scenarios due to significant avoided impacts. The beneficial effect on the environment is dominated by the removal of pharmaceuticals when using EDIP assessment and by the phosphorous removal when using USEtox and ReCiPe methods. In the latter case, pharmaceuticals' impact has a negligible contribution, which makes the need of advanced technology questionable. However, in order to evaluate the local effects of the process, the study should be complemented by the consideration of other criteria, such as bacteria resistance, and the application of an Environmental Risk Assessment (ERA). Despite toxicity, the two assessments give a similar ranking of the net impacts among the technologies, with ozonation being the preferable option. This finding is in accordance with the choice of two European WWTPs for this technology to improve their pharmaceuticals removal.

Interestingly enough, the two valuation methods give rise to the same technology ranking (thus supporting the decision process), but with two perspectives concerning pharmaceuticals toxicity. Toxicity models suffer of high uncertainties in LCA and even more for emerging pollutants like pharmaceuticals. An improvement of toxicity database and integration with other tools like ERA would probably lead to more reliable results.

\title{
TORS06-07
}

\section{Comparative life cycle assessment of gaseous biofuels production from waste-based industrial effluents}

\author{
P Masilela, R Melamu, A Aboyade, H Von Blottnitz
}

\section{University of Cape Town, CAPE TOWN, South Africa}

Recovery of energy from waterborne organic wastes is becoming increasingly widespread, in the form of methane-containing biogas. At the same time, modifications to anaerobic digestion to instead produce biohydrogen are becoming better understood. Hydrogen potentially offers significantly higher energetic efficiencies than methane as an energy carrier, esp. through its use in fuel cells. Both of these energy carriers can be produced from various waste organic residues sources including industrial waste water, food waste, animal wastes etc., in addition to purposely grown energetic crops. During technology development, it is advisable that a life cycle assessment be conducted in order to evaluate the benefits and short-comings of modifications to the energy system. The aim of this study is to compare the energetic and environmental performance of bio-methane and the bio-hydrogen production processes from brewery effluent. The comparison is done on the basis of removal of COD in effluent: the system boundaries include production of ancillary chemicals, energy, the actual treatment process and the conversion of the recovered energy into the form of electricity, heat or transport service. The data indicate that bio-methane might be better suited for the application in combined heat and power systems, whilst bio-hydrogen shows better performance by application in fuel cell vehicles as transportation fuel: a system expansion is thus included to affect the comparison. The origin of the replaced energy-carrier is shown to have a strong influence on the energetically and environmentally preferred choice, but energetic efficiency in conversion processes, esp. the performance of fuel cells in vehicles, are also important parameters. 


\section{TORS06-08}

\section{Use of hydrated lime to improve environmental footprint of hot mix asphalt and road durability}

TS Schlegel $^{1}$, DP Puiatti ${ }^{2}$, H-J Ritter ${ }^{3}$, D Lesueur ${ }^{4}$, C Denayer ${ }^{5}$, J Petit $^{5}$, A Shtiza $^{6}$

${ }^{1}$ EESAC, DUINGT, France

${ }^{2}$ Lhoist France, 168 RUE DE RIVOLI, 75044 PARIS,, France

${ }^{3}$ Federation of German Lime Industry (BVK), ANNASTRASSE 67-71, 50968 COLOGNE, Germany

${ }^{4}$ Lhoist Research \& Development, RUE DE L'INDUSTRY, 1400 NIVELLES, Belgium

${ }^{5}$ Carmeuse Group, RUE DU CHÂTEAU 13A, 5300 SEILLES,, Belgium

${ }^{6}$ European Lime Association (EuLA), 1000 BRUSSELS, Belgium

Hydrated lime in the Hot Mixed Asphalt (HMA) has been known to have several beneficial effects in the overall road performance (moisture damage and frost, decrease bitumen ageing) and as a result the extension of road durability. European Lime Association (EuLA) has conducted a life cycle assessment (LCA) study to compare the environmental impact of the classical Hot Mixed Asphalt (HMA) versus modified HMA (with $1.5 \%$ of hydrated lime) for the lifetime of a road. By using the ISO 14040-14044 standards, it was shown that thanks to the 25 percent extension of the road durability, the use of hydrated lime in Hot Mix Asphalt leads to a decrease in the overall environmental footprint over the lifetime of a road (50 years). The key outcome of the EuLA study is that the use of modified HMA in the wearing course has clearly the lower environmental footprint for the main environmental impact categories: energy consumption, abiotic depletion, climate change, air acidification, photochemical oxidant formation, stratospheric ozone depletion and eutrophication. Additionally for each maintenance step avoided, formation of traffic jams by the maintenance works is avoided. The results from this study have been validated by an external critical reviewer. The results from this study have an overall benefit for the sustainability development in the road construction sector. Additionally the results of this study are in line with the recent EU initiatives on raw materials, sustainability principles and financial constrains which require optimizing the available financial and resources in raw materials.

\section{TORS06-09}

\section{The research and application of life cycle assessment in Chinese materials industry}

\section{ZR Nie, ZH Wang, XZ Gong, SP Cui, F Gao, Y Liu \\ Beijing University of Technology, BEIJING, China}

For the production, manufacture, application, and disposal of materials, numerous energy and resources are consumed, and environment deterioration occurs as a result. Life Cycle Assessment (LCA) is a technique for systematically analyzing a target from cradle to grave. It is an effective tool that not only gives a detailed information of environmental profiles of a material or a product, more importantly, the value of life cycle thinking lies in its ability to provide the decision-making basis for sustainable development, making the products, industry and even the whole industry chain act more in line with the principles of sustainable development. The aim of this paper is to provide a review of recent developments of LCA methods and applications of materials life cycle assessment in China. In the sections on LCA methodology the characterization model of land use and abiotic resource depletion as well as the weakness of Life Cycle Impact Assessment were discussed. In relation to the applications, the Chinese materials database (SinoCenter Database) and several representative case studies such as life cycle analysis of civilian buildings and metal production in China were introduced in this article. 


\section{TORS06-10}

\section{Urban water cycle eco-efficiency assessment using LCA and LCC}

DM Marín $^{1}$, SMC Mc Ennis $^{1}$, MR Reyes $^{1}$, G Feijoo $^{2}$, JR Rieradevall $^{3}$, F Hernandez-Sancho $^{4}$

${ }^{1}$ CETaqua, Water Technology Centre, CORNELLÀ DE LLOBREGAT, Spain

${ }^{2}$ Dpt.Chemical Engineering, University of Santiago de Compostela, SANTIAGO DE COMPOSTELA, Spain

${ }^{3}$ Institute of Env. Science and Technology, Universitat Autònoma de Barcelona, CERDANYOLA DEL VALLĖS, Spain

${ }^{4}$ Water Economics Group, University of Valencia, VALENCIA, Spain

The continuous trend towards increasing urbanization brings to the fore the issue of urban sustainability. As part of urban systems, the urban water cycle should limit its environmental impact while providing sufficient drinking water supply and waste water treatment to growing cities.

The AQUAENVEC project (funded by the European Commission) aims to provide decision-making tools to optimize eco-efficiency in the urban water cycle, through environmental and economic life-cycle approach (LCA and LCC). The recently released ISO14045 on eco-efficiency is proposed as a new framework to address the integration of economic and environmental performance. The environmental and economic impact of the urban water cycle activities (water extraction, drinking water treatment, transport and distribution, sewer networks and waste water treatment) and their reduction potential are analysed in parallel and merged by relating the environmental assessment to the product system value assessment.

In a first step, the methodology is applied to two case studies: one in the Mediterranean area, on the east coast of Spain (Catalonia) and the other on the Atlantic coast (Galicia). Catalonia and Galicia have different climates: in the Mediterranean area, precipitation is scarce, with high seasonal and yearly variability, while Galicia receives more constant rain amounts throughout the year. The water stress in Catalonia is increased by a high population density, which reaches twice that of Galicia. Different characterisation factors are used for each region, which enables to analyse how disparities in water availability and water use patterns affect the sustainability of the urban water cycle.

The two main challenges in this first step are the implementation of correct regionalisation factors and the inclusion of water use as an impact category linked to resource depletion. Furthermore, water quality parameters of inlet and outlet water effluents in treatment plants should be also included in order to account for the higher removal efficiency of more polluting technologies. In addition, further research on specific inventory data for the water sector is being carried out, especially for chemicals used in water, waste water and sludge treatment.

The second phase focuses on the development of an eco-efficiency assessment tool, applicable to any urban area, which enables decision-makers to obtain guidelines as to best-practices to improve eco-efficiency of the urban water cycle. Indicators promoting the sustainable use of natural resources and reuse of end-products will be integrated to the generic tool thus aiming to achieve a sustainable management of the urban water cycle.

\section{TORS06-11}

\section{Use of natural resources in the building sector: Sustainability of natural plaster materials}

\section{$\underline{\text { G Dotelli }}{ }^{1}$, PVA Melià ${ }^{1}$, G Ruggieri ${ }^{2}$, S Sabbadini $^{1}$}

${ }^{1}$ Politecnico di Milano, MILANO, Italy

${ }^{2}$ Università dell'Insubria, VARESE, Italy

The request for green building materials and technologies is fast spreading all over western countries thanks also to the continuously increasing public awareness towards global sustainability. Despite a larger and larger use of natural materials in the building sector, there is a lack of deep and clear understanding about how green they are. Among the tools that nowadays can be used to assess quantitatively the environmental friendliness of a product or a process, Life Cycle Assessment (LCA) is certainly one of the most reliable. In the last decade the number of products analyzed by this tool is enormous and the trend is positive even for the future. However, notwithstanding the huge number of LCA studies focused just on the building sector which can be found in 
the international literature, still few works are devoted to natural materials.

In the present work the case study of two earthen plasters is presented. They are a viable option to synthetic products based on cement or lime. A natural earth plaster is composed of three main elements, typically sand, clay, and fibre. Sand provides structural strength and makes up the bulk of any earthen plaster mix. Clay is the binding agent and largely determines the earthen plaster's colour. Fibres such as short, chopped straw are common and important additions to earthen plasters because they help make the plaster strong and resistant to cracking.

The LCA study has been done in collaboration with an Italian producer of these plasters (Fornaci Brioni); so the study is based on a large corpus of primary data. Detailed inventory data are presented according to the perspective "from cradle to gate" and the impact assessment of the two products is analyzed using carbon and ecological footprints as well as Eco-indicator 99.

A comparative analysis between natural plasters and synthetic ones, based on cements and lime, is presented and discussed. Results strongly depend on the impact assessment method adopted and sometimes are counterintuitive.

\title{
TORS06-12
}

\section{Environmental assessment of building in existing structures - a bottom-up approach}

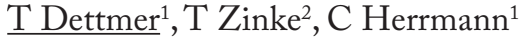

${ }^{1}$ TU Braunschweig, BRAUNSCHWEIG, Germany

\section{${ }^{2}$ KIT, KARLSRUHE, Germany}

In Europe, the sustainable utilisation of urban areas and existing buildings is becoming more and more important. Thus, urban concentration, modernisation and redevelopment will lead to a growing market of the refurbishment and modernisation segment of the building industry.

Due to rising resource and energy prices as well as to a growing awareness of the environmental impact of human activities (e.g. global warming) sustainability has also become a topic for the building industry. The comparison of different constructive alternatives regarding their sustainable performance necessitates a life cycle spanning assessment of ecological, economic and social aspects. Accordingly, LCA and LCC are the methods of choice, as first case studies and ongoing activities in the area of building certification and international standardisation show. Current rating systems for building construction (e.g. Bewertungssystem Nachhaltiges Bauen des Bundes - BNB) utilise criteria sets for quantitative assessments. These criteria sets were developed in top-down approaches. Nearly all studies in this field refer to new buildings whereas research on the transferability of these concepts to the assessment of existing buildings is still in an early stage.

Building activities in existing structures bear some specific challenges when it comes to sustainability assessment. In contrast to the construction of a new building, the observed life cycle starts with the partly deconstruction of the existing building. Also all subsequent steps of refurbishment and modernisation as well as the further lifetime expectancy still depend on the existing building to a great extent. Its flexibility and suitability for disassembly and recycling mainly determine the possible architectural and engineering options and thereby the economic and ecological impact of the related activities. Due to this strong influence of the individual characteristics of the existing building, a bottom-up approach should reveal if current assessment schemes meet the special needs of building in existing structures.

Therefore, two different scenarios for an existing office building in Dortmund (Germany) were compared in an LCA study to support the decision if the building should be modernised or knocked down and substituted by a new building from an environmental point of view. The availability of data about the used materials in the existing building (type and mass) were the first challenge to be faced. Constructional drawings from decades ago (not available digitally) had to be used as a basis for the necessary calculations. Additionally, only few and unspecific LCI datasets for demolition processes are available in today's standard LCI databases, but demolition processes of partly deconstruction differ significantly compared to the knocking down of a whole building. The longevity of buildings and the related time spans to be considered in the LCA have been another challenge.

Results of the case study helped to get a better understanding of the main drivers and critical aspects regarding an environmental advantageousness of building in existing structures, of how to support related decisions of constructors and to identify the shortcomings of current assessment schemes. 
This case study was part of the project "Bauen im Bestand"(building in existing structures) in the NASTA research cluster. It is funded by the German Federal Ministry of Economics and Technology based on a decision of the German Bundestag.

\section{TORS06-13}

\section{Comparative life cycle assessment (LCA) of a green roof system with VYDRO ${ }^{\circledR}$ substrate versus two conventional green roof systems using the CEN/TC 350 framework}

$\underline{\text { KMM Peeters }^{1}}$, C Spirinckx ${ }^{1}$, S Verbeke ${ }^{1}$, F Invernizzi ${ }^{2}$, R Weggelaar ${ }^{2}$, S Kotaji ${ }^{2}$

${ }^{1}$ VITO, MOL, Belgium

${ }^{2}$ Huntsman Polyurethanes, EVERBERG, Belgium

The use of green roofs in cities has enlarged the last decade. Green roofs can potentially mitigate problems related to storm water runoff, air pollution and energy of buildings. Huntsman recently entered the market with a polyurethane-based foam that can function as water retention layer for green roofs. The VYDRO substrate is a hydrophilic material that stores up to 30 times its own weight in water and supports therefore a rapid growth of vegetation. Compared to conventional substrates (lava/basalt and other bulky substrates), the foam has a much lower weight and can thus be installed on a larger range of roofs.

The present study looks into the potential environmental impacts of a green roof using a water retention layer with VYDRO ${ }^{\circ}$ substrate, compared to two conventional systems: a green roof with basalt/lava substrate and a green roof with demolition material from construction. The potential environmental impacts are investigated in both temperate and Mediterranean climate, taking into account the need for additional construction material due to heavier roof weights.

A comparative life cycle assessment (LCA) according to ISO 14040 and ISO 14044 was applied, using the CEN/TC 350 framework on sustainability of construction frameworks and more specifically the EN 15804.

The functional unit for the LCA has been defined as follows: "the installation of a $500 \mathrm{~m}^{2}$ extensive green roof on a concrete roof with a water retention capacity of $301 / \mathrm{m}^{2}$ (temperate) and $601 / \mathrm{m}^{2}$ (Mediterranean), with a reference service lifetime of 30 years, looking at the complete life cycle from cradle to grave and considering the roof weight impact on the building structure and the need to add any additional construction material".

The results of the LCA for a green roof with VYDRO ${ }^{\circ}$ substrate in a temperate climate show that most environmental impacts are related to the production of the raw materials for the VYDRO ${ }^{\infty}$ substrate (Methylenediphenyl diisocyanate and long chain polyether polyols). For the green roof with VYDRO ${ }^{\circ}$ substrate in Mediterranean climate the transportation of the relatively small amount of basalt/lava that is needed in the construction is almost equally important. For the modeling of the transportation steps fuel formulas were used relating the fuel consumption and emissions of a certain truck to the effective load of the truck.

When looking at the conventional green roof systems, the transportation phase becomes even more important in the environmental profile. In temperate and Mediterranean climate the green roof with VYDRO ${ }^{\circ}$ substrate scores better in most environmental impact categories based on life cycle impact assessment mentioned in the EN 15804.

From the comparative LCA study it can be concluded that the application of VYDRO ${ }^{\curvearrowleft}$ substrate in green roofs can help reduce the potential environmental impacts of the complete life cycle of green roofs.

VYDRO $^{\circ}$ is a registered trademark of Huntsman Corporation or an affiliate thereof in one or more, but not all, countries.

VYDRO@huntsman.com

www.thevydroeffect.com 


\title{
MPRS06-01
}

\section{A new modeling framework for environmental assessment of waste and energy systems}

\author{
J Clavreul, A Damgaard, TH Christensen
}

DTU Environment, KGS LYNGBY, Denmark

EASETECH, a new module-based decision support tool has been developed. The model is built on the knowledge and understanding from more than 10 years of development and use of the waste-dedicated LCA model EASEWASTE. EASETECH integrates in a new framework the same concepts from EASEWASTE while giving the user more flexibility and new functionalities. It allows the user to assess the environmental performance of complex systems that involve different materials and energy carriers.

The specificity of EASETECH compared to other LCA software lies in the handling of material flows via a functional matrix characterising flows in terms of numerous chemical and physical properties and as mixtures of several material fractions. These flows are brought to different kinds of modules that can be combined freely to model processes and form complex systems. In this way the software combines LCA and material and substance tracking (inspired from material and substance flow analysis).

Initially the EASEWASTE model originated from the need of bringing LCA into the field of waste management so several modules are particularly adapted to thermal and biological treatments of materials, as well as landfilling and application of sludge or processed waste on agricultural land. EASETECH is built with a more generic framework allowing for any transformation of material and energy flows. The generic modules can then be combined and adapted to specific needs, focusing e.g. on gas emissions over time, energy conversions, wastewater treatment or use on land.

In addition, new functionalities compared to the earlier versions include (1) the possibility of importing datasets in the ecoSpold 2 format (e.g. used in the ecoinvent 3 database), (2) an improved graphical user interface with easy construction of complex systems, (3) the possibility of combining modules in a free manner, (4) the possible parameterisation of processes allowing easy sensitivity analyses and uncertainty propagations with Monte Carlo analysis, (5) the possibility of changing the time horizon for inventory calculation of particular processes (landfilling and use on land) and (6) better presentation of the LCA results and material and substance flows of the modelled system using Sankey diagrams.

\section{MPRS06-02}

\section{Modified and mechanized car dismantling for improved profitability, recycling rate and environmental performance of end-of-life vehicle management}

\author{
T Rydberg $^{1}$, C Jensen ${ }^{1}$, SA Skenhall ${ }^{1}$, M Ljunggren Söderman ${ }^{2}, J_{\text {Felix }}^{3}$ \\ ${ }^{1}$ IVL Swedish Env Res Inst, GÖTEBORG, Sweden \\ ${ }^{2}$ IVL Swedish Environmental Research Institute, GÖTEBORG, Sweden \\ ${ }^{3}$ Chalmers Industrial Technologies, GOTHENBURG, Sweden
}

The overall objective of this project was to study modified ELV s treatment to obtain: a) an increased profitability for the actors in the recycling chain; b) increased recycling rate compared with today and with the aim of reaching $95 \%$ of which at least $85 \%$ material recycling (in accordance with the ELV Directive, 2000/53/EC); and c) improved environmental performance of the overall system.

A survey on current practice and ideas for improvement of Swedish dismantlers and a benchmark analysis on practices elsewhere were carried out. These main strategies for improvement were then elaborated: increase in manual dismantling and recycling of metallic and non-metallic materials, quality improvement of iron and steel fractions after fragmentation and the subsequent sorting, and increase in mechanical dismantling.

Practical dismantling tests were carried out and analyzed with respect to weight, material composition and time of removal as well as possible alternative treatment options and how this would affect costs and revenues for the actors in the recycling chain. Theoretical calculations were performed for a hypothetical post shredder residue plant adapted to Swedish conditions. A brief bill-of-material-based calculation of the environmental performance for the various options was also carried out. 
The results indicate that there is currently limited possibility to extend the dismantling of discarded vehicles that would contribute both to a greater profitability for the actors in the recycling chain and an increased recycling rate. Separate dismantling of copper-rich parts seems the most promising option. Some opportunity also exists with selected plastic parts, however with weaker economic incentive. Results from our practical tests on mechanical dismantling indicate to reduce time and costs of operation compared to manual dismantling. Shredder residue recycling by post-shredder techniques is not in operation in Sweden, but available cost estimates indicate lower cost than for manual and mechanical dismantling. At least, the cost of managing the shredder residue through the identified techniques seems to be considerably lower than the cost of the current management in the form of landfilling and incineration.

A recycling rate of $95 \%$ can be obtained by extended dismantling of plastics or by recycling of generated shredder residue. Treatment of the shredder residue by any of the studied techniques gives a recycling rate of the shredder residue of about $85-95 \%$, which gives an overall recycling rate of the vehicle of $96.8-98.4 \%$. The very high recycling rates are obtained because materials used for construction purposes on landfills or used to replace conventional fuel in cement production in blast furnaces count as recycling.

From the current material recycling rate, it would be sufficient to dismantle, manually or mechanically, and recycle the largest plastic parts, e.g. the bumpers and the fuel tank, to reach the $85 \%$ level and thus eliminate the need to invest in technology to recover the shredder residue.

Based on economically feasible manual dismantling, an extended recycling of copper-containing parts (from current 13.1 to $13.8 \mathrm{~kg}$ for the reference vehicle) and plastics (from zero to $58.6 \mathrm{~kg}$ ) provides an environmental benefit compared with current management. The additional recycling corresponds to a saving of $1 \mathrm{~kg} \mathrm{CO} 2 /$ ELV for copper, and $180 \mathrm{~kg} \mathrm{CO} / \mathrm{ELV}$ for plastics.

\section{MPRS06-03}

\section{Sludge as a multifunctional resource - system expansion to include recycling of phosphorous from Danish wastewater treatment plants}

M Thomsen ${ }^{1}$, M Niero ${ }^{2}$, B Hasler $^{1}$, L Martinsen $^{1}$, P Tychsen $^{3}, \underline{\text { M Pizzol }}^{1}$

${ }^{1}$ Aarhus University, ROSKILDE, Denmark

${ }^{2}$ University of Padova, PADOVA, Italy

${ }^{3}$ Krüger A/S, SØBORG, Denmark

Since 1987, where the first Aquatic Action Plan came into force in Denmark, the Danish wastewater treatment plants (WWTPs) have gone through technological upgrading to improve their efficiencies regarding the reduction of the content of organic matter, Nitrogen $(\mathrm{N})$, Phosphorus $(\mathrm{P})$, metals and organic pollutants in the effluent wastewater flows. Efficiency has increased significantly resulting from centralization and extended treatment procedures meeting the required water quality objectives according to the Aquatic Action plans, the Water Framework Directive and the Urban Waste Water Treatment Directive. As such the WWTPs meet the challenge of producing clean effluent water within a restricted end-of-pipe technology infrastructure, dedicated to remove environmentally disturbing substances from wastewater to protect the aquatic environment as well as health and safety of citizens. However, a parallel tendency toward multifunctional properties of the centralised WWTPs has emerged as a response to the anticipated scarcity in the global phosphorous resource, and this has led the Danish authorities towards a process of setting up regulatory goals for P- recycling for the Danish WWTPs.

The goal of the present LCA study is to assess and compare the environmental performance of 4 different technological solutions for the extraction of $\mathrm{P}$ as fertilizers starting from influent waste water flow, stepwise until the final dewatered sludge.

The functional unit of the product system is the treatment of $1 \mathrm{~m} 3$ of inlet water (carbon-enriched polluted inflow wastewater). The Danish WWTPs are multifunctional product systems as they provide multiple services such as the production of: clean water; a P enriched solid material, i.e. the sludge, to be used as fertilizer (while respecting the quality criteria defined within Sludge Directive); and methane for energy self-supply, thus improving the energetic performance of the system. As such, the plants have been optimized in respect to fixating nitrogen, lowering the $\mathrm{N}$-emission to air and water, precipitation or biological assimilation of water soluble components and microbial degradation of organic pollution by purpose of producing clean effluent water and minimal air emissions. 
As the primary function of the WWTPS is to fulfill the WFD and Aquatic Action plan requirements for reduced effluent wastewater outflow to the Danish marine and freshwater system, by retaining anthropogenic components in the sludge, it is relevant to adress and analyse the potentials of using and improving the quality of the sludge from Danish WWTPs as a resource for energy and fertiliser. This is done according to changes in the inflow water quality, technological and structural development of the WWT system, and as part of the study the economic potentials and incentives of producing fertilisers from sludge is analysed. The development in the environmental performance of the Danish WWTPs from 1990 until now, in terms ofquality of the output flows from the WWTPs, is thus presented based on available data. Trade-offs in environmental performance indicators measuring climate mitigation and environmental impacts and the influence on the quality of the final sludge are assessed according to four different treatment process combinations representative for Danish WWTPs, and the financial and welfare economic consequences of producing fertilisers from sludge are assessed.

\section{MPRS06-04}

\section{Life cycle assessment of clinker manufactured in Mexico with two types of fuel: coke or coke and refuse derived fuel}

\section{LP Güereca, CR Juárez}

\section{Universidad Nacional Autónoma de México (UNAM), MÉXICO D.F., Mexico}

Cement is the key constituent of concrete, which is the second most consumed material worldwide after water; it production involves the sintering of a proportioned mixture of limestone and clay to produce the clinker. Cement manufacture is an intensive energy consuming industry because it requires large amounts of energy to maintain the temperatures of the kilns over $2000{ }^{\circ} \mathrm{C}$. The consumption of cement is mainly given by the construction sector, thus it is closely linked to the economic cycle. According to the projections, world cement consumption could reach 3.4 billion tons by 2020, with the corresponding increases in energy use, raw materials and pollutant emissions.

On the other hand, the growing of population and the changes in the consumer habits, have caused an increase in municipal waste generation, which requires integrals waste management systems that considers treatments and final economically possible disposition alternatives, environmentally efficient and socially acceptable. In this sense, the cement industry could have a key role as an alternative waste management treatment offering by one hand, an alternative waste management treatment at the same time that avoid the use of fossil fuel due to the use of Refuse Derived Fuel (RDF) as an alternative fuel.

In order to investigate the potential of alternative fuels derived from municipal solid waste as secondary fuels in cement industries, the Instituto de Ingeniería at Universidad Nacional Autónoma de México (UNAM), are developing a project which objective is to develop a comparative Life Cycle Assessment of cement clinker production using $100 \%$ pet coke versus a mix of $80 \%$ pet coke and $20 \%$ RDF. This study considers real data from a cement plant and waste management and selection systems in Mexico. The functional unit is 1 ton of clinker, and takes into account since the extraction of raw materials in the quarry, milling, blending and cement kiln to produce clinker; considering in each process, the associated transport, generation and use of electricity, pet coke and $\mathrm{RDF}$, atmospheric emissions, water discharges and solid waste generation. The RDF is comprised of $32 \%$ plastic, $50 \%$ paper and cardboard, $10 \%$ textile and $8 \%$ wood. The environmental impact categories analyzed are acidification, abiotic depletion, eutrophication, stratospheric ozone depletion, global warming, human toxicity, terrestrial eco-toxicity and formation of photo-oxidants according to CML2001. Additionally an evaluation of some social and economics aspects is been conducting.

The preliminary results show that the use of RDF as secondary fuel in cement kilns offers environmental benefits in the impact categories analyzed. Results of this project shows the environmental benefits of municipal waste co-processing in kiln cement in Mexico, which could be a good example of cooperation strategies between municipalities and cement industries. In order to obtain these collaborations, results of this study are being presented in municipal forums and meetings. 


\section{MPRS06-05}

\section{Assessing environmental impacts of a multifunctional biogas production system}

$\underline{K R}$ Manninen $^{1}$, S Koskela ${ }^{1}$, J Sorvari ${ }^{1}$, A Nuppunen ${ }^{2}$

${ }^{1}$ Finnish Environment Institute, HELSINKI, Finland

${ }^{2}$ Gasum Oy, HELSINKI, Finland

Biogas, as one of the renewable energy, can have a significant role in the energy market in the future. Biogas production also provides a feasible waste management option since it enables the recovery of valuable nutrients from the digested sludge for use as fertilizers. Biogas production systems thereby represent multifunctional systems where co-products are generated in addition to the main product. This multifunctionality has implications for the life cycle analysis.

We determined the life cycle environmental impacts of a biogas production system using an Excel based calculation tool, specifically developed for this purpose. The biogas production system we studied includes the following stages: anaerobic digestion; upgrading and end use of biogas as traffic fuel; refinement of reject water separated from the digested sludge; end use of liquid nitrogen fertilizer; and the end use of the solid fraction separated from the digested sludge. The system generates approximately $85 \mathrm{TJ}(2.8 \mathrm{MW})$ biomethane per year from about 80000 tons of manure, waste energy crops and sewage sludge. Biogas is upgraded to biomethane using amine based chemical absorption before it is conveyed via a natural gas distribution system to refueling stations.

We chose to use the substitution approach in order to take into account the avoided emissions of the chemical fertilizers' production. The studied impact categories were climate change, terrestrial acidification, freshwater eutrophication, photochemical oxidant formation and particulate matter formation. We used 1 MJ produced biogas as the functional unit.

In the sensitivity analysis we studied the effect of different energy production and biogas upgrading technologies on the environmental impacts. The studied energy production systems were natural gas CHP, biogas CHP, and natural gas heat boiler together with grid electricity. The upgrading alternatives included amine based chemical absorption, a water scrubber and cryogenic technique. In addition, an uncertainty analysis will be run for the most critical parameters involved in the calculations.

\section{MPRS06-06}

\section{Comparative life cycle assessment of treatment and disposal of sewage sludge: An Italian case study}

\section{$\underline{\text { G Barberio }}^{1}$, L Cutaia ${ }^{1}$, V Librici ${ }^{2}$}

${ }^{1} \mathrm{ENEA}, \mathrm{ROMA}$, Italy

${ }^{2}$ Aquaser, ACEA Group, ROMA, Italy

The management of sludge from wastewater treatment plant (WWTP) becomes interesting due to the increasing amount and the high percentage of energy consumption (respect to the total of WWTP) for the operation as they require treatment before disposal. From other hand, the sludge recovery and utilization is an option strongly promoted as it is in compliance to the European recommendations for reducing landfill disposal and, moreover, seems to be economically and environmentally convenient, as the waste valorization leads to energy and material recovery. In fact, from literature studies, it could be found evaluations on use of sludge as secondary raw material in cement production and on different sludge treatments like as thermal, thermochemical and biological in separate or combined applications.

The aim of this study is the comparison of environmental performance of five different options for WWTP sludge management: agricultural land application with and without lime stabilization, landfilling with and without lime stabilization and composting as alternative biologic treatment. The study has been developed in collaboration with an Italian firm, AQUASER srl, an enterprise of ACEA spa group, among the major Italian operators in the field of sewage sludge management focused on recovery and disposal of waste, produced by wastewater treatment plants. Actually, the sludge landfilling is the main end-of-life option utilized in Italy but the country has to reduce the sludge landfill disposal from $25 \%$ to $5 \%$ by 2020 , in line to the European estimation[1]. So, there is the need to improve sludge treatment solutions to address the choice towards options that guarantee safety end environment protection and economic advantages and social sustainability. 
An operative tool to assess and compare the environmental sustainability of the systems is the methodology of Life Cycle Assessment (LCA). In this paper a comparative LCA study has been carried out and the function for all the systems I defined as the end-of-life of WWTP sludge throughout treatment and/or disposal, according to the Italian law.

From composting system, a new marketable product is obtained and it substitutes part of fertilizers applied on soils so, the LCA study considers the avoided impact associated to the reduced production of fertilizers. The amount of avoided fertilizers is calculated on the basis of specific culture and surface on which compost or sludge are applied.

In the last years the composting option was growing and, as in other European countries, Italy has also undertaken a voluntary certification programme for quality compost (both for the product and the process) promoted by the Consortium of Italian Compostors (CIC).

The results of this study encourage to pursue improvements in the system of sludge recovery using life cycle approach tools and it is a successful example of exchange of knowledge and expertise between the research activities and the application into firms to better understand and characterize the footprint of products and processes and to stimulate ecoinnovation.

[1] EC, DG Environment, 2010, Final report, "Environmental, economic and social impacts of the use of sewage sludge on land”, Milieu Ltd, WRc and RPA.

\section{MPRS06-07}

\section{Challenges in applying LCA in landscaping}

FMW Silvenius, S Kurppa, O Niemeläinen

\section{MTT Agrifood Research Finland, HELSINKI, Finland}

Waste management is one part of the life cycle assessment investigations. Waste is not always just harmful, benefit can be got by recycling and utilization, but the modeling of these can be complicated. This article is describing the challenges to measure and assess environmental impacts of composting biowaste and sludge and possibilities to utilize the compost as part of a substrate in landscaping. The investigation is part of an EU Life+-project called Application of LCA for sustainable green cover management using waste derived materials (LCA in landscaping). In the project, life-cycle assessments are made to several recycled-based substrate materials. The system boundaries of the study contain two parts: not only the production of the substrate material was included: also lawn establishment and maintenance of the lawn areas are investigated. The system boundaries contain mining, transportation, sludge composting including ammonia, nitrous oxide and methane emissions and fuel consumption of the activities of sludge treatment, spreading of the substrate and other activities related to establishment of the lawn, production chain of fertilizer and lime and nutrient leach and greenhouse gas and ammonia emissions of the life cycle of a lawn. The calculations will be done to different life span of the lawn, from five to twenty years. In addition to carbon footprint, this study will provide information on environmental impacts such as primary energy use, eutrophication, acidification, ecotoxicology and water footprint. Also cost-benefit analysis will be made in the investigation, so not only environmental impacts will be studied. it is expected that lawns, which have a substrate of recycled materials consume less fertilizers but on the other hand the mowing need may be higher. Different types of substrates are also going to be investigated containing different amounts of composted materials, peat, sand and other materials.

The investigation gives new perspectives to Life Cycle Assessments in the area of waste management. It gives bases to use substitution methodology or consequential approach in modeling the waste flows of different product systems: the recycled based substrates replace conventional substrates and the waste flows also contain nitrogen and phosphorus, which replace mineral fertilizers.

The LCA will be based on a wide investigation: there have been established demo areas and pot trials, where the functionality of different recycled based materials have been tested and one data has so far been gathered from one producer of composted organic waste and two wastewater treatment plants. Nitrous oxide emissions have already been observed to have a remarkable contribute to carbon footprint of recycled-based substrates according to literature and measurements made in one Wastewater Treatment Plant. Nitrous oxide of emissions of maintenance and establishment of lawn areas are going to be measured too. The investigation will be ready in autumn 2014. 


\section{MPRS06-08}

\section{LCA of construction and demolition waste management strategies: Case study of Rio de Janeiro, Brazil}

\section{RA Nunes}

Darmstadt University of Technology, DARMSTADT, Germany

This research investigates the options for handling and disposal of construction and demolition waste (C\&D) waste in the city of Rio de Janeiro, using the Life Cycle Assessment (LCA) methodology. The objective is to identify the most suitable C\&D waste management alternatives based on their environmental impacts. Scenarios were developed using five main alternatives for disposal of C\&D waste, which are: recycling at source of the waste generation, stationary recycling centres, disposition in former quarries, inert landfill and landfilling of municipal solid waste. The results of LCA show that the scenario consisted of $20 \%$ recycling at the source and $80 \%$ deposition in old quarries has the lowest environmental impacts within the scenarios. Sensitivity checks in relation to waste composition, recycling assumptions, transport and valuation system were carried out and almost no changes in the results were perceived.

\section{MPRS06-09}

\section{Evaluation of long-term cost-effectiveness of the smart recycling for sustainable development}

\section{Fujii, T Fujita, S Ohnishi, T Togawa}

National Institute for Environmental Studies, TSUKUBA, IBARAKI, Japan

Carbon reduction in rapidly growing material industries in developing counties where remarkable economic development is taking place is a critical issue. To cope with this, not only the energy saving of industrial processes but also the fuel shift to low carbon energy sources such as biomass and recyclable wastes are required. Utilization of urban wastes in material industries such as iron and cement (urban symbiosis) also contributes to promote effective use of wastes with maximum efficiency and, as a result, leads to cost saving of waste disposal.

Promotion of cost effective recycling is a key to enhance sustainability not only in developing countries but also in developed countries where administration budget for wastes treatment has been decreasing because of aging society and a declining birthrate. Smart recycling we propose is a system of wastes recycling and disposal aiming such an urban symbiosis by utilizing existing facilities effectively. Plastics, paper and food wastes are separately collected and processed into versatile raw materials and fuels at a regional pre-treatment center instead of incineration or landfill.

In this study, we evaluate the cost-effectiveness of the system from a long-term standpoint. The result will be affected by several events such as change in resource price, population increase or decrease, elevation of labor cost, promotion of reduce and reuse etc. Through the analysis, we will discuss what are important for a recycling and waste disposal system to raise probability of reduction of environmental burdens and resource consumption on the present and the future.

This research was supported by the Environment Research and Technology Development Fund (K113002 and K2413) of the Ministry of the Environment, Japan.

\section{MPRS06-10}

\section{Challenges in performing an LCA of an emerging technology: Active windows with micro mirror arrays}

\section{U Neumann, M Hiete}

\section{University of Kassel, KASSEL, Germany}

Though daylight illumination in buildings has the least environmental impacts and the highest spectral quality and comes at no costs, design for daylight use in buildings is challenging as there is a trade-off between daylight use and cooling demand. Users might also get blinded or bothered by a too high luminosity. External sun blinds effectively reduce such effects but at the expense of a strongly reduced daylight use. As high-maintenance products external sun blinds are also rather expensive, difficult to operate and hardly applicable in high-rise 
buildings. MicroElectroMechanical System (MEMS) technology allows developing active windows with micro mirror arrays between two layers of flat glass. The angles of the micro mirrors are controlled by applying a voltage. Compared to external sun blinds such active windows are supposed to be maintenance-free and thus less expensive and widely applicable, allow a fast and only partial blind of selected areas of a window etc. The contribution addresses environmental impacts over the life cycle of active windows which so far are produced on a laboratory scale only. Therefore a scenario-based approach is proposed to take into account uncertainties related to the production processes at full scale including different levels of success of process optimization. Additional uncertainties arise for example in the use stage with user behavior as an important factor (it is expected that active windows result in a higher share of daylight use as for example blinding can be more specifically controlled). Overall, the contribution analyzes the different challenges associated with an LCA of an emerging product like active windows and proposes a scenario-based approach to address them.

\section{MPRS06-11}

A case-study comparison of life cycle inventory methodologies commonly applied to LCA studies in the built environment, including the qualification and quantification of the associated ancertainty

$\underline{\text { DK Wolff }}^{1}$, AP Duffy ${ }^{1}$, GP Hammond ${ }^{2}$

${ }^{1}$ Dublin Institute of Technology, DUBLIN, Ireland

${ }^{2}$ University of Bath, BATH, United Kingdom

Life Cycle Assessment (LCA) is defined as the evaluation of the environmental impact of a product throughout its life cycle, including raw material extraction, manufacturing, and disposal. It is unique in that it takes a holistic approach to environmental impact assessment, and thus identifies 'hot spots' in a product's life cycle. Because of this, LCA has the potential for supporting business and policy-making decisions based on reducing a product's environmental impact, while ensuring the impact is not transferred to other parts of the life cycle. There are, however, well known limitations of LCA, including poor data quality and availability, the use of non-scientific assumptions and decisions, and variations in the computational methodology applied. Because of these limitations, the results from LCA studies have been criticized, and it has been recognized that making comparisons across studies is difficult, if not impossible.

The International Organization of Standardization (ISO 14044) sets guidelines to follow when conducting an LCA study in order to ensure that the limitations of a study are reported; however, a specific computational method to follow when conducting an LCA is not stated. As a result of this, various methodologies for Life Cycle Inventory (LCI), Life Cycle Impact Assessment, and Uncertainty computation have been used. This paper discusses the results of a case-study comparison of three commonly applied LCI methods, as well as the methods used to quantify and qualify the uncertainty.

The case-study chosen was the construction of a housing estate in Ireland. Three separate LCAs were conducted using three different LCI methods- Process, Input-Output, and Integrated Hybrid Analysis. The data for all three LCAs was obtained from a Bill of Quantities for the housing estate, the ICE database, the Ecoinvent database, and the Input-Output and Sectoral Emissions Tables published by the Central Statistics Office for Ireland. The system boundary for each LCA was defined as cradle-to-site, including the construction process, and the functional unit used was defined as one housing estate consisting of $27,000 \mathrm{~m}^{2}$ of living space. Since the intention of this study was to compare the various LCI methodologies and their uncertainties, the impacts assessed were limited to the Global Warming Potential and Embodied Energy. The methods were compared in terms of their ease of application, compliance with ISO guidelines, differences in the results obtained, and quantified uncertainty.

For this case-study, the uncertainty in each LCA was categorized into three types- Parameter, Model and Scenario. Parameter Uncertainty was estimated using Monte Carlo Simulations, and Model and Scenario uncertainties were estimated by determining alternative choices and calculating the impact of these alternatives on the overall result. The Parameter, Model and Scenario uncertainties were integrated throughout the LCA in order to quantify the uncertainty of the overall result. This paper further stresses the significance of conducting uncertainty analysis in all LCA studies, as the degree of uncertainty has a large influence on the outcome, especially if the study is being used in support of business or policy-based decisions. 


\section{MPRS06-12}

\section{Luxembourg's waste management footprint}

A Di Maria ${ }^{1},{\underline{\text { E Igos }^{2}}}^{2}$ P Hild ${ }^{1}$, A Marvuglia $^{1}$, E Benetto $^{1}$

${ }^{1}$ Public research centre Henri Tudor, ESCH-SUR-ALZETTE, Luxembourg

${ }^{2}$ Public Research Centre Henri Tudor, ESCH-SUR-ALZETTE, Luxembourg

The production of construction and demolition waste (CDW) isincreasing in Europe. CDW poses significant problems not only for its hazardous nature, but mainly for the relevant volume generated. CDW can include many kinds of different materials: inert materials (concrete, tiles), hazardous materials (bitumen, contaminated wood) and valuable materials (plastics and paper packaging).

According to different studies, Luxembourg has one of the highestper-capita productions of CDW among European countries. In order to fulfill the increasingly stringent requirements of the European regulation, there is a need to assess the current CDW management system, in order to give recommendations to national stakeholders concerning the reduction of the environmental impacts linked to this kind of waste. The study assessed (through Life Cycle Assessment, using the software SimaPro and the impact assessment method $\mathrm{ReCiPe}$ ) the environmental impacts related to the different waste management processes for CWD in Luxembourg. Two case studies were analyzed: waste flows from a construction site and waste flows from a demolition site, both located in Luxembourg. The data about waste production and management were supplied by SuperDrecksKëscht (SDK), the Luxembourgish agency for sustainable management.

The outcomes show that in both cases, the most significant impacts (on most of the considered impact categories: climate change, human toxicity, etc.) are caused by the incineration of materials (contaminated wood, plastics, waste paints). Even though inert materials constitute the biggest flow in terms of weight and volume, their impacts are relatively low, except for the impact category "urban land occupation", as they are entirely disposed in landfills. Lastly, some scenarios were elaborated at the aim to assess the environmental benefits due to the recycling potential of currently not recycled materials (inert waste, plaster, bitumen). The final results show that the recycling of these materials yielded in an important reduction of the environmental impacts. For inert waste recycling, assuming a $80 \%$ share of recycling gives rise to a reduction of $41 \%$ in the damage category "human health", $28 \%$ in the damage category "ecosystems"and $47 \%$ in the damage category "resources". For plasterboard recycling, assuming an $80 \%$ share of recycling gives rise to a reduction of $177 \%$ of the impacts in the category "human health", mainly due to the avoided impacts related to the avoided process gypsum mining. Finally, for bitumen recycling all the scenarios assuming an $80 \%$ share of recycling show a negative overall impact (avoided impacts) for each and every damage category.

The study highlights the processes and waste flows playing a significant role in terms of environmental impacts in the waste management system in Luxembourg (namely the materials which undergo incineration). The results of the study can thus be used to identify the "hot spots" of the CDW treatment cycle and give the baseline for recommendations in terms of alternative, more environmentally sound, waste management solutions. 


\title{
MPRS06-13
}

\section{Understanding the potential environmental advantages and disadvantages of building reuse and retrofit}

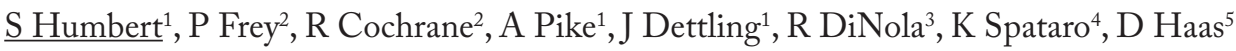

${ }^{1}$ Quantis, LAUSANNE, Switzerland

${ }^{2}$ National Trust for Historic Preservation, WASHINGTON DC, United States of America

${ }^{3}$ Green Building Services, PORTLAND, United States of America

${ }^{4}$ Cascadia Green Building Council, SEATTLE, United States of America

${ }^{5}$ Skanska, SEATLLE, United States of America

Each year in the U.S., approximately 1.7 billion square feet of buildings are demolished and approximately 5 billion square feet of newly constructed buildings are added to the total building stock. The environmental impacts of this cycle of demolition and new construction are poorly understood, as are the opportunities to gain carbon savings through building retrofit and reuse. As communities across the country take action to reduce greenhouse gas emissions associated with the building sector, understanding the potential environmental advantages and disadvantages of building reuse and retrofit is essential. Until now, little has been known about the climate change reductions that might be offered by reusing and retrofitting existing buildings rather than demolishing and replacing them with new construction. This panel will present the results of a study, 'The Greenest Building: Quantifying the Environmental Value of Building Reuse,' the most comprehensive analysis to date comparing the environmental impacts of new construction compared to retrofit and reuse of existing buildings. The study was coordinated by the Preservation Green Lab, a programmatic office of the National Trust for Historic Preservation, in partnership with Cascadia Green Building Council, Quantis LLC, Skanska, and Green Building Services. Utilizing a Life Cycle Analysis (LCA) methodology, an internationally recognized approach to evaluating the potential environmental and human health impacts associated with products and services throughout their respective life cycles, the study compares the impacts of reuse to new construction for six different building typologies, including a single-family home, multifamily building, commercial office, urban village mixed-use building, elementary school, and warehouse conversion. It also evaluates these building types across four U.S. cities, each representing a different climate zone, i.e., Portland, Phoenix, Chicago, and Atlanta. The panel will discuss the following significant findings: (1) Reuse Matters. Building reuse typically offers greater environmental savings than demolition and new construction. It can take up to 80 years for a new energy efficient building to overcome, through efficient operations, the climate change impacts created by its construction. (2) Scale Matters. Collectively, building reuse and retrofits substantially reduce climate change impacts. Retrofitting, rather than demolishing and replacing, just $1 \%$ of the city of Portland's office buildings and single family homes over the next ten years would help to meet $15 \%$ of the county's total CO2 reduction targets over the next decade. (3) Design Matters. The environmental benefits of reuse are maximized by minimizing the input of new construction materials. Projects that require a significant amount of new materials can reduce or even negate the benefits of reuse. The research presented at this session is intended to serve as a resource for those who influence and shape the built environment, including policy makers, building owners, developers, architects, engineers, contractors, real estate professionals, and non-profit environmental, green building and preservation advocacy groups. 


\title{
RS-07: Tools and new approaches for sustainability assessment
}

\section{TORS07-01}

\section{User experiences of a streamlined sustainability assessment tool}

\author{
$\underline{\text { S Horn, H-L Pesonen }}$ \\ University of Jyväskylä, JYVÄSKYLÄ, Finland
}

The LCA community has recently identified that in addition to LCAs, life cycle based full sustainability assessments should be further developed for the usage in decision-making (Klöpffer 2008, Valdivia et al, 2011). Especially it has been identified that it is of interest of the LCA community to encourage a discourse with business decision-makers in order to enable the LCA-based methodologies to be further understood and utilized in decision-making (Rebitzer and Schäfer 2009).

A streamlined, rapid assessment tool called Sustainability SWOT for a first-cut approach to a sustainability assessment, which uses an easy-to-read and familiar tool for business people has been tentatively proposed by Pesonen (2007) and evaluated by Pesonen and Horn (forthcoming 2012).

The underlying study will provide a more detailed follow-up examination of the tool. The study's main contribution will arise from gaining deeper knowledge about the application of the Sustainability SWOT with various types of users about their user experiences, the ways of how the Sustainability SWOT is able to generate changes in the entire value chain as well as the hindrances businesses are in general facing in incorporating the life cycle perspective and optimizing the value chain.

The data will be gathered during the end of the summer in form of focused interviews with actual users of the tool. These users are representatives of the organizations participating in the first phase of the study, thus having applied the Sustainability SWOT in real-life (Pesonen and Horn forthcoming 2012).

About the results of the study, indications can be found from first round that changes in different forms are likely to materialize and are transferable along the supply chain. However as a result of this study specific and in-depth experiences from businesses will be expected. These will be valuable for the LCA community by generating a discourse with business decision-makers as well as to use this discourse to understand the needs of businesses in terms of life cycle optimization. The results of the study will also allow a detailed account of the ways the tool is able to generate the changes along the value chain, which will amplify the prospects of a wider application of the tool.

References:

Klöpffer W (2008) Life cycle sustainability assessment of products (with Comments by Helias A. Udo de Haes, p. 95). Int J Life Cycle Assess 13(2):89-95

Pesonen H-L (2007) Sustainability SWOTs - New method for summarizing product sustainability information for business decision making. A paper presented in the LCM 2007 conference. Available in http://www. lcm2007.org/presentation/Mo_3.10-Pesonen.pdf. Accessed 10 December 2011

Pesonen H-L, Horn S (2012) Evaluating the Sustainability SWOT as a streamlined tool for life cycle sustainability assessment. Int J Life Cycle Assess, forthcoming.

Rebitzer G, Schäfer JH (2009) The remaining challenge - mainstreaming the use of LCA.Int J Life Cycle Assess 14:S101-S102

Valdivia S, Ugaya CML, Sonnemann G, Hildenbrand J (eds) (2011) Towards a Life Cycle Sustainability Assessment. Making informed choices on products. Paris ISBN: 978-92-807-3175-0 


\section{TORS07-02}

\section{Developing and testing a model which is based on Nordic consensus on evaluating bridge sustainability}

\section{$\underline{\text { L Høibye }}^{1}, \mathrm{H}$ Bratteb $\varnothing^{2}$}

${ }^{1} \mathrm{COWI}$ A/S, VEJLE, Denmark

${ }^{2}$ Norwegian University of Science and Technology, TRONDHEIM, Norway

Infrastructure has proven to be a large contributor to the total environmental impact. Traditionally, focus has been on costs - but this situation is about to change. The Nordic countries have joined forces due to a common interest in developing sustainable bridges.

The four Nordic Road Directorates has financed the development of tools for evaluating the environmental, economic and aesthetical performance of bridges. The ultimate scope of the project was to create the basis for refined and improved decisions and thus in the end reduce the potential impacts.

Three excel tools are ready for implementation by the national road authorities prior to the final use by consultants, municipalities etc. The tools can be applied to assess the performance of bridges during every phase of a bridge's service life.

Several initial tests of the tools have been performed to evaluate the performance and practical applicability of the LCA and LCC tools.

For the Danish Road Directorate a smaller bridge crossing a highway has been tested.

The ReCiPe methodology has been used to calculate most environmental impacts. Regarding toxicity, USEtox is the chosen method in order to use the state-of-art knowledge to describe the impacts caused by toxic substances.

By using the LCA tool, it is possible to focus and thus reduce the largest contributors to the environmental impacts. In the early stages e.g. the feasibility study, the daily traffic is by far the most important contributor. So, the physical length of the bridge and adjoining road is vital.

When the trace is decided upon, the material consumption contributes to considerable impacts which can be optimized and on many cases reduced. It is possible to use the tool to identify the most important materials and test the effect of choosing materials with reduced impacts. Examples are the use of fibre reinforced concrete, using ground blast furnace slag etc. which has been evaluated using LCA to assess the potential environmental impacts contrary to traditional cement and reinforcement.

Generally, the phases construction, repair (including traffic disturbances), maintenance and end-of-life are less important to the total potential environmental impacts during the entire life cycle of bridges.

The study illustrated that: a) Bridge LCA is a applicable tool for all phases of bridges, b) the application of LCA for materials assessments is unique for reducing the potential environmental impact, c) sustainability and durability often go hand in hand, d) many material producers are not yet prepared for the upcoming focus on sustainability, carbon footprint and environmental product declarations which is rapidly emerging, e) using LCA for assessing the potential impacts has huge potentials for improving the performance and thus also reduce the impacts significantly by applying Bridge-LCA in different ways specific for the individual phase of the bridge project, f) Bridge-LCA can be expanded to include other types of infrastructure projects. 


\section{TORS07-03}

\section{Beyond eco-efficiency: Measuring environmental sustainability by extending LCA with network analysis}

$\underline{\text { M Pizzol }}^{1}$, M Scotti $^{2}$, B Vedres ${ }^{3}$, M Thomsen $^{1}$

${ }^{1}$ Aarhus University, ROSKILDE, Denmark

${ }^{2}$ The Microsoft Research, Univ. Trento-Centre for Computational and System Biology, ROVERETO, Italy

${ }^{3}$ Center for Network Science, Central European University, BUDAPEST, Hungary

The present work describes how Network Analysis (NA) could be used to complement Life Cycle Assessment (LCA).

LCA is based on the principle of quantifying the environmental burden of a complex system by measuring multiple sets of key attributes (e.g., amount of GHG emitted, abiotic resources used, etc.), and by combining this information into indicators. LCA provides a partial assessment of sustainability, as it focuses only on "ecoefficiency"(i.e., among two systems providing the same service, the one using less natural resources should be preferred). Nevertheless, sustainability is also related to system persistence/inertia in response to disturbance (stability) and capacity of withstanding perturbations by quickly recovering from damage (resilience).

This deficit in sustainability assessment could be filled by using $\mathrm{NA}^{1}$ in support to LCA. NA was originally conceived within the domain of economy, it has been applied extensively to study ecosystems, and recent applications of NA to sustainability assessment of human systems have been developed as well ${ }^{2}$. Networks are conceptual structures representing systems as composed of interconnected nodes exchanging a common currency. Data needed for the construction of networks are organized in input-output matrices that are mass-balanced as with LCA. Several indices of performance can be computed for such networks by using mathematical algorithms. These indices can quantify multiple dimensions of sustainability (e.g., stability and resilience) at system-level. Moreover, NA allows comparing consistently human systems with ecosystems; environmental sustainability can be measured in absolute terms on the hypothesis that the most sustainable human systems are those mimicking ecosystems (strong sustainability).

We applied NA for two case studies: 1) a water management system in Denmark; 2) the European natural gas pipeline network. These are compared with a series of ecosystems by using several indices of system-level performance (e.g., AMI-Average Mutual Information, A-Ascendency, FCI-Finn Cycling Index). Results clearly show that improving sustainability means balancing efficient processes with flexible structures, at whole system level. Ecosystems can achieve such balance, whereas human systems tend to prioritize efficiency, thus evolving towards rigid structures that are unable to respond to situations of stress or damage. This leads to fragile architectures, increasing risks of collapse in case of extreme events.

LCA focuses on flow intensities within a system (quantitative aspects) and estimates eco-efficiency, whereas NA evaluates the structure of the system flows (qualitative aspects) and allows to measure levels of stability and resilience, thus being an extremely valuable sustainability assessment tool. NA applies to single-currency networks (only one substance is exchanged within the system, e.g. water), while in LCA several substance-flows are simultaneously addressed (e.g., $\mathrm{CO}, \mathrm{NO}, \mathrm{Cd}$..), determining the emergence of multi-currency networks. To accommodate NA into the LCA framework, ad-hoc approaches are needed; the conversion of material flows from different currencies into emergy seems the most promising.

${ }^{1}$ Ulanowicz R: Quantitative methods for ecological network analysis. Computational Biology and Chemistry 2004, 28(5-6):321-339.

${ }^{2}$ Bodini A, Bondavalli C, Allesina S: Cities as ecosystems: Growth, development and implications for sustainability. Ecological Modelling (in press). 


\title{
TORS07-04
}

\author{
Assessing the environmental and economic impacts of industrial sectors: A process-based approach \\ D Amienyo, HK Jeswani, A Azapagic \\ The University of Manchester, MANCHESTER, United Kingdom
}

The economic input-output life cycle assessment methodology has traditionally been applied for estimating the life cycle impacts of industrial sectors. However, this approach has several limitations including its reliance on sector-level aggregates which may not be representative of the specific sub sectors which comprise a particular industrial sector. In an attempt to better understand the life cycle impacts of industrial sectors; this paper presents a bottom-up approach based on the process-based life cycle assessment and life cycle costing methodologies, with theUKbeverage sector as a case study. The impacts considered include global warming, resource consumption, life cycle costs and economic value added.

The environmental and economic impacts have been estimated in accordance with the ISO 14044 life cycle assessment methodology and the SETAC Code of Practice for environmental life cycle costing, respectively. The results are then extrapolated to the sectoral level using a bottom-up approach which combines the product-based methodologies with market analysis. The findings of this study suggest that the UKbeverage sector is responsible for over 3.5 million tonnes of $\mathrm{CO}_{2}$ equivalent emissions annually, with the carbonated soft drinks and beer sub sectors responsible for the largest contributions. Economic value added from the beverage sector has also been estimated at over $£ 15.8$ billion annually or $11 \%$ of total gross value added from theUK manufacturing sector. The study highlights the trade offs between the economic input-output and processbased life cycle approaches for sectoral impact assessment.

\section{TORS07-05}

\section{Hybrid LCA towards sustainable management of metals: Quality- and dilution losses in recycling}

$\underline{\text { SN Nakamura }^{1}}$, HO Ohno ${ }^{2}$, KM Matsubae ${ }^{2}$, YK Kondo ${ }^{1}$, KN Nakajima ${ }^{3}$,TT Tasaki ${ }^{3}$, TN Nagasaka ${ }^{2}$

${ }^{1}$ Waseda University, TOKYO, Japan

${ }^{2}$ Tohoku University, SENDAI, Japan

${ }^{3}$ National Institute for Environmental Studies, TSUKUBA, Japan

Metals can in theory be infinitely recycled in a closed-loop without any degradation in quality. In reality, however, open-loop recycling is more typical for metal scrap recovered from end-of-life (EoL) products because mixing of different metal species results in scrap quality that no longer matches the originals. Further losses occur when meeting the quality requirement of the target product requires dilution of the secondary material by adding high purity materials. Standard LCA usually does not address these losses. This paper presents a novel approach to quantifying quality- and dilution losses, by means of hybrid input-output analysis. We focus on the losses associated with the recycling of metals from end of-life vehicle (ELV) due to the uncontrolled mixing of alloying elements. For a given quality of scrap in terms of mixing, the ratio by which scrap needs to be diluted in a remelting process is determined. Also determined is the amount of demand for the primary output of the remelting process including those quantities needed for dilution. Application to a high-resolution Japanese IO table supplemented with data on ferrous materials including different grades of scrap indicates that a nationwide avoidance of these losses could result in a significant reduction of $\mathrm{CO} 2$ emissions. Implications of recycling for the overall balance of scrap will also be discussed. 


\title{
TORS07-06
}

\section{Sustainability assessment and methodology for optimizing the recycling of flat panel displays}

\author{
HVK Ljungkvist ${ }^{1}$, T Rydberg $^{1}$, T Ekvall $^{1}$, J Felix $^{2}$
}

${ }^{1}$ IVL Swedish Environmental Research Institute, GOTHENBURG, Sweden

\section{${ }^{2}$ Chalmers Industrial Technologies, GOTHENBURG, Sweden}

Statistical trends show rapid increase in electronic waste volumes from Swedish (and European) households. As an example, the net inflow of flat desktop monitors to Sweden was 10500 tons in 2010 (SMED report $105,2012)$, with waste volumes in the same order of magnitude. These large and increasing numbers pose a challenge for existing and future treatment systems, if material resources from this complex waste stream are going to be successfully recycled. Toxicity is another important aspect to consider, since both screen composition and proposed recycling processes involve hazardous substances. The Swedish joint R\&D project "Sustainable Recycling of Flat Panel Displays (HÅPLA)"is an initiative to develop a comprehensive solution for the recycling of flat screen TVs and computer monitors, particularly those based on liquid crystal technology (i.e. LCD screens). By involving several steps and actors in the value chain such as manufacturers of flat screen TVs and monitors, WEEE collection organization, WEEE recyclers, recycling equipment suppliers and environmental labeling organizations, a better understanding is provided of the complex conditions influencing the life cycle of flat screens.

The present paper reports on selected assessments made within the project, specifically related to the sustainability rating of different recycling scenarios and the compilation of a "Sustainability toolbox" for a multifaceted evaluation of the end of life options for flat screens. One component in the toolbox is Life cycle assessment (LCA). In line with the project scope, the LCA is limited to the end of life treatment of flat screens, based on existing treatment paths for end of life flat screens in Swedish waste streams. One kilo of LCD screen waste is used as reference flow, using the material composition suggested by Salhofer et. al 2010. The modeled treatment scenarios involve large-scale shredding, manual dismantling or semi-automated dismantling, with the reference scenario being pre treatment and sorting for material recycling combined with incineration. Evaluation of the scenarios are performed and compared with existing processes, using LCA software. The aim is to provide a rating for the treatment scenarios with regard to climate impact,

recyclability and resource scarcity (ELU). In addition to LCA, the complete Sustainability toolbox consists of four more tools, namely Work environment evaluation, Chemical risk assessment, Financial assessment and Cost benefit analysis.

\section{TORS07-07}

\section{Electricity producing technologies and electricity markets in ecoinvent version 3}

\section{K Treyer, CB Bauer}

\section{Paul Scherrer Institute, VILLIGEN PSI, Switzerland}

Accurate and specific life cycle inventory (LCI) data for power generation and electricity supply are important prerequisites in LCA for an evaluation of the environmental performance of a broad range of products and services. Therefore, such high-quality data are a key element in sustainability assessment: for individual decisions from the consumer's perspective, for decisions of companies on strategies, as well as for policy.

The present study provides LCI data for all important electricity producing technologies and electricity markets (supply mixes) in 50 countries all over the world, covering $84 \%$ of worldwide electricity production on a country-specific level. These LCI data of the electricity sector are one important pillar of the database "ecoinvent version 3", the world's leading supplier of consistent and transparent LCI data.

In order to support the increasing use of ecoinvent by LCA practitioners worldwide, the new v3 contains LCI data of electricity generation and supply (markets) of additional 18 countries around the world compared to ecoinvent v2. Among them are important economies like Australia, Canada, India and Russia. Almost all electricity generation technologies - fossil, nuclear and renewable - contributing to national production are available as country-specific inventory data. The electricity markets of all countries are determined with the annual production volumes of the contributing technologies, the electricity imports from neighbour countries, and transformation and distribution losses on high, medium and low voltage level. Also new features could be 
added to the electricity datasets: Extensive use of parameters and variables make the datasets more transparent and life cycle analysts can themselves easily change e.g. the efficiency or the lifetime of a power plant type, or they can adapt the yield for photovoltaic electricity to a specific region. Furthermore, the marginal electricity mixes additionally available to the average mixes can be used in consequential analysis.

The new inventory data show significant country-specific variations in the environmental burdens of electricity generation, both on the individual technology level as well as on the electricity market level. For example, the levels of key air pollutant emissions from coal power plants depend heavily on legal regulations on air pollution and therefore the installed emission control systems. Compared to South Korea with comparatively “clean" power plants, particulate matter emissions in countries like Chile can be a factor of 1000 higher. Variations in $\mathrm{SO}_{2}$ and $\mathrm{NO}_{\mathrm{X}}$ are much smaller in a range of a factor up to 30 for $\mathrm{SO}_{2}$ and 10 for $\mathrm{NO}_{\mathrm{X}}$. On the market level, the environmental profile of the electricity supply mix predominantly depends on the contributions of individual energy carriers and technologies to the country-specific mix. Among the 18 new countries in the ecoinvent database, the highest shares of renewables (basically hydro power) can be found in Canada, Tanzania and Peru. On the other hand, fossil resources dominate the power supply in Australia, Iran, and Saudi Arabia.

With the expansion of the electricity sector in ecoinvent v3 and the new LCI data, the database can serve as a powerful instrument to decide on sustainable electricity sources for decision makers in companies and politics, be it on a small level for companies or on a large level for political setting of the course for a future sustainable energy supply in a country.

\title{
TORS07-08
}

\section{If you cannot measure it, you cannot manage it. Assessing environmental sustainability at higher education institutions}

\author{
M Faghihimani \\ University of Oslo, OSLO, Norway
}

Sustainability is becoming an integral part of university life. A global trend among universities shows that they are revising their mission and restructuring their courses, research programmes and operations on campus to include sustainability in their perspectives. Assessing environmental impacts and benchmarking universities according to their Greenness however is still a new field.

In 2010 we at the Sustainability office of Oslo University (UiO) have designed and used 50 indicators to assess Environmental Sustainability (ES) in 20 universities, benchmark them and compare our own ES status with those international universities. The indicators classified in 5 categories: Sustainability in Governance, Sustainability in Operation, Sustainability in Education Sustainability in Research and Sustainability in other related activities. The study has implemented system theory and considered sustainability in a holistic approach for higher education institutions.

The result showed an unsatisfying score for $\mathrm{UiO}$ which scored among the lowest sustainable universities with regards to environmental challenges. However this study motivated us to step up our ES efforts by offering Best Green University Practices based on he research project that we carried on to the leadership team. It has started by proposing a short and long term plan which suggested particular actions such as endorsing sustainability policy, allocating budget, staff, creating carbon account, shifting to renewable energy, as well as engaging students, collaborating with researchers, working with municipalities, NGOs and raising awareness and capacity building activities. The recent analysis (2012) has shown a dramatic improvement in ES status of $\mathrm{UiO}$.

This paper aims at presenting the importance of assessing environmental impact and sustainability status, as well as sharing best green practice and its benefit in improving sustainability affairs at higher education institutions. 


\title{
TORS07-09
}

\section{Comparing process LCA and IO-LCA: Electricity generation in a solar thermal power plant in Spain}

\author{
C De la Rúa, Y Lechón, N Caldés
}

CIEMAT, MADRID, Spain

On the grounds of promoting sustainable development, any product, process or service must be evaluated in order to assess its environmental and socio-economic impacts. Responding to this concern, a new integrated innovative tool, named Life Cycle Analysis -Input Output (LCA -IO) for Spain, has been developed. This analytical tool allows a fast and effective assessment of environmental and socioeconomics impacts of any product, process, project or investment policy along their life cycle, taking into account the environmental and socioeconomics particularities of Spain.

One advanced energy system has been assessed using this tool: electricity generation in a parabolic-through solar thermal power plant in Spain. These results have been compared to those obtained using another analytical tool - Life Cycle Assessment (LCA). By doing so, it has been possible to validate the environmental estimations resulting from the LCA -IO as well as identify its strengths and weaknesses.

As expected, most environmental impacts estimated by the LCA -IO tool are higher than those estimated by the LCA. This fact can be explained because the LCA -IO tool avoids the definition of the system limits, so that all processes and activities involved in the system are considered.

Nevertheless, some exceptions have been found, mainly associated to $\mathrm{N} 2 \mathrm{O}$ and $\mathrm{CH} 4$ emissions. The aggregation level of some economic sectors in the developed tool has been identified as the reason of such exceptions. In that sense, of particular importance are the sectors (i) Chemistry Industry and (ii) Electricity production and distribution, which include activities and products with very different environmental profile.

Some additional discrepancies between the two analytical tools arise due to differences between the national emissions inventory and the emissions database considered in the process LCA.

The newly LCA -IO tool simultaneously considers notable socioeconomic impacts, such as economy activity as well as employment generation, which allows carrying out a more complete analysis and holistic approach from the sustainability point of view.

\section{MPRS07-01}

\section{Application of LCA to urban metabolism as method for gauging urban sustainability}

\author{
$\underline{\text { BP Goldstein }}{ }^{1}$, M Birkved ${ }^{1}$, MB Quitzau ${ }^{3}$
}

${ }^{1}$ Technical University of Denmark, KGS. LYNGBY, Denmark

${ }^{2}$ Aalborg University, AALBORG, Denmark

Cities will play a growing role in the sustainability of society in the future as they increasingly become the dominant form of human settlement. Since 2008, for the first time in human history, more than half of the Earth's population dwells in cities. Cities have historically posed pollution issues due to high levels of industrial activity and their large consumption of goods and energy. In response to these issues, industrial ecologists developed urban metabolism (UM) as a quantitative sustainability assessment (QSA) method to study the flow of materials through urban ecosystems. However, the overarching principle of using mass as a basis for quantifying sustainable urban development (SUD) fails to take into account (i) the toxicological impact potentials (IPs) of emissions from cities and (ii) the embedded material and energy flows from upstream and downstream processes associated with a city's consumption. This study/presentation/etc. aims to combine UM with LCA methodology to account embedded mass and energy flows and provide a more holistic and standardized QSA methodology enabling comparison of different cities. By combining UM and LCA it was hoped that the true environmental IPs of a city's metabolic activities would be more fully measured. Hybrid UM-LCA models were developed for five cities using the product system modeling software GaBi 4.4 utilizing the EcoInvent 2.2 database. The ReCiPe LCIA method was employed in order to provide comparisons between cities at both midpoint and endpoint impact levels. Hotspot analysis was performed on selected indicators to gauge the success of specific SUD policies and provide potential areas for improvement and suggest policy development. The study found that in terms of impacts, mass based UM methods that ignore upstream and downstream mass flows only accounted for a fraction of total resource use in a city over 
a time period in comparison to the hybrid UM-LCA method used in this study. The use of midpoint and endpoint impacts was found to provide improved measurement of cities' ecological loading over standard UM methods. Additionally, it was found that allometric scaling of midpoint impacts to population generally showed a super linear relationship between population growth and a city's pollution loading, indicating that efficiencies in resource utilization are potentially being outstripped by increased consumption in cities. The normalization of impacts to a per-inhabitant level was able to provide an assessment measure of which cities were providing inhabitant services at the lowest environmental expense, and what related policies/consumptive habits contributed to this. To explore the issue of decoupling and judge whether the transition from primary and secondary to tertiary industry in a cities economy truly leads to lower environmental impacts when embedded flows are accounted for, Environmental IPs are further related with economic indicators. The data gathering process highlighted shortcomings in the bookkeeping of cities, particularly with waste characterization and the private consumption of urbanites, bringing awareness to the need for cities to improve data collection as well as for higher levels of government promote the tracking of goods domestically and not only across national borders. Overall, the hybrid UM-LCA was successful as a QSA tool for SUD, but improvements in modeling and gaps in data must be addressed before the method can be brought to maturity.

\title{
MPRS07-02
}

\section{Modelling choices: How the database choice affects the LCA results}

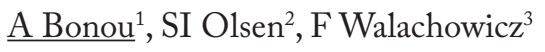 \\ ${ }^{1}$ Siemens A/S, BALLERUP, Denmark \\ ${ }^{2}$ Technical University of Denmark, LYNGBY, Denmark \\ ${ }^{3}$ Siemens AG, BERLIN, Germany
}

Different commercial or public LCA databases provide data on generic processes claiming accuracy, transparency and representativeness. Once the practitioner has access to the databases these processes are available to be used alternatively with no restrictions during the modelling process. But does it matter for the final LCA results which database the LCA practitioner uses? To answer the question generic unit processes describing the same service from PE, Ecoinvent and ELCD databases have been compared in an industrial case study. The results a) demonstrate the importance of database choice during modelling, b) attempt to raise the awareness of LCA practitioners on the importance of such choices and c) raise the question on how to account for the uncertainty of modelling decisions.

\section{MPRS07-03}

\section{Life cycle assessment of building concepts and designs during the planning phase}

\author{
C Wartha ${ }^{1}, \underline{\text { D Rixrath }}^{1}$, E Hasler $^{2}$
}

${ }^{1}$ University of Applied Sciences FHS Burgenland GmbH, PINKAFELD, Austria

${ }^{2}$ University of Applied Sciences Joanneum, GRAZ, Austria

In order to calculate the environmental life cycle impact of different building concepts and designs during the planning phase, a calculation tool was developed based on the Austrian Energy Certificate. The tools first component determines the building geometry. Users can choose from several predefined basic building shapes (rectangle, L, U and $\mathrm{O}$ shape). To define the building different data sets can be selected. There are data sets for proportions and types of windows and several other building components like foundations, exterior and interior walls, roof construction, and others. The tool calculates variations in environmental life cycle impacts relative to a predefined reference configuration. The energy consumption for heating and cooling during the utilization phase of the building is calculated based on an Austrian standard data set.

In order to calculate the environmental life cycle impact of different building concepts and designs during the planning phase, this database was designed. It contains LCA results for different types of building components, and is structured according to the different life cycle stages. The environmental impacts of manufacturing, maintenance, deconstruction, and disposal or recycling of the different building components are included in the database. 
The LCA results were calculated using a commercial LCA software with primary data for the building components composition and secondary data for the component materials. The energy consumption for cooling and heating during the utilization phase of the building was calculated according to the guideline 6 (energy saving and thermal insulation) of the Austrian Institute of Construction Engineering. All LCA-data are based on energy and transportation systems, as well as climate data, that are typical for Austria. In order to quantify the environmental impact the CML2001 method was used.

Several authors have demonstrated that LCA results do highly dependent on the choice of allocation method. This applies for both, multi-output processes during the use phase and recycling processes during the end-oflife phase of products. The effect of the choice of different recycling allocation methods was analyzed. Four different recycling allocation methods (cut-off method, 50/50 method, extraction-load, and disposal-load) were applied to each of different selective building components. The results of using the extraction load method and the cut-off method were similar, as well as the results which are calculated with the disposal-load method and the 50/50 method. Based on these results two different allocation methods, the 50/50-method and the cut-off method were applied for all components. Both results are included in the data-base to show their impact on the overall result.

\title{
MPRS07-04
}

\section{Modelling economic and environmental impacts of the Finnish mining sector}

\author{
M Tuusjärvi ${ }^{1}$, I Mäenpää2 ${ }^{2}$ S Vuori ${ }^{1}$, S Kihlman ${ }^{1}$ \\ ${ }^{1}$ Geological Survey of Finland, ESPOO, Finland \\ ${ }^{2}$ Thule Institute, University of Oulu, OULU, Finland
}

Metal mining industry is currently experiencing a significant boom in Finland, and the mined volumes have already surpassed previous all-time highs. The deposits coming under utilization differ in type from previous as the complexity and scale of the operations has risen. This requires application of new technologies in mining and presents challenge also in estimation of impacts towards environment and economy. In our research we are modelling the material flows, energy use, emissions and the economic and employment effects of the Finnish mining sector from 2008 to 2020. The mining model is a bottom-up model, where technical characteristics of each currently working, in construction phase being, decided, planned or expected mines are described. The alternative scenarios are designed by differing assumptions of the scale of the ore extraction in each mine at the end year. The mining model can be also integrated in the economy-wide environmentally extended input-output (EEIO) simulation model ENVIMAT ${ }^{\text {scen }}$ of the Finnish economy. In EEIO model the economy-wide economic and environmental impacts of the escalating mining sector can be assessed. One important economy-wide character of the mining sector is the effect on the foreign trade. Finland has a relative large basic metal industry which is currently largely depended on the imported mining products, metal concentrates. The products of the booming domestic mining industry will partly replace imports, partly create new refining activities and partly go into exports. We exploit the international LCA databanks (Ecoinvent) to model the environmental impacts of the corresponding product flows at the global level. Thus we can assess the environmental sustainability of the Finnish mining sector also at the global level. 


\title{
MPRS07-05
}

Life cycle impacts assessment as a support for risks management: The case of chemotherapy drug waste in a Brazilian hospital

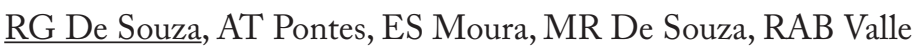 \\ Federal University of Rio de Janeiro, RIO DE JANEIRO, Brazil
}

The main purpose of chemotherapy is to kill cancer cells, but chemotherapy drugs are toxic to normal cells as well as cancer cells. Its administration involves preparation of medicine and infusion in the patient, both with serious risks for the health team, for patient and for society, because of the characteristics of chemotherapeutic products. Other problem is the waste from these activities, which needs a special care. As this waste and its management can be hazardous to the environment and people, it is necessary to assess the risks associated to it. Risks management is an important managerial tool for many types of activities, as it brings a complementary approach for decision makers. It involves activities such as: define impacts scale; identify stakeholders; categorize risks; identify risks; do quantitative and qualitative risks analysis; plan responses to risks. Life Cycle Assessment (LCA) can be a valuable supporting tool for all these activities. In the modeling phase, it can help the identification of stakeholders and potential risks. In the Impacts Assessment (LCIA) phase, it supports the impacts scaling, risks categorization, quantitative and qualitative analysis. A straight contribution from LCIA is the quantification of severity levels of impacts from each risk. This way, LCA scenarios should consider those impacts of risks occurring, as well as their probabilities, instead of just modeling the ideal scenario where no risks occur. The objective of this work is to develop and implement a methodology for integrating LCA in risks management. We apply the methodology in the case of the administration of chemotherapy in the public hospital of Rio de Janeiro, and its waste management. In this context we identify potential risks, assess the probabilities and impacts for some of them, model and integrate risks scenarios, and evaluate what are the most critical ones. We expect that this work contributes for a better decision making for managing this type of medicine, in order to improve the safety of health team, patients and waste management workforce. 


\title{
RS-08: Sustainability of nanotechnologies and nanomaterials
}

\section{TORS08-01}

\section{LCA applied to nanotechnologies: A critical review}

\author{
A Laurent ${ }^{1}$, O Jolliet $^{2}$ \\ ${ }^{1}$ Technical University of Denmark, LYNGBY, Denmark \\ ${ }^{2}$ University of Michigan, ANN ARBOR, United States of America
}

The field of nanotechnologies has experienced a tremendous development over the past years and an increasing number of products containing nanomaterials (i.e. nano-products) are reaching the market. This calls for scientifically sound and operational tools to assess and manage their environmental sustainability. Life cycle assessment (LCA) is such a tool, but how has it been applied in this field up to now? And how can it be better applied in practice? To address these questions and assist LCA practitioners, we conducted a critical review of LCA applied to nano-products until 2012. 43 LCA-claimed studies were retrieved from the scientific literature, most of them being post-2008 studies. When put in perspective with nano-product commercialization, the distributions of the studies in industrial sectors and in different types of embedded nanomaterials suggest that LCA applications lag behind the penetration of nanotechnologies on the market by few years, thus showing limits in the use of LCA at early product development stages. Among the identified critical aspects related to the LCA practice, the two overarching dimensions of an LCA, i.e. broadly-encompassing impact coverage and full life cycle inclusion, require special attention as they often turn out to be severely cut down. Two thirds of the studies have thus put a dominant focus on sole assessments of energy requirements and climate change impacts, while toxicity assessments have received much less attention. Likewise, the nano-product life cycle is often truncated to its single production stage and often disregards the use and disposal stages, which can equally be relevant in terms of potential environmental impacts. Our critical analysis also highlighted the need for providing recommendations on specific methodological points to move towards a better practice of LCA applied to nano-products. These include (i) the application of cut-off criteria in system boundary settings, where a mass proportion threshold is not advisable, (ii) the definition of the functional unit, which should reflect the context in which the nano-products are being used, (iii) the inventory modelling, where LCA practitioners should seek for representative data on manufacturing process units and for releases of nanoparticles throughout the nano-product life cycle, and (iv) the assessment of toxicity-related impacts, in which nanoparticle-specific effects should be included based on continuous advances in the field.

\section{TORS08-02}

\section{Addressing challenges faced in the LCA of nanomaterials: Metal organic frameworks and beyond $\underline{\mathrm{O} \text { Griffiths }}$}

University of Bath, BATH, United Kingdom

This work outlines the methodological challenges of conducting LCAs on emerging nanomaterials, presenting potential solutions to address these. Areas of uncertainty lie in the present LCA methodology when used for new technologies and processes, such as those associated with nanomaterials. This paper will focus on the solvothermal synthesis of the metal organic framework (MOF) chromium terephthalate, aka MIL-101, as an exemplar material.

Over the past two decades an abundance of literature concerned with the synthesis and touted applications of nanomaterials has been published. Nanomaterials have properties distinct from bulk material counterparts, creating the possibility for improved and new functionalities in far-ranging scientific fields such as catalysis, solar energy, materials enhancement to medicine and beyond.

MOFs are cage-like crystalline structures with pore sizes in the range of 2-50 $\mathrm{nm}$. The defining characteristics of MOFs are their extremely high porosity, > 8,000 $\mathrm{m}^{2} / \mathrm{g}$, selectivity towards certain gas molecules, and tuneable electronic, magnetic and functional group structures. Recognised MOF applications include heterogeneous catalysis, gas separation/filtration and storage of hydrogen. $\mathrm{CO}_{2}$ and other gases. Thus far no commercial 
adoption of MOFs has occurred, and assessments covering their embodied impacts relative to existing materials and applications are lacking. Without suitably accurate environmental assessments any potential benefits, for a given application, are unquantifiable.

A cradle-to-gate LCA is presented in this study, whereby measurable upstream process inputs and emissions for the solvothermal synthesis of MIL-101, at laboratory scale, are characterised. In the context of this study an expected early finding is a large potential environmental impact due to the high energy requirement for the material synthesis, this finding is in keeping with other nanomaterials. Process energy use is a relatively easily measured input, and the characterised environmental impacts are founded on established technology routes. However, other impacts are often negated from emerging and niche technology systems due to the uncertainties and difficulties in data collection for unique process steps.

Quantifying impacts due to the chemical reactants and specialist capital equipment used is a challenging obstacle in the production of detailed life cycle inventories. Current datasets available to LCA practitioners lack data for chemicals that most Chemists would consider commonplace. Data unavailability is an issue that affects the current chemical industry and will hinder progress in future assessments of nanotechnology; nanomaterial bottom-up synthesis routes are analogous, at least in part, to other fine chemical production techniques.

In response to lacking inventory data, methodological solutions implemented by the study's authors for tackling LCA data uncertainties for emerging materials are presented. Transparent qualitative and quantitative assumptions based on literature sources, patents, chemical stoichiometry and engineering process modelling tools will be presented for the MOF synthesis. However, a potentially more universal output from this work is a framework for those assessing other niche and emerging technology outputs. Only through collaborative and unified research efforts can the verification of potential environmental impacts of emerging materials be robust, consistent and keep pace with technology rollout.

\section{TORS08-03}

\section{LCA of metal nanomaterial production}

$\underline{\text { M Miseljic }^{1}}$, EG Alvarado Diaz ${ }^{2}$, SI Olsen ${ }^{1}$

${ }^{1}$ Technical University of Denmark, LYNGBY, Denmark

${ }^{2}$ CIMAV, Centro de Investigación en Materiales Avanzados, CHIHUAHUA, Mexico

The use of engineered nanomaterials (ENMs) in commercial product has reached a new stage, where consumers in their daily life are frequently encountered with products containing this new material class. Metal and metal-oxide nanomaterials are among the most commonly used ENMs in products. Potential life cycle impacts arise from all life cycle stages of the ENM products. Currently there are many unknowns related to the inputs and outputs from production of ENMs and the potential impacts that arise from that and we need to better understand and map the impacts that arise from the raw material extraction and manufacturing of ENM products. Further in the life cycle, i.e. the use and disposal, additional difficulties are observed in accounting for potential impacts e.g. the potential health impacts related to release of nanoparticles.

This case study considers the production of ENM $\left(\mathrm{Ag}, \mathrm{ZnO}\right.$ and $\mathrm{Mg}(\mathrm{OH})_{2}$ applied as additives in polypropylene (PP), and the production of PP with conventional additives that provide similar properties as the ENMs. Different scenarios of nanoproducts consisting of metal ENMs and PP were compared with current use of additives in PP products through a detailed cradle-to-gate LCA study. The results show that the ENMs do not contribute substantially to the impact profile of nanoproducts, but the PP plastic has the main responsibility. The main reason is the rather low amounts of ENM added. Further the comparison showed that nanoproducts have less impacts associated to them compared to the PP products containing conventional additives due to the improved material functionality and properties that ENMs contribute to. 


\title{
TORS08-04
}

\section{A framework for establishing sound inventory data of the production of engineered nanomaterials $\&$ of the releases of nano objects along the complete life cycle}

\section{$\underline{\text { R Hischier }}$}

\author{
Empa, ST. GALLEN, Switzerland
}

In recent publications (like e.g. Hischier \& Walser, 2012) it was shown that there are actually only few Life Cycle Assessment (LCA) studies of engineered nanomaterials (eNM) published so far; studies that are moreover far away from what is considered nowadays "comprehensive" and "sound"LCA studies. Thus, I am currently developing a generally applicable framework for a comprehensive and adequate modelling of the production of eNM, taking into account possible emissions of nanoparticles to the environment (not only in the production, but along the complete life cycle), and translate this framework then into exemplary life cycle inventory (LCI) datasets for the production of eNM; using an on-going FP7 project about various coating systems as an application case.

Actually, within this framework two topics of concern and their different strategies have to be distinguished - (a) the modelling of conjunctions with technosphere (i.e. the direct material and energy inputs into the production process of eNM), and (b) the modelling of releases of nano objects during the various life stages.

For the first element, a thorough analysis of the different approaches for the modelling of chemical production processes within the ecoinvent database (reported in Hischier et al., 2005) concerning their applicability in the area of the production of eNM has been established. This analysis shows clearly that due to their broad process variability (including the yield of the used technologies), only a case-specific unit process data collection strategy can work; resulting - when following the quality requirements from the ecoinvent Centre, reported in Frischknecht et al., 2005 - in transparent, comprehensive and adequate gate-to-gate inventory datasets; datasets that can then easily be integrated into a variety of different database systems with background LCI data. However, due to the fact that most production processes of eNM are today (still) proprietary processes the fulfilment of the term 'comprehensive' asks still considerable efforts. An exemplary case study for this point will be shown during the presentation.

Concerning the second issue, I currently develop in my (on-going) research a stepwise procedure for the identification of those properties that are required in order to model emissions of nano objects in an adequate and compatible manner with the current practice in LCI/LCIA modelling. The objective of my work there is an identification of existing relationships between the properties of emissions of nano objects and the relevant parameters defining environmental effects that are concerned by this type of emission (i.e. toxicological aspects). In the presentation the outcome of this, at the moment on-going work, and its consequences for the investigations on the above briefly mentioned coating systems will be presented.

\section{References:}

Hischier R, Hellweg S, Capello C (2005) Different Approaches how to investigate Chemicals. Int J LCA 10 (1):59-67.

Hischier R, Walser T (2012) Environmental Sustainability Assessment of Engineered Nanomaterials: State of Art \& Strategies to Overcome Existing Gaps. Science of the Total Environment 425:271-282.

Frischknecht R, Jungbluth N, Althaus H-J, Doka G, Dones R, Hellweg S, Hischier R, Nemecek T, Rebitzer G, Spielmann M (2005) The ecoinvent Database: Overview and Methodological Framework. Int J LCA 10 (1):3-9. 


\title{
TORS08-05
}

\section{LCA of nano-enabled products: Filling data gaps}

G Janer, C Hidalgo, D González, E Fernández-Rosas, G Vilar, E Mas del Molino, M Escamilla, S VázquezCampos

\author{
Leitat Technological Center, TERRASSA, Spain
}

Conducting LCA for nanotechnologies is challenging because the impacts associated to the effects on human and environmental health of the released nanomaterials are not yet introduced in LCA databases. The Nanopolytox project was designed to fill in some of these data gaps for nanocomposite applications. Accelerated aging conditions were used to evaluate the release of nanomaterials during the use phase of nanocomposites. The amount of material released ranged from 0.02 to $0.58 \%$, depending on the polymeric matrix and the nanofiller used. The composition and particle size of the released material was evaluated using different analytical techniques. In addition to use phase simulations, recycling and end-of-life processes were also simulated to evaluate possible transformations occurring on the nanomaterials. The understanding of such transformations is important because changes in coatings, size or shape are likely to change the hazardous potential of the nanomaterials. The released nanomaterials may cause adverse effects on human and environmental health. Using USEtox as a starting point, we have developed a general methodology to derive fate, human health and ecotoxicological factors for nanomaterials. Regarding human health hazards, different approaches were considered depending on the availability of data for each nanomaterial: no experimental data, only physicochemical data, in vitro data, and type of in vivo data, and on the route of exposure. One of the difficulties in the derivation of the ecotoxicological factor is the influence of the test system conditions on the outcome of the experiments. Presence/absence of food, suspended organic matter, and nanomaterial dispersion methods can dramatically change the ecotoxicological effects of a nanomaterial. For that reason decision criteria were suggested on how to select input data for ecotoxicological factors. Despite these particularities, the general concept and methodology around the derivation of human and ecotoxicological effect factors are however unchanged vs. conventional compounds. In contrast, the derivation of the fate factor for nanomaterials required some more in-depth modifications of the standard methodology. The analytical challenges to identify NM and their transformations in the environment are hampering the progress of environmental fate evaluation. Despite these limitations, there are a considerable number of studies available that describe the behaviour of nanomaterials in the environment. The mathematical models behind the derivation of the fate factors in USEtox were modified to incorporate the most common (and useful for fate evaluation) characterization data for NM, and to be able to account for the specific fate behaviour of NM. For example, dustiness, density, and aggregation/agglomeration have been incorporated. As a case study, this methodology was applied to evaluate the LCA of MWCNT nanocomposites for outdoor applications.

\section{MPRS08-01}

\section{New coating technologies - what does 'more sustainable' mean?}

\section{DF Peñaloza}

\section{SP Technical Research Institute of Sweden, STOCKHOLM, Sweden}

Traditional coatings for corrosion protection of steel often involve hazardous compounds or VOC emitting solvents. This is why a new coating strategy employing inherently conducting polymers, ceria nanoparticles and nanoclays has been proposed by the FP7 project Steelcoat. The project includes a sustainability assessment of the proposed coating system supported by toxicity tests. As the project develops, the data collected and the toxicity testing will give certain results, but a reference point is necessary in order to determine if the proposed strategy corresponds to the driving force of its conception as a more sustainable option. Defining the meaning of "what a more sustainable technology should be"became a necessary stepping stone towards the main goal of the sustainability assessment. This required an analysis of the specific case of steel coatings, identifying the aspects of sustainability that must be in focus with a long-term perspective according to the lifetimes of the product under development. The result of this work was a series of sustainability criteria that will be assessed for the products developed along the project and for current reference technologies. Among the most relevant sustainability aspects dealt with are toxicity of components, release of potentially toxic substances, energy requirements of production, associated costs, technical performance and environmental impact during the product life cycle. To assess and weight these criteria a methodology that fits the specific needs of the project was developed, in an attempt to deal with potential trade-offs between different criteria and including aspects 
from other frameworks. Furthermore, the challenges and limitations for the performance of sustainability assessments for emerging technologies and modelling of non-existing systems have been identified. Among the main identified challenges are the low compatibility of existing indicators with emerging technologies, the uncertainties of process up-scaling and the lack of toxicity assessment models for nanoparticles.

\title{
MPRS08-02
}

\section{Characterization of aggregation and dissolution rate constants of metal oxide nanoparticles in freshwater archetypes}

\author{
B Salieri $^{1}$, S Righi $^{1}$, SI Olsen ${ }^{2}$ \\ ${ }^{1}$ University of Bologna, RAVENNA, Italy \\ ${ }^{2}$ Technical University of Denmark, LYNGBY, Denmark
}

The assessment of the potential impacts posed by the production, use and application of ENPs (engineered nanoparticles) is an imperative to well evaluate their real benefit. Although, the ENPs offer environmental benefits, for example with their application in soil/water remediation, concerns on their potential environmental impact are on debate. Despite the NPs are already released into environment, the evaluation of the environmental exposure is still far to be reached due to the lack of knowledge in the field of risk assessment (Som C., et al. 2010 ). The assessment of the environmental exposure needs the knowledge of the environmental behavior of the NPs in the environment media (for example freshwater, air, soil, etc.). In the last couple of years, framework to assess the exposure or risk assessment of NPs has been developed ( Mueller N., et al. 2008; Gottschalk F., et al. 2010 ). There are evidences that the ambient chemistry parameters influence the fate processes and the toxicity of the NPs ( Levard C., et al. 2012; ). Focusing on the freshwater compartment, physical-chemical parameters such as $\mathrm{pH}$, natural organic matter (NOM), ionic strength are directly involved on the processes of dissolution and aggregation. Whereas the processes of aggregation and dissolution has been referred as important key factors in the field of nano (eco) toxicity. In fact, studies evidenced that the aggregation process leads adhesion of the NPs $\left(\mathrm{n}-\mathrm{TiO}_{2}\right.$ ) to the body of the organism (Daphnia magna) and influencing the mobility (Baun A., et al. 2010; Dabrunz A., et al. 2011 ). As well, the dissolution of metallic nanoparticle ( $\mathrm{n}-\mathrm{ZnO}$ ) due to metal ions released from metal oxide particles. (Xiong D., et al.2011), could influence the toxicity. These researches highlight that the bioavailable forms is strictly related to the environmental chemical condition. It is evident that in order to determine the likely bioavailability to organisms of metal oxides nanoparticles is crucial to determine the chemical fate in the environmental compartment (Johnston BD., et al. 2010). In line with current understanding is that nanoparticles form colloids in freshwater. Praetorius et al. (2012) have developed a fate model for describing nanoparticle river behavior by modeling aggregation using relationships established for colloids, and considering NP-specific processes such as dissolution and aggregation. The applicability of the model of Praetorius et al. 2012 was demonstrated for $\mathrm{n}-\mathrm{TiO}_{2}$ emitted to the river of Rhine. Their model requires input parameters specific for the river of interest, such as ionic composition and $\mathrm{pH}$, and is therefore well suited for site-specific assessments, such as ERA. In this study, Praetorius A., et al. 2012 model will be applied on 12 set of water-types in European Union (EU) ( Ghandy N., et al. 2010 ). The model will be applied on $\mathrm{n}-\mathrm{TiO}_{2}$ and $\mathrm{n}-\mathrm{ZnO}$ to calculate freshwater and nanoparticle-specific aggregation and dissolution rate constants. The characterization of the aggregation and dissolution rate constants in several freshwater archetypes is aiming to evaluate the dominating fate processes. Moreover the results will permit to explore the effect of variability in freshwater chemistry and to improve the knowledge on the NPs behavior in freshwater. The calculation of aggregation and dissolution rate will be improved in USEtox model to calculate the fate factor for metallic nanoparticles. 


\title{
MPRS08-03
}

\section{Life cycle assessment of novel catalytic technology for water purification based on nanocatalysts}

\author{
P Yaseneva, X Fan, T Morgan, A Lapkin
}

University of Warwick, COVENTRY, United Kingdom

The project MONACAT (FP7) developed several novel catalytic systems for eliminating aqueous pollutants such as nitrates, bromates and pharmaceuticals, based on carbon nanofibrous catalysts packed into structured supports, such as woven fabric or monoliths. The environmental benefits of the purification technology extend beyond the simple advantages of purified water; they also include increase in process efficiency through process intensification. Looking at this aspect the general improvement in environmental impacts might seem obvious. However, production of carbon nanomaterials is characterized by high energy and materials inputs and thus may result in an increased environmental burden.

The comparative life cycle assessment (LCA) of two catalyst production technologies (novel Pd/CNF/SMF and conventional $\mathrm{Pd} / \mathrm{Al}_{2} \mathrm{O}_{3}$ catalysts) gave a decisive set of results, indicating the catalyst with palladium catalytic sites upon carbon nanofibre supports using sintered metal fibre structured discs, provided a substantially less harmful impact than the conventional catalyst, which could be seen in every indicator category in the CML 2001 impact assessment approach. However, calculation of cumulative energy demand (CED) has shown that less energy is needed for the production of a conventional $\mathrm{Pd} / \mathrm{Al}_{2} \mathrm{O}_{3}$ catalyst. The analysis of obtained results allowed to identify the most energy consuming steps in the $\mathrm{Pd} / \mathrm{CNF}^{2} / \mathrm{S}^{3} \mathrm{MF}$ catalyst production and suggest alternative scenarios. 


\title{
RS-09: Sustainability of bio-based products and biotechnologies
}

\section{TORS09-01}

Challenges in developing a sustainability assessment framework for a new bio based packaging material Experiences and findings from the Flexpakrenew project

\author{
HK Pihkola ${ }^{1}$, CL Hohenthal ${ }^{1}$, MLJ Kuisma ${ }^{2}$, SI Veuro ${ }^{1}$ \\ ${ }^{1}$ VTT Technical Research Centre of Finland, ESPOO, Finland \\ ${ }^{2}$ Aalto University School of Business, HELSINKI, Finland
}

The paper presents the main results and findings from a sustainability assessment conducted as a part of an EU-funded project Flexpakrenew. The goal of the Flexpakrenew project was to develop a flexible packaging paper from renewable resources to reduce packaging industry's reliance on barrier films that are derived from petroleum. The goal of the sustainability assessment was to lead the development towards environmentally friendly raw materials and to communicate the sustainability of the packaging material developed. Based on the experiences from the project, challenges related to building a sustainability assessment framework for an emerging technological solution will be discussed.

The technical challenge in the project was to develop a flexible paper, based on multilayered structure that achieves barrier properties competitive with those of plastic films. There are multiple uses for which thin and flexible packages with barrier capacity are needed. The study focussed on packages for dry foodstuff, such as dehydrated soup or flour. The goal was to substitute the petroleum based layers with bio based materials and to increase the biodegradability of the new packaging material.

To be able to evaluate the sustainability of the new packaging material, a sustainability assessment framework was defined. In the assessment framework, the specific sustainability goals of the Flexpakrenew project were complemented with more general sustainability demands related to fibre based packaging. The whole life cycle of the packaging material was considered. Potential environmental aspects and impacts were evaluated applying life cycle assessment (LCA). Furthermore, screening of the potential economic and social impacts and evaluation of the competitiveness of the new packaging material was conducted. The results were summarized applying SWOT analysis.

Three cases were included in the assessment: a reference case and two Flexpak cases (Case 1 and Case 2). The results of Cases 1 and 2 indicated positive trends in terms of environmental sustainability. The percentage of bio based materials was increased from zero to circa $50-60 \%$ in both Flexpak cases. However, there seemed to be uncertainty and thus weaknesses in terms of economic and technical dimensions of the solutions. At the moment, the solutions are not available in industrial production scale.

The main challenges in the sustainability assessment were related to defining a suitable reference case for assessing the performance of the new packaging material and in gathering data for the assessment. Other challenges were related to assessing the potential impacts of a product that is only available in laboratory scale. An important aspect was also the timing of the sustainability assessment. The results of the sustainability assessment should be available at an early stage of the project to be able to communicate the results and to guide the R \& D work towards sustainable solutions. However, the ability to conduct the sustainability assessment is dependent of the progress within the project since the assessment requires data from the experimental work conducted. 


\title{
TORS09-02
}

\section{Using life cycle assessment to document sustainability benefits of enzymes applied in the leather industry}

\author{
ЈH Kløverpris, JK Raman
}

Novozymes, BAGSVÆRD, Denmark

The leather industry is highly developed but also an industry generating substantial amounts of solid waste and waste water with high levels of BOD, COD, nitrogen, and sulfides. As for many other industrial operations, the energy and auxiliaries used in leather tanneries contribute to global warming, acidification, photochemical oxidation, and other environmental impact categories.

The unhairing process in which hair is removed from raw animal hides is known to be one of the most polluting processes in leather manufacturing, mainly due to the use of lime (generating sludge for disposal) and sulphides (resulting in toxic waste water).

Enzymes (biological catalysts) can be used to reduce the use of lime and sulfides (among other things) in the unhairing process but the right mix of enzymes balanced with the right mechanical processing is key to achieving satisfactory results.

The present LCA considers the environmental implications of shifting from conventional unhairing to an alternative enzymatic concept known as Beamhouse Biosolutions Bovine. In the conventional process, hair is chemically dissolved (hair-burn) and, in the enzymatic process, hair is primarily loosened and removed by filtration (hair-save). The functional unit of the LCA is the unhairing of 1 ton of bovine hides.

The study was conducted when the enzymatic concept moved into full scale production optimization in a modern European tannery during 2011. At that point, the enzymatic concept provided leather quality results satisfactory for upholstery and furniture. The LCA was conducted at this stage to allow for environmental considerations during the final process optimization and to develop solid documentation of the environmental implications of shifting to the enzymatic concept. Following the completion of the LCA, the enzymatic concept has been further developed to become a more broadly applicable process for most leather types, incl. leather for shoes and for the fashion industry. Process changes mainly concern the mechanical part of unhairing where rotation of the drums in which hides are being unahired has been reduced. This only has a minor influence on the LCA.

The enzymatic concept reduces lime sludge generation in the tannery by more than 50\%. The sulfide concentration in the waste water discharged directly from the unhairing processes (tested prior to waste water treatment) decreases by $70 \%$ and ecotoxicity of the untreated waste water is reduced by a factor of more than 10 . The enzymatic process decreases BOD, $\mathrm{COD}$, and $\mathrm{N}$ in the sludge phase of the waste water but not significantly in the water phase.

In a life cycle perspective, the enzymatic process reduces contributions to global warming, acidification, eutrophication, and photochemical ozone formation (smog). Fossil energy and water use is also reduced. At the present developmental stage of the enzymatic process, there is a trade-off in agricultural land use but realistic optimization of enzyme production would reverse this trade-off. Using the hair by-product from the enzymatic process for energy production could provide further environmental benefits.

The LCA has been reviewed in accordance with the ISO standard by a panel of three experts and now serves as documentation for how pollution from the leather industry can potentially be substantially reduced. The case study thereby illustrates how LCA can be used to create awareness about new and cleaner technology. 


\section{TORS09-03}

\section{Life cycle assessment study of a biopolymer based weed control system}

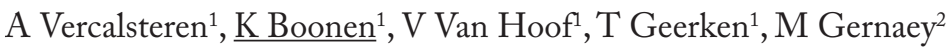

${ }^{1}$ VITO, MOL, Belgium

\section{${ }^{2}$ DS Technical Nonwoven, DENDERMONDE, Belgium}

DS Textiles (DAM), a Belgian company originating from the textiles industry, is currently performing a LIFE+ project which has the overall aim to develop, test and demonstrate the application of several biopolymer based systems for agricultural and public/private gardening use that may replace fossil fuel based systems in the future. Part of the project encompasses the assessment of the environmental performance of this new system using the LCA-methodology as described in ISO Standards 14040 and 14044. The study assesses the environmental impacts from cradle to grave of the application closest to market introduction: a biopolymer based weed control system for public open spaces. Information on the environmental impact is considered as relevant knowledge to be able to i) get respective information about the environmental impacts of the weed control system, over the whole lifecycle of the product, i.e. from cradle to grave, ii) enable to communicate on environmental aspects of the DAM material directly to customers and other stakeholders and iii) focus improvement activities on the most important impact-generating process phases. At a later stage in the LIFE+ project these results can be used as an input for two other applications: fertility mat and erosion protection system.

Data for this specific LCA are gathered in close collaboration with the company and its main supplier NatureWorks. The ILCD recommended impact assessment methods are applied and compared to other scientifically relevant methods such as ReCiPe.

The presentation will discuss the goal and scope definition and data inventory, with a focus on the modelling of more complex life cycle phases such as use and end of life of this biopolymer system. The environmental profile will be presented and results and conclusions following from different LCIA methods will be discussed.

\section{TORS09-04}

Attributional and consequential life cycle assessment of bioethanol-based PVC

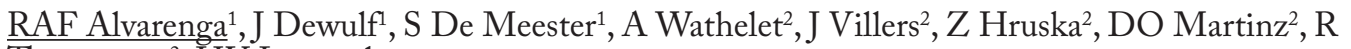
Thommeret $^{2}, \mathrm{HV}$ Langenhove

${ }^{1}$ University of Ghent, GHENT, Belgium

${ }^{2}$ Solvay S.A., BRUSSELS, Belgium

Literature suggests that the most concerning environmental impact category in the life cycle of the polyvinyl chloride (PVC) is the depletion of non-renewable resources, mainly due to the fossil feedstock for ethylene. For this reason, bioethanol is considered as another source for ethylene in the PVC production chain. The objective of this paper was to perform a cradle-to-gate attributional and consequential life cycle assessment (LCA) of bioethanol-based PVC resin, and compare it to its reference product (fossil-based PVC). In the attributional approach we created two scenarios for bioethanol-based PVC, based on current data (2010) and on prognosis for 2018, and compared them with fossil-based PVC; while in the consequential approach, we compared solely the prognosis of the bioethanol-based PVC from 2018 with the fossil-based PVC. For the life cycle inventory we used primary data from Solvay S.A. and secondary data from literature. We used several midpoint indicators and the Recipe Endpoint H/A for the impact assessment. In the attributional approach, at midpoint level, bioethanol-based PVC from 2010 and 2018 presented better results than fossil-based PVC for non-renewable resource use and climate change, but worse results for other environmental impact categories (e.g. biodiversity and ecotoxicity). At single score endpoint level, the two bioethanol-based PVC scenarios showed better results than fossil-based PVC (up to 66\% lower). Within the bioethanol-based PVC scenarios, the results for 2018 were better than for 2010 for all environmental impact categories, corroborating that higher efficiency (at the crop field and bioethanol production) and reduction of burnt harvest ought to reduce environmental impacts. In the consequential approach, at midpoint level, the environmental impact categories responded differently for the different degrees of indirect land use change (iLUC), and some of them generated gains to the environment in the three scenarios, including non-renewable resource use. At single score endpoint level, the results showed environmental gains if iLUC was kept below $5.7 \%$ of the sugarcane cultivation area. 
Even though bioethanol-based PVC had better results in comparison to fossil-based PVC at the attributional approach, improvements should be sought to minimize other environmental impact categories, e.g., biodiversity, eutrophication and ecotoxicity. The effects of iLUC, assessed through the consequential approach, were based on assumptions and therefore subject to uncertainties, but the assessment performed was important to provide quantitative information for the stakeholders on how the environmental gains of the bioethanol-based PVC should not be nullified by iLUC impacts.

Acknowledgements: The authors thank the European Commission for financing a PhD scholarship grant by the project "Euro Brazilian Windows II (EBWII)", from the program Erasmus Mundus External Cooperation Window (EMECW); Prof. Dr. Aldo Roberto Ometto, from Escola de Engenharia de Sao Carlos (EESC) - Universidade de Sao Paulo (USP), and Dr. Otavio Cavalett, from the Brazilian Bioethanol Science and Technology Laboratory (CTBE), for their important contributions at the sugarcane and bioethanol production systems. This work was partly supported by the EU-funded PROSUITE (full title: "Development and application of a standardized methodology for the PROspective SUstaInability assessment of Technologies"), Grant Agreement Number 227078.

\title{
WORS09-01
}

\section{Lifecycle assessment of BioMTBE- a 2nd generation biofuel}

\author{
R Mehta, J Boelhouwer, PS Sreenivasan
}

\section{SABIC, BANGALORE, India}

Today, more and more attention is given to the sustainability of biofuels in terms of greenhouse gas reduction potential versus fossil fuels. With this growing concern, it is important to quantify the greenhouse gas (GHG) savings attained from production and use of a biofuel. In 2009, European parliament passed renewable energy directive (RED 2009/28/EC) for the promotion of the use of renewable sources of energy for its community. ${ }^{1}$ RED has laid down mandatory national (EU members) target of $10 \%$ share of energy from biofuels in transport petrol and diesel consumption by 2020. Apart from laying down national targets for biofuels, RED has laid down a sustainability criterion for biofuels and bioliquids. All biofuels to be sold in EU should fulfill this sustainability criterion to qualify them as sustainable biofuels. RED states that GHG emission saving from the use of biofuels and bioliquids shall be atleast 35\% in 2010, 50\% with effect from 1 Jan 2017 and 60\% with effect from 1 Jan 2018 for installations where production started on or after 1 Jan 2017.

Methyl tertiary-butyl ether (MTBE) is gasoline oxygenate with high octane number and low volatility. Commercially, fossil MTBE is produced from the reaction of isobutylene and methanol. Isobutylene can be obtained from isobutane dehydrogenation, byproduct streams from ethylene plants, refinery FCC units. Methanol is manufactured from steam reforming of natural gas. The methanol part of MTBE can be easily replaced by renewable sources. The bioenergy content of gasoline can be increased by splash blending of biomethanol or by blending the biomethanol part through bioMTBE. Methanol does not have similar properties as gasoline i.e. methanol has high vapor pressure and increases the RVP of gasoline. BioMTBE has high energy content and low vapor pressure, thus it acts as an ideal vehicle to blend biomethanol in gasoline.

SABIC is a bioMTBE manufacturer and produces it by replacing methanol part of MTBE through bioroute. The biomethanol feedstock is sourced from a biomethanol manufacturer. RED states that biofuel manufacturers need to report actual GHG savings for their biofuel production pathway against fossil reference. RED has provided default scores for various biofuels pathways in annexure V. However, RED does not give default scores for biomethanol and bioMTBE produced from crude glycerine pathway. In the absence of default scores, it becomes necessary to calculate GHG emissions for biomethanol and bioMTBE from crude glycerine pathway to validate if their production is sustainable. SABIC conducted cradle to use phase lifecycle assessment of biomethanol and bioMTBE manufactured and marketed in EU. Reported literature data on mass and energy requirements and emissions was used. This LCA study followed the RED methodology for quantification of GHG savings arising out of production and use of biofuels. Functional unit was $1 \mathrm{MJ}$ of energy supplied by biofuel used as a transportation fuel.

Lifecycle GHG emissions for biomethanol were calculated to be $23.9 \mathrm{gCO}$, eq/MJ. For bioMTBE, GHG emissions for cradle to filling station were $17.2 \mathrm{gCO}_{2} \mathrm{eq} / \mathrm{MJ}$ and use phase $\mathrm{GHG}$ emissions were $57.1 \mathrm{gCO}_{2}$ eq/MJ. As directed by the RED, GHG savings from production and use of these biofuels were compared against fossil gasoline. Results showed that biomethanol and bioMTBE from crude glycerine easily qualifies under the EU RED with $71 \%$ savings in lifecycle GHG emissions for biomethanol and renewable part of bioMTBE. 


\title{
WORS09-02
}

\author{
What is the best use of sugar crops? Environmental assessment of two potential applications: Biofuels vs. \\ bioproducts
}

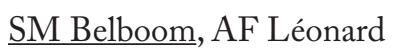

University of Liège, LIÈGE, Belgium

Agricultural crops became through years an attractive option to increase European energy independence.Brazil has taken this opportunity since the seventies by using sugar cane bioethanol as vehicle fuel. The development of biofuels production is more recent inEurope. Due to temperate climates, bioethanol production is mostly based on wheat and sugar beet, this latter being considered as the 'equivalent' sugar crop to sugar cane for Europe.

Biofuel is the most common application of bioethanol but its transformation into bioethylene through a dehydration step and then its polymerization into bioplastic can be an alternative as already found in Brazil. This paper will consider both potential uses and compare them using Life Cycle Assessment methodology.

Common boundaries of the systems comprise the cultivation step for both crops, i.e. sugar cane and sugar beet, with all associated energetic and fertilizer consumptions, the transportation step from field to the industrial plant, the sugar crops transformation into hydrate bioethanol, the by-products valorisation and the specific endof-life. For the biofuel scenario, a dehydration step using molecular sieve is added to get anhydrous bioethanol. For the biopolyethylene scenario, industrial dehydration and polymerization steps are added.

Direct comparison between both scenarios is not possible due to different products uses. The comparison was then performed for both scenarios between the bio-based product and its fossil equivalent. ReCiPe 2008 method was used at midpoint level to get the environmental impacts.

As expected, the impact of bio-based products in climate change and fossil fuel depletion categories decreases compared to the fossil counterparts. For other categories, difference is less significant and results are often better for fossil products. Land use change impact was implemented to assess its importance. Depending on assumptions, the greenhouse gas emissions from crop implementation on a natural land can counteract the previous mentioned benefits.

To get an idea of the performance of each considered bioethanol use, a single score relative to the amount of sugar cane and sugar beet cultivated on one hectare was calculated using the endpoint level of $\mathrm{ReCiPe}$ 2008 methodology. The environmental gain was then evaluated comparing the bio-based product use with the classical one. The highest performance was obtained for the bioplastic scenario based on sugar cane followed by the sugar beet bioplastic. The E5 biofuel based on sugar beet reaches a slightly lower gain. The E85 fuel obtains less gain due to the higher amount of biofuel needed to drive the same distance as using fossil fuel. When taking the land use change into account, the best gain is given by the sugar beet bioplastic.

On the one hand, this study shows the importance of assumptions, especially in the agricultural field, on the obtained results. On the other hand, it points out that considering bioethanol as a chemical intermediate and not a fuel can be better from an environmental point of view.

\section{WORS09-03}

\section{Comparative life cycle assessment of Danone Activia cups made from polystyrene and polylactid}

\author{
B Kauertz, A Detzel, $\underline{\text { C Deibl }}$
}

IFEU - Institute for Energy and Environmental Research, HEIDELBERG, Germany

The consumer product industry increasingly pursues environmentally friendly packaging applications as part of a sustainable product strategy. For this purpose, the use of bio-based plastics instead of their petrochemical conventional counterparts provides a potential alternative. Therefore, in 2011 the food-products company Danone launched a bio-based packaging of the yoghurt Activia in several European countries. This new cup is made from Polylactidacid (PLA), a bio-based polymer from corn starch and replaces the previously used Polystyrene (PS) cup.

In parallel to the product development a life cycle assessment was carried out by IFEU-Heidelberg in order to obtain insights about the environmental impact profile of the new PLA cup in comparison to the current PS 
(Polystyrene) cup. The LCA study was published in March 2011 in accordance to the ISO standards 14040/44 including a critical review by three independent experts.

The study was designed to reflect the specific supply chain of Danone allowing thus identify areas of improvement still during product development. It also required considerations regarding the adequate modeling of postconsumer PLA cups within existing integrated packaging waste disposal systems given the fact that Danone PLA cups would significantly increase the presence of PLA waste in existing packaging waste streams.

A particular focus of the study was the assessment of corn farming in the US in the context of the ongoing debate about edible crop use for non-food applications and related discussions such as land use change, genetically modified organisms and sustainability certified farming practices.

Eventually the study was an important element for Danone`s product-related communication towards customers and consumers. It also formed the based for WWF's decision to allow for use of its panda logo on the packaging.

\section{WORS09-04}

\section{Natural fibre reinforced plastics and solid wood - a comparison of terrace floorings using LCA}

\section{$\mathrm{S} \mathrm{Feifel}^{1}, \underline{\mathrm{M} \mathrm{Schmid}^{2}}, \mathrm{O} \mathrm{Stübs}^{2}$}

${ }^{1}$ Karlsruhe Institute of Technology (KIT), EGGENSTEIN-LEOPOLDSHAFEN, Germany

${ }^{2}$ SKZ - German Plastics Center, Business Unit Sustainability, WÜRZBURG, Germany

Due to emerging markets for environmentally benign products there is an increasing need for transparent and reliable evaluation. The required ecologic information might result from a comparison of products based on Life Cycle Assessment (LCA).

The objective of this contribution is a comparison of terrace floorings using LCA. Terrace flooring is mostly made of wood, but in recent years the use of novel materials has evolved: wood polymer composites (WPC). These compounds made of the matrix polymers PP, PE or PVC (ca. 20-65 \%), wooden fibers (ca. 30-75\%) and additives (ca. $5 \%$ ) have the potential to unite the advantages of plastics and wood. Firstly, WPC - as plastics - is a highly durable and freely formable material, which generally delivers the opportunity to be recycled. In addition, WPC can be extruded just as pure thermoplastic polymers. Secondly, the high filling grade of wood fibers provides cost benefits over pure polymers and possible environmental benefits by replacing fossil resources by a renewable one. Wood deckings, which are well-known and standardized products, show good workability as well as durability and possess high acceptance in the market.

In this LCA, three different types of WPC, differing in composition and geometry are compared to two wood decking materials, consisting either of Bilinga (as tropical wood) or of pressure impregnated pine (as regional wood) with an identical geometry. Functional unit is $1 \mathrm{~m}^{2}$ covered terrace. Data sources are industry and Ecoinvent. Transport processes are modeled according to one common reference to be consistent, identical process steps are excluded.

The impact assessment is done with CML 2001. The impact categories assessed are global warming (GWP), acidification (AP), ozone depletion (ODP), photochemical ozone creation (POCP), and eutrophication potential (EP). Inventories shown separately are cumulated energy demand (CED), cumulated energy demand non-renewable resources (CED fossil), and cumulated energy demand renewable resources (CED renewable).

Two aspects are essential for this assessment. Firstly, the influence of the maintenance during the floorings' use-phases needs to be assessed, i.e. the application, type, and frequency of paintings and cleaning. Secondly, the life-time of a terrace may differ from its technical durability. A flooring might be replaced due to esthetic reasons, even if there is no functional failure yet. To clarify these aspects a survey on terrace owners and customers was conducted, addressing questions about maintenance behavior, the grade of material satisfaction and, based on examples, the level of weathering that leads to flooring substitution. The results of this survey are included in the LCA as 'shares of maintenance' and 'times of production'.

The results of the LCA will identify the most advantageous product concerning environmental effects.

Furthermore, the achieved LCA is used to create a life cycle management instrument for small and medium enterprises. The tool "Elwood 2"enables producers of WPC deckings to identify the ecological and economical improvements they can achieve by variations in, e.g., WPC recipes and designs, in transports or energy efficiencies. Finally, it allows a benchmarking with the wooden alternatives. 


\title{
WORS09-05
}

\section{Assessing sustainability of a low-input single-farm vegetable box-scheme using emergy and LCA methodology}

\author{
$\underline{\text { MV Markussen }}^{1}$, M Kulak ${ }^{2}, \mathrm{~T} \mathrm{Nemecek}^{2}, \mathrm{H}$ Ø stergård $^{1}$
}

${ }^{1}$ Technical University of Denmark, Lyngby, Denmark

${ }^{2}$ Agroscope Reckenholz-Tänikon Research Station, Zurich, Switzerland

Sustainable development implies necessarily making use of renewable resources to a larger extent. Thus a sustainability assessment has to identify hotspots for reducing use of non-renewable resources and potentials for substitution of these with renewable resources. LCA as well as emergy assessment provide tools for such analyses. Emergy is defined as the total solar exergy directly or indirectly required to make a given product or service and is measured in solar equivalent joules (seJ). The two methodologies are to a large extent based on the same type of inventory of energy and material flows, but are based on different theories of values and system boundaries. LCA draws system boundaries around the studied system as supported by human dominated processes (resource extraction, refining, transportation etc.), whereas emergy accounting in addition considers processes occurring in natural systems and, thereby, also includes all direct and indirect flows of freely available resources such as sun, rain and wind. Another difference is that emergy accounting typically includes labor in order to take into account the indirect resources from society, e.g. infrastructure, needed to support the system. However, the emergy method lacks some of the standardization and robustness of LCA. In this study we apply both methods to the same case study. The case considered is an organic stockless vegetable farm of 7 ha in UK which distributes its products in weekly boxes to 250 local consumers. The farm has systematically and successfully worked on reducing external inputs. The system provides over 70 varieties of seasonal vegetables as well as biodiversity conservation and other ecosystem services. As a main goal of the study was to locate opportunities for sustainability improvements for the food production, we chose the yearly production of the whole farm as the functional unit. Analyzing a single product brings the risk that improvements for one product are achieved at the expense of other products. Contrary to expectation, emergy flow from the local renewable sources sun, rain and wind makes up only 16\% (1.6\% if including emergy support from labor) of the total emergy input to the system. The local non-renewable source ground water makes up 6\%. Emergy flow of goods from society makes up the rest with fuel (28\%), electricity (18\%), woodchip compost (13\%), potable water (8\%) and machinery (6\%) being the most important. Hotspots for minimizing resource use are fuels and electricity. Substitution of these would require the use of renewable energy. However, an increase in inputs from society may imply a lower net-yield to society from the farm and would thus be less desirable. The LCA data are currently being analysed and these results as well as the comparison between LCA and emergy analysis will be presented at the conference. In conclusion, from a biophysical perspective, agricultural systems primary societal function is to convert local renewable flows of sun, rain and wind into food, fodder and fiber by investing a minimum of products and services from the society. Thus it is desirable to maximize farms' use of local resources relative to imported resources. The emergy assessment's unified measure of local and imported and renewable and nonrenewable resources adds an extra insight that can potentially lead to other suggested actions for improving sustainability. Acknowledgements: The research was supported by EU grant no. KBBE-245058-SOLIBAM.

\section{WORS09-06}

Economical-ecological optimization using life cycle assessment and material flow cost accounting for a wood based product - an empirical study

\section{$\underline{\text { R Rieckhof }}$}

\section{TU Dresden, DRESDEN, Germany}

The scarcity of resources increasingly motivates the shift to resource efficient manufacturing. With various monetary and non-monetary instruments green controlling has contributed over the past decades to the integration of environmental cost and resource conservation by internalizing external effects in data collection and data presentation. Moreover, international standardization organizations help to establish green controlling instruments by improving standardization, legitimation and credibility. The most promising standardized instruments are life cycle assessment (DIN EN ISO 14040 and DIN EN ISO 14044) as well as material flow cost accounting (DIN EN ISO 14051). Life cycle assessment quantifies the material flows and the 
corresponding environmental impacts of processes, production lines or services throughout their life cycles in physical units. Material flow cost accounting visualizes material flows in physical and monetary units. By combining both methodologies, it is possible to identify economical and ecological optimization potentials and support more resource efficient decisions in various corporate compartments, such as accounting, product development or process optimization. We contribute to the existing literature by reviewing existing empirical papers combining life cycle methodologies to support decision-making. Furthermore, we present the results of an empirical study which combines carbon footprinting and material flow cost accounting for the joint production of a wood-based product and its by-products. The carbon footprint results indicate that the material loss is the main contributor to the global warming potential. The material flow cost results show that the costs are split almost equally between the product and its by-products. On the basis of this green controlling approach, firms can identify economical-ecological optimization potentials and support more resource efficient decisions. We have identified several adaption measures for resource and technology optimization yielding an environmental impact and cost reduction. In the short term, for example, fossil materials could be replaced by more ecological alternatives from renewable resources. In the medium term, optimization potentials could be found in the creation of a heat cycle. In the long term a combined heat and power plant can be constructed. While life cycle assessment can visualize environmental impacts, material flow cost accounting can demonstrate internalized environmental costs resulting from inefficiencies and reprocessing, but not external environmental impacts. Thus, a combination of both results focuses on the advantages of both methodologies to optimize the use of natural resources and internalized as well as not (yet) internalized environmental impacts. The proposed approach is a first step towards improving resource efficiency and internalization of environmental impacts. However, in order to form the basis for decision-making, a multi-dimensional approach is needed combining for instance both presented methodologies with multi-criteria decision making. Moreover, further focus should be on the wide choice of allocation and internal pricing options which strongly influence the results of a study.

\title{
WORS09-07
}

\section{Environmental sustainability assessment of short forestry - wood chain for alpine wood furniture}

\author{
N Mirabella ${ }^{1}, \mathrm{~V}$ Castellani ${ }^{1}, \mathrm{~S}$ Sala ${ }^{2}$
}

${ }^{1}$ University of Milan Bicocca, MILAN, Italy

${ }^{2}$ JRC-EC - Institute for Environment and Sustainability, ISPRA, Italy

An exhaustive Life Cycle Assessment (LCA) was performed in order to evaluate the environmental impacts induced by implementing a short-supply chain in the Alpine region. Forest supply industry represents one asset of the Bio-economy and it is a leverage sector across Europe, even if not properly capitalized. A case study was carried out in Italy (Lombardy Region) to investigate the improvements provided by a short-supply chain scheme, choosing an area where the forest management follows the PEFC scheme. The case study is part of a wider sustainability assessment project, BOMO (BOsco-MObile, Forest-Furniture), in which environmental aspects as well as socio-economic potential and viability of use for forests located in Lombardy are analyzed. The present study entails: (1) the assessment of forestry operations, in order to provide a guide that could help decision-makers in choosing the most sustainable and useful operational modes in the given local context; (2) the subsequent furniture production, designed applying eco-design criteria and Green Public Procurement requirements. The main goal of this study was to assess the environmental sustainability of the whole supply chain, giving recommendations for its future development and planning.. LCA methodology, adopting ReCiPe 2008 as LCIA method, was performed to quantify the potential environmental impact associated to the system under study. The main forestry activities were assessed under different scenarios: four options related to traditional operational methods and one option of advanced mechanized scheme. Concerning the furniture production, a school-desk manufacturing was assessed under a cradle-to-gate perspective, including the energy consumption, ancillary products, emissions and transports related. Use and end-of-life stages were not included. Data related to the inputs and outputs of the process are primary data and were obtained by onsite measurements; where necessary, these were complemented with bibliographic sources. Furthermore, the assessment was complemented by a number of scenarios analysis.

Results highlight the following issues: (i) in this context, the use of traditional operational mode is proved to have lower environmental burdens, compared to advanced one; (ii) a short supply-chain scheme allows minimizing impacts related to transports, which mostly contribute to the total environmental burden of the products; (iii) the study proved how eco-design and GPP criteria can improve the environmental performance of furniture goods.

Finally, from the results, four main issues need to be further investigate: i) influence of the impact assessment methods in assessing the role of bio-based product, as $\mathrm{ReCiPe} 2008$ doesn't account for renewable resources; 
ii) capability of LCA to comprehensively address potential benefits induced by the use of certified biomass; iii) conditions under which the technology assessment may be influenced by the local context ;iv) possible integration of the environmental sustainability assessment with other dimensions e.g. the local supply chain social and economic fallout on local employment and economy.

\title{
WORS09-08
}

\section{Consistent inclusion of deforestation in life cycle assessment of food products}

\author{
S Humbert, V Rossi
}

\section{Quantis, LAUSANNE, Switzerland}

Deforestation is recognized as being one of the major cause of greenhouse gas (GHG) emissions and destruction of ecosystems. It is also recognized that the majority of deforestation of natural ecosystems is associated with agriculture and agroforestry. On a world scale, GHG emissions from deforestation associated with agriculture and agroforestry are of the same order of magnitude as all other GHG emissions associated with agriculture and agroforestry production systems.

The sector of food and beverage is rapidly incorporating the method of life cycle assessment (LCA) to address issues such as labelling, "food eco-design"but also to inform consumers and non-governmental organizations asking for more transparency on the environmental performance of food and beverage products.

However, among major limitations in doing LCAs on food and beverage products is the lack of consistent consideration of impacts associated with deforestation in inventory database and impact assessment results. Therefore, there is a need to develop and incorporate transparent and reliable data on deforestation in inventory databases and impact assessment results in order to increase accuracy of food and beverage LCAs.

Different approaches exist to address deforestation in LCA: the most common approach is to actually neglect this issue; the GHG protocol suggests to allocate deforestation to the cultures that have grown in the country where deforestation occurs; another approach is to allocate deforestation equally to all land cultivated in a specific area (normally the country); finally, another approach is to allocate deforestation to the culture on the boarder of the forest being deforested, assuming that it is this culture that causes deforestation.

In any cases, deforestation is most of the time not considered, which can be a significant bias for products produced in countries experiencing significant deforestation such as those in the tropics.

In this context, at Quantis, we are evaluating the influence of incorporating deforestation consistently in inventory databases and impact assessment results, using the different approaches as sensitivity studies.

The presentation will show the contribution of deforestation in overall food and beverage LCA studies, using different allocation systems.

Results show that neglecting deforestation can cause a major underestimation of GHG emissions and other ecosystem impacts associated with products produced in tropical countries, such as palm oil, coffee, sugar cane, soybean or beef. In some cases, deforestation can double the GHG and ecosystem impacts as compared to when deforestation is neglected. For example, if considering the average annual Brazilian deforestation rate of $0.8 \%$ (in ha deforested/ha used for farming), the GHG emissions associated with green coffee production can double.

In addition - and this is something even more neglected in most LCA food studies - to be consistent, impacts of deforestation should also be considered in studies indirectly using such products, as for example, potential impacts from deforestation in LCAs of European milk production where part of the dairy cows fodder is based on soybean produced in regions where deforestation occurs.

This presentation will highlight the cases when deforestation should be considered with care to evaluate the actually potential environmental impacts of food and beverage products. 


\section{MPRS09-01}

Environmental sustainability assessment of bio-based products: A case study of a disposable diaper

N Mirabella ${ }^{1}$, V Castellani ${ }^{1}$, S Sala ${ }^{2}$

${ }^{1}$ University of Milan Bicocca, MILAN, Italy

${ }^{2}$ JRC-EC - Institute for Environment and Sustainability, ISPRA, Italy

Bio-economy strategies are increasingly developed towards the capitalization of renewable resources to increase resource efficiency and non-renewable resource dependence. In the last few years, several bio-based products have been developed as result of eco-innovation strategy. Nevertheless, to evaluate comprehensively the environmental benefit of bio-based products is paramount relevant to carry out life cycle based study, as being "bio-based"is not deemed sufficient to ensure the absence of environmental impacts.

In this study, a cradle-to-gate Life Cycle Assessment of a bio-plastic based diaper was performed. The product has several innovative elements as results of the implementation of eco-design principles in its development. The aim of the study is the evaluation of the environmental benefit gained through eco-innovation, whilst identifying further areas of improvement. The bio-based diaper has been evaluated using a "cradle-to-gate"life cycle assessment (LCA), including: production and transport of raw materials to the factory; manufacturing of the diaper; energy consumption; air emissions treatment system and recycling of production wastes. The functional unit is one diaper, assuming an average size amongst the different commercial options. In order to highlight potential areas of improvement and to compare environmental performance of the product, it was performed: i) a sensitivity analysis based on three different impact assessment methods adopting: ReCiPe 2008, IMPACT 2002+ and Cumulative Energy Demand (CED), ii) a comparison with commercial traditional diapers.

Contribution analysis suggested that source and production of raw materials used in WIP diaper manufacturing contribute the most to the potential environmental impacts. Adopting ReCiPe method, pulp and sodium polyacrylate (SAP) present the highest environmental burdens in WIP diaper system. Pulp is identified in characterization stage as the most relevant source of impact, but the result is justified by the amount of pulp used for diaper manufacturing (more than $50 \%$ of the total weight). On the contrary, even if SAP amount in the diaper is negligible, the component presents significant toxicity-related impacts superseding any other materials or components. Applying IMPACT2002+ method, the polylactic acid (PLA) relative contribution to the toxicity increased due to its production phase. Regarding the evaluation of CED, results show that non-renewable energy related to fossil fuels is reduced for WIP diaper compared to standard one, while use of renewable energy increases.

Integrating eco-innovation and eco-design principles in product conception in the bio-based diaper lead to a better environmental profile compared to standard one. Nevertheless, there are several areas of improvement to be considered in order to further improve the environmental performance. First of all, the reduction of SAP content in diaper may decrease the toxicity related impacts. Second, even if biopolymers may imply a positive effects on production life-cycle of the diaper several concerns arose due to land-use related issues. The ongoing development of more robust impact assessment model for land use will result in better assessment of the biobased product. In conclusion, introduction of biopolymers in diaper composition is preferable when compared to standard diaper, but the environmental sustainability of the bio-based products could be further enhanced in order to avoid burdens shifting.

\section{MPRS09-02}

\section{Life cycle impact assessment of a selection of green solvents}

\section{HH Khoo, LL Wong}

Institute of Chemical and Engineering Sciences, JURONG ISLAND, Singapore

The choice of solvents critically impacts on the processes and environmental performances of chemical and pharmaceutical industries. Some solvents are considered 'green' because they can be made from biomass feedstock such as corn stover, sugarcane bagasse and cellulose. A comprehensive environmental analysis and evaluation of any bio-solvents should account for the entire life cycle because the environmental impacts within the production chain may simply shift from one area to other areas. Seeking sustainability has resulted in various footprint methods being developed. Aligned with the goals of sustainability, Life Cycle Assessment (LCA) has be applied in the evaluation of solvent selection due to the holistic approach of addressing not 
just carbon footprint issues but also a wide range of environmental impacts. In this case study, LCA is used to evaluate some selected green solvents from cradle-to-factory gate. By considering a large number of resource flows, energy use and emissions generated within the solvent production chain, several potential environmental burdens are addressed, such as global warming potential (carbon footprint), acidification, eutrophication, as well as, land use and water use during the agriculture stages of producing biomass feedstocks. While land use change is a complex issue in LCA, land use in terms of the area of land occupied per specific amount of agriculture biomass resource will be considered.

\title{
MPRS09-03
}

\section{Comparison of environmental performance of tractor and animal traction using a hybrid-LCA}

\author{
$\underline{\mathrm{AK}} \mathrm{Cerutti}^{1}, \mathrm{JTosco}^{1}, \mathrm{~S} \mathrm{Bruun}^{2}, \mathrm{~A} \mathrm{Calvo}^{1}$ \\ ${ }^{1}$ University of Turin, GRUGLIASCO, Italy \\ ${ }^{2}$ University of Copenhagen, COPENHAGEN, Denmark
}

Since the origin of agriculture and shortly after the end of the Second World War, animal traction has supported humans in most field operations. Animal traction allowed human populations to grow faster because it significantly increase agricultural yield with a minimum increase of energetic inputs. The introduction of mechanization in agriculture and forestry completely changed this. Nowadays, animal traction is largely used in the developing part of the World and, sometimes, in specific contexts such as mountain areas, due to the difficulties of using tractors, and for rural farm holidays for commercial appeal.

Nevertheless a debate is carried out about the environmental sustainability of animal traction in comparison with tractors, because supporters of mechanical management highlight that tractor impacts are related to a small consumption of fuel related to the feed consumed by animals. Furthermore impacts of tractors have to be related to a larger amount of traction obtained by a traction compared to animals, due to the difference in power exerted by the two different "machines".

Therefore this study assess the environmental performance of animal traction in comparison of tractor traction, in a case study, using a combined functional unit consisting of two different operations: the management of $1000 \mathrm{~m}^{2}$ of soil for horticultural production and the deforestation needed to obtain $100 \mathrm{~kg}$ of wood. Impacts of both operations made by donkeys were evaluated in the "La Masca"farm in Roccaverano (Asti, Northern Italy) and by field data on the same operation made by tractors in a similar production system and then related to the specific functional unit.

In order to compare the environmental burdens per working hour of donkeys and tractors, the impacts generated in the full life of the two "machines"were divided by the estimated working hours in their whole life. Therefore, in the case of donkey, the full feeding and stabling requirement were considered taking into account the real mechanical hay-making in Roccaverano to produce the hay. This was one of most challenging aspects of the study because it involved the modeling of the donkey.

As several by-products or services are provided during the provision of the functional unit in the two systems of donkey and tractor management, it is not possible to consider it directly in a standard LCA. Therefore, we applied a hybrid input-output/LCA methodology in which the environmental contribution of services were accounted as the impacts per $€$, obtained by NAMEA (National Accounts Matrix including Environmental Accounts) evaluations. This hybrid method has both the typical strength and weakness of mixing a bottom-up approach with a top-down analysis. With this method all processes involved in the lifetime of donkeys and tractors are accounted (also services without basic goods) but, as the NAMEA matrix refer to the National level, the emission associated to a service may not be sufficiently accurate to the local context.

The results show a better environmental performance of animal traction both per surface of managed soil and per weight of ready-to-be-sold wood. Considering just the Global Warming Potential category, animal traction operations reduce impacts by $50,45 \mathrm{~kg} \mathrm{CO}$ eq. / $1000 \mathrm{~m}^{2}$ of managed soil (about $94 \%$ ) in the agricultural operation and the impacts by $0,97 \mathrm{~kg} \mathrm{CO}$ eq. $/ 100 \mathrm{~kg}$ of wood (about $72 \%$ ) in the forestry operation. 


\title{
MPRS09-04
}

The importance of land use in a comparative life cycle assessment of a timber construction and a solid structure in residential buildings

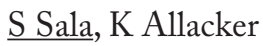

Joint Research Centre- European Commission, ISPRA, Italy

Life cycle assessment is one of the most well-known and widely accepted approaches to assess the environmental impact of buildings. Land use occupation and transformation is one of the impact categories with a high level of uncertainty and where impact modelling is still weak. Current European standards and norms related to the construction sector such as EN15804, NEN 8006, AFNOR and BRE Environmental Profiles do not include it. Land use might however be very relevant for the construction sector, both in terms of space occupied by buildings and land use needed for the acquisition of resources. This paper demonstrates the importance and relevance of land use and resources modelling in life cycle assessment of buildings.

A case study is presented in which the life cycle environmental impact of a timber construction is compared to a solid construction for residential buildings based on a comprehensive approach. As the insulation requirements have become more severe timber constructions have gained importance in many European countries. The advantage of such timber constructions is the reduced wall (and roof) thickness compared to solid constructions because the insulation can be put (partly) between the loadbearing structures. It is moreover assumed that timber constructions will gain even more importance as the insulation requirements are getting more severe (e.g. the increasing energy performance over time foreseen under the EU Directive 31/2010 (recast)). The International Reference Life Cycle Data System (ILCD) recommendations are followed to assess the different impact categories. Land use is focussed at in more detail through a sensitivity analysis of the assessment model. Moreover, the impact on the closely related abiotic and biotic resources, such as sand, clay and timber, are discussed.

A newly built single family detached dwelling located in Belgium is studied. Both the timber frame variant and solid structure variant fulfil current (2012) energy performance requirements. The whole life cycle of the building is assessed, from resource extraction, through the production of the materials, the use stage, demolition and end-of-life treatment. All consequences due to the choice for a certain construction option are taken into account, such as the necessary maintenance and replacements. The life cycle impact on all impact categories is investigated and a detailed analysis is made of land use.

Based on the case study for the relevance and importance of the assessment of land use and biotic resources in life cycle assessment are demonstrated. Issues for further research are highlighted and some critical elements concerning the environmental profile of timber based products compared to products of alternative building materials are emphasised.

\section{MPRS09-05}

\section{A sustainability assessment of the implementation of anaerobic digestion as a biomass valorization strategy}

\section{$\underline{\text { S De Meester, J Dewulf }}$}

\author{
Ghent University, GHENT, Belgium
}

Anaerobic digestion for the valorization of biomass is a technology that has big advantages in comparison with alternatives such as composting (energy generation) and incineration (nutrients valorization in the digestate (e.g. as fertilizer)). The microbial diversity in the digester allows conversion into biogas of almost all biomass sources, amongst others organic waste streams and therefore this technology is more and more often applied in combination with other production routes, making it a very suitable option in biorefineries. This presentation focuses on the results of the sustainability assessment of this technology performed in the framework of the FP7 PROSUITE project (Prospective Sustainability Assessment of Technologies; http://www.prosuite.org). The environmental and economic impact assessment will be elaborated by focusing on the choice of feedstock, on the comparison with the reference situation, on the impact of using digestate as a fertilizer and on the value of tools developed in the project that can be used to model the environmental and economic data inventory for assessments. This is added with the first results of the social screening and with an outlook to further progress.

Reference: De Meester, S., Demeyer, J., Velghe, F., Peene, A., Van Langenhove, H. and Dewulf, J., The 
environmental sustainability of anaerobic digestion as a biomass valorization technology, Bioresource Technology, 2012, doi: http://dx.doi.org/10.1016/j.biortech.2012.06.109

\title{
MPRS09-06
}

\section{Competition for wood: Sustainability assessment of the different uses of wood in south-east Germany}

\author{
C Lubenau, G Weber-Blaschke, K Richter
}

Technische Universität München, Holzforschung München, FREISING, Germany

An increasing competition for wood resources between the manufacturers of wood and lignofiber based products as well as energy wood products is expected to arise in Germany in the next two decades because of the political promotion of wood-based energy products. The goal of this study is to analyze the effects of increasing wood utilization for energy purposes on the Bavarian forest-wood chain with respect to different scenarios through the year 2030. A life cycle assessment approach was used to assess the global warming potential and primary energy use of different wood products. The impact of changes in wood supply on the primary manufacturing of wood and paper commodities is currently being analyzed including the effects of possible wood imports. Also addressed are the effects of imports of wood products on the Bavarian secondary manufacturing of wood based products. The effects of substitution of wood products by non-renewable materials will also be analyzed. First results for the impact on the manufacturing of primary wood products will be presented.

\section{MPRS09-07}

\section{Life cycle assessment of starch products - methodology and data availability as a challenge}

\author{
A Vercalsteren, E Dils, $\underline{\text { K Boonen }}$
}

VITO, MOL, Belgium

Both industries and consumers are paying more and more attention to the environmental impacts of the goods and services they produce or use. This also accounts for the customers of European starch producing companies. In the past few years, the number of questions on the carbon footprint, water footprint and other environmental impacts related to starch products has increased significantly. Therefore, the European starch federation (Association des Amidonniers et Feculiers, the AAF) started the initiative to conduct a life cycle assessment of the products their members produce (as an update of the Ecoprofiles for starch products that are developed more than 10 years ago). Through this study they want to communicate well substantiated environmental information of starch products on a sector level. As well, the AAF wishes to obtain useful information on the consequences of methodological choices for their products, especially in the framework of ongoing initiatives like the French "Grenelle" and the European SCP Roundtable on Food.

The LCA study for the European Starch Industry distinguishes 2 successive phases. During the pretesting phase, only a limited dataset is used and only the carbon footprint is calculated. The main focus during this phase was the methodology definition: which allocation rules and system boundaries to be used, how to tackle the issue of biogenic carbon, especially for communication purposes etc. The LCA results of this phase are as such not representative for the European Starch Industry. Sector-representative environmental profiles are developed in a second phase. During this phase a complete sector study is made in which also other environmental impacts than carbon footprint are calculated. An extensive dataset is used, representative for the member companies of the AAF. The methodology as defined during the pretesting phase is used during the latter phase.

The presentation will focus on the different methodological options when making a cradle-to-gate LCA study for starch products instead of on the absolute environmental profiles. Focus lies on the methodological aspects like allocation rules and their consequences for the environmental profiles. Furthermore the process of gathering sector-representative data will be presented, but also data availability aspects and possible improvements in the future will be discussed. 


\title{
MPRS09-08
}

\section{Preliminary life cycle assessment of energy and carbon results of high ligno-cellulosic biomass pyrolysis coupled with anaerobic digestion}

\author{
V Bandini, S Righi, D Marazza, C Torri, A Buscaroli, B Salieri, D Fabbri, A Contin \\ University of Bologna, RAVENNA, Italy
}

Lignin, the most abundant aromatic biopolymer on Earth, is extremely recalcitrant todegradation. Therefore, the presence of lignin in the biomass constrains and challengesthe improvement of bioconversion techniques. This paper presents a preliminary lifecycle assessment of an innovative combination of technologies to convert high lignocellulosicbiomass into useful products, primarily energy and fuels. The experimental process exploits residual biomasses with high ligno-cellulosic contentfor the production of biogas and consists on the combined use of thermo-chemical(pyrolysis) and biological (anaerobic digestion) pathways and would allow for a widerrange of exploitable residual biomasses, higher yields, product diversification and otheradvantages for agro-energy industries and the environment.Residual biomass energy sources - such as manure and corn "stover"(cobs, leaves, etc.)or other by-products of farming or other activities - represent a low cost feedstocksource that can be used for energy production. Moreover, the employment of residualbiomass might be less controversial than those of harvested biomass, which raiseenvironmental concerns or issues related to competition with food needs. These concernsand issues have resulted in growing interest in alternative, non-edible biomassresources. Corn stover, typically composed of 35区 $40 \%$ cellulose, 20区 $25 \%$ hemicellulose, and $15 \nabla^{\prime} 20 \%$ lignin, is a very abundant agricultural residue whose raw substrate isrecalcitrant to bioconversion. This represents the major obstacle to its costeffectiveexploitation. The experimental processing of corn stover through a pyrolytic pre-treatment provides adigestible feed for anaerobic bacteria producing biogas. The process provides also somevaluable coproducts, such as biochar and digestate which can be used as soil fertilizers. The experimentation has been conducted at a laboratory scale and is divided into threesteps: 1) drying of corn stover; 2) pyrolysis of the corn stover, with the production of biooil,gas and biochar and 3) anaerobic digestion of bio-oil and gas, with the production ofmethane, $\mathrm{CO} 2$, digestate. The functional unit was defined as $10 \mathrm{t}$ of dried corn stover, the system boundariesinclude the three above-mentioned steps. This first assessment has focused on the energy and carbon balance of the process. Calculations have been conducted with experimental data, when available, and with datafrom literature, always assuming a conservative approach, in particular regarding theamount of biooil obtainable from the pyrolysis of corn stover, pyrolysis energyconsumption, heating requirements, methane yield. Results show a ratio between spent and produced energy always higher than 1, with amean value of $2.6 \pm$ 1.3. The pyrolytic pre-treatment allows for an 2.5 fold increase ofthe carbon available for bio-methanation. As for the $\mathrm{C}$ balance, apart from the avoided emissions due to fossil fuels replacement, arelevant contribution is given by biochar, which appears able to store $\mathrm{C}$ in soils and iswidely studied for this property. Results have been compared to the conventionalanaerobic digestion of corn stover.

\section{MPRS09-09}

\section{Crotonic acid production by thermal degradation of transgenic biomass and recycled bio-plastic - a sustainability assessment}

\section{Nawaz, JA Posada, MK Patel \\ Utrecht University, UTRECHT, Nederland}

Scarcity of fossil resources and increasing environmental burden caused by the usage of these resources led to an increased interest in finding alternatives to fossil based fuels, chemicals and materials. Polyhydroxyalkanoates (PHAs) are well-known biopolymers derived from renewable feedstocks. However, the energy use for the purification of PHAs is the key environmental and economic concern. In addition, these polymers exhibit short carbon cycle and loose bio-based carbon reserve during biodegradation. On the other hand, there is an opportunity to produce valuable chemicals by thermal degradation of PHAs i) without purification to polymergrade PHA and ii) at the end of their life cycle, which can substantially reduce the environmental impacts.

Crotonic acid is one of the chemicals that can be produced by thermal degradation of PHAs. It is currently being produced through a fossil route but if produced via bio-based route, can serve as a building block for various bio-materials, e.g. crotonyl methyl esters, butyl crotonate etc.

In this paper, two emerging technologies for the production of Crotonic acid are evaluated regarding their sustainability performance, i.e. flash pyrolysis of transgenic biomass and chemical recycling of PHAs. The applied methodologies are techno-economic analysis and Life cycle assessment (LCA) based on mass and 
energy balances obtained by process design and simulation using Aspen Plus. Non-renewable energy use and climate change are the impact categories considered in this analysis. Two allocation methods, i.e. cut-off approach and waste valuation, are applied to assign environmental burden to the recycled polymer. Finally, results obtained from all processes are analyzed and compared with the fossil route for the production of Crotonic acid.

\section{MPRS09-10}

\section{Life cycle assessmentof biobased composite materials from flax fibers and linseed oil polymer}

Y Deng $^{1}$,W Dewulf ${ }^{2}$, K Van Acker $^{1}, J_{R}$ Duflou $^{1}$

${ }^{1} \mathrm{KU}$ Leuven, Leuven, Belgium

${ }^{2}$ Groep T, Leuven, Belgium

Driven by the worldwide fossil energy depletion and global warming, research efforts on applying materials from renewable resources areincreasing. In this presentation, a composite material design based on flax fibers and linseed oil is evaluated from an environmental perspective. First, functional equivalence is discussed: flax fibersareamong the strongest natural fibers, while linseed oil contains several functional groups which can be chemically modified and hence crosslinked into thermoset polymers. The studied biobased composite possesses relatively high mechanical properties compared to other biobased material structures due to the crosslinking capability and the composite structure. It can alsobe manufactured through traditionalmanufacturing techniques, such as resin transformation manufacturing. The compatibility with traditional methods implies the possibility of commercial large-scale production. The substrate material in printed circuit boards (PCBs) is given as an example where full functional equivalence is achievable.

Subsequently, a full environmental impact evaluation through life cycle assessment(LCA) is presented. The LCA targets two goals. First, the study provides an assessment of the environmental impact of flax fiber and seed oil polymer production. Sincethese biobased materials are both quite common in Europe, suchbasic assessments provide useful data feeding into the evaluation of any future derived product.Furthermore the study evaluates the aforementioned composite materialbased on the production and end-of-life phases in comparison to traditional glass fiber/epoxy compositesin order to identify the potential environmental benefit. The aforementioned example of the substrate material in PCBs is used as a demonstrator for this purpose.

The LCA comparison, based on the ReCiPe methodology, favors the biobased composite for most impact categories including climate change, fossil depletion, and human and terrestrial ecotoxicity. However, the biobased composite has a higher impact on eutrophication, and land occupation, which are common issues for agricultural products. To provide an overall value, the aggregated weighted eco-points score is obtained as well. The biobased composite is found to be $1.16 \mathrm{ReCiPepoints} \mathrm{lower} \mathrm{than} \mathrm{traditional} \mathrm{epoxy/glass} \mathrm{fiber} \mathrm{composite}$ for $1 \mathrm{~m}^{2}$ of PCB substrate. However the higher land occupation posts considerable concern over biobased materials for conflicts with food cultivation.

Subsequently, a sensitivity analysis addresses the influence of the chosen allocation principle on the environmental impact. The economic allocation principle results in a significant increase in all impact categories than the mass allocation principle. Nevertheless, in both cases the biobased composite design has a lower environmental impact than the conventional composite material. Finally, the question of the applied allocation principle is briefly extended to the use of external databases: the allocation principle applied for the foreground processes may not be consistent to that applied in the background data, which are directly retrieved from the external database. For many LCA studies, relying on external databases, a consistent application of allocation principles throughout the study is therefore not warranted. 


\section{MPRS09-11}

\section{Petroleum-based and bio-based products in comparison}

\section{Rigamonti, M Grosso}

Politecnico di Milano, MILANO, Italy

The past decade has witnessed an increased consumer and government interest in replacing petroleum-based products with those made from or with bio-based resources. As the array of bio-based products has increased, so too has the interest in evaluating the energy and environmental impacts of these products.

The study presented in this paper was commissioned by a company that produces flexible foam polyurethane. The polyurethane is obtained by reaction between polyols and isocyanates in the presence of suitable catalysts. The polyols used are usually of fossil origin, but the company is developing a new product with a high content of soy-based polyols. The aim is to compare the environmental impacts of the conventional raw materials with those of the new raw materials, to evaluate a possible contribution to safeguard the environment by the new product.

A comparative analysis of the processes of production of petroleum-based polyols with those of soy-based polyols was therefore carried out. The comparative analysis was performed using the methodology of Life Cycle Assessment (LCA), which evaluates both direct and indirect impacts.

In the analysis of both types of polyols, the impacts associated with the consumption of reagents and energy are included. For polyols of petrochemical origin the impacts associated with direct emissions into air and water and those associated with the production and disposal of residues of the process are included too.

Under the assumptions made, it can be concluded that the production of polyols from soybean oil results in lower consumption of fossil fuel energy, lower consumption of non renewable resources and lower emissions of greenhouse gases than the production of polyols derived from petrochemicals. In contrast, other indicators show a greater impact for polyols from soybean oil compared to those derived from petrochemicals.

\section{MPRS09-12}

\section{Ecological and economical assessment of wood biomass production in Japan}

$\underline{\text { MO Makoto }}^{1}, \mathrm{~K} \mathrm{Hayashi}^{2}, \mathrm{M} \mathrm{Fujii}^{3}, \mathrm{H} \mathrm{Ito}^{2}, \mathrm{~T} \mathrm{Ota}^{2}, \mathrm{Y} \mathrm{Chen}^{2}$

${ }^{1}$ Nagoya University, NAGOYA, Japan

${ }^{2}$ EcoTopia Science Institute, Nagoya University, NAGOYA, Japan

${ }^{3}$ National Institute of Environmental Studies, TSUKUBA, Japan

Potential of wood biomass productions were assessed by a process-based-model, cost analysis, and ecologicalfootprint-like indices in Aichi prefecture, Japan. Forest ecosystems cover in Japan approximately 68\% of the total land surface. However, Japanese plantation forests are currently not well managed, which has resulted in the underuse of domestic timber and degradation of the forest ecosystem, while large amounts of wood biomass are imported from overseas. To estimate potential of wood biomass production, the forest ecosystem model (BGC-ES2) simulates biomass growth under various forest management practices (thinning and harvesting). The cost calculation model estimates the cost of each stage of wood biomass production, which depends on the productivity of forestry machines and the forest location. The occupation rate is defined by usage time span of land, energy, materials, and labors against the available amounts per a unit time span for the wood biomass production. The index is a kind of ecological footprint considering the environmental capacity. In the results, the current forestry management was not efficient for the production of wood chips from view points of cost and occupation rate. Modified management (arranging the thinning schedule to promote secondary growth, increasing the rotation length, and increasing the managed area) improved the situation. We finally indicated that wood chip production can be sustainably supplied, ecologically and economically, from the region for an energy plant. 


\title{
MPRS09-13
}

\section{Updating South African biofuel LCA studies with new inventory data relating to synthetic liquid fuels}

\author{
A Aboyade, H Von Blottnitz \\ University of Cape Town, CAPE TOWN, South Africa
}

The difficulty in obtaining country or regional specific inventory data remains a key challenge for applying LCA as a decision support tool, particularly in developing countries. Organizations involved in LCA research in such countries often have to use databases and inventories developed in Western Europe or North America. In South Africa, one area where such simplification may significantly influence the reliability of LCA results pertains to transport fuels. Close to $40 \%$ of South Africa's gasoline and diesel are produced by coal-to-liquids and gas-to-liquids processes, which are significantly more carbon-intensive than conventional oil-refining on which most existing inventories are based. Recently, a simple life cycle inventory dataset of the coal-to-liquids process was developed as one of the first steps in developing country-specific datasets for South Africa. In this paper, the results of applying this newly developed liquid fuel inventory in the system expansion step of previously published LCA studies focused on biofuel production from sugarcane feedstock are presented. The study highlights the need for increased effort in adapting foreign inventory datasets to local conditions, particularly when assessments based on such data is aimed at enable decision making on the sustainability of key products and services.

\section{MPRS09-14}

\section{The effects of sensitivity analysis in determining the optimal environmental pathway of energy crop production in Ireland}

\author{
F Murphy, K McDonnell, G Devlin
}

University College Dublin, Dublin, Ireland

In Ireland, the cultivation of energy crops as a source of energy has gained prominence in recent years as the country endeavours to reduce greenhouse gas emissions. Despite the reported environmental benefits associated with the use of biomass for energy, intensive energy crop cultivation involves potential negative environmental effects. The life cycle of an energy crop requires the use of energy and raw materials in several respects; in the extraction of raw materials (fuels, minerals), in production and transportation of system inputs (fertilizers, pesticides), and in field operations required for crop cultivation. Energy crop cultivation also results in emissions to air, soil, and water which have effects on the environment. It is essential that all effects, positive and negative, are considered in a holistic manner to enable a comprehensive evaluation of the system. Life cycle assessment (LCA), a multi-impact assessment tool, is particularly suitable for the sustainability assessment of complex agricultural systems. In this LCA study, the environmental effects of energy crop, willow Salix sp. and Miscanthus sinensis x Giganteus, production in Ireland are determined. The impact categories considered include global warming potential, acidification potential, and eutrophication potential. Sensitivity analysis is an important tool that can be used in LCA to determine the influence of one or more input parameters (e.g. fertiliser use) on the value of results (e.g global warming potential). Sensitivity analysis should focus on the most important issues in order to achieve meaningful results. The holistic nature of LCA analysis allows the identification of hotspots in the system; points of critical contributions to key environmental impacts. In this study, key hotspots in the production of energy crops are identified, including; crop maintenance, harvesting, and transport. Sensitivity analysis is carried out by examining the effects of changes in these key variables on the environmental impacts of energy crop production. As such, the use of sensitivity analysis highlights management practices which may help in determining the optimal energy crop production pathway in Ireland. 


\title{
MPRS09-15
}

\section{Production of wood-based ethylene in Sweden - what are potential environmental hot spots}

\author{
C Liptow $^{1}$, AM Tillman $^{1}$, GA Taylor ${ }^{2}$
}

${ }^{1}$ Environmental Systems Analysis, Chalmers University of Technology, GÖTEBORG, Sweden

${ }^{2}$ University of New Mexico, Dep.of Chemical and Nuclear Engineering, ALBUQUERQUE, NM, United States of America

In an effort to reduce its environmental impact, the chemical industry has recently started to increase the use of biomass instead of fossil feedstocks. As a result, base chemicals such as ethylene are no longer only produced from fossil oil and gas but, as in the case of ethylene, also from Brazilian sugarcane. However, from a European perspective, sugarcane has considerable drawbacks, among others the absence of close-by, large scale cultivation areas. Therefore local, European biomass options such as wood need to be investigated for their suitability.

In our life cycle assessment, we studied the environmental impact of producing ethylene from wood in Sweden. As a practical supply scenario, the minimum industrial plant size of 50,000 tonnes ethylene per year was evaluated. Since wood ethylene is not commercialized yet, data derived via process simulation was used to assess the environmental impact of some of the processes in the product chain.

We found that production of the enzymes used in the life cycle has a considerable share on all investigated environmental impacts. This was also the case when using future instead of currently investigated enzyme dosages. However, at these lower dosages the ethylene's overall impact decreased considerably, and enzyme production was no longer totally dominating the environmental impact, which highlights the need to lower enzyme consumption and/or improve enzyme production. In addition, the step of ethanol production was found to release significant amounts of emissions, making process design improvements worth continued investigation. Furthermore, our study assessed a relatively small production scale. However, in the long run, biomass-based base chemicals such as ethylene need to be available in large volumes. This may introduce new environmental issues, making investigations into large-scale production necessary.

\section{MPRS09-16}

\section{Environmental impact assessment of microalgae cultivation in Finnish conditions}

$\underline{\text { KR Manninen }^{1}}{ }^{,}$M Sonck $^{2}$, K Spilling $^{1}$

${ }^{1}$ Finnish Environment Institute, HELSINKI, Finland

${ }^{2}$ Fortum Keilaniemi, Fortum, Finland

Algae based biofuel production seems to be a promising technology. Compared with conventional energy crops, algae cultivation does not need to compete with food crops for land use because they can be produced areas unsuitable for crops. The grow rate is faster than for higher plants and can contain high amounts of e.g. lipids used for biodiesel production. The problem of algae based biofuels are mainly related to cost issues and energy consumption. With life cycle assessment the main bottlenecks for developing this technology sustainably can be identified and thus affected.

Mass cultivation of microalgae, requires supply of $\mathrm{CO}_{2}$, to maintain optimal $\mathrm{pH}$ and to prevent carbon limitation of growth. Taking the advantage of high photosynthetic potential of microalgae, algal mass cultures may be used to trap $\mathrm{CO}_{2}$ emissions from power plants and industry. In addition, the impacts of nutrient production can be decreased by using waste streams of other commercial activities or municipalities.

The case study will be carried out to assess the environmental impacts of algae cultivation under Finnish conditions. The focus will be on the energy and mass balances, and the study will be based on lab scale, experimental data complemented with literature. The potential of using flue gas from a coal fired power plant will be compared with pure $\mathrm{CO}_{2}$, as the carbon source for the algae. Additionally, nutrients from waste water will be used, recycling the nutrients, which would increase the resource efficiency.

The results of the study will be used to assess potential of algae cultivation as a bioenergy source, as a carbon sequestration technology and for reclamation of wastewater. Additional studies will be needed to examine also the end use of algae, in order to consider its prospects as carbon storage or carbon recycling. 


\title{
RS-10: Life cycle sustainability assessment
}

\section{WORS10-01}

\author{
Sustainability in international standardization
}

\section{$\underline{\text { K Christiansen }}$}

Danish Standards Foundation, Denmark

Overview of how sustainability and sustainability assessment are addressed in standards and ongoing standardization work of ISO and CEN - from sustainability issues in standardization in general to buildings and biomass. Standards are intended to harmonize provisions and recommendations but also standardizers have hard work ahead as the many somehow differentiating initiatives demonstrates. The presentation will give an overview and examples of conflicts and ideas for solutions e.g. initiatives on biomass and biofuels or buildings: - CEN Technical Committee (TC) 383 Sustainability produced biomass for energy applications was created in 2008 in order to work on European Standards dealing with sustainability principles, criteria and indicators including their verification and auditing schemes for biomass for energy applications. This includes greenhouse gas emission and fossil fuel balances, biodiversity, environmental, economic and social aspects and indirect effects within each of the aspects. - ISO/PC 248, Sustainability criteria for bioenergy. ISO/PC 248 brings together international expertise and state-of-the-art best practice to discuss the social, economic and environmental aspects of the production, supply chain, and use of bioenergy, and identify criteria that could prevent it from being environmentally destructive or socially aggressive. The building sector has similar initiatives in both ISO and CEN on standards for sustainability; examples from this sector will be included if time allows. ISO 26000 on social responsibility and the up-coming ISO Guide 82 on addressing sustainability issues in standardization will be used as framework documents for the assessment.

\section{WORS10-02}

Holistic sustainability evaluation methods including the social dimension for industry and agriculture

PR Saling $^{1}$, JS Schoeneboom ${ }^{1}$, FM Frank ${ }^{1}$, M Gipmans ${ }^{2}$

${ }^{1}$ BASF SE, LUDWIGSHAFEN, Germany

${ }^{2}$ BASF Plant Science GmbH, GB/K, BERLIN, Germany

BASF has pioneered the assessment of the sustainability of chemical products and production processes through the development and use of its Eco-Efficiency Analysis as well as SEEBALANCE analysis. Whereas SEEBALANCE can be applied to different industries and businesses, AgBalance was designed by BASF as a new method to assess the sustainability performance of agricultural production systems. The tools are used by $\mathrm{BASF}$ and its customers to assist strategic decision-making, facilitate the identification of product and process improvements, enhance product differentiation as well as to support the dialogue with opinion makers, NGOs and politicians.

Both, detailed in-depth results of individual impact indicators, as well as aggregated results and a single sustainability evaluation score are output of AgBalance and SEEBALANCE. Sensitivity analyses can be employed to study the robustness of the model results, and to investigate trade-offs or the response to external influences. Scenario Analyses can model different situations by simulating new sets of inputs followed by an assessment of improvement potentials of the analyzed system.

Being comparative methods, the relative performances of several alternatives are assessed according to a predefined customer benefit. This enables the identification of strengths and weaknesses of each alternative and is the starting point for optimization and thus sustainable development.

Next to specific factors for the environment and economy as in Eco-Efficiency Analysis, SEEBALANCE and AgBalance include 24 social indicators to assess the sustainability in relation to key stakeholder groups as defined by UNEP-SETAC. For example, the stakeholder group "Consumer"includes indicators directed at consumer confidence in agricultural products such as Residues in feed \& food, the stakeholder group "International Community"assesses among others the extend of Imports from Developing Countries and the stakeholder group "Future Generations" is covered by assessing e.g. Social Security funds or the amount of Trainees in the 
sector. The category "Farmer" is assessed by indicators such as Wages and Salaries or occupational diseases.

These multicriterial, holistic life cycle based approaches for all three pillars of sustainability in combination with a defined aggregation and summary of single results ends in easy understandable graphs. Different scenarios can be worked out additionally to support decision-making processes.

Specific developed Quick Scan tools can give a basic overview of the situation of alternatives in this context. They help to initiate studies or to work out some single Key Performance Indicators for a general orientation. They can be worked out with a higher throughput than the other studies, but will not deliver the full set of information.

References:

Saling P., Kicherer A., Dittrich-Krämer B., Wittlinger R., Zombik W., Schmidt I., Schrott W., Schmidt S. (2002): Eco Efficiency - The Method; Int. J. LCA 7(4), pp. 203-218

Shonnard, D.R., Kicherer, A., Saling, P. (2003); Industrial Applications Using BASF Eco-Efficiency Analysis: Perspectives on Green Engineering Principles, Environmental Science and Technology, 2003, 37(23), pp. 53405348

Schmidt, I., Meurer, M., Saling, P., Kicherer, A., Reuter, W., Gensch, C-O. (2004), in Greener Management International, ABI/INFORM Global, ed. S. Seuring, Greenleaf Publishing Ltd., Sheffield; 45, p. 79.

Kölsch et al. (2008), Int. J. Sustainable Development (11), No. 1

\title{
WORS10-03
}

\section{'Visual footprint' a new assessment tool to measure corporate sustainability leadership integrating LCA \& SLCA aspects - a Sri Lankan case study}

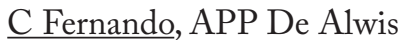

University of Moratuwa, Katubedda, Sri Lanka

Carbon footprint studies and publishing of corporate sustainability reports increased significantly during last few years in Sri Lanka. However the 'corporate value' indexes are still not covering these indicators with appropriate weights. Though transparent reporting and dissemination of corporate policies are major components of corporate reporting, local assessing prominence given for these aspects is comparably low. Only eleven out of top hundred respected companies performed any kind of an LCA or carbon footprint. 50\% of the carbon footprint calculated companies / corporate neither ISO 14001 certified nor sustainability report published. This analysis concludes the drive for the LCA's or carbon footprint is probably not driven through corporate environmental leadership however mostly through customer requirements. It also emphasis the corporate leadership, as a valued social dimension is not properly assessed using current criteria. Customized corporate social assessing tools are more suitable for developing nations than following general criteria's. Introduction of 'Visual footprint' tries to cover as an assessment tool; focusing on social corporate sustainability through SLCA's and ecological footprint through LCA's. The proposed customized assessment criteria aligned with the three general sustainability assessment aspects: footprinting, policies and transparent reporting; fundamentals of triple bottom line. 'Visual footprint' is a function of four direct indicators. They are : published life cycle assessments (carbon footprint, water footprint, etc), implementation of systems to sustain the triple bottom line performance - mainly ISO 9001, 14001 and OHAS 18001, magnitude of transparency through sustainability reporting and measure corporate social responsibility leadership through top management commitments and investments on SLCA beyond CSR. Calculating 'Visual Footprint' will be easy through gathering existing assessment results like: sustainability reporting, social accountability assessments and industry based ecological footprints, etc; hence this is not extra costing. The weight for each aspect can be derived considering the industrial category - hotels, apparel manufacturing etc; which provide a self intra assessment for the related industrial category and inter assessment within overall corporate. Defining of the weight can be done through a national independent body in an unbiased manner. Assessment of corporate by looking at wider and balanced approach can be achieved though the indicator 'Visual Footprint' and this can be implemented with the agreement of national sustainability assessing bodies. Also this assessment initiative will change and broader the corporate mindsets from narrowed competition and customer focused initiatives to an overall sustainability initiatives. 


\title{
Investigation of the prospective use of the Eco-Care-Matrix - an empirical study
}

\author{
$\underline{\text { K Skelton }}^{1}$, TH Joergensen ${ }^{2}$ \\ ${ }^{1}$ Aalborg University, AALBORG, Denmark \\ ${ }^{2}$ Siemens Wind Power, AALBORG ØST, Denmark
}

A variety of different environmental assessment tools have been developed and used by companies over recent years in order to assess and communicate product related environmental impacts. One example is Siemens AG, where the role of Life Cycle Assessments (LCAs) and Life Cycle Costing (LCC) has become increasingly important for the assessment of products and production processes to support decision making throughout the product development process while also communicating results externally with customers.

In 2004, Siemens AG developed the Eco-Care-Matrix (ECM), in collaboration with the Technical University of Denmark. The ECM is a graphical representation which compares both the environmental effects (y-axis) and cost effectiveness (x-axis) of anything from a product to a complete industry technology or system solution, with those of a reference product, technology or system. It utilizes LCA/LCC methodologies to make these comparisons. The ECM has been extensively used by one of Siemens' divisions, where it was incorporated both internally in their green product lifecycle management (PLM) and externally in the results of their Environmental Product Declarations (EPDs). It has proved to be an effective tool for illustrating impacts while also highlighting improvements for that division.

A second division of Siemens is currently enhancing its product related environmental activities and is looking to integrate Ecodesign concepts and tools throughout its PLM. A pilot project analyzing the application of the ECM was recently conducted for two purposes: firstly, to familiarize users with the tool and collect preliminary product impact results and secondly, to determine the tools usefulness for both internal and external environmental communication. Impact assessment results were collected through use of a LCA/LCC analysis and feedback was gathered from the relevant communication and engineering stakeholders through a separate set of group interviews.

This paper is primarily concerned with the second part of the pilot - determining from a user's perspective, whether or not the ECM is actually an effective communication and decision making tool and its potential use in this additional division. Three points of view are reflected in the article:

1. Interview responses from the ECM developers in Siemens corporate functions which indicate what has been the evolutionary development (and use) of the tool and what is the expected future developments (and use) of the tool based on the results of the pilot project

2. Interview responses from the original Siemens division who have extensively applied the ECM to indicate the application of the eco-tool and discuss experiences

3. Interview responses from various functions (e.g. EHS, sales \& marketing, PLM \& engineering) from the interested division to indicate if and how the tool could potentially be used in their business unit

The two central questions answered are: (1) If the ECM has been successfully used in one division for eight years, why has it not been expanded and extensively used to date by other company divisions?, and (2) What aspects of the eco-tool need to be developed further in order to gain more acceptance and become routinely applied? 


\title{
WORS10-05
}

\author{
Safeguarding the needs of future generations in life cycle sustainability assessment \\ TJ Mattila, J Seppälä, P Leskinen
}

Finnish Environment Institute, HELSINKI, Finland

According to the classical definition sustainable development "meets the needs of the present without compromising the ability of future generations to meet their own needs."Logically this is a multi-criteria problem, with two main criteria: the needs of the current generation and the needs of future generations. Although some development may be beneficial to all generations, in most cases the criteria are in conflict (i.e. the impact of current decisions are felt only after several decades). Keeping the goals separate allows the evaluation of trade-offs in the tradition of multi-criteria decision analysis.

However this classical view of sustainability is not compatible with current life cycle assessment (LCA) practices, where environmental impacts are integrated over both space and time. Technically LCA reduces sustainability to a single criteria problem . Although LCA results contain several subcategories, the basic transparency between two (often) conflicting goals is lost. This results in problems in normalization and weighting stages of interpreting the results.

In this study we examine, how the interpretation of LCA changes if results are presented in two categories: "present impacts "and "impacts to the next generations". This allows the decision makers to look at the results also from the viewpoint of the next generation. The approach is illustrated with results from case studies from mining, forestry and nuclear power. The aim is to provide a starting point for discussion about the temporal differentiation of LCA results.

\section{WORS10-06}

Social and economic impacts in environmental indicators - electronic industry product case study

$\underline{\text { PR Valerio }}^{1}$, SD Mancini ${ }^{2}$, BF Gianeli ${ }^{2}$

${ }^{1}$ FIT/UNESP, SOROCABA, Brazil

${ }^{2}$ UNESP, SOROCABA, Brazil

The life cycle analysis methodology (LCA) allows the mapping and quantification of the environmental impacts of a product. When trying to map just the environmental impacts of a particular product some additional factors have significant influence on the results and should be considered on a life cycle analyze. Among those aspects, we can bring to spotlight the ones studied here, the socio economic and cultural factors of a region where the consumer and the product are inserted. It becomes even more relevant in the technology industry, where product acquisition can be considered cost expensive and the products have a relative short life time period with length correlated to consumer's economic reality. This study has been developed after identifying a considerable difference in disposal habits of electronic products in different cultures. Reuse and recycling rates in different countries and due to social economic issues can be verified as very divergent. This study was developed based on the need to quantify the influence of the environmental impacts generated by these cultural differences. The results comparing that kind of data are important for industry and government for the drawing and specification of the best policies of electronic waste's disposal considering local issues and minimizing environmental impacts regionally. The biggest obstacles were to find data regarding electronic waste in different regions, these data is not yet fully mapped and when mapped it is often not publicly disclosed. This article presents the most relevant aspects, from the standpoint of industry, considering different economic realities can create different realities of use, production and disposal of electronic equipment converging to different environmental impact. It compares the environmental impact of a product in two different social realities considering the differences in product disposal. We used a printer as an example and case study, data on materials used in the composition of the product were collected and the weights of each subpart of the printer were related to the materials. An analysis of the life cycle of the product was made using the SimaPro tool without taking into account energy consumption and transport and the results have been exercised by simulating different socioeconomic and cultural realities and material composition.

Considering the printer original material composition and the percentages of recycle (42\%), reuse $(27 \%)$ and landfill(31\%) disposal, defined as the reality of a specific area in Brazil, the indicators of global warming, climate change, Ozone layer depletion an fossil fuels use were evaluated and compared to 5 other different scenarios. 
The results found until now indicate that the printer evaluated would show a $25 \%$ reduction on fossil CO2 equivalent emissions by changing HIPS for ABS in some parts of the product and that the recycle efforts should be focus on some specific materials and improvements on take back logistics according to each social economic reality rather than on the entire equipment and similar process for different realities.

\title{
WORS10-07
}

\section{A multi-criteria comparison of solar photovoltaic systems using thin-film or crystalline silicon panels in a UK context.}

\author{
$\underline{\mathrm{R} \text { Howard, R Rogers }}$ \\ University of Bath, BATH, United Kingdom
}

The production, performance and economics of photovoltaics have continually improved over the last few decades in terms of cell efficiency, silicon usage, operational output and cost. Thin-film PV cells are becoming increasingly competitive with the more established crystalline silicon panel cells and intuitively it would be imagined that a cell which uses less material should have a lower environmental impact. This research compares the two classes of PV modules to see if one has a clear advantage in installations of similar capacity. The research uses a combination of financial analysis, life cycle assessment and a broader assessment of the impact of emissions from electricity generation to analyse the situation in the UK in 2012. The life cycle assessment has been conducted on a cradle-to-grave basis, which in contrast to most previous PV LCAs incorporates the downstream emissions and impacts associated with the disposal and recycling of the solar cells. Crucial elements looked at over the course of producing the life cycle inventory and conducting an impact assessment include: silicon and other material inputs, the UK and other power mixes assumed across the operational and production stages, process-specific emissions and the impact that the dismantling process, using recycled materials in construction and the final recycling of component parts has on the overall environmental performance of these PV cells. The performance of both types of cell is modelled for a cloudy and a sunny location of similar latitude using historic hourly solar radiation data. This will predict how the systems would perform under real ambient light levels and temperatures. The aim of the research is create a holistic understanding of the prospects and performance of decentralised solar systems in the UK and to see if there is a case for having different feed-in tariff rates for the two types of cells.

\section{WORS10-08}

\section{Use of LCA, LCC and SLCA-approach for sustainability assessment of water treatment technologies - a case study}

\author{
A Lehmann $^{1}$, M Finkbeiner ${ }^{1}, \mathrm{H}_{\text {Lehn }}^{2}$, J Kopfmüller ${ }^{2}$ \\ ${ }^{1}$ Technische Universität Berlin, BERLIN, Germany \\ ${ }^{2}$ Karlsruhe Institute for Technology, KARLSRUHE, Germany
}

Within an Integrated Water Resources Management project in Indonesia, alternative technologies for water treatment are analyzed with respect to their sustainability performance: Life Cycle Assessment (LCA) is conducted to analyze potential environmental impacts; additionally, Life Cycle Costing (LCC) is applied to consider economic aspects and Social Life Cycle Assessment (SLCA) is examined to include the social dimension as well. Four technologies are considered: ultrafiltration, chlorination, UV disinfection and slow sand filtration. They were tested in a pilote plant in Germany, which was then recently shipped to the projects' investigation area (Wonosari, Yogyakarta province) to continue the tests and to adapt the technologies to the local conditions. Preliminary investigations carried out in Germany identified energy consumption during operation as main contributor to potential environmental impacts. Consequently, ultrafiltration as energy intensive technology shows worst results; UV-disinfection slightly better ones than the chlorination. Regarding the economic dimension, the ultrafiltration technology has both highest acquisition $(\sim 8000 €)$ and operation costs; the latter results from the high energy demand $\left(\sim 12 \mathrm{kWh} / \mathrm{m}^{3}\right)$. Compared to ultrafiltration, the UV disinfection and chlorination technologies appear to be more cost effective due to their lower acquisition costs $(<4200 €)$, lower energy consumption $\left(\sim 0,5 \mathrm{kWh} / \mathrm{m}^{3}\right.$; leading to $90 \%$ of cost saving during operation) - and their high treatment capacity. Data for LCA and LCC were obtained from measurements in the pilot plant, LCA databases, own assumptions and literature; the technologies' life time (assumed to be 10 years) 
is considered in the calculations. The comparative technology analysis is based on the functional unit, defined as $1 \mathrm{~m}^{3}$ oftreated water, assuming that (for pre-filtrated water) a quality meeting the WHO standards can be achieved. However, the water quality differs; odour and taste of chlorinated water may be relevant for consumers' acceptance and thus should be considered in a social analysis. Regarding working conditions during operation: different risks for human health are related to the technologies, deriving from the use of the UV lamp, chemicals and cleaning agents (for ultrafiltration). From a life cycle perspective differences regarding the social performance of the technologies mainly occur due to different conduct of involved companies, but which are not known yet. Thus, related sectors (energy, transport, and chemicals) have been examined using the Social Hotspot Database (SHDB), which indicates medium to very high risks for social impacts in Indonesia and consequently a high improvement potential. Though nowadays sustainable development is a declared goal in many programs and policies, including water management in Indonesia, often costs are still the main drivers for most decisions. From this perspective, chlorination would be the preferable technology. Here, this coincides well with the results from the environmental analysis. However, results from the test phase in Indonesia have to be awaited. As it is crucial to consider the social dimension in decision processes, social risks have been determined using the SHDB and literature data. However, for the time being - and at least in this study (due to data uncertainty and lack of contextual data) they cannot be used to give valid recommendation regarding the choice of the more sustainable technology option.

\section{MPRS10-01}

\section{Selecting indicators in a life-cycle sustainability analysis of district heating}

\section{$\underline{\text { T Ekvall }}^{1}$, E Ahlgren ${ }^{2}$, O Cintas Sanchez ${ }^{2}$, A Fakhri ${ }^{2}$}

${ }^{1}$ IVL Swedish Environmental Research Institute, GÖTEBORG, Sweden

\section{${ }^{2}$ Chalmers University of Technology, GÖTEBORG, Sweden}

Sustainability is a broad concept with a large number of environmental, economic and social aspects. Any sustainability assessment can cover a selection of these aspects only. The choice of aspects and indicators is vital, since it can heavily affect the conclusions of the assessment.

We compare four methods to select indicators for a life-cycle sustainability assessment of the integration of district-heating systems on the Swedish west coast. They are distinguished by their level of generality (general or case-specific approaches) and by the type of actors involved in the selection (researchers and/or stakeholders). It is clear, from this comparison, that stakeholder involvement can greatly affect the choice of indicators. Our results indicate that stakeholders in a case-specific approach put a greater emphasis on economic indicators and less emphasis on environmental indicators, compared to an approach dominated by environmental researchers. The selection of indicators is, however, likely to depend on the selection of stakeholders involved.

A case-specific approach that involves stakeholders increases the chances that the results of the assessment are accounted for in the decision process. A general set of indicators for sustainability assessment, developed by researchers, risks being too long to be practical while still failing to cover indicators identified as important by stakeholders in individual case studies.

We found it effective to involve stakeholders in the selection of case-specific indicators through an OpenSpace workshop. A key challenge, in this context, is to obtain a sufficiently large and representative group of stakeholders to participate in the workshop. 


\title{
MPRS10-02
}

\section{LCA and SLCA of substitution alternatives for brominated flame retardants}

\author{
N Jonkers, L Brugman, H Krop, H Van Ewijk
}

IVAM UvA, AMSTERDAM, Nederland

Brominated flame retardants (BFRs) are used in a wide range of commercial products, but unfortunately sometimes have negative effects in the environment. Therefore, they need to be substituted by less harmful substances. Several halogen-free flame retardants (HFFRs) already exist on the market. However, the available information about their environmental and toxicological impact is limited. In the EU-project ENFIRO, the substitution options for BFRs are evaluated from both a technical, environmental and social perspective. For the Life Cycle Assessments, FRs in a laptop were chosen as case study.

Toxicity characterization factors of the FRs studied were determined using the USES-LCA2 model, and used in the ReCiPe method. Specific attention was paid to FR emissions during the use phase (volatilization from electronics) and in the waste phase (leaching from landfills). Formation of brominated dioxins out of BFRs during improper electronics waste treatment had a strong impact on the LCA-scores. Differences in energy use during FR production had a stronger influence on the environmental profiles of different FRs than (eco) toxicological effects due to environmental emissions of FRs.

A Social Life Cycle Assessment on BFR substitution was performed as well. Based on the SETAC/UNEP Guidelines, a method for data inventory, performance and impact assessment was developed. The SLCA focused specifically on the FR production phase, as the changes in impact were mainly expected in this phase.

\section{MPRS10-03}

\section{Role of the LCA in the planning of brownfield revitalisation}

\author{
KS Tóth, L Roncz \\ University of Miskolc, MISKOLC-EGYETEMVÁROS, Hungary
}

The need for the reintegration of brownfield sites has been increasing across Europe even in the world, in parallel the demand toward sustainability evaluation of these reusing activities has grown as well.

Due to the industrial restructuring and the collapse of heavy industry the number of brownfield sites had rapidly multiplied in the Central-European countries including Hungary. The management of brownfield sites is especially a big question for those areas and settlements which were heavy industrial centers. For example in Hungarian big cities like Miskolc or Salgótarján the socio-economic development has been limited by the large brownfield sites which became a 'natural' sight and part of the urban city structure as they are situated in and around the settlement. The rehabilitation of these footprints of the former heavy industry can be the key to the creation of reusable and livable urban spaces and a solution for the mitigation of environmental damage as well. However to assure these, a relevant assessment method is needed to choose the optimal ways among the options of re-usage.

Although generally accepted concept and method for measurement has not been introduced in Europe, either at national levels, but it would be important to determine general sustainability criteria for brownfield development. Such list of criteria would be useful since revitalization projects are supported, but we need to understand and perceive the economic, social and environmental consequences of these project achievements.

Recently, a growing number of literature address the rehabilitation of brownfield sites from which numerous taking a holistic approach or applying life cycle analysis making it clearly significant that it is important to assess the long-term impact of reuse and in this way to support decision making.

In this paper we focus on the brownfield sites of the North Hungarian region applying LCA approach considering not only the environmental but economic impacts and the social dimension of the reuse options. As a review, the current available researches should be analysed that can provide new conceptual approaches within the topic of brownfield revitalisation. Based on the literature and former experiences a more accurate indicator framework can be built on the special cases, which all together can lead to a proposal on applied project indicators of tendering schemes for brownfield revitalisation support of Regional Operative Programmes. Moreover LCA analysis can give an exact feedback on the environmental impact remediation efforts in light of the regional goals. 


\title{
MPRS10-04
}

\section{Supply chain planning with sustainability considerations: A multi-objective modeling approach}

\author{
M Birkved $^{1}$, Y Wang $^{1}$, R Akkerman ${ }^{2}$, M Grunow $^{2}$ \\ ${ }^{1}$ Technical University of Denmark, KGS. LYNGBY, Denmark \\ ${ }^{2}$ Technische Universität München, MÜNCHEN, Germany
}

This work proposes a modelling framework for combining supply chain planning and sustainability assessment, illustrating how sustainability assessments of logistic activities can be improved by supply chain planning input, and especially that supply chain planning can in turn make use of the results from sustainability assessments. We use mathematical programming for the supply chain planning and life cycle assessment for the modelling and quantification of the environmental impacts. We illustrate the benefits of our integrated framework for a case of production, distribution and storage of food products produced on industrial scale, studying several important planning decisions like temperature treatments and choice of packaging materials.

By analyzing the resulting supply chain decisions, we are able to present a comprehensive overview of economic considerations and environmental impacts. The framework is widely applicable and leads to more comprehensive economic and environmental assessment of supply chains. Trade-offs between these two dimensions of sustainability are in this way easier to quantify and illustrate.

Even though we only discuss one case example in this paper, we feel that the framework presented is widely applicable and leads to a more comprehensive sustainability assessment. We used the case to show that our framework is especially beneficial in the design of supply chains, and the introduction of new technologies or product concepts.

\section{MPRS10-05}

\section{Life cycle sustainability assessment for the production of high-grade concrete from construction and demolition waste}

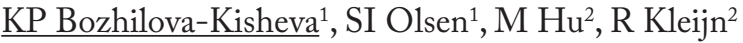 \\ ${ }^{1}$ Technical University of Denmark, LYNGBY, Denmark \\ ${ }^{2}$ Leiden University, LEIDEN, Nederland
}

Life cycle sustainability assessment (LCSA) aims at assessing a system from three different perspectives environmental, economic and social. The assessment of the three different aspects are based on methodologies, standards, codes of practice or guidelines, setting certain rules and limitations on how to approach the assessed product, service, technology or system with respect to the functional unit, cut-off rules, etc. Can the same rules and guidelines hold when conducting the three assessments together? Is there any overlap between the assessment and how do we define this overlap? Is it enough to define the functional unit of a life cycle sustainability study according to the rules for conducting (environmental) life cycle assessment or is it also necessary to consider social and economic aspects when defining the functional unit?

Under the framework of the FP7 EU Project Advanced Technologies for the Production of Cement and Clean Aggregates from Construction and Demolition Waste, a case study in life cycle sustainability assessment is conducted for the production of high-grade concrete from construction and demolition waste. The study presents results from the separately conducted assessments in accordance with the state-of-the-art methodology and review of methodology application for each assessment and on the basis of the available data at the current stage of the project. The case study analyzes areas of overlap between the different assessments, necessity of change in cut-off rules, necessity to include other aspects of the assessed product, service, technology or system, which are also relevant for the life cycle costing and social life cycle assessment).

Acknowledgements: This abstract is realized through the financial support of the European Commission in the framework of the FP7 Collaborative project Advanced Technologies for the Production of Cement and Clean Aggregates from Construction and Demolition Waste (C2CA), Grant Agreement No 265189. 


\title{
RS-11: LCA of transportation and communication
}

\section{WORS11-01}

\author{
Comparative LCA of an electric light weight and conventional vehicle in urban driving
}

HE Dura ${ }^{1}$, M Weil $^{1}$, AT Aebi $^{2}$

${ }^{1}$ KIT/ITAS, KARLSRUHE, Germany

\section{${ }^{2}$ S.A.M. Group AG, OENSINGEN, Switzerland}

Resource consumption and emissions have become a major problem of individual passenger transport (IVT). Improvements of efficiency measures of conventional internal combustion engine vehicles (ICEVs) were not able to offset the overall trend of increasing transport volume, increasing size of the vehicle fleet as well as individual vehicles. At the same time an increasing discrepancy in terms of vehicle properties and actual mobility needs can be observed. Thus, depletion of fossil resources, air pollution and global warming caused by the transport sector remain significant environmental problems.

One option to solve these is the design of completely new types of vehicles with alternative propulsion systems, such as electric vehicles (EV), and light weight constructions to enable a new kind of mobility. In order to identify possible ecological advantages or drawbacks, a comparative life cycle assessment (LCA) of a conventional most frequently used ICEV and a light weight EV was conducted. The assessment was performed in the context of problems arising from IVT such as over dimensioning of current vehicles, resulting direct and indirect air pollution and resource depletion as well as noise disturbance. Thus, the study is not aiming at a direct technology comparison, but rather evaluates the use of a prospective vehicle specifically designed for urban commuting as opposed to a conventional all round vehicle.

The performed LCA included all three life cycle stages of the vehicles: production, use and end of life treatment. In a base line scenario both vehicles' lifetime was set to $150.000 \mathrm{~km}$, where the life time of the EV-battery was set to $75.000 \mathrm{~km}$. Two alternative scenarios were considered: (1) 100\% renewable energy for production as well as propulsion and (2) prolonged life time of the vehicles of $300.000 \mathrm{~km}$. Results show that the light weight EV has a substantially lower environmental impact than the conventional ICEV. Different driving factors of the environmental burdens were identified. While the production phase, the indirect emissions from electricity generation and the lifetime significantly contribute to the environmental performance of the EV, the indirect and direct emissions during the use phase are the largest for the ICEV. Due to the light weight construction of the EV it only requires a small battery $(7 \mathrm{kWh})$, significantly reducing its ecological impact.

Since the consumers' acceptance of a vehicle is largely determined by the use phase, possible benefits and shortcomings of the vehicles in urban application were additionally assessed in a more holistic comparison using a benefit analysis. The assessment was based on target criteria, reflecting current problems of IVT in urban areas. The EV fulfills most mobility needs desired in range, size and space as well as direct emissions to air, which are non-existent due to the electric drive train. On the other hand the criterion of noise emissions is somewhat overachieved. Also the ICEV has a good performance in most criteria; however, it significantly over-achieves mobility needs in a lot of criteria such as size and range and performs very badly regarding direct air emissions and noise.

This leads to the conclusion that small sized light weight vehicles with an electric drive train have the ability to reduce a majority of the problems arising from urban IVT, while at the same time providing the necessary amount and quality of mobility. 


\title{
WORS11-02
}

\section{Meta-analysis of lithium-ion traction battery LCAs}

B Simon

Helmholtz Institute U1m, EGGENSTEIN-LEOPOLDSHAFEN, Germany

In the $20^{\text {th }}$ and $21^{\text {th }}$ century the importance and usage of electricity have been increasing, due to the versatile field of application. The use of electricity as fuel for personal and goods transportation gives chance to decrease of local air pollution, noise and other anthropogenic impacts. The electric energy storage system can be considered as the key element of electric propulsion and demands advanced technologies to fulfill the requirements of driving range (energy density), -speed (power density) and -behavior (load characteristic). Lithium ion batteries (LIBs) have sufficient power- and energy density, in comparison to other electrochemical energy storage systems to fulfill the requirements for appropriate driving range and -speed of full electric vehicles. But which environmental burdens are connected to the production and use of such an energy storage systems?

Life cycle assessment (LCA) offers an excellent method for the identification of environmental impacts regarding new production technologies. Despite of the standardized procedure and scientific interdisciplinary fundaments, significant differences could be identified between LCAs of the same product. What are the causes of these deviances? The systematic comparison of the considered case studies helps to understand the applied methods, points out the used assumptions and uncertainties.

The conducted meta-analysis investigates the following five LCA studies of lithium ion traction battery production can be found among the international public papers:

Majeau-Bettez et al. (2011) (Environ. Sci. Technol. 2011, 45, 4548-4554);

Notter et al. (2010) (Environ. Sci. Technol. 2010, 44, 6550-6556)

Zackrisson et al. (2010) (JOCP 2010, 18, 1519-1529);

Bauer (2010) (Study of Paul Scherrer Institute Switzerland) and the

USEPA (2012) Study of US EPA Program DfE; EPA 744-R-12-001 Lithium-ion Batteries and Nanotechnology for Electric Vehicles: A Life Cycle Assessment

The issues of composition of battery cell and -pack; quality of used datasets; functional unit; system boundaries; sensitive assumptions; differences in results; feasibility of comparison were discussed. The result helps to understand the reliability of present LCAs in this field, which are cited and used in further studies.

\section{WORS11-03}

The environmental impact of fluid milk delivery systems for the in-home consumption in the U.S. - LCA study

\author{
J Burek, G Thoma, DS Kim \\ University of Arkansas, FAYETTEVILLE, United States of America
}

The purpose of this LCA, funded by Innovation Center for U.S. Dairy, was to provide the U.S. milk processing and packaging industries with information that would allow them to engage in more sustainable approaches, reduce environmental impacts, and validate those reductions through science-based LCA models.

The system boundaries encompassed the following life cycle (LC) stages: raw milk production, container material and formation, milk processing, distribution, consumption, and disposal of containers. It also included milk loss across the LC stages. In addition, the results of the post-farm gate supply chain were reported. Total of 12 in-home and 6 on-the-go delivery systems were modeled and here the main results the in-home consumption containers were presented: 1 gallon ( 4 liters), 1/2 gallon ( 2 liters), and 1 liter polyethylene $(\mathrm{PE})$, polyethylene terephthalate (PET), and paperboard based chilled and ambient containers.

A set of LCIA models from the most recent impact assessment methods available was selected: IPCC's climate change, ReCiPe's marine eutrophication, photochemical oxidant formation, and freshwater eutrophication, USEtox's human toxicity and ecotoxicity impact categories, and ReCiPe's damage category, ecosystems.

The total average LCIA results of the dairy delivery systems per 1,000 $\mathrm{kg}$ milk consumed were as follows: 
climate change 2,070 kg CO, e, non-renewable fossil energy 12,553 MJ, freshwater depletion $201.42 \mathrm{~m}^{3}$, marine eutrophication $4.68 \mathrm{~kg} \mathrm{~N}$ eq., photochemical oxidant formation $7.06 \mathrm{~kg}$ NMVOC, freshwater eutrophication $0.98 \mathrm{~kg}$ P eq, ecosystems $5.49 \mathrm{E}-05$ species.yr, human toxicity $4.54 \mathrm{E}-05 \mathrm{CTUh}$, and ecotoxicity 10,363 CTUe. The raw milk production contributed across the impact categories from 25 percent to 98 percent with the largest impacts (>90 percent) to water depletion (irrigation at farm field), eutrophication (nutrient run-off), ecotoxicity, and damage to ecosystems. In the post-farm gate assessment (excluding raw milk) the container LC stage contributed from 1 percent to 50 percent across the impact categories, and the processing plant stage between 1 and 85 percent, with the largest contribution to climate change, non-renewable fossil energy, toxicity, photochemical oxidant formation, and ecosystem categories for the container LC stage and eutrophication for the milk processing LC stage.

The LCIA results of the post-farm gate assessment show differences in environmental impacts arising from the container packaging (material and conversion) and distribution mode (ambient or chilled); however, the main impact drivers were similar across the options: climate change is driven by the electricity, container material, and refrigeration where applicable; non-renewable fossil consumption by the container material and transport; water depletion by water use in the clean-in-place (CIP) process at the processing plant stage, and dishwashing at the consumption stage; eutrophication by the waste water treatment (WWT), toxicity by coal mining tailings disposal, and total ecosystem impact by climate change related impacts and land use related activities. To conclude, reductions in irrigation and nutrient run-off in farm milk production and, in the context of the packaging and processing plant stages, energy consumption along with reduction in CIP and WWT volume will have broad beneficial impacts, both environmental due to the reduction in emissions related to water and fossil energy, as well as, economic through cost savings.

\section{WORS11-04}

\section{High speed rail in Norway: Method, results and reception in use of LCA for policy analysis}

\section{IB Pettersen, H Håvard}

\section{MiSA, TRONDHEIM, Norway}

The Norwegian Railway Authority recently completed an evaluation of high-speed concepts covering several possible end-stations for a line from Oslo. The greenhouse gas emissions (GHG) analysis is presented here, describing the analysis method, results found, and the reception of the study in the public debate regarding high-speed rail development.

The LCA model covers scenarios for high-speed rail and competing long-distance transport in Norway. All technologies are modeled with technology improvement up to 2050. Market and energy data are extracted from the complementary studies within the assessment, with markets modeled for generated and transferred traffic up to 2060. Draft alignment plans were developed by four planning groups, detailing alignment route and type of line end-to-end on all corridors. In all, the GHG evaluation covers 12 high-speed rail alignments, each representing new line distances of $230-560 \mathrm{~km}$. Several of the proposed alignments have more than 50\% of the distance in tunnels.

The GHG evaluation shows that the best carbon payback period for an investment in high-speed rail is 36 years, for one of the alignments proposed between Oslo-Trondheim. Two of the alignments connecting OsloBergen also have positive payback periods. None of the other alignments pay back in terms of GHG emission within the 60 year assessment period. Scenario analysis shows that the main results are robust for technology development in transport and electricity markets.

We identified infrastructure challenges and market issues to control the carbon performance of high-speed rail. A review of international high-speed rail markets shows the Norwegian situation to be at the low end of the scale. A mountainous landscape leading to large portion of tunnels only increase the emissions related to development of the line. Although electricity for operation is relatively clean, the small market cannot counter large emissions in construction of the line. Lines that do show positive GHG effects within the assessment period have significant transfer of passengers from air traffic.

Our evaluation shows improvements that would significantly reduce emissions and shift the ranking of payback period for the lines. These were not considered in the original assessment due to time constraints and limitations in the assessment scope, but are tested for the purpose of this paper. Improvements include slight adaptations in the requirements regarding train speed and better line scheduling, with large effects on some of the described rail alignments.

How has the study been received in the public debate? Market and economy has been the main focus in the 
debate, which points to expanding the commuter line towards the south of Norway as the most interesting concept. From a GHG perspective however, this requires a large tunnel share and leads to very little transfer of traffic from air, and is therefore not promising as a GHG reducing measure. The discussions both before and after release of the final report showed the misunderstandings present regarding operational phase and construction, where the significance of construction is underestimated by many. Extrapolating GHG assessments for European lines has not showed very useful, as the markets served cannot be compared. On a large scale, most stakeholders consider high-speed rail to be a commuter system rather than a service for national long-distance transport.

\title{
MPRS11-01
}

\section{LCA comparison of two systems for bread packaging and distribution}

\author{
S. Koskela ${ }^{1}, \mathrm{H}_{\mathrm{Dahlbo}}{ }^{1} \mathrm{LJudl}^{1}, \mathrm{M}-\mathrm{R}$ Korhonen $^{1}, \mathrm{M}^{\mathrm{Ninninen}}{ }^{2}$
}

${ }^{1}$ Finnish Environment Institute, HELSINKI, Finland

${ }^{2}$ Stora Enso Oyj, IMATRA, Finland

Typically, packaged bread is delivered from bakery to retailers in plastic crates, which serve as secondary packaging during the transportation and storage of bread. An alternative to the plastic crates could be the use of corrugated cardboard boxes (CCB). The goal of this study was to compare the life cycle environmental impacts of the two product systems for bread distribution and delivery. The main difference between the systems was the material of the distribution crates, either plastic or corrugated cardboard. The main focus of the study was on the distribution of bread from bakery to retailers. However, the product systems also included the manufacturing of delivery boxes and packaging materials for the bread, bread making (including agriculture) and the waste management of bread residues and crates. The functional unit of the product systems was 8 loaves of bread delivered in one crate/box to retail.

We compiled the study as a matrix LCA. The main sources of data were site-specific manufacturing data, generic data from LCI databases and previous studies. The impact categories analysed in the LCIA were: climate change, terrestrial acidification, freshwater eutrophication, photochemical oxidant formation, particulate matter formation, fossil depletion and cumulative energy demand.

The delivery network in our systems covered the whole of Finland. Transportation was a significant contributor to the environmental impacts, thus, transport distances, modes of transport and load were the most important variables. Typically in LCA, transport emissions are calculated with a weight-limited approach. This approach does not take into consideration volumes of the transported loads which might be a crucial issue for lightweight products large in volume. Therefore we implemented another method of calculating transport emissions. We combined the methodology of the Finnish calculation system for traffic exhaust emissions, Lipasto, with generic LCI data. This allowed us to calculate the impacts of transport in a more case-specific manner.

The results show that the environmental impacts of manufacturing one plastic crate are higher than those of one CCB box, but the fact that crates are reused 700 times decreases the impacts notably. However, our study indicated that the overall impacts of the plastic crate system are higher than those of the CCB box systems. This is mainly due to the fact that a plastic crate is heavier than a CCB box which has an effect on the transportation emissions. The impacts of the CCB box systems are lowered by recycling of the fibres. The overall conclusion is that replacement of plastic crates by CCB boxes in bread delivery has a reduction potential in all of the analysed impact categories.

We encountered several methodological issues during the study. One of them was the carbon sequestration in forests, which plays an important role in the life cycle of wood fibre based products (here the CCB box). Unfortunately no scientific consensus has yet been reached to incorporate $\mathrm{CO}_{2}$ removal of forest in product specific assessment. Therefore we applied a conventional approach and allocated no benefit from carbon sequestration to CCB box system. We propose that sequestration of carbon should be included in the calculations when the scientific consensus has been reached.

This study was conducted as part of the MMEA research programme managed by the Cluster for Energy and Environment and funded by TEKES and the participating partners. 


\title{
MPRS11-02
}

\author{
Life cycle assessment of the innovative electric vehicle concept MUTE \\ B Reuter, C Imser \\ Technische Universität München (Technical University Munich), GARCHING / MUNICH, Germany
}

Electric cars are expected to play a key role in creating a sustainable way of living based on renewable energy forms. The focus today is set mainly on greenhouse gas emissions, which are responsible for global warming, while other environmental damage receives less attention. In particular, the production of an electric vehicle battery is responsible for a significant share of its overall environmental impact, especially through the emission of acidic substances. The size of the battery not only plays a vital part in the total environmental balance of the vehicle, but is also a key parameter for its economic competitiveness and usability. For these reasons, the Technische Universität München has developed an innovative concept for an electric vehicle that stands out due to its low weight and thus its high driving efficiency. The aim was to create a product profile for the everyday use of a high share of the European population, rather than to integrate all available functionalities for a maximum number of possible applications. Safety and cost, of course, were still fundamental aspects throughout the entire development process. The result is called MUTE, a small-scale car for two passengers with a curb weight of only 500kg including a $100 \mathrm{~kg}$ battery pack which enables a range of more than $100 \mathrm{~km}$ due to its high driving efficiency with a consumption of only $7.5 \mathrm{kWh} / 100 \mathrm{~km}$ (NEDC). The high efficiency allows a reduction in the necessary battery capacity, which in turn decreases the vehicle's purchase cost and its environmental impact during both manufacture and use.

In order to evaluate the advantages of this vehicle concept, a life-cycle assessment (LCA) has been conducted and all relevant indicators have been compared to those of conventional vehicles with an internal combustion engine (ICEV) and battery electric vehicles (BEV). For this study, we used the LCA software GaBi 5.0 with data provided by its related database as well as data from ecoinvent V2.2. The impact of manufacture, use and disposal were assessed for a scenario of a total mileage of 120,000 km within a vehicle lifetime of 10 years. Thus, the indicators for global warming potential, ozone depletion, acidification and eutrophication were calculated (according to CML 2001) together with damage to human health and ecosystems (according to Eco-Indicator 99).

The results show that the production phase is responsible for a larger share of the overall environmental impact than in the case of ICEV.It is also observed that the greenhouse gas emissions are significantly lower compared to other BEV, not only during use, but also during the manufacturing process. Furthermore, the possibility of using a relatively small-sized battery without constraining the vehicle range decreases significantly the associated emissions and thus improves the environmental impact of the vehicle.

The vehicle concept described above has several advantages such as low environmental damage, low energy consumption when driving and reduced costs due to the modest requirements in terms of installed battery capacity. Further, the decreased amount of necessary raw materials means a high efficiency in material and resource use. All these beneficial effects show that the approach of noticeably downsizing BEV should seriously be considered by car producers and policy makers, in order to obtain both high environmental compatibility and improved economic competitiveness of BEV compared to conventional ICEV.

\section{MPRS11-03}

\section{Ecodesign of operating energy rack for full electric vehicle}

IS Sanfelix, MM Messagie, S Rangaraju, JV Van Mierlo

Vrije Universiteit Brussel, BRUSSELS, Belgium

Reducing carbon emissions from road transport as well as the increase of fuel price in the last years together with the uncertainty in oil supply security are important issues within the European framework that makes vehicles with electric propulsion (hybrid or full electric cars) to be considered as an attractive option in the pathway towards low emission vehicles. This possibility implies that large scale productions of different components for electric vehicles (batteries, racks, cells, etc.) need to be developed to improve the deployment of the electric vehicles in Europe.

The Operating Energy Racks for Full Electric Vehicles project (OPERA4FEV) is a European project under the 7th Framework Programme of the European Commission. It aims at improving the manufacturing of the 
benchmark battery racks in a more eco-friendly way. In order to obtain a product with same characteristics as the current one but with enhanced environmental competences, the metal will be switched to thermoplastic as a main component and all the parts involved in the rack (cooling system, printed circuit boards..) will be redesigned.

To carry out the redesign of the mentioned rack, the life cycle assessment (LCA) methodology has an important role in the whole project. It will be used to assess the potential environmental impact of the different options considered in the study. Following this methodology, several scenarios will be modelled and performed. As part of the work that will be carried out using LCA it is included a Key Environmental Performance Indicator (KEPI) at the beginning of the study; once the materials and components of the battery rack have been defined after the KEPI, a complete LCA of a full electric vehicle will be performed to compare the use of a current battery rack and the one that has been redesigned in the project.

By applying LCA as methodology for the ecodesign of the presented project, the aim is also to identify weak points during the entire LCA study; from the goal and scope definition and functional unit to data collection and impact assessment. This way it is meant to propose solutions to the weak points found and obtain a tailored methodology to apply LCA for ecodesign for electric vehicles.

The purpose of the present poster is then to present the work planned to be carried in the LCA part of the OPERA4FEV project and to include some of the preliminary results obtained in the first tasks already carried out.

\section{MPRS11-04}

\section{Challenges in assessing environmental impacts of smartphones}

\section{JJudl, J Seppälä, T Mattila, S Koskela, P Kautto}

Finnish Environment Institute, HELSINKI, Finland

Mobile communication has grown rapidly in recent years, lead by a five-fold increase of cellular subscriptions during the past decade. The growth has been driven to a large extent by increased demand for communication services particularly in developing countries ( $75 \%$ of cellular subscriptions worldwide), such as China or India. According to current statistics more than six billion people use mobile phones and there are about a billion mobile broadband subscriptions worldwide. About one fifth of all mobile phones in use today are smartphones, devices closely reliant on mobile broadband.

In terms of environmental sustainability assessment, improving material and energy efficiency of mobile devices or reducing packaging has been one of the main visible activity in the industry. To our knowledge, only a few published scientific studies actually focus on environmental impacts of other parts of the system of mobile communication. This can be for example the externalized energy consumption in 'cloud services' and networks. In our opinion, omitting energy consumption, construction and maintenance of mobile networks and of the Internet in the sustainability assessment of mobile devices produces a wrong overview about environmental impacts of smartphones and mobile communication as such. Expanding the system boundary and including these is essential for understanding the real environmental consequences of the use of smartphone devices. This approach however brings new challenges, such as understanding the behaviour of networks in relation to the user profile or allocation of energy consumption within the network to different tasks which it performs. In our research within the FP7 PROSUITE project, we focus on identifying these challenges and we try to define a methodology for life cycle assessment of mobile communication from the viewpoint of environmental sustainability assessment. We focus on analyzing the environmental impacts associated with both production and use of the devices as well as of the mobile networks and the Internet, without which they could not function. However, we do not see smartphones only as resource consumers. Due to their multifunctionality they also have the potential to help to reduce environmental impacts of various human activities, e.g. through remote applications or by replacing dedicated devices. We demonstrate our approach on a case study. It illustrates how production and use of smartphones are associated with environmental impacts. The study shows that the impacts mostly depend on the way how consumers use their devices. This causes both challenges and opportunities in terms of sustainability development in the future. 


\title{
MPRS11-05
}

\section{Challenges in environmental assessment of new media solutions - case studies of Alma Media newspapers}

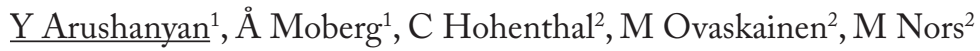 \\ ${ }^{1} \mathrm{KTH}$ Royal Institute of Technology, STOCKHOLM, Sweden \\ ${ }^{2}$ VTT Technical Research Centre of Finland, HELSINKI, Finland
}

In the media sector, recently new means of distribution, new platforms for accessing media and consequently new media products have been introduced. With new products potential environmental impacts related to activities of media companies are changing. Finnish media publisher Alma Media commissioned an LCA study in order to learn more about environmental impacts related to their mature and emerging products. Based on this, the current paper aims to present potential environmental impacts related to printed and online newspapers, focusing on their differences and challenges in assessing, comparing, communicating and acting on the results. Three newspapers are studied as cases, covering upstream printing house supply chain, printing house activities, delivery to readers and final disposal for print versions; electronic storage and distribution, the relevant share of electronic devices manufacturing and disposal and electricity needed for downloading and reading for online versions; content production for both.

Mainly generic data was used for online products assessment, since specific data were not available. The specific data for the more mature print products were detailed but less comprehensive than generic. The implication is increased uncertainty and difficulties in communication of results. Environmental performance of both printed and online newspapers is dependent on various characteristics of the newspaper and its readers, including e.g. format and number of pages for print versions, and type of device used and its total use, size of content download and reading time for online versions. User practices may be changing as emerging products get more mature, which will influence environmental performance.

Print and online versions give rise to different types of environmental impacts and the distribution of impacts in the life cycles differ. Printed newspaper impacts largely occur in the printing house supply chain and in delivery to readers, whereas online newspapers impacts are mainly connected to the electronic devices supply chain, and to some extent electricity used for reading and distribution. Impacts of printed newspapers studied occur more locally with paper manufacturing and printing located in Finland. Impacts related to online versions largely occur in other countries. Also, new value chain actors are involved, which are not directly related to the media company. Different actions for improvement may be necessary for emerging media products, as well as new types of collaborations.

Comparison of online and print versions is not straightforward as different benefits are provided and reader practices differ. Although emerging media products may be considered substitutes for print counterparts, this is not necessarily the case. The choice of functional unit of assessment proved crucial for the comparison. Different functional units were used (one year, one reader and week, one reading hour). Comparing print and online versions Alma Media online newspapers showed lower environmental impacts than their print versions per year and also per reader and week. However, impacts per reading hour were lower for printed newspapers in some cases. Using different kinds of perspectives, e.g. through different functional units, gives more information and increased knowledge. Complexity in assessing, comparing, communicating and acting on emerging media products was experienced in this study. Further studies and action need to be taken. 


\section{MPRS11-06}

\section{Carbon and ecological footprints of a magazine: Print vs. tablet editions}

M Achachlouei, Å Moberg

KTH Royal Institute of Technology, STOCKHOLM, Sweden

Information and communication technology (ICT), in competition with traditional applications, is providing new ways to access media content. Similar to print media, ICT-based media has environmental benefits and burdens alike. The overall goal of the present study is to assess the potential environmental impacts"'from a life cycle perspective"'of a print magazine with its electronic version read on tablets. Important goals are to identify which activities give rise to the main impacts, in both print and tablet editions, and to identify the key factors influencing the overall environmental impacts, in both editions. Moreover, data gaps and uncertainties are addressed.

The methodology used in the study is life cycle assessment (LCA). The environmental impacts assessed include climate change, cumulative energy/exergy demand, metal depletion, photochemical oxidant formation, particulate matter formation, terrestrial acidification, freshwater/marine eutrophication and fossil depletion.

The results indicate that it is hard to compare print and tablet editions of a magazine due to difficulties in defining the function, and that different functional units indicate different preferences in terms of environmental impacts. Also, differences between emerging (low number of readers and low reading time per copy) and mature (high number of readers and higher reading time per copy) tablet versions leads to various results in the comparison between print and tablet versions.

The studied tablet version in its emerging stage gives rise to higher potential environmental impacts per reader than the print version; however with an assumed mature tablet version the impacts are generally lower per reader. This illustrates clearly the importance of the number of readers to spread the environmental impacts over. 


\title{
RS-12: LCA of food products
}

\section{MPRS12-01}

\author{
Sustainability assessment of diets-environmental and health aspects
}

EM Karlsson, CM Witthöft, KE Röös, MCE Sundberg

Swedish University of Agricultural Sciences, UPPSALA, Sweden

Food choices affect both the environment and health. When assessing the sustainability of diets both these aspects need to be considered. Health impacts as a consequence of dietary habits and environmental impacts from food production occur at different stages of the food chain. The present interdisciplinary study presents a detailed evaluation of health effects from dietary habits and an environmental assessment, linking food intake and primary production. The aim was to develop a model for evaluating whole diets from both environmental and health perspectives. In a case study this model was used to compare three Swedish diets: the Swedish Nutrition Recommendations Objectified (SNO) as the recommended diet from the Swedish National Food Agency, the habitual diet of the Swedish population as assessed in the national food consumption survey "Riksmaten 2010-11" and a Low Carbohydrate High Fat (LCHF) diet which is popular but under debate regarding environmental sustainability and effects on health. The food production required for the intake of a specified amount of each food item was estimated using published factors for waste in the food chain and weight losses during cooking and preparation of foods. Three environmental impact categories were included: global warming potential, land use and land use biodiversity damage potential (BDP). Data was gathered from previous LCA studies for global warming potential and land use. Land use and its location were determined from statistics on yield and trade. BDP from land use was assessed applying the method developed by de Baan et al. (Int J Life Cycle Assess 2012). The number of primary products included was limited to 50, due to the level of detail in food intake statistics and the availability of LCA data and yield statistics. The health impact of the diets was determined by evaluating the intake of energy, macro- and micronutrient for compliance with Nordic Nutrition Recommendations 2004. For the LCHF diet a land use of around 0.44 ha land per capita was required, substantially higher than the current Riksmaten diet with 0.33 ha and the recommended SNO diet with 0.25 ha. For all diets, around $60 \%$ of the land use was located in Sweden and around 30\% in Europe. The LCHF diet had a Global warming potential of 2.3 ton $\mathrm{CO}_{2}$-eq per capita and year compared to the Riksmaten and SNO diets with 1.7 and 1.4 CO -eq, respectively. Biodiversity damage potential (BDP) was dependent on area occupied, therefore the LCHF diet with the highest land use had the highest BDP.

The recommended SNO diet showed, as expected, compliance with dietary recommendations for all microand macronutrients, demonstrating that the new model is valid. The other two diets Riksmaten and LCHF resulted in too high intakes for particular nutrients, e.g. saturated fatty acids and cholesterol, and in a too low intake for e.g. fiber, which is detrimental for sustaining health potentially promoting e.g. cardiovascular diseases and cancer.

Summarizing, the new model allows for a simultaneous evaluation of diets from environmental and health perspectives. It provides a tool for estimating health and environmental impact when modulating diets according to either national public health or environmental targets.

\section{MPRS12-02}

\section{Life cycle analysis of pesticide affects: case of tomato production in greenhouses in Antalya}

\section{Yelboga, MNM}

Akdeniz University, ANTALYA, Turkey

Tomato production in Antalya sub-region maintains its importance for both domestic and overseas market. In the region, tomato is produced and cultivated through different production techniques. However, the product for which the most input is used per area is tomato, in Antalya province. The objectives of the study are to assess and analyze the affects of pesticides use for tomato production in greenhouses in Antalya. This study is based on experimental data from fields, gathered through a survey and observations of producers' methods of production. Survey is conducted via face-to-face questionnaires with producers. Therefore, the sampling method is used to determine the number of producers. The survey is made in different locations using the classified random sampling 
method in the research.According to sampling calculation,148 conventional small-scale producers are interviewed.

Life Cycle Assessment method used in this project is one of the ecological analyses. In the study, the evaluation is carried out in the categories of abiotic depletion, acidification, eutrophication, global warming, toxicity, freshwater and seawater ecotoxicity. The materials emitted to water with the usage of pesticides bring along accumulation by subsiding in water. Accumulated materials cause toxicities by moving towards sea with flowing waters and rains. Therefore, environmental impact to the marine water is high in this study. Producers play important role in ensuring the sustainability of available possibilities and resources for the future. Hence, the regulation and consumption of pesticides should be registered and supervised by authorities.

\section{MPRS12-03}

\section{Comprehensive life cycle Assessment for cheese and whey products in U.S.}

DS Kim ${ }^{1}$, G Thoma $^{1}$, DW Nutter ${ }^{1}$, R Ulrich ${ }^{1}$, G Norris ${ }^{1}$, F Milani ${ }^{2}$

${ }^{1}$ University of Arkansas, FAYETTEVILLE, United States of America

${ }^{2}$ University of Wisconsin, MADISON, United States of America

A comprehensive cradle-to-grave life cycle assessment (LCA) has been conducted to determine a baseline for the environmental impacts associated with cheddar and mozzarella cheese consumption in the United States. SimaPro 7.3 was used as the primary modeling software. Operational data was collected from 17 cheese manufacturing plants representing $38 \%$ of cheddar production and $24 \%$ of mozzarella production in the U.S. Incoming raw milk, cream or dry milk solids are allocated using a milk solids mass balance. Revenue-based allocation was applied for remaining in-plant processes. For an average moisture content of 36.8\% for cheddar as sold at retail, the carbon footprint is $8.60 \mathrm{~kg} \mathrm{CO}$ e per $\mathrm{kg}$ cheddar cheese consumed with a $95 \%$ confidence band of 5.86 to $12.2 \mathrm{~kg} \mathrm{CO}_{2} \mathrm{e}$ per $\mathrm{kg}$ consumed. Additional metrics and normalization of the results are also discussed.

\section{MPRS12-04}

\section{The LCA of extraction processes in the food industry}

S Decossin, E Vermersch, A Allard

Institut Catholique des Arts et Métiers (ICAM Lille), 6 rue Auber, 59000 LILLE, France

Safe products, sustainable processes and employment are more and more attractive for the food industry in Europe.

The meCagrO2 project answers to this demand by the creation of a researches and innovations cross-border platform to enable the sustainable development of the food industry.

The meCadrO2 involves four universities: ICAM and ISA (France), the University of Exeter (England) and KaHo Sint-Lieven (Belgium).

The contribution of the Energetics department of ICAM (Institut Catholiques des Arts et Métiers) in the meCagrO2 project is about the activity 2. The research field of this activity is on processes of vegetable oil extraction (hydrodistillation and extraction with subcritical fluids) and cooling (vacuum cooling and superchilling) in the food industry. In an environmental point of view, it is about study the life cycle assessment, the carbon footprint, the evaluation of the global Supply Chain and food wastes metrics and by-products valorization.

More particularly, our researches deal with the development of new evaluation methods of the environmental impact and new processes.

Our final goal is to obtain a criticism of the environmental impact measure trough a life cycle assessment, first on the hydrodistillation process and then on the process of extraction with subcritical fluids. 


\title{
RS-13: Sustainability of materials and manufacturing technologies
}

\section{MPRS13-01}

\author{
Life cycle inventory of some selected industrial minerals: A study from the IMA-Europe
}

\author{
A Shtiza, R Doome, MW Wyart \\ IMA-Europe, BRUSSELS, Belgium
}

The European Industrial Minerals Association (IMA-Europe) is an umbrella association which brings together nine European and one international association covering more than 500 producers in the field of industrial minerals. IMA members are specialised in manufacturing tailored products based on the needs of the market and various applications. The main industrial minerals covered by IMA-Europe are the following: calcium carbonate (CCA-Europe); borates (EBA); lime (EuLA); andalusite, mica, sepiolite \& vermiculite (ESMA); bentonite (EUBA); feldspar (EUROFEL); silica sand (EUROSIL); talc (EUROTALC); diatomite (IDPA); kaolin and plastic clays (KPC-Europe). Industrial minerals exist around us and form an integral part of modern life: a family house contains up to 150 tons of minerals, and a car up to $250 \mathrm{~kg}$. Minerals make up $50 \%$ of paint and up to $50 \%$ of paper, whereas ceramics and glass comprise $100 \%$ mineral content. Industrial minerals are also essential components of today's most eco-efficient products and technologies such as wind turbines and photovoltaic panels.

Awareness about the impact of products and services on the environment has induced various companies to apply widely known methods and standards to quantify the environmental impact of their products. In order to respond to authorities and to provide European average representative environmental footprint values, IMA-Europe conducted a life cycle inventory (LCI) study for its member companies, following the ISO 14040-14044 standards. Eight industrial mineral products were selected for the IMA LCI, namely: calcium carbonate, ball clay, crude blended feldspar, dry milled feldspar, dry silica sand, kaolin coarse filler, very fine milled silica sand and wet silica sand. The selection of these products was made based on high-volumes at which they are manufactured and the multiple applications in which they are used. The reference flows were calculated for $1 \mathrm{~kg}$ of dry industrial mineral. The boundaries of the LCI were from "cradle-to-gate". Cradle being the extraction of the raw materials and gate the industrial site before being shipped to the costumer for a particular use. To determine the environmental impact, the following impacts were assessed: 1 . Mineral extraction; 2. Transportation from quarries to the plant; 3. Processing stages within the industrial site; 4. Transportation of the consumable and (semi-)finished products within the industrial site; 5 . Packaging of the final products. The transportation of the finished products to the costumer was not taken into account. For all the above mentioned steps, data collection was organized in representative industrial sites.

Based on the production processes required to produce these industrial minerals and the overall energy consumption, it was possible to group the various products into three families. Family I: Calcium carbonate superior to $63 \mu \mathrm{m}$. It also includes: Wet silica sand, Crude blended feldspar and Ball clay. Minerals of this family are extracted, with or without crushing, and without drying. Family II: Kaolin coarse filler. It also includes: Dry silica sand. This family corresponds to minerals that are extracted with or without crushing before drying. Family III: Very fine milled silica sand and dry milled feldspar. Minerals of this family are extracted with crushing, dried and dry milled. Energy consumption per family is $1 \mathrm{MJ}, 2 \mathrm{MJ}$ and 2.5-3 MJ per kilogram of dry mineral respectively. 


\section{MPRS13-02}

\section{Life cycle inventory of quicklime and hydrated lime: A study from the European Lime Association (EuLA)}

TS Schlegel ${ }^{1}$, B Naffin ${ }^{2}$, D Gregoire ${ }^{3}, \underline{\text { A Shtiza }}^{4}$, E Despotou $^{4}$

${ }^{1}$ EESAC, DUINGT, France

${ }^{2}$ Lhoist Research \& Development, RUE DE L'INDUSTRY, 1400 NIVELLES, Belgium

${ }^{3}$ Carmeuse Group, Blvd de Lauzelle 65, 1348 LOUVAIN-LA-NEUVE, Belgium

${ }^{4}$ European Lime Association (EuLA), 1000 BRUSSELS, Belgium

European Lime Association (EuLA) covers 95\% of the European lime production, and represents around 100 companies in Europe. Lime is a versatile material which is used in many different applications, such as in steel, agriculture, environment, chemical industry and so on. Due to increasing concerns about the environmental impacts of products placed on the market, EuLA has decided to use a scientific and quantitative approach to answer the requests for the environmental footprint of lime products namely the Life Cycle Assessment standard series ISO 14040-14044. Life cycle inventory (LCI) from cradle (limestone extraction) to gate (lime plant) in is based on data for the reference year 2007, which were provided from the different lime manufacturers across Europe. The outcome of the EuLA LCI study is the most comprehensive and representative set of European data provided from the lime manufacturers for the production of quicklime and hydrated lime, which covers up to $73 \%$ of the total European lime production. In accordance with the ISO requirements, the outcome of the study was validated by an external critical reviewer. The LCI study is part of a larger life cycle study initiated by EuLA in order to assess the overall environmental performance of lime products in various applications and uses. This inventory provides valuable and reliable data also to downstream users intending to carry out their own LCA to cover their products.

\section{MPRS13-03}

\section{Comparative LCA of production of different carbons for their use as anode in Li-polymer battery}

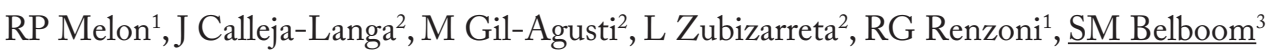

${ }^{1}$ University of Liege, LIÈGE, Belgium

${ }^{2}$ Instituto Tecnológico de la Energía, VALENCIA, Spain

${ }^{3}$ University of Liège, LIÈGE, Belgium

New materials are required for higher energy densities for extended run time, ensure high lifetime, reduce the cost and increase the safety of the Li-polymer battery. Concerning the anode, SOMABAT project proposes another alternative carbon anode materials as carbon xerogels and carbon materials obtained from agrowastes. These types of carbon materials make possible to improve the electrochemical performance, cost of the anode and reduce the environmental impact in its production.

Focused on the sustainability of the Li-polymer battery, the environmental impact of the carbon anode materials is analyzed using a Life Cycle Assessment (LCA) methodology according to requirements ILCD Handbook [1].

This comparative LCA considers the production of carbon materials from the extraction of resources, transport of raw materials, up to synthesis of these materials. Functional unit is $1 \mathrm{~g}$ carbon material obtained in the laboratory, so all data used in this analysis are real data which come from laboratory experiments, except for the convective drying which is an estimation from literature[2,3].

The synthesis of carbon materials from orange skin is carried out by natural drying and milling of orange skin followed by pyrolysis under controlled atmosphere and temperature then by cooling. On the other hand, carbon xerogels are obtained by homogenization and aging of synthesis reagents with controlled temperature followed by convective drying and pyrolysis under gas flow and controlled temperature. Then the sample is cooled at room temperature.

The used method to evaluate environmental impacts is ReCiPe endpoint. The results, in single score (Figure 
1), show that the concerned impact categories are, in descending order: fossil depletion, climate change with impact on human health, particulate matter formation, human toxicity and climate change ecosystems. These impacts are due to the electricity demand, which is produced from mainly fossil resources, for heating steps and the consumption of nitrogen. These impacts are the same for the both syntheses because the pyrolysis step is the predominant step for the both processes. However, the synthesis of carbon xerogel requires more energy step so its final score is higher than that of carbon from agrowastes.

Figure 1. Comparison LCA of two carbon procedures.

Acknowledgments

The research leading to these results has received funding from Seventh Framework Programme of the European Comission (7PM / 2007-2013). Grant Agreement No. NMP3-SL-2010-266090 (SOMABAT).

\section{MPRS13-04}

\section{Parameterisation of the dyeing process for the environmental optimisation of the textile production chain}

$\underline{\text { MC Faist Emmenegger }}{ }^{1}, \mathrm{~K}_{\text {Meyer }}{ }^{1}, \mathrm{~S} \mathrm{Guzzetti}^{2}, \mathrm{M} \mathrm{Gioacchini}^{2}, \mathrm{H}$ Zeller$^{2}, \mathrm{R}_{\mathrm{Zah}}{ }^{1}$

${ }^{1}$ Empa, DÜBENDORF, Switzerland

${ }^{2}$ Hugo Boss, COLDRERIO, Switzerland

More and more consumers value textile products made respecting the environment and the workers, while still having a reasonable price. The project EcoLogTex will deliver a new methodology and a tool to evaluate alternatives for textile supply chains taking into account the impact on the environment through Life Cycle Assessment (LCA), as well as costs and timing, while at the same time satisfying corporate social responsibility constraints. The results of this project will allow textile companies to efficiently optimize their supply chains and suppliers to benchmark themselves.

A main requirement for the tool is therefore to study textile production pathways to determine the areas where data are needed and to collect these data. A second main requirement is the ability to model the processes along the chain to link design options with the respective environmental impacts. Using this tool, a designer will be able to evaluate the impacts associated with the choice of fibre, colour and intensity as well as with the location of the production processes.

In this paper we present a simplified approach to the parameterization of the dyeing process to allow an easier evaluation of its environmental impacts. This study will also help the dyeing mill to better evaluate and control inputs and outputs and therefore the production costs.

\section{MPRS13-05}

\section{Life cycle assessment of colloidal silica production}

MC Collotta, G Tomasoni, M Alberti

University of Brescia, ITALY, Italy

Colloidal silica is a suspension of fine amorphous, nonporous, and typically spherical silica particles in a liquid phase. The application fields of colloidal silica in industry are numerous, since it is a key ingredient for the production of many industrial and domestic products, including detergents, chemical feedstocks, paper, construction materials and adhesives. Although it plays an important role in many industrial processes, there's no evidence in literature of life cycle assessment of colloidal silica production. The goal of this paper is the analysis of the environmental impact of colloidal silica production process using the life cycle assessment methodology and the Eco-indicator 99 impact assessment method. Among the different production processes available, the most prominent technique today employed for the manufacturing of colloidal silica is considered, which is based on the ion-exchange method.This method is divided in two steps: the first step goes from raw material to sodium silicate (water glass) and the second step from sodium silicate to colloidal silica through the phases of cation exchange, nucleation/polymerization and concentration. In the case analysed, concentration is performed up to a solution of $37 \%$.The paper also reports in detail inventory data for the production process of 
colloidal silica, in order to made available necessary information for subsequent life cycle analyses of industrial processes employing colloidal silica. This work is supported by the European Union through the Life+ funding program (COSMOS project LIFE08 ENV/IT/000434).

\section{MPRS13-06}

\section{An assessment of the availability and quality of LCI data on packaging materials to support The Sustainability Consortium's SMRS program}

\section{$\underline{\text { B Satterfield }}^{1}$, M Mistry $^{2}$, A Johnson ${ }^{2}$, S Mandlebaum $^{2}$, X Liao $^{2}$, S Humbert $^{1}$}

${ }^{1}$ Quantis, LAUSANNE; Switzerland

${ }^{2}$ GreenBlue, United States of America

Much effort is being deployed in ensuring more sustainable packaging, and Life Cycle Assessment has been widely used as a tool to help guide decisions related to better packaging. This being said, the information available on different types of packaging varies widely, hampering the ability for decision makers to make their packaging more environmentally friendly.

A review has been performed of available life cycle inventory (LCI) data for materials, manufacturing, and endof-life steps related to packaging. The overall objective of this work was to provide informational support to the Packaging Working group of The Sustainability Consortium in developing the Sustainability Measurement and Reporting System (SMRS).

The data review is global in scope and covers data related to packaging. All available databases and literature were reviewed, including, for example, the databases Ecoinvent, GaBi, Plastics Europe, US LCI, and the Korea LCI database. In all, the review looked at over 100 pieces of literature, 65 databases and software modules, and thousands of individual datasets. In addition to data availability, the review includes information about the datasets to evaluate data quality: geography; time period; transparency; data completeness; and descriptions of technological relevance and data sources. The amount of data for each material and geography was then compared with global production of high production volume materials. The main findings cover material representativeness; data consistency, transparency, and documentation; end-of-life processes; geographic representativeness; and data access and format.

The findings presents a snapshot of the current state of LCI data available worldwide. It was found that although LCI data for standard packaging material exists, the geographical scope and the quality of the data varies widely. Moreover, data on less standard packaging material is much less available (e.g., bioplastics), as is is for components such as adhesives and inks. Potential actions are suggested to address this state of affairs which are relevant to all packaging related stakeholders. 


\section{RS-14: Guidelines and standardization in LCA}

\section{MPRS14-01}

\section{Harmonizing LCA methodology for the European construction sector}

$\underline{\text { S Lasvaux }}^{1}$, JG Gantner ${ }^{2}$, B Wittstock ${ }^{2}$, T Saunders ${ }^{3}$, B Bosdevigie ${ }^{4}$, M Bazzana $^{4}$, NS Schiopu ${ }^{1}$, EJ Jayr ${ }^{4}$, J Chevalier ${ }^{4}, \mathrm{~J} \mathrm{Hans}^{4}$, KL Lentz ${ }^{2}$, A Braune ${ }^{3}, \mathrm{Z} \mathrm{Gytevai}^{3}, \mathrm{~J} \mathrm{Anderson}^{3}, \mathrm{~A} \mathrm{Yates}^{5}$, T Barrow-Williams ${ }^{5}, \mathrm{C}$

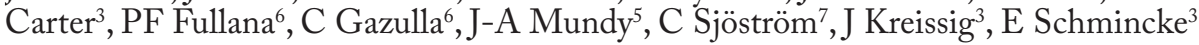

${ }^{1}$ Centre Scientifique et Technique du Bâtiment, ST MARTIN D'HÈRES, France

${ }^{2}$ Fraunhofer Institute for Building Physics, Dept. Life Cycle Engineering, ECHTERDINGEN, France

${ }^{3} \mathrm{PE}$ International, LONDON, United Kingdom

${ }^{4}$ Université Paris-Est, CSTB, Division Environnement, ST MARTIN D'HÈRES, France

${ }^{5}$ BRE Global Ltd., WATFORD, United Kingdom

${ }^{6} \mathrm{ESCI}, \mathrm{BARCELONA}$, Spain

${ }^{7}$ Prof Ch Sjöström Consultancy, GÄVLE, Sweden

Throughout Europe's construction industry, Life Cycle Assessment is increasingly used in research projects and in daily practice. Building certification schemes like the British BRE, the French HQE or the German DGNB rely on LCA to assess the environmental performance of buildings. Environmental Product Declaration (EPD) programs are gaining relevance at national and European levels. The European Joint Research Centre (JRC) actively develops and propagates the ILCD handbook. Furthermore, the European standardization bodies provided a set of standards on LCA in the construction sector. The upcoming European Construction Products Regulation (CPR) is expected to be based on LCA to address the new essential requirement "sustainable use of natural resources", which is a pre-requisite for the marketing of construction products in Europe from January 2013.

However, one major obstacle to broad application of LCA in Europe's construction industry is the lack of consistent, practically applicable metrics and guidance for practitioners on how to conduct consistent LCA studies. This barrier had been identified by the Energy-efficient Buildings European Initiative (E2B EI), who set up the European research project EeBGuide to provide metrics and operational guidance for constructionrelated projects, especially within the E2B EI that use LCA as an evaluation tool for project results. The main focus of EeBGuide lies on providing scientifically sound, yet practical guidance.

The project's major outcome is a guidance document, setting provisions for conducting LCA studies and giving guidance on how to do this. The document has a section on buildings - new and existing - and a section on construction products. It is structured according to both the usual steps of the LCA framework (e.g. goal and scope definition, inventory analysis, impact assessment, interpretation) and to the life cycle stages of the new European standards EN 15804 and EN 15978 (e.g. production, construction process, use and end of life stages). The provisions and guidance are also divided according to different study types (screening, simplified or complete LCA). These study types give for example the possibility to conduct a LCA study in an early stage of a research project by focusing e.g. on default values and adapted calculations rules.

The guidance document covers all aspects of the LCA studies by applying the provisions from the European standards as well as the ones of the ILCD handbook, wherever applicable. Involvement of external reviewers and experts was also a very important point for ensuring the applicability of the EeBGuide. Two expert workshops as well as an online public consultation phase were carried out in 2012. The last step of the project included the practical implementation of the guidance document in LCA case studies and training courses. In total, six case studies have been selected: two for new buildings, two for existing buildings, one for a usual construction product and one for an energy-efficient product. The final version of the guidance document is now supported by interactive information hub. In a near future, EeBGuide will provide the basis not only for consistent LCA results across construction-related research projects, but also may be used by building LCA tool developers or building certification schemes. 


\title{
MPRS14-02
}

Applicability, contribution and limitation of new international standards for IT services environmental footprint characterization: Feedbacks and key learnings on the LCA of a cloud computing service

\author{
XL Durieux ${ }^{1}$, Orgelet $^{2}$, D Prunel ${ }^{2}$ \\ ${ }^{1}$ France Telecom Orange, PARIS, France \\ ${ }^{2}$ Bureau Veritas Codde, MOISANS, France
}

The stake to measure correctly and of a standardized way the environmental impacts of Cloud services is essential because on one hand the services of this type develop very strongly, and on the other hand their environmental virtues are often emphasized without always bringing convincing elements.

It is for these reasons that Orange Business Services realized the LCA of one of its offers of Cloud Computing. We then updated the LCA within the framework of the project 'ICT Footprint' initiated by the European Commission to examine the compatibility and the feasibility of new sector-based standards.

Our experience feedback of application of the ITU-T L.1410 and of the ETSI TS 103199 is twofold.

1. Methodological aspects

A) At first from a general point of view: the comparison of both texts shows a strong compatibility. Their main contributions live for us in the requirement of consideration of all the activities necessary for the service, and for the precision given onto the software scope, i.e. to take into account only the specific software. The points on which texts should evolve would be firstly the indication of reference values default, secondly the reduction of certain requirements which are today specific in some tools of LCA even though the information which we remove from them is not so important. Finally, but it is the inherent problem of the standards, the very large number of optional points. In fine, the comparison of the results of LCAs led by different teams or tools remains impossible.

B) Then from a practical point of view, with the case of a Web hosting service. To answer the requirements in terms of estimate of the impacts of the activities and of the software, we used the data available on workload (man/days) to which we allocated a carbon emission factor per worker stemming from the carbon assessment of the organization. We present this pragmatic approach that gives to the LCA a good coherence at the same time internal (the same method and the emission factor both for activities and for specific software) and external (with regard to ITU-T L.1420, on organizations impacts).

2. Effect of the application of the two methodologies on the estimated environmental impacts

A) We did not notice difference as regards equipments.

B) For the software part, the modification of the scope (specific only vs. all software) and of the approach (estimate by loads vs. a $\mathrm{K} €$ to $\mathrm{K}$ eq $\mathrm{CO} 2$ conversion) gave a reduction of its share in the global impact of the service, but especially a strong reduction of the uncertainty.

C) Take into account the service provider activities (and network provider activities) increased the greenhouse gas emissions of the order of $35 \%$.

In conclusion these new methods establish a real contribution mainly because they give a frame to handle the software and the activities in a service LCA. And we have been able to show how important it is. In order to benefit at best from these standards, two points seem essential to us. On one hand the biggest transparency possible to the retained / excluded elements and to the applied processing in the LCA report. On the other hand, within a given organization, the elaboration of guidelines which fix the approaches and the choices. It will give the coherence from an LCA to another, and a better global efficiency. All in all we will then be able to better approach the reality in phase of LCA, and thus to better guide the action in phase of eco-design. 


\title{
MPRS14-03
}

\author{
Who takes the blame? - PEF vs. EPD ${ }^{\circledR}$ burden distribution in a case study of a tire - turf - fuel material \\ utilization sequence
}

\author{
E Hallberg, SA Skenhall, T Rydberg
}

IVL Swedish Environmental Research Institute, GÖTEBORG, Sweden

In recent years, several environmental profiling schemes for products have emerged. They may differ, e.g. regarding how recycled material and recycling is dealt with, which leads to different burden distribution depending on which scheme is used. The international $\mathrm{EPD}^{\circledR}$ system, that was the first scheme to be established, requires the practitioner to use "zero burden", i.e. not include burden from previous life cycles when modeling recycled material. In contrast, "embodied burden"mean the environmental burden from previous life cycles of the material, and this approach is currently proposed in the PEF (product environmental footprint) guide draft document. The EPD ${ }^{\circledR}$ system will favor a buyer of recycled material, since no burden from previous life cycle is included, in contrast to use of virgin materials. The PEF approach, on the contrary, will favor the seller of a material to recycling, since the embodied burden will follow the material into the next life cycle. Thereby, the PEF approach punishes the end user of a material in order to encourage recycling. However, it could also discourage use of recycled materials if they come with an environmental burden. Due to these differences it was of interest to illustrate how the actors in three subsequent life cycles of a material are rewarded in the respective approaches. The aim was to illustrate the consequences of including the burden of a material either in the beginning or end of the chain.

We have studied the implication of these methodological differences in a case study comparing three different materials for synthetic turf infill; recycled tire rubber, virgin synthetic rubber EPDM, and virgin thermoplastic elastomer TPE. I in the EPD ${ }^{\circledR}$ approach the use of the virgin materials in turf, i.e. EPDM and TPE, will bear the burden of the virgin materials production, while in the PEF approach this embodied burden will be handed over into the next utilization of the material. As an example, when using the $\mathrm{EPD}^{\circledR}$ approach, the turf will be held responsible for the total virgin EPDM material production and upstream system, in our case about 50,000 $\mathrm{kgCO} 2 /$ turf. In contrast, when applying the PEF methodology the burden of the virgin material production will not be allocated to the turf, but be transferred into any next utilization, e.g. energy production. In our calculation the remaining burden for the turf will then be $10,000 \mathrm{kgCO} 2 /$ turf. For the tire rubber system, the turf will have a burden of about 5,000 $\mathrm{kgCO} 2 /$ turf with both the $\mathrm{EPD}^{\circledR}$ and the PEF approaches.

So, who bears the burden of the materials along the utilization sequences? To analyze this, the adjacent life cycles of the materials were included. For the tire rubber, the previous cycle is as rubber in a car tire, while the subsequent cycle is as energy resource. For EPDM and TPE there is only a subsequent phase as energy resource. The results suggest that for tire rubber, the car manufacturer will be favored by the PEF methodology, but not by the EPD ${ }^{\circledR}$ approach. The energy producer, on the contrary, will be favored by the EPD ${ }^{\circledR}$ methodology and disfavored by the PEF approach. The same holds for the energy producer in the EPDM and TPE utilization sequences. What the case study results indicate, is that the choice of methodological approach regarding recycling and recycled materials, can heavily influence incentives for actors to use recycled material or not. It can also influence the choice between materials for a certain application. 


\section{MPRS14-04}

\section{A new industry standard for sustainability classification of offshore suppliers}

\section{JB Pettersen, C Solli}

\section{MiSA, TRONDHEIM, Norway}

A variety of commercial and non-commercial systems for sustainability rating, classification and accreditation of products and projects exist today, covering buildings, infrastructure projects, electronics, and a selection of businesses. Most cited examples include BREEAM, LEEED, CEEQUAL, and EPEAT. We present a review of the schemes, with the intention to extract requirements and designs for a sustainability classification scheme for the offshore oil and gas supplier industry.

Offshore suppliers cover a diverse range of activities, therein office and accounting services, maintenance and risk assessment, technical equipment, offshore personnel and services, as well as the construction and operation of large-scale offshore installations and vessels.

Our presentation discusses commonalities identified by the review and evaluates these towards the environmental aspects for a selection of companies, with the intention to split the industry into a short list of industry segments and develop relevant common requirements and unique requirements for each segment. Sustainability is where possible evaluated quantitatively, by combination of input-output modeling for businesses and physical LCA for products and installations.

Oil and gas operators in Norway require that all suppliers over a certain contract size fulfill requirements for a quality management system, and relevant additional certificates for offshore activities. Declaration and maintenance of the classification is currently managed by a commercial actor. The sustainability classification scheme proposed in this paper outlines environmental requirements to supplement the prior system, to include emissions, waste, and resource aspects.

The oil and gas industry is a large sector in Norway and internationally, with significant emissions to air from fossil combustion and to water from activities offshore. Offshore installations are also significant consumers of energy and materials through their life-cycle. This paper presents a first effort to devise a common sustainability classification scheme for the oil and gas sector, with the potential to significantly improve the sustainability performance of a globally important industry. 


\section{SS-01: Teaching sustainability: Paving the way to a common understanding and meaningful actions}

\section{TOSS01-01}

\section{A strategy for teaching sustainability assessment}

\section{$\underline{\text { SI Olsen }}$}

Technical University of Denmark, LYNGBY, Denmark

Educating engineers to be active in sustainable development is by no means a trivial task and the challenge has been pursued by several universities and organizations around the world. At the Technical University of Denmark (DTU), Department of Management Engineering, research and teaching are focused on engineering management tools. In the division for Quantitative Sustainability Assessment (QSA) the research and teaching is embedded in Life Cycle Assessment (LCA) and Life Cycle Management (LCM) tools. Our vision is that all engineers graduating from DTU are taught a basic knowledge about sustainability and the methods and tools to assess the sustainability of their decisions. Our strategy for the teaching address three target groups and follows two routes.

- One route provides in-depth education for students aiming to specialize in quantitative sustainability assessment. A variety of courses ranging from production level through company level to society level will be offered.

- The second route aims to present concepts of sustainability and potential impacts of the specific technology field as well as methods and tools for specific domains, i.e. nano technology. It is targeted two groups of students at the different technological domains at DTU; those specifically working in innovation and technology development and engineers developing solutions based on existing technologies.

The DTU curricula will integrate sustainability assessment in introductory courses at bachelor level, whereas master level courses goes more in detail with the specific sustainability issues for that technology domain and introduces quantitative tools to assess sustainability. The proposed strategy embeds sustainability throughout the engineering curriculum.

\section{TOSS01-02}

\section{Science Master's Program (SMP) in sustainability: Fueling innovation through graduate education}

$\underline{\text { U Krogmann, D Silver }}$

\section{Rutgers University, NEW BRUNSWICK, United States of America}

In 2010, Rutgers, The State University of New Jersey, started a new state-wide professional science master's (PSM) degree framework across all three of its campuses in Newark, New Brunswick, and Camden, New Jersey, US. The goal of the new degree program is to train the next generation of individuals to assume key integrator and leadership roles in science-intensive industries and to help translate research into commercialization to fuel innovation and economic growth in New Jersey and the U.S. There are a number of novel aspects of this program. This new professional science master's program involves students in a multidisciplinary cohort experience in which they pursue a concentration of courses in one of several well-defined "green-themed"science disciplinary concentrations/tracks, including biotechnology (especially biofuels), sustainability, urban environmental analysis and management, and industrial mathematics, combined with a common set of business "plus"courses, including finance and accounting, management, communications, innovation, commercialization, and ethics. The sustainability track is designed to help students identify, analyze and better understand connections among social, environmental, technological and economic systems. Designed upon a systems analysis approach, this program provides a broad understanding of the forces driving these systems. It also provides specific tools and skills to measure, predict and influence key processes that influence sustainability. The four core sustainability science courses include an introductory course in sustainability, one course related to environmental fate and transport and ecosystem ecology and global change, one course related to industrial ecology, life-cycle assessment and resource sustainability and one course related to choices among energy technology options. In addition to the four core science courses the students select four elective science courses. The science courses 
include a research experience component to provide students exposure to cutting-edge research. Students complete a tightly integrated capstone course in which they learn how to evaluate, convert, and commercialize science, engineering and technology discoveries into new economic ventures. The program maintains strong liaisons with local industry through creation of an active industrial advisory board which provides guidance, networking, research internship opportunities, and ultimately, employment for students. First experience shows that the sustainability track is very attractive to potential students. However, this field is still evolving and relatively new to industry.

\title{
TOSS01-03
}

\section{Teaching LCA at an advanced level - accomplishments and challenges}

\author{
$\underline{\text { S Løkke}^{1}}$, JH Schmidt $^{1}, \mathrm{M}$ Thrane $^{2}$
}

${ }^{1}$ Aalborg Univerisy, AALBORG, Denmark

${ }^{2}$ DuPont (Nutrition and Health), ÅRHUS, Denmark

The number advanced courses available for $\mathrm{PhD}$ students and professionals with an interest in life cycle assessment (LCA) tools is very limited. Therefore, the Danish Centre for Environmental Assessment (DCEA) and the LCA research team at Aalborg University has been offering this type of course at a regular basis since 2006. The series of courses started with an international Expert Seminar and PhD course (Thrane et al. 2007) partly funded by the Nordic Council of Ministers (Norforsk). The course has since maintained the original idea of introducing state of the art discussions of the contemporary challenges that should be met by LCA practitioners and method developers, and the content has following been a combination of the latests developments within the major challenges in life cycle inventory and life cycle impact assessment. The paper discusses the development the course has undergone since 2006, the teaching methods deployed including use of problem based learning (PBL), the experiences from discussions of CLCA vs. ALCA, and it provides recommendations for future LCA teaching and learning. Furthermore, the paper introduces discussions from the latest course October 29-30, 2012, which is arranged together with the International Life Cycle Academy. At this course rebound effects is discussed in a critical perspective alongside consequential modelling (CLCA), attributional modelling (ALCA), indirect land use changes (iLUC), and input-output based LCA (IOLCA).

Thrane, M., Riisgaard, H., Dengsøe, N. \& Christensen, P. 2007, 'Bridging environmental and economic assessments for decision support: Experiences from an international Expert Seminar and $\mathrm{PhD}$ course in environmental assessment tools', International Journal of Life Cycle Assessment, vol. 12, no. 1, pp. 63-65.

\section{TOSS01-04}

\section{Learning by doing - bringing real-life case studies into the classroom}

$\underline{\text { MZ Hauschild }}^{1}$, A Laurent $^{1}$, C Mølgaard ${ }^{2}$, F Walachowicz $^{3}$

${ }^{1}$ Technical University of Denmark, LYNGBY, Denmark

${ }^{2}$ Moelgaard APS, COPENHAGEN, Denmark

\section{${ }^{3}$ SIEMENS, BERLIN, Germany}

To increase the application of LCA and to strengthen the technical qualifications of future LCA practitioners, continuous and effective LCA education is essential. We share the experience gained through teaching an LCA course continuously at M.Sc. level at the Technical University of Denmark for more than 15 years. The course has received a growing interest over the years and now attracts more than 50 students every year. The students come from a variety of backgrounds from design and innovation over food and building engineering to environmental engineering. The course is taught in English, and the share of students from universities abroad is also significant with ca. 40\% non-Danes in the last 3-4 years. The originality of the course is its consistent pedagogical principle of 'learning by doing' which is reflected in the combination of lectures in LCA methodology and theory, assignments and performance of an LCA in a real life case in collaboration with an industrial partner. Lectures introduce the methodology of the different LCA phases and assimilation of the different methodological principles is checked with graded assignments throughout the duration of the course. In parallel. the students are initiated to actual LCA practice by the conduct of a group proiect on a real-life 
case study in which they implement the methodology shortly after being introduced to it. The groups have 4-6 members selected to ensure that their combination of backgrounds and competences matches the needs of the case study that they will work on.

Through the industrial cases, the students, who interact directly with the case companies in a role as consultants, are confronted with the challenges of performing LCA. They see where the challenges and main uncertainties lie, they get a deeper understanding of some of the pragmatic choices that were made when developing LCA methodology, and they learn how to overcome difficulties in e.g. data collection. Furthermore they get an understanding of the iterative nature of LCA as they are forced - through imposed deadlines throughout the course - to proceed through a screening and two consecutive iterations.

Since the initiation of the course, more than 100 case studies have been run, covering a broad variety of products and services from different sectors such as waste management, furniture, building industry, food, electrical equipment and even funerals.

The case studies are a source of synergies between the students, who can apply the learnt concepts on concrete and exciting products or services, and companies, who can profit both in terms of their own learning by participating in the LCA process and from the results of the LCA. Two different examples are shown to illustrate these synergies. The first relates to the example of a large company that provided a whole series of case studies covered by different teams of students in the same, which resulted in new activities tried out in the course. The second focuses on a product from a small-sized company, for which the LCA results from the course later influenced the product design and manufacture. By telling these "success stories", we thus aim to (i) provide inspiration for LCA course providers, who seek for improving their teaching methods, and (ii) make industrial stakeholders aware of opportunities and benefits they can gain by offering real-life case studies and undertaking direct collaboration with university LCA courses.

\section{TOSS01-05}

\section{Teaching life cycle management with an integrated approach of business game and lecture}

\section{Herrmann, $\underline{\text { P Egede }}$}

\section{TU Braunschweig, BRAUNSCHWEIG, Germany}

The prerequisite for the understanding of scientific theories and methods as well as for personality development and preparation for a future professional career is the ability to analyze situations, to apply knowledge, to reflect effects of own doing and if necessary to alter the taken approach. However, many lectures in academic teaching focus primarily on the acquisition of knowledge. Yet, good reproduction of knowledge in tests is no guarantee that students can apply this knowledge successfully in real situations. Therefore, universities often offer classes in which soft-skills are taught in order to fill this gap. However, these classes are mostly outsourced to special seminars, separated from the professional scientific field. This separation makes the transfer of these skills into a technical context difficult. Therefore, it is necessary to integrate the teaching of soft-skills and knowledge into one course. This integration is the purpose of the lecture Product- and Life Cycle Management and the accompanying business game Holistic of the Institute of Machine Tools and Production Technology of the Technische Universität Braunschweig. Since 2009, Holistic has been developed in cooperation with the University of Art Braunschweig. It has elements of board games as well as computer games and takes about 8 hours to play. The participants compete against each other in different companies that are formed out of the bankruptcy estate of a car manufacturer. It is the task to make the new companies successful focusing not merely on economic aspects but also on social and ecological criteria. The students play the business game and also regularly receive different tasks during or outside class. One example could be the calculation of the life cycle costs of a machine tool the production management of the company wants to buy. Another example is the use of a smart app in order to make a management decision during class for which the outcome can be calculated immediately. As a next step, this integration is currently developed further in form of the teaching concept PlayING. PlayING is the fusion of a lecture with a business game in order to enhance and support the teaching in class with the concept of game-based learning. It does not merely combine the two elements but allows frequent feedbacks and interdependencies in order to achieve regular training situations to apply theoretic knowledge. PlayING is composed of a rapid alternation of context and action phases. Context phases convey knowledge. Action phases allow an active participation of the students which enables them to make individual experiences and understand an abstract theoretic subject. In addition to this structure, a consistent narrative is crucial for a strong immersion of the students. Therefore, PlayING is embedded in a fictional scenario that is carried out throughout the whole concept. This can be made of fictitious companies to which the students belong to as employees but also any other thematically appropriate narration. During the action phase the scenario is put more into the foreground. But small narrative elements during the context phase 
strengthen the perception of a real life situation. This fusion of interactive lectures and the business game allows the students to apply the theoretic knowledge they gained during the lectures immediately and creates a very fruitful learning environment.

\title{
TOSS01-06
}

\author{
Role-plays for teaching sustainability - paths towards ethical, critical, systemic and transdisciplinary \\ thinking
}

V Gasso-Tortajada, C Jakobsen, FW Oudshoorn

Aarhus University, TJELE, Denmark

Sustainability is becoming a key subject on the agenda of a variety of courses at pre- and postgraduate levels. The paradigm of sustainability demands a higher level of complexity and a broader scope than the traditional education approaches usually provide. It demands specific competences such as ethical, critical, systemic, and transdisciplinary thinking. But, how can these competences be effectively acquired? The aims of this paper are to suggest role-play as an effective learning activity for developing such competences, and to illustrate our experiences in teaching sustainability through role-plays at postgraduate level. The general concept of role-play that we propose consists of enabling students to act as the stakeholders of a real-life based scenario consisting of a decision-making process that implies a sustainability dilemma. The role-play that we implemented, for instance, simulated a national convention about an amendment of bioenergy subsidies where different stakeholders (e.g. government, bioenergy industries, farmers, NGOs and consumers) debate and contribute to decision making. Before the role-play starts, the facilitator introduces the scenario and distributes the roles. The students, then, prepare the role arguments based on facilitator notes and a discussion with the stakeholder peers. During the role-play, the students seek to defend their position and negotiate with other stakeholders to promote a decision-making output compatible with their interests. After the role-play, a reflection stage takes place to reinforce and elaborate on the concepts introduced by the activity. Preliminary-testing observations showed that the proposed concept of role-play promoted active, emotionally engaged, communicative and experimentally open attitudes among the majority of the students. It, moreover, disclosed the diversity of postures towards sustainability of the different stakeholders, and the complexity of decision making processes involving a sustainability dilemma. This disclosure engaged students in a process of ethical and critical inquiry under systemic and transdisciplinary scopes. Some drawbacks, however, were also present as introvert students tended to play a more passive role, and the activity required a relatively high amount of time. Preliminarytesting observations support the hypothesis that role-play can be an effective learning activity for developing the competences that the paradigm of sustainability demands; however, a more robust evaluation of the activity effectiveness needs to be implemented.

\section{TOSS01-07}

How to integrate LCA in industry to promote its usefulness and avoid greenwashing

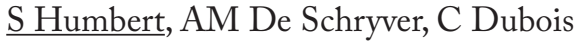

\section{Quantis, LAUSANNE, Switzerland}

Life cycle assessment (LCA) is a widely applied tool used to quantify environmental impacts of activities. Scientific developments to support and improve accuracy of LCAs are continuously evolving. This results not only in increased knowledge and opportunities but also in a challenge to keep on top of the latest practices, methods, databases and tools on the market. Within this broad and complex field, there is a growing need for practitioners and industrial users to know (i) how to perform LCA, (ii) how to apply LCA, and (iii) how to understand and challenge LCA results through critical assessment.

In this presentation we will provide an overview on why LCA can be difficult and confusing for industry, what are the current needs for LCA training at the company level, and what are the most critical and difficult issues to tackle. Examples of mistakes or unclear communication in public documents will be presented to point out the importance of maintaining criticism and the risk of conscious or unconscious greenwashing.

As LCA practitioners, Quantis supports various companies to apply LCA, to understand the results and to communicate the results that will result in positive actions. In our training workshops, several topics are 
discussed such as the importance of life cycle thinking, the use of multiple indicators and burden shifting. An overview on regulations and standards (PEF, ILCD, ISO standards) as well as available methodologies and practices help to define the current capabilities of LCA. Additionally, we will discuss how to deal with data gaps, as well as how to interpret and use the results considering all assumptions and decisions made while maintaining reliability, both of which are extremely important. Through close collaboration, stakeholders (e.g., sustainability directors, sustainable sourcing coordinators and marketing directors) are guided on how to understand, interpret and communicate the results using marketing language without losing scientific validity. Ideally, such training and education will take place in advance of the study. This is achieved by involving the right people at the start of the project as well as for brainstorming sessions on the results and their use and for developing the (internal or external) communication strategy. Finally, a number of communication tools can support this process such as dynamic or static web-based tools (footprint calculators), printed materials (leaflets, reports), data visualization graphics (charts) and a communication program support (Q\&A, FAQ). Some effective examples will be presented in this presentation.

\title{
TOSS01-08
}

The International Life Cycle Academy: A quality network for teaching in quantitative sustainability assessment - the why and the how

\author{
B Weidema, M Brandão, JM Watson \\ International Life Cycle Academy, BARCELONA, Spain
}

Quantitative sustainability assessment is still a relatively new topic both at academic and continuous professional education levels. Several challenges exist:currently many educational programmes in sustainability are still limited to teaching concepts and normative, qualitative and semi-quantitative methods, while practical experience shows that quantitative results from systems analysis are often counter-intuitive and therefore, offer new and deeper insights. Current programmes are, in practice, limited to environmental impact assessment with inadequate attention to social and economic disciplines, while top-down approaches to impact assessment show the importance of a consistent integration of the latter. Likewise, social and economic assessments are often taught in isolation from the more biophysically founded sciences of systems analysis and impact assessment. A truly comprehensive and interdisciplinary sustainability assessment is still in its infancy.

Current sustainability education programmes focus on the analysis of the status quo and fail to adequately address assessment aspects with inherent ethical and social implications and potential. They also fail to address the application of assessment tools to the challenges of radical technology development and societal decisionmaking processes, which is essential for any lasting real-life impacts of the analyses.

The International Life Cycle Academy is an association of universities and researchers dedicated to overcome the outlined challenges by combining their experiences and expertise, both in terms of teaching methods, tools and materials, and in terms of scientific quality and content. The Academy is dedicated to spreading their experiences and expertise, in order to raise the quality of education in quantitative sustainability assessment, with any interested audience, not limited to the member universities.

Each member of the Academy has a unique expertise and contribution. For example, some members contribute expertise in problem-based learning, while others have much experience with direct involvement of industries and work-place learning. Also, in terms of scientific disciplines and modelling approaches, the member universities differ and contribute to create a truly interdisciplinary forum for development. Besides the exchange of expertise and teaching tools and materials, the Academy is now working on developing best-practice criteria for quality assessment of teaching in quantitative sustainability assessment as a first step towards mutual recognition and quality enhancement of courses. 


\title{
TOSS01-09
}

\section{Teaching environmental assessment methods to agronomists: didactical problems and opportunities for their curriculum}

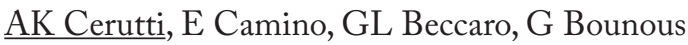 \\ University of Turin, GRUGLIASCO, Italy
}

Environmental sustainability was recently included in the academic education, enriching the curricula of undergraduate and graduate programs across Europe. However in the agricultural context the approach to environmental sustainability is often limited to critically examining the problematic effects of the use of specific pesticides or other substances, but a systemic vision of sustainability in food production is missing.

Environmental assessment methods (EAM) may significantly contribute to promote a more holistic vision of agriculture, as they require to model agricultural systems (highlighting connections and fluxes) and to grasp the complexity of environmental effects of management strategies, by applying a variety of assessment methods and categories.

InItalyfew agricultural courses include the teaching of environmental assessment methods (EAM), mainly because of the persisting academic separation of environmental and agricultural disciplines. At the Department of Agriculture, Forestry and Food Science,UniversityofTurin(Italy) a short pilot laboratory (6 hours) about the application of EAM in agriculture has been proposed in 2011 and 2012 to students of three master courses: Agricultural Sciences and Technologies, Food Sciences and Technologies, Science and Culture of theAlps. Students were involved in a lecture (3 hours) about EAM, followed by a 3 hours group-work, in which - according to specific guidelines - they examined a scientific paper focused on a EAM application in the agricultural sector. Students were then asked to give a short report of the group activity and a brief oral discussion.

At the end of semester 30 students were asked to highlight benefits and difficulties of this learning experience. From their comments it was possible to identify interesting remarks in the following aspects:

(I) System thinking. Application of EAM requires to describe the energy flows and material cycles of the system under study, and to decide the allocation of environmental impacts to specific phases of the production.

(II) Holistic view of productive systems. The need to identify boundaries between technical and natural systems for impact assessment highlights the strong interconnection between the two of them.

(III) The problem of efficiency. The application of a variety of assessment methods may highlight that productions efficient from an agronomic point of view may not be so from an environmental point of view.

(IV) Interpreting labels and indicators. Students highlighted their difficulties in understanding the environmental meaning of some well known labels and the risk of greenwashing.

(V) Conceptions about sustainable agriculture. During the group work students were asked to highlight (if possible) the paradigm of sustainability of the authors of the scientific paper and to discuss it: so they were able to reflect on the complexity of the concept on 'sustainability'.

All these aspects may have a positive outcome in the professional life of the future agronomists, even if they will not apply any EAM in their activity. Relying on the results of this educational research, the Authors will prepare a questionnaire to be applied before and after the next laboratory in order to highlight paradigms of sustainability and to assess - in the framework of action-research - the effectiveness of the course in promoting a more holistic vision of agricultural issues. 


\title{
MPSS01-01
}

\section{Teaching management of sustainable development in an integrated lecture at the university level}

\author{
$\underline{\mathrm{R}}$ Scheumann $^{1}, \mathrm{M}$ Traverso $^{2}, \mathrm{M} \mathrm{Finkbeiner}^{1}$
}

${ }^{1}$ Technische Universität Berlin, BERLIN, Germany

\section{${ }^{2}$ BMW Group, MUNICH, Germany}

The goal of this lecture is to transfer knowledge on how to use the different methods and tools in order to be able to manage and to enhance sustainable development of products and manufacturing processes.

An efficient strategy for sustainable development needs at least five components: definition of clear goal and measurable targets, identification and selection of a valid set of indicators, stakeholder involvement at the earliest stage, definition and introduction of standards, norms and economic incentives, and finally a monitoring stage. At first, the definition of goals and measurable targets in terms of sustainable development is needed to keep the focus as well as to be able to monitor the chosen strategy. Also the stakeholder analysis and involvement should be addressed for each step of the desired strategy. The next step is to select an appropriate set of indicators which address the three areas of sustainability. Then the collection of data for all relevant indicators as well as economic incentives is needed. Finally, the achieved results should be cast into politics to gain legislative support. Already now it becomes clear, that the challenge in teaching this topic can be seen in structuring the learning material while still picturing the complexity of the pathway to reach a more sustainable development. The lecture is held in English and addresses master students due to the requirement of some basic knowledge on e.g. LCA. Experience has shown that the course is very attractive for foreign exchange students and a big opportunity for German native student to learn, write and discuss in a foreign language with the option for inter-cultural exchange - because the standard curricula in Germany are still held in German only.

The lecture itself is dived into three blocks. At first the focus lays on the analytical instruments and how they can be used to manage sustainable development. The students learn or recap their knowledge of MFA; LCA; carbon, water, and ecological footprint; and LCC. In order to consolidate, learn and recap this theoretical background they have to read and discuss case studies on LCA and LCC in group and plenary sessions. The second block concentrates on the items: CSR, S-LCA, LCSA, and Life Cycle Sustainability Dashboard (LCSD). The point of view targets both enterprises and products in a broader approach that allows an inclusion of the third component of sustainability: the social impacts. The students are now in the role of an entrepreneur and have to adopt business strategies and activities that meet the commercial success of the enterprise and its stakeholders, and respect people today and in the future. Different reporting initiatives, the more graphical illustration of the LCSD, as well as LCSA are used as a decision support tool at the service of democracy within the complexity of decision-making in the 21 st Century. The last unit covers the topics: stakeholder and stakeholder processes as well as communication strategies to integrate the three areas of sustainability in the assessment of communities and countries performances. It is shown how the stakeholders can be identified, analysed and mapped, engaged, and finally managed. By doing so, it becomes clear that a clear communication strategy or even better a strategic communication is needed. To impart a deep understanding of the concept the students undertake group work to identify the audience, stakeholder, risks opportunities, etc.

\section{MPSS01-02}

\section{Sustainability in energy engineering curriculum}

$\underline{\text { H Mälkki }^{1}}, \mathrm{~K}$ Alanne $^{1}, \mathrm{JV}_{\text {Paatero }}{ }^{1}, \mathrm{~L} \mathrm{Hirsto}^{2}$

${ }^{1}$ Aalto University, ESPOO, Finland

${ }^{2}$ University of Helsinki, HELSINKI, Finland

Higher education aims to educate engineers so that they are able to make correct sustainable choices. Their choices have consequences to the whole society where energy is used. An energy-intensive society needs professionals because all energy production and use have impacts to the environment one way or another. Regarding future trends in energy, sustainable solutions should be based on the long-term goals in ecology, economics, and both energy and material efficiency. In this sense, sustainability brings a challenging combination of contradicting issues into teaching energy engineering. Energy engineers need systemic understanding and that is why new skills, environmentally-conscious education and other training activities are necessary in transition to energyefficient technologies when working in industry. Engineers should be trained to utilize renewable energy 
technologies and at the same time to be aware of the principles of sustainability. Integrating various learning environments would help the students to enhance their sustainable energy expertise and possibly develop their multidisciplinary and interdisciplinary skills throughout education. However, sustainability remains to be implemented in the energy degree programmes. This kind of situation seems to be true also in other universities outside of Finland. This paper presents the main findings about sustainability and life cycle assessment (LCA) education based on the curriculum analysis of energy engineering in Aalto University. In addition the paper presents the preliminary results from a survey, where the role of sustainability and LCA in energy engineering has been explored through a survey to European Universities. Future plans to promote sustainability in energy education and to create critical thinking in solving energy problems have also been discussed.

\section{MPSS01-03}

\section{Integrating sustainability and LCA in a course on LCA and energy systems - concept and experiences}

\section{G Piringer}

University of Natural Resources and Life Sciences, Vienna, VIENNA, Austria

In the spring of 2012, the author developed an introductory block on sustainability as part of a course on the life-cycle assessment (LCA) of energy systems at an Austrian university of applied sciences. The course has been taught for the first time in the summer of this year. It is aimed at second-semester, continuingeducation students in a master's degree programme on sustainable energy systems. The objective of the course's sustainability block was to embed the LCA method in a larger context and to provide background information on sustainability. The course is currently taught mainly as a direct-instruction type lecture. The sustainability block constitutes the first part of the lecture. It is introduced by a definition of the term sustainability and a short outline of its history. The topic is further developed by an overview of three sustainability frameworks, and the block ends with a discussion of several metrics of sustainability. The metrics provide a point of referral later in the course when life-cycle impact assessment methods are presented. Sustainability is briefly revisited in a subsequent block on LCA fundamentals, where LCA is presented as a tool to support sustainability-related decision-making in the context of life-cycle sustainability analysis. Besides giving details on the structure of the course and its sustainability block, the presentation will outline the curricular environment of the course, learning outcomes, as well as student feedback and lessons learned.

\section{MPSS01-04}

\section{Sustainability seminars to promote life cycle thinking among calue chain partners}

CM Alles $^{1}$, SR Veith ${ }^{2}$, E Thiele ${ }^{2}$, S Cappelle ${ }^{2}$

${ }^{1}$ DuPont International Operations Sarl, LE GRAND-SACONNEX (GENEVE), Switzerland

${ }^{2}$ DuPont, BRUSSELS, Belgium

DuPont is on a mission of Sustainable Growth, i.e. the creation of shareholder and societal value while we reduce our environmental footprint along the value chains in which we participate. Through our science-driven innovation and global collaboration, we create solutions that help address the world's critical needs of food, energy, and protection. A common understanding and a shared vision of sustainability are essential enablers of successful collaborations across companies, sectors and geographies.

To promote life cycle thinking among our immediate value chain partners, DuPont Titanium Technologies recently hosted a three-day forum with customers from over twenty companies in the Europe, Middle East and Africa region. The event provided an excellent platform for open discussions and mutual learning. Seminar topics included life cycle thinking, collaborative approaches to sustainability between members of a value chain, and guidelines for formulating sound and credible environmental marketing claims. A life cycle assessment workshop allowed participants to put the theory of the ISO 14040 standard series into practice. DuPont experts in sustainability assessments led the training and workshop, while external guest speakers provided additional perspectives on the importance of cooperation among value chain partners in reducing footprints.

Positive feedback and concrete suggestions from seminar participants encouraged us to plan follow-up events with smaller groups on a range of specific sustainability topics, and to engage more deeply in joint efforts to assess and improve value chain sustainability with specific customers. 


\title{
MPSS01-05
}

\section{Die Lernfabrik - teaching sustainability in production engineering}

\author{
C Herrmann, S Thiede, G Bogdanski, P Egede
}

\section{TU Braunschweig, BRAUNSCHWEIG, Germany}

The energy and resource consumption of production plants becomes increasingly important for companies. Drivers are for example the rising prices for raw materials and energy and the scarcity of strategic resources (economic perspective). However, also the strong environmental impact through energy and resource consumption (e.g. impact on global climate, destruction of the environment - ecological perspective) and the resulting public debate (e.g. concerning climate change, nuclear energy, renewable energies) are important factors. However, the awareness and necessary background knowledge to analyze and improve the energy and resource efficiency is often not consistently available. In addition, the relevance of the topic is difficult to teach as the related energy flows (e.g. electricity consumption) cannot be seen and their impact is rather indirect (e.g. climate impact of energy consumption). The energy and resource consumption of factories is determined by a large variety of individual consumers - for a goal oriented analysis and improvement, a holistic definition of the factory system is necessary. To avoid problem shifting all relevant energy and material flows of a plant must be considered. Accordingly, all major systems of a plant need to be taken into account: production (individual processes and machines as well as process chains), technical building services (e.g. compressed air, renewable energies) and the building shell. Therefore, the Institute of Machine Tools and Production Technology of the Technische Universität Braunschweig has developed a concept to raise awareness and convey the necessary understanding of the relations and dependencies to improve the energy and resource efficiency of productions plants. Under the headline 'Die Lernfabrik' ("The learning factory") the latest research results on sustainability in production are presented and the successful transfer of these results into companies, especially small and medium-sized enterprises (SMEs), are shown. "Die Lernfabrik"aims at providing a "live"experience of innovative methods, tools and technologies and a systematic development of specific approaches to increase the awareness of professionals (e.g. managers of production) but also of students or trainees as future drivers and 'influencers". "Die Lernfabrik" is currently divided into eight stations where different subjects of 'energy and resource efficiency in production' are presented in an easy-to-understand manner, at some stations also interactively. Research results and their implementation in various industries (e.g. machinery and equipment, printed circuit board manufacturing, textile industry) are shown at the stations (1) Energy cockpit, (2) renewable energies, (3) the energy transparent machine and (4) efficient compressed air use. These results are supplemented by contributions from more than 15 years of research at the institute in the field of 'sustainable production', (5) alternative coolants and (6) de-oiling of metal swarf. Additional stations are (7) the green office (energy efficiency in office areas) and (8) a teaching concept for energy efficiency. 'Die Lernfabrik' is based on the findings of the project 'EnHiPro"(improving energy and auxiliary flows in production). The project EnHiPro is funded by the German Federal Ministry of Education and Research within the framework concept 'Forschung für die Produktion für morgen"(Research for Tomorrow's Production). 
Abstracts 


\title{
SS-02: LCA networks: What exists and how do they work?
}

\section{WOSS02-01}

\author{
Mapping and characterization of LCA networks \\ A Bjørn, M Owsianiak, A Laurent, C Molin, TB Westh, MZ Hauschild \\ Technical University of Denmark, KGS. LYNGBY, Denmark
}

Dissemination of methodological development within Life Cycle Assessment (LCA) and feedback from users outside academia is crucial for the continued application of LCA as a decision support tool. LCA networks can potentially play an important role in this, but no comprehensive overview and characterization of LCA networks is available. The purpose of this study is to provide an up to date mapping of global, regional and local LCA networks and to characterize them according to their structure and activities. A tentative LCA network definition has been developed, followed by a mapping based on i) a literature review of previous mapping studies, ii) a web search aimed at identifying additional LCA networks and iii) a stakeholder inquiry distributed via online LCA fora. The characterization of networks was based on responses from a survey sent to all identified networks. We identified 100 networks located primarily in Europe and the Americas. The networks are mainly small-to-medium-sized (less than 100 members). Academia and industry are well represented through memberships of networks, while other institutions, such as EPAs and non-governmental organizations are only represented in less than $30 \%$ of the networks. The networks have a large focus on disseminating LCA activities, developing life cycle inventories and impact assessment methods and supporting case studies, whereas emerging disciplines such as social LCA, Input/Output based LCA and Life Cycle Sustainability Assessment are so far only covered by less than $40 \%$ of the networks. Over time an increasing trend in the number of formed networks is observed. This development correlates with the number of LCA related scientific publications on a global basis. Likewise a correlation can be observed between the number of LCA networks per continent and the number of LCA publications originating in each continent. Thus the level of scientific production and network activities within regions tend to follow each other, although the causal relation between the two parameters has not been identified. Our mapping may serve as a starting point in future research on the role of LCA networks. In line with this we advocate the creation of an on-line platform with the purpose of facilitating communication and knowledge sharing between LCA networks.

\section{WOSS02-02}

\section{The ILCD data network: A distributed IT infrastructure for sharing and searching quality-assured LCA data}

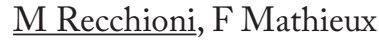

EC JRC, ISPRA, Italy

In the Integrated Product Policy Communication of 2003, the European Commission recognised Life Cycle Assessment (LCA) as "the best framework for assessing the potential environmental impacts of products". Since then, life cycle approaches were further strengthened in EU policies through the Sustainable Production and Consumption / Sustainable Industry Policy Action Plan Communications that encompasses various policies (e.g. Eco-design for Energy-related Products Directive, Footprint initiative, etc.). Within this context there is an urgent "need to improve data availability and quality worldwide by internationally cooperating on LCA data and methods". To address this situation and to foster standardization, the International Reference Life Cycle Data System (ILCD) Data Network has been developed by the European Commission's Joint Research Centre (DG JRC).

The ILCD Data Network (ILCD DN) aims at providing consistent and quality-assured LCI data through the web, with easy access via searches, filtering, and sorting. The data sets in the network can come from any data developer/owner, e.g. industry, national LCA projects, research groups, and consultants. The data will be published by the developer/owner under its own conditions, e.g. for free, for fee, via registration, etc.

The ILCD DN will comprise LCA data from different databases increasing data sharing but raising a consistency problem. While, within specific databases, quality are ensured due to the development of modelling 
principle, across databases there can exist significant differences. This includes modelling approaches (e.g. system boundaries definition), allocation approaches and nomenclature of flows denoted in the inventories. Bridging these differences to ensure the efficient exchange of data is one of the ever challenges in the field of LCA. Moreover, some current research activities are aiming to broaden LCA application perspective from the geographical perspective. This will have a great influence on the LCA data aspect and will increase the need for well documented datasets.

The ILCD Entry-level Requirements have been developed in order to set minimum quality requirements for datasets registered to the ILCD DN. This level of requirements has been put in place to quickly increase the access to properly documented LCI data sets. These requirements together with the use of the ILCD data format and related tools will allow the practitioner to work with a common set of elementary flows, LCIA methods, etc. At the same time the data sets are identified according to the quality-level they adhere to. It is important to highlight that all data in the network have to be in line with ISO 14040 and 14044, that is part of the entry-level requirements.

ILCD DN IT feature will allow managing LCI datasets subscription and selection, only ILCD Entry-level compliant datasets will be registered to the Network. This will guarantee to the LCA practitioners to find only high quality and well documented data enabling selection of coherent and appropriate data for their study.

After detailing this justification of the ILCD D N, this paper will describe the ILCD DN features, the role of contributors (e.g. node administrator, registry administrator, visitors) and will illustrate its application for the management of LCA data networks.

The benefits of using such a tool by LCA regional networks will be highlighted.

Finally, this paper will summarise the current development stage of the ILCD DN.

\section{WOSS02-03}

\section{Network among production engineering researchers - CIRP LCE (life cycle engineering scientific community)}

\section{Alting, MZ Hauschild}

Technical University of Denmark, LYNGBY, Denmark

CIRP is an International Academy for Production Engineering with academic members from more than 40 countries. The members are elected bases on international recognition and scientific contributions within production.

In 1992 CIRP established a working group on Life Cycle Engineering to bridge the gap between the world of production engineering and the growing environmental awareness. Decisions made in production engineering are determining for the environmental consequences of the design and the production along the life cycle stages and hence for the impacts associated with our industrial production and use of products.

The work in CIRP has focused on these issues and progressed the last 20 years and today LCE is an established activity and most of the members are including the environmental dimension in their work. Drawing on the deep insights of the society's members into production processes like welding, grinding or cutting, the community is currently compiling a life cycle unit process database for manufacturing processes under the $\mathrm{CO}_{2} \mathrm{PE}$ !-Initiative (Cooperative Effort on Process Emissions in Manufacturing).

For more than 15 years CIRP LCE has hosted a yearly international Life Cycle Engineering conference with broad attendance also from outside the CIRP community.

The CIRP Life Cycle Engineering community is a very strong network of researchers with deep insight into production engineering and interest in environmental aspects of their technology. It would be of high value to strengthen the collaboration between the production engineering field and the environmental field, e.g. by establishing joint activities between CIRP and SETAC. 


\title{
WOSS02-04
}

\section{Life Cycle Assessment in Mexico: Overview and development of the Mexican LCA network}

\author{
$\underline{\text { LP Güereca }^{1}, \mathrm{~N} \text { Suppen }^{2}}$
}

${ }^{1}$ Universidad Nacional Autónoma de México (UNAM), MÉXICO D.F., Mexico

${ }^{2}$ Centro de Análisis de Ciclo de Vida y Diseño Sustentable, MÉXICO D.F., Mexico

The use of Life Cycle Assessment (LCA) in Mexico has increased over the years. In the early stages of implementation in the country, the methodology was mainly used by government with a strong focus in solid waste management and criteria development for green public purchasing. Since 2002 different organizations have adopted the life cycle approach for decision making: Government and policy makers have reinforced the importance of the methodology in laws and regulations for application in a wide range of sectors, such as construction, biofuels, tourism and waste management, among others. Industry is growing in the development of studies and communication of LCA results, likewise the academic sector is including the topic in different academic programs in order to be able to cover the demand of the industrial and government needs. Research has also been carried out by different institutions in important sectors and with focus in developing national datasets and LCIA methodologies. The results presented in this paper were obtained by means of the next data gathering processes: a) analysis of bibliographic sources, b) questionnaires and interviews, and c) the experience of the authors in project development. The analysis of the information obtained shows that during the last ten years, nine scientific articles have been published in peer reviewed journals, 69 works has been presented at international conferences and a wide range of LCA studies have been developed for several governmental and private institutions. Additionally, three LCA courses has been formally implemented in master degree programs and capacity building is offered regularly by Instituto de Ingeniería at Universidad Nacional Autónoma de México and the Center for Life Cycle Assessment and Sustainable Design in short training courses. One of the most important achievements in LCA in Mexico during the last year is the conformation of the Mexican LCA Network (MELCAN), founded by 31 practitioners in November 2012. MELCAN is a free of charge association seeking to contribute with LCA expertise to the formulation of strategies and to promote the quality and integrity of LCA studies conducted. At this moment the statutes of MELCAN have been developed, the web site is constructed and the first Mexican LCA Seminar is being organized.

\section{WOSS02-05}

\section{From data formats to business opportunities}

E Rex, S Palander

\section{CPM - Chalmers University of Technology, GOTHENBURG, Sweden}

CPM is a Swedish competence center on applied life cycle thinking, hosted by Chalmers University of Technology in Gothenburg. CPM way of working is characterized by close interaction between academia, applied research institutes, industry and government. Current partners are Chalmers, KTH, IVL, SP, ABB, AkzoNobel, SCA, SKF, Volvo Group and the Swedish EPA. Our common vision is to improve products' and services' environmental performance by "credible and applied life cycle thinking globally".

CPM started 1996, by Chalmers University of Technology, the national funding agency NUTEK and a range of Swedish industries. In early years, the main focus was on methodology development of life cycle assessment (LCA), and on developing database structures, nomenclature and quality requirements for life cycle data. During the years we have seen a broadened perspective into applied life cycle thinking and life cycle management. Life cycle thinking is global, but needs to be translated and implemented into business opportunities or new policies. To make it happen it is of importance to build up capacity and a broader understanding for applications of life cycle thinking among decision-makers at all levels.

The development of the area has lead to a new and wider way of working for CPM. From mainly connecting academic researchers with companies' environmental experts we now approach a wider range of professionals and business functions. From running long research projects we now also work with short-term discussions, to ensure an increasing exchange of experience between experts situated in different functions and organizations. This could include exchange in both practical hands-on activities and upcoming research.

In response to the changed needs, we have experimented with different ways of working:

- Research projects: Identify research and collaborations. Support dissemination of results 
- Working groups: Initiate and facilitate open discussions and exchange experience.

- Scientific infrastructure: Build up a resource forum and joint monitoring of international development.

- Communication: Be a natural information hub

The broader scope and target group for the new way of working leads to new challenges. Some of our main difficulties include:

Reaching out to new functions - How to communicate life cycle thinking in an understandable and motivating way to new business functions? When communicating the life cycle perspective you will directly be placed in the "LCA box", which we find difficult to avoid. How to reach out to a broader community?

Providing concrete business benefits - To reach top managers'level we need to be more specific in communicating the benefits of working with the life cycle perspective. Concrete business cases and (short term) financial benefits are requested, for both implementing a life cycle perspective and for engaging in capacity building and networks.

Keeping a neutral and proactive arena - We are often expected to come up with adapted solutions but have no intentions in acting consultancies. We aim to stay non-profit organization to provide a neutral arena and a high credibility. Available funding makes it difficult to act strategically and proactively on the national and international arena, as financial means are tied to specific topics and stakeholders.

Despite these challenges, we are experiencing a growing interest in life cycle thinking and network building, from industry, academia and government.

\section{WOSS02-06}

\section{Mainstreaming life cycle approaches in Northern France through the collaborative platform [avniR]}

JK Bricout, $\underline{\mathrm{N} \text { Adibi }}$

Cd2e - Plateforme [avniR], LOOS EN GOHELLE, France

The Northern France region has been actively pursuing a transformation towards more sustainable economic models for many years. The non-for profit organisation cd2e was established there in 2002 to support the development and growth of environmental sector. As early as 2007, cd2e and their partners identified LCA as a much needed decision-making tool to help industry integrate environmental solutions, and inform the development of new sectors.

Cd2e created the [avniR] platform in 2009 to bring together multiple stakeholders around this challenging issue. This collective approach was needed to foster the supply and demand for LCA in parallel. On the demand side, [avniR] works with industry clusters and public authorities to explain life cycle approaches and develop collaborative projects. On the supply side, [avniR] provides training and a "hub"for academics and consultants to improve their capacity in Life Cycle Assessment, eco-design and LCA based communication.

Over 100 people have been trained in LCA/LCM through the platform, and more than 30 individual projects have been supported. [avniR] organised its first international conference in 2011, and first ecodesign prize in 2012.

The strategy for helping businesses and policy makers integrate life cycle thinking is based on some key concepts:

.Life Cycle Management (LCM) capacity should be built into existing support organisations, so that businesses receive advice and tools from organisations that they already know and trust

. Tools and actions to support LCM integration need to be adapted to different sectors to make them as relevant as possible to SMEs

.Training and research capacity also needs to be developed to respond to needs of businesses

After three years of applying these concepts in an opportunistic fashion, the textile, seafood, packaging and mechanical sectors have developed strategic action plans to mainstream LCM into their businesses, education and research organisations in 2012. This represents a unique initiative to mainstream life cycle thinking across multiple sectors in a region.

This presentation will develop on the challenges and successes of trying to create widespread awareness of life cycle thinking in a region, whilst developing the competences necessary to transform awareness into action. 
Future hopes and ambitions of [avniR] will be shared with a view to increasing collaboration with other life minded networks and actors.

\title{
WOSS02-07
}

\section{CASE-LCA network - experiences from the beginning}

\author{
$\underline{\text { KS Tóth }}^{1}$, B Milanovic 2 , D Milankovic ${ }^{2}$, Hodolic ${ }^{2}$
}

${ }^{1}$ University of Miskolc, MISKOLC-EGYETEMVAROS, Hungary

${ }^{2}$ University of Novi Sad, Faculty of Technical Sciences, Trg Dositeja Obradovica 6, 21000 NOVI SAD, Serbia

In the developed countries, awareness of environmental protection and LCA method is high and as such, needs to be transferred to less developed countries to help and include them in the same path of development. By joining together, LCA centers and Scientific and Research institutes have set in motion an initiative for better and faster development and application of LCA methodology in less developed countries. The network aims to establish the international cooperation and communication between countries of Central and Southeastern Europe and to create a network that will unite both Scientific and Research institutes and LCA centers. The reasons and the needs for creation of such network are derived from the analysis of the current situation and from consideration of possible solutions to existing problems. After several months of intensive negotiations, the CASE-LCA Network has been established in September 2011. The official Kick-of meeting was organized in Novi Sad on 23rd September 2011. CASE-LCA represents a network of Scientific and Research institutes and LCA centers from Central and Southeast Europe. CASE-LCA network is open for cooperation with individuals, companies and organizations that are willing to accept life cycle approaches. It is consisted of seven partners which also constitute the founding board: 1. University of Novi Sad, Serbia; 2. Poznan University of Technology, Poland; 3. University of Miskolc, Hungary; 4. University of J. E. Purkyně in Ústí nad Labem, Czech Republic; 5. University of Ljubljana, Slovenia; 6. Josip Juraj Strossmayer University of Osijek, Croatia; 7. University of Central Europe in Skalica, Slovakia. The mission of CASE-LCA is to establish a platform for knowledge and expertise exchange within the members' countries. The mission is the promotion of life cycle thinking at all levels in society within the members countries, increase in awareness and promotion of the adoption of LCA among industry, government, and NGOs, and promotion of networking among LCA practitioners and researchers. Other goals are to assist companies that have a need for environmental assessment of products in a life cycle perspective, to secure that the development of tools and methods for the life cycle approach within the network members builds on a solid scientific basis, and to promote productorientated environmental work in companies (Life Cycle Assessments and Product-Orientated Environmental Management Systems). Educational activities within the network includes sharing of knowledge, experience and expertise through scientific conferences and other meetings organized within the network and hosted by network members; intensifying the integration and application of the LCA method in research, scientific, educational, government and industrial sector and also improving their mutual cooperation and communication; joint acting enables the possible access to European funds for the application of joint high-budgetary projects etc. Scientific activities within the established network include various research directions that will contribute to the overall development and integration of the LCA methodology and also will create a better utilization of research potential within the countries of Central and Southeastern Europe. Innovative activities include transfer of knowledge and results gained through research and educational sector into the industry sector. 


\section{WOSS02-08}

\section{LCADB.sudoe: Life cycle inventories database of the southwest of Europe}

$\mathrm{M} \mathrm{Gasol}^{1}$, ES Sanyé ${ }^{2}$ J Rieradevall ${ }^{2}, \mathrm{C} \mathrm{Arnoult}^{3}, \mathrm{VB}$ Bellon $^{4}, \mathrm{M}$ Pradel $^{5}, \mathrm{~L} \mathrm{Lardon}^{3}, \mathrm{PR}$ Roux $^{4}, \mathrm{AC} \mathrm{Dias}^{6}, \mathrm{~L}$ Arroja $^{6}$, M Rigola $^{7}$, SM Morera $^{7}, \mathrm{X}$ Gabarrell $^{2}$

${ }^{1}$ Inèdit Innovació s.1., CABRILS (BARCELONA), Spain

${ }^{2}$ Universitat Autònoma de Barcelona -Sostenipra-, BELLATERRA (BARCELONA), Spain

${ }^{3}$ Supagro, MONTPELLIER, France

${ }^{4}$ IRSTEA, MONTPELLIER, France

${ }^{5}$ CEMAGREF, MONTPELLIER, France

${ }^{6}$ Universidad de Aveiro, AVEIRO, Portugal

${ }^{7}$ Universitat de Girona, GIRONA, Spain

During the life cycle inventory (LCI) phase the data collection and modeling of the system (e.g. product) is performed. This need to be done in line with the goal definition and meeting the requirements derived from the scope phase. The LCI results are the input to the subsequent LCIA phase (ILCD 2010). The objective of this paper is to present the design and structure of the LCADB.sudoe database and explain how to share Life Cycle Inventory datasets in the on-line application (http://1cadb.sudoe.ecotech.cat/) for the SUDOE LCA and also all LCA users. Methods. The database presented in this chapter is being developed in the context of the Ecotech-Sudoe project (ECOTECH-SUDOE project,soe2/P2/E377). An on-line application and a protocol of dataset compilation were developed to facilitate the introduction of datasets of primary data by different users (LCA practitioners, decision-makers in companies and designers and engineering's of products, processes and services, etc.). Dataset questionnaire was created reviewing the criteria considered in Ecoeditor of ecoinvent database and ILCD editor of ELCD database. Hence, compatibility between data of the LCADB.sudoe and ecoinvent and ELCD requirements was ensured. The partners of Ecotech Sudoe project and institutions of Spanish LCA Network have shared datasets in this first version of LCADB.Sudoe Finally all the datasets are reviewed by an expert committee before its publication. Results. The entire database contains initially 30 dataset about some productive sectors of SUDOE area. For their scope, the inventories that we can expect to find in these databases, are related to important productive sectors such as agriculture, cities, energy production, manufacture process, services, transport, use \& consumption, waste treatment, water and so on. More than 20 institutions of the Spanish LCA network and partners of Ecotech-Sudoe project from France, Portugal and Spain have been participated in this first sharing of datasets. Conclusions. As indicated a great scientific team in LCA (Rebitzer et al, 2004), "the databases that provide LCA inventories of high quality data (transparent and coherent) of frequent use products are useful and necessary, especially for development of products in a company". Secondary data providers, typically for the background system, are public or private and national and international LCI databases, consultants, and research groups. In this sense some experiences and databases have been developed: LCI (Life Cycle Inventory) of PNUMA/SETAC that had establish a revised database and updated (ELCD) or ecoinvent, among others (Gabi Team LCAFoods). LCADB.sudoe aims to complete and share life cycle inventory (LCI) data with other existing life cycle databases above-mentioned in this section with the final objective of improving productive sectors of Sudoe area (South of France, Spain and Portugal). 


\section{WOSS02-09}

\section{Regional and country based LCA networks: Multi-stakeholder and multi-region collaboration for consistent LCA data and related databases}

\section{$\underline{\text { G Sonnemann }}$}

University of Bordeaux, TALENCE, France

The UNEP/ SETAC Life Cycle Initiative organized a Pellston-type workshop in 2011 in Shonan Village, Japan, based on which the Global Guidance Principles for LCA Databases (Shonan Guidance Principles) where developed. The workshop was organized by a multi-stakeholder steering committee. As a basis for coming up with these guiding principles a variety of guidelines used in various regions were reviewed. The Shonan Guidance Principles specify how the generation of LCA data and the management of related databases need to occur.

Further development of the guidance principles is needed so that they can be used in a practical way for training and other applications. To achieve this is one of the targets and actions identified for a flagship project within Phase 3 of the Life Cycle Initiative. Overall, this flagship project foresees the systematic implementation of the Shonan Guidance Principles to ensure that practice follows the guidance.

Regional and country based LCA networks are seen as important elements of this implementation strategy. They have already demonstrated their value for the organization of awareness-raising events on the Shonan Guidance Principles. It is anticipated that they will also be crucial for upcoming training events.

Database managers are identified as central actors in the Shonan Guidance Principles. Therefore, establishing multi-stakeholder and multi-region collaboration worldwide among database mangers that in general are part of a regional and country based LCA networks is seen as an other key element of a global roadmap for capability development on the generation of consistent LCA data and the management of related databases.

\section{MPSS02-01}

Linking research activities and their implementation in practice in the construction sector: The LCA Construction 2012 experience

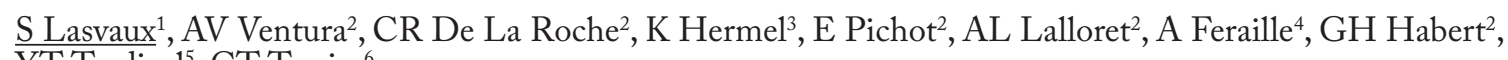
YT Tardivel $^{5}$, CT Tessier ${ }^{6}$

${ }^{1}$ Centre Scientifique et Technique du Bâtiment, ST MARTIN D'HÈRES, France

${ }^{2}$ IFSTTAR, Département Matériaux, NANTES, France

${ }^{3}$ IFSTTAR, PARIS, France

${ }^{4}$ Laboratoire Navier, ENPC, CHAMPS-SUR-MARNE, France

${ }^{5}$ SETRA, PARIS, France

${ }^{6}$ IFSTTAR, Département Structures et Ouvrages d'Art, NANTES, France

Numerous research activities about LCA applied to buildings, and more recently to civil engineering, have risen over the past decades. Environmental stakes are particularly important in construction because any initial decision has always long term consequences. In addition, the construction sector both generates and recycles huge amounts of waste; it is generally considered as an important contributor to climate change and induces irreversible changes in local environments. To face these stakes, industries invest into so-called « green innovations ", and national or local public authorities are demanding scientifically based decision support such as LCA. For the time being, LCA research appears to be fragmented between LCA practitioners in various construction fields and LCA methodologists. However, LCA practitioners in the construction sector share identical methodological questions. For example, drastic variations which inevitably occur between the early and operational stages of construction projects have led many research institutions to develop their own dedicated LCA software tools. These tools are however seldom comparable, since they generally use different databases and assumptions. Only close cooperation between LCA methodologists and construction scientists can lead to appropriate methodological developments.

To help linking the research activities and their implementation in practice, the idea of organizing an 
international symposium on LCA \& Construction was launched in 2011 by IFSTTAR (the French Institute for Transport, Development and Networks) and CSTB (the French Scientific and Technical Centre for Buildings). This symposium took place in Nantes from 10-12 July 2012 under the scientific auspices of 3 international organizations: RILEM, the International Union of Laboratories and Experts in construction materials, systems and structures, ISIE, the International Society of Industrial Ecology, and SETAC, the Society for Environmental Toxicology and Chemistry. It was also encouraged by EcoSD, the French networks of researchers and industrials in eco-design, and LirGEC, the regional network of researchers in civil engineering.

The scientific program of the first two days included presentations in the following topics: life cycle inventory data, methods for buildings, decision and management, LCA case studies for buildings and infrastructures, dynamic LCA, service life and indicators, methods for construction materials, end of life, waste and allocations. The LCA Construction 2012 symposium also aimed at providing an insight into societal demands in the construction sector during the last day. To that purpose, invited experts from various public or private organizations presented the latest development based on LCA on various topics such as standardization, regulations, product development and building design. Round tables addressed both the limits of LCA applied to the construction sector and the current use of LCA based on existing knowledge. Needs for future research as well as a better articulation of the on-going implementation of LCA by the different stakeholders were identified.

The organizing committee finally believes that such an initiative contributes to create a forum for the exchange of recent developments and research results amongst researchers. This can be a first step before launching international and regional networks in LCA applied to the construction sector.

\title{
MPSS02-02
}

\section{EcoConnexion, an online discussion platform for ecodesign professionals seeking for everyday knowledge sharing}

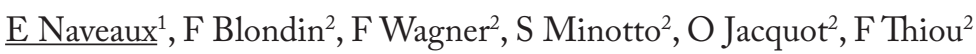

${ }^{1}$ Alternative Energies and Atomic Energy Commission (CEA), France, GRENOBLE CEDEX 9, France

${ }^{2}$ EcoConnexion, PARIS, France

EcoConnexion platform is a forum for ecodesign stakeholders.

This forum enables contacts between students, young practitioners and eco-design professionals who wish to pass on their experience. Helping young people entering the profession and sharing environment related knowledge is the platform central idea. Every contributor can share doubts and difficulties; ask any questions and bring solutions in any areas of expertise related to environmental issues studies. This site was created to discuss Eco-design, LCA, Carbon footprint, Environmental communication and management topics.

In order to join the network EcoConnexion and access messages, newcomers have to ask to be a contributor to participate. They can then contribute to class, company, association or topic group debates. For instance, topics such as compatibility between databases and methods in LCA or European Eco-Management and Audit Scheme management tool or job offers are now under discussion.

Initially in french language and with more than 200 members, the forum has now an english section to allow international participation. You can visit us on http://forum.ecoconnexion.net.

international symposium on LCA \& Construction was launched in 2011 by IFSTTAR (the French Institute for Transport, Development and Networks) and CSTB (the French Scientific and Technical Centre for Buildings). This symposium took place in Nantes from 10-12 July 2012 under the scientific auspices of 3 international organizations: RILEM, the International Union of Laboratories and Experts in construction materials, systems and structures, ISIE, the International Society of Industrial Ecology, and SETAC, the Society for Environmental Toxicology and Chemistry. It was also encouraged by EcoSD, the French networks of researchers and industrials in eco-design, and LirGEC, the regional network of researchers in civil engineering.

The scientific program of the first two days included presentations in the following topics: life cycle inventory data, methods for buildings, decision and management, LCA case studies for buildings and infrastructures, dynamic LCA, service life and indicators, methods for construction materials, end of life, waste and allocations. The LCA Construction 2012 symposium also aimed at providing an insight into societal demands in the construction sector during the last day. To that purpose, invited experts from various public or private organizations presented the latest development based on LCA on various topics such as standardization, regulations, product development and building design. Round tables addressed both the limits of LCA applied 